\title{
Beginning and Intermediate Piano Students' Experiences Participating in Evaluative Performances
}

\author{
By
}

Nancy Eleanor Christel Mitchell

A thesis submitted in conformity with the requirements

for the degree of Doctor of Philosophy

Graduate Department of Music, University of Toronto

Copyright by Nancy Eleanor Christel Mitchell 2012 


\title{
Beginning and Intermediate Piano Students' Experiences Participating in Evaluative Performances
}

\author{
Nancy Eleanor Christel Mitchell \\ Doctor of Philosophy \\ Graduate Department of Music, \\ University of Toronto
}

2012

\begin{abstract}
Evaluative performances, such as festivals and conservatory examinations, frequently play a large role in formal piano study. Many teachers and parents assume that requiring students to participate in these evaluations will result in several benefits, including increased discipline and motivation, exposure to a balanced and rigorous music curriculum, and access to helpful feedback from expert adjudicators and examiners. However, not all students experience positive outcomes as a result of their participation in evaluative performances. Using a multi-method approach that incorporates grounded theory and narrative inquiry, this research provides insight into how beginning and intermediate piano students experience participating in festivals and examinations and what factors contribute to the quality of students' experiences.

Positive experiences with evaluative performances are characterized by positive emotional outcomes, meaningful music learning, and the development of a strong musical identity. The theoretical model developed through this research presents several important contributors to students' positive experiences with evaluative performances, including students' understandings, values, and goals related to music learning, and their abilities and inclinations as performers. The entire learning process must take place within a supportive relational context. When students have positive experiences with evaluative performances, their self-efficacy is heightened. They also experience self-determination regarding their music studies and their
\end{abstract}


involvement in evaluative performances. The self-efficacy and self-determination that follow students' success and positive experiences motivate further involvement in music study. 


\section{Dedication}

To David, Noah, and Benjamin 


\section{Acknowledgments}

I am grateful for the support and encouragement I have received from a many people throughout this process.

I would like to thank my external reader, Prof. Lisa Lorenzino, for her astute comments that guided the final version of the thesis document. I also greatly appreciate the contributions of Prof. Midori Koga and Prof. Cameron Walters, who encouraged the possible practical applications of my research.

I have had the honour to work with supportive and insightful committee members: Prof. LoriAnne Dolloff provided guidance that shaped the narrative element of my research, and Prof. Bina John provided constant support and encouraged my growth as a teacher/researcher.

My supervisor, Prof. Lee Bartel, has challenged me to be thorough and rigorous in my research and to remember always the "so what." I am grateful for his words of encouragement, for his tirelessness in reading countless drafts, and for his guidance in refining the visual model.

My husband, David, has provided practical, emotional, and intellectual support without which this degree would not have been possible. My precious boys, Noah and Benjamin, were born during this time and have enriched my life with so much love and laughter.

Finally, I owe an immense debt of gratitude to the participants of this research, who welcomed me into their lives and shared the richness of their knowledge and experience so that I and others could learn from it. I will always be thankful for their eagerness to support this project. 


\section{Table of Contents}

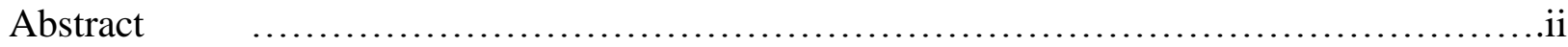

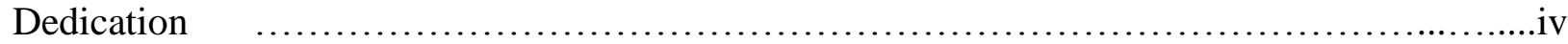

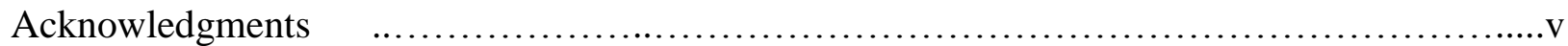

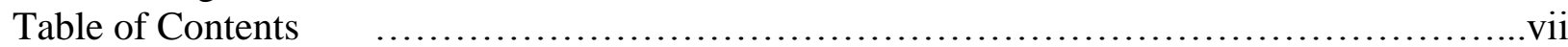

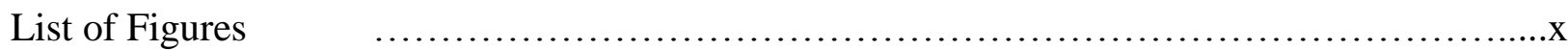

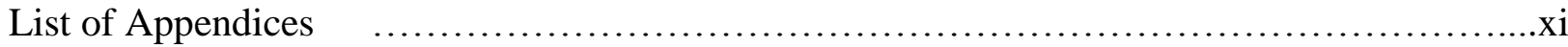

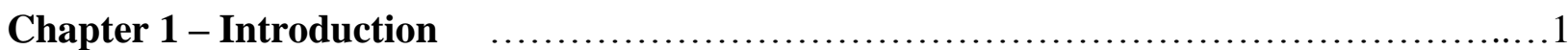

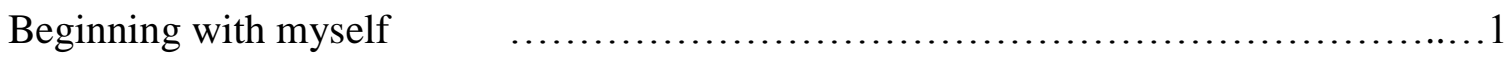

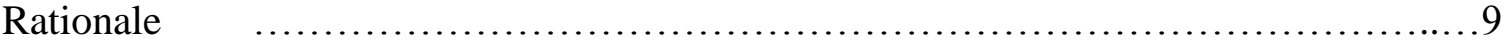

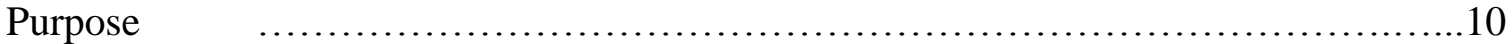

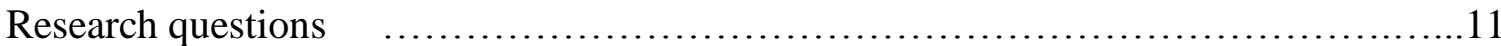

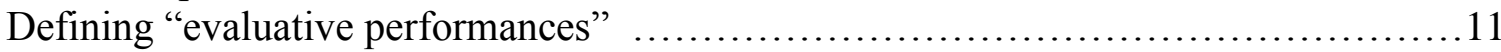

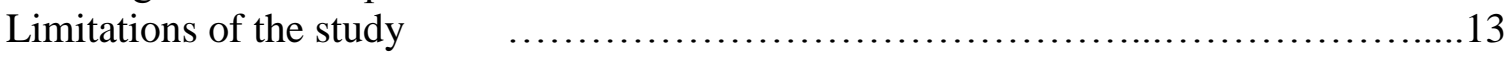

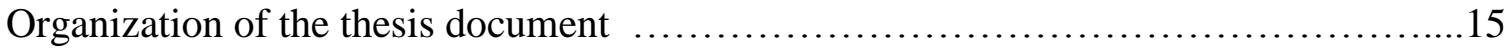

Chapter 2 - Examining the Central Constructs $\quad$........................................ 17

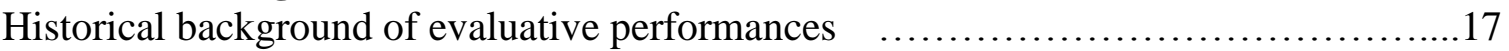

Educational context of evaluative performances $\quad$................................21

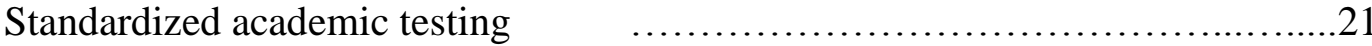

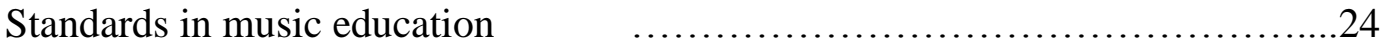

Relating evaluative performances to standardized assessment and curriculum ....................................................26

Relating evaluative performances in music to competition in other athletic and artistic discipline $\quad$............................................. 30

Establishing the research gap: existing literature on evaluative performances $\quad$......34

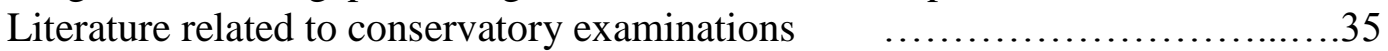

Literature related to music festivals and competitions $\quad$...................4 42

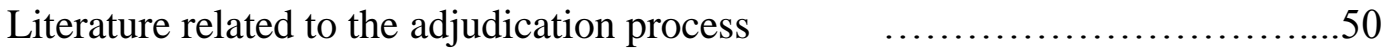

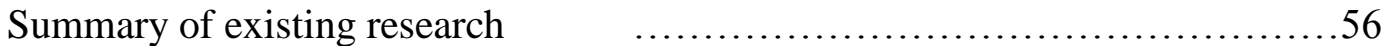

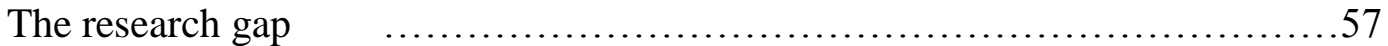

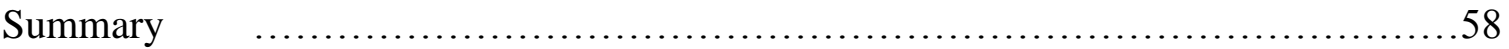

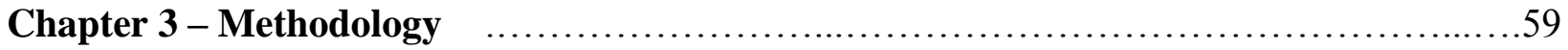

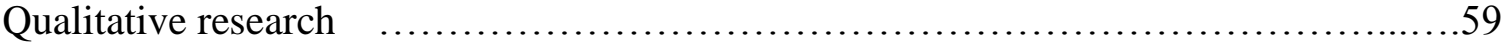

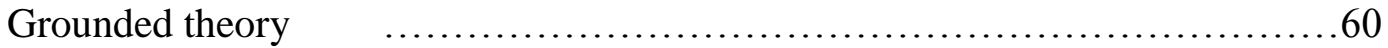

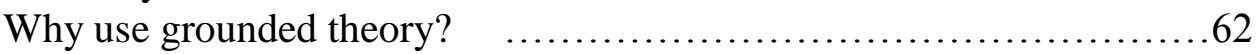

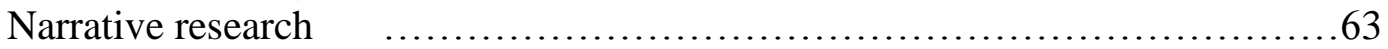

Why use narrative research? ….................................63

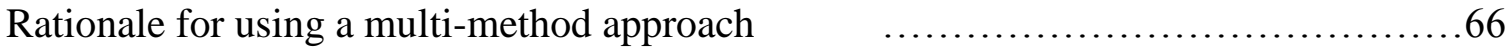

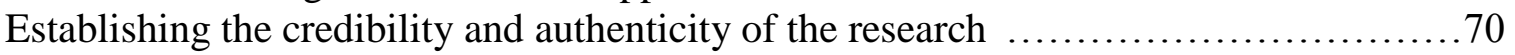

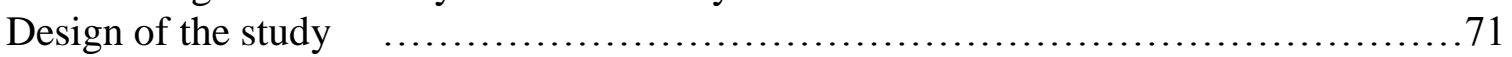

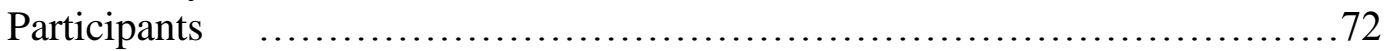

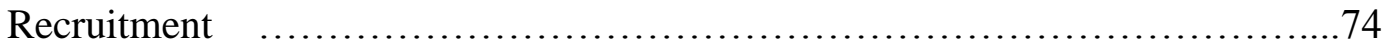

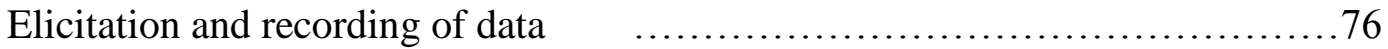


Current Students $\quad$................................................ 76

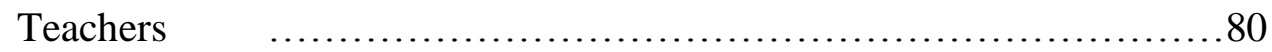

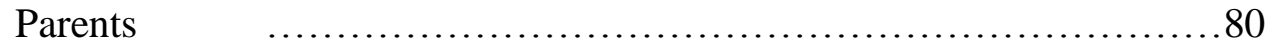

Former Students $\quad$.............................................. 80

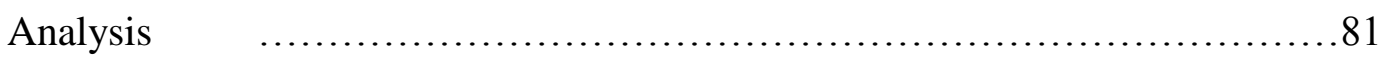

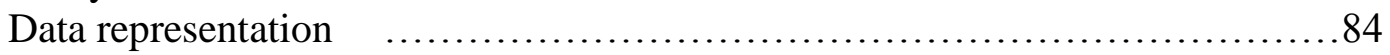

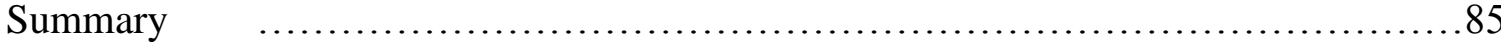

\section{Chapter 4 - Setting the Stage: Introducing the Participants and the Process of}

Participating in an Evaluative Performance ................................ 87

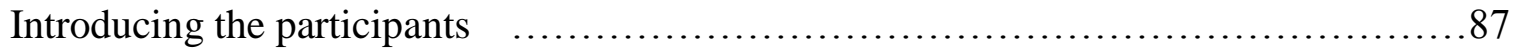

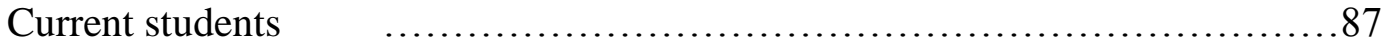

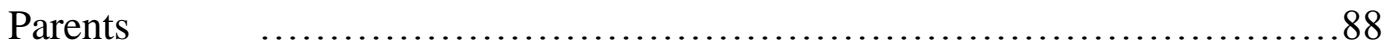

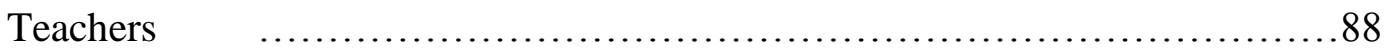

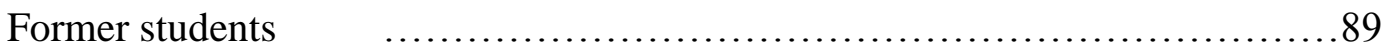

The process of participating in an evaluative performance $\quad$............................ 89

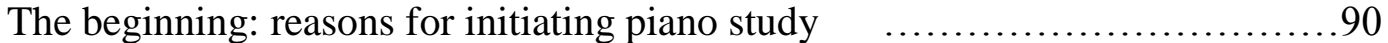

Music study becomes more serious: students' introduction to evaluative

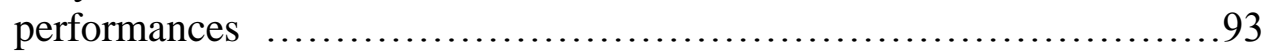

Practice makes perfect: students' preparations for evaluative performances ......97

The big day: students' performance experiences $\quad$.............................101

Participant voices $\quad$............................................... 104

The experts: students' perceptions of adjudicators and examiners $\quad$.............112

Judgment day: students' responses to feedback from adjudicators and

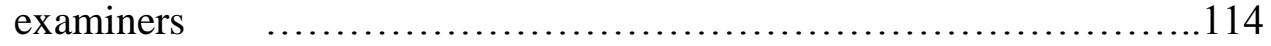

What next? The influence of students' experiences with evaluative performances

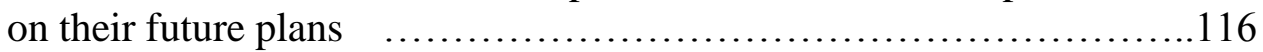

Why participate in evaluative performances? ................................... 118

Perceived benefits of evaluative performances $\quad$........................118

Perceived drawbacks of evaluative performances $\quad$..........................122

Summary

Chapter 5 - Engagement in Music Learning Through Participation in Evaluative

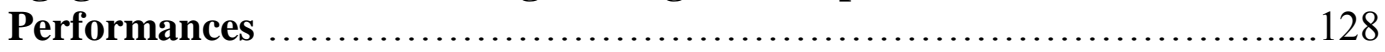

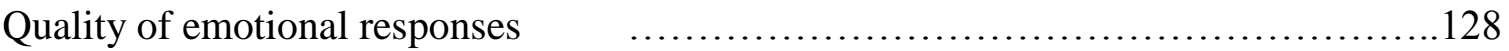

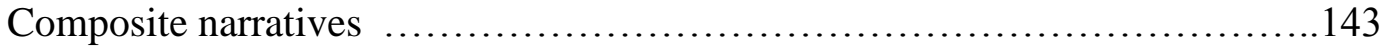

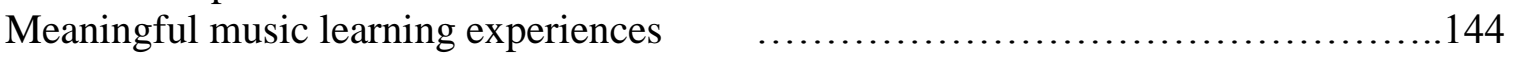

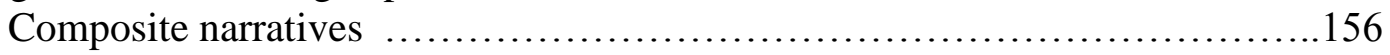

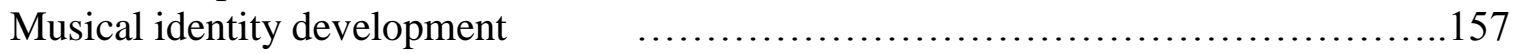

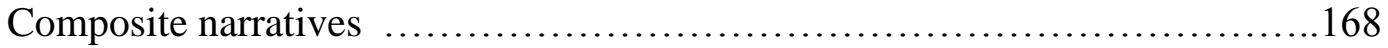

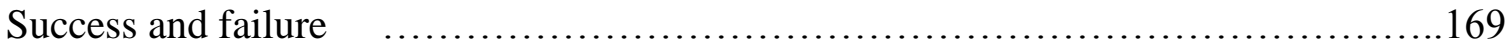

The importance of positive experiences: self-efficacy and self-determination $\quad$.....174

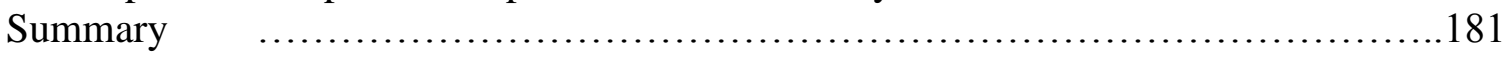

Chapter 6 - Personal Characteristics that Influence Students' Engagement in Music Learning through Participation in Evaluative Performances ..............183 
Student as a music learner: understandings, values, and goals $\quad \ldots \ldots \ldots \ldots \ldots \ldots \ldots 183$

Composite narratives ..................................................206

Student as a performer: the thrill of the stage and the throes of anxiety $\quad \ldots \ldots \ldots \ldots . .207$

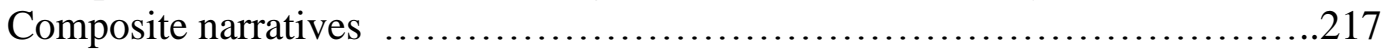

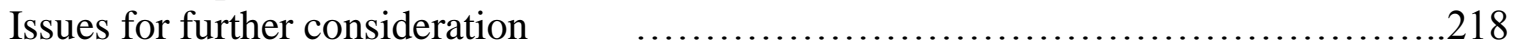

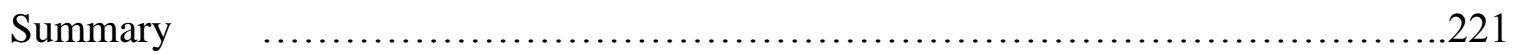

Chapter 7 - The Importance of the Relational Context of Learning $\quad$...................222

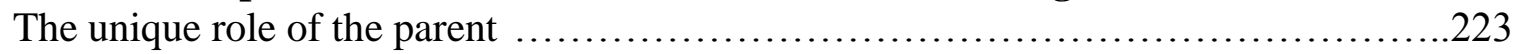

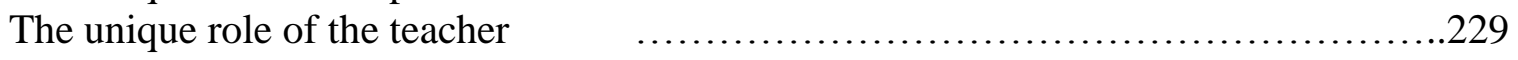

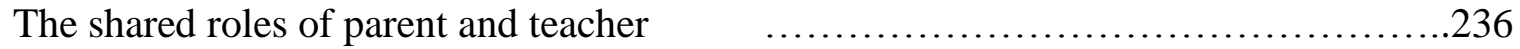

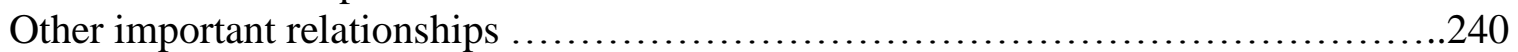

Why is the relational context so important? ........................................242

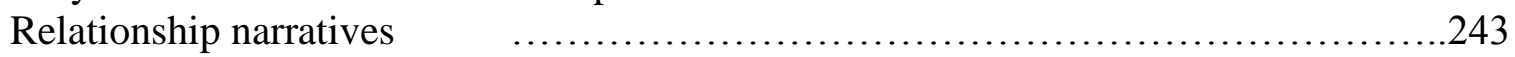

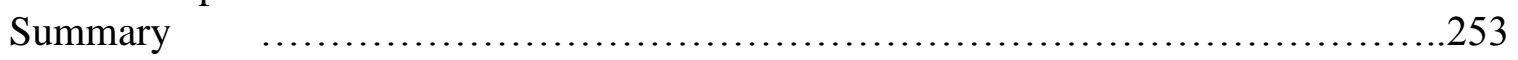

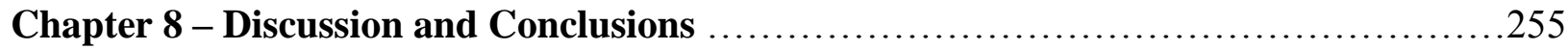

Grounded theory of student engagement in music learning through evaluative

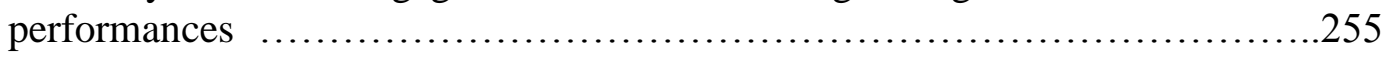

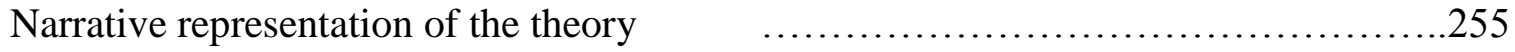

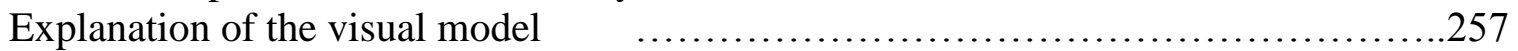

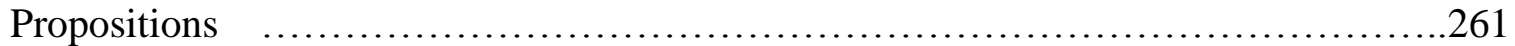

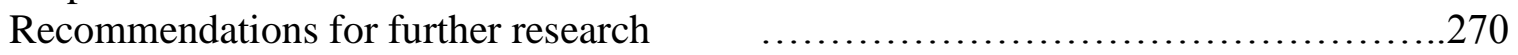

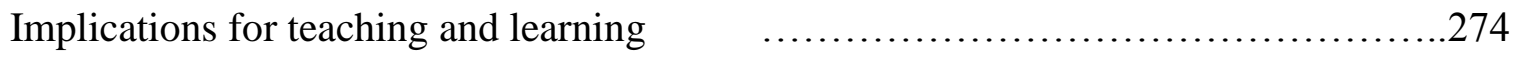

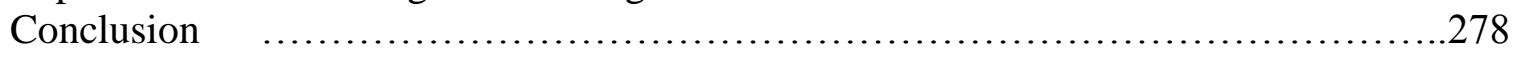

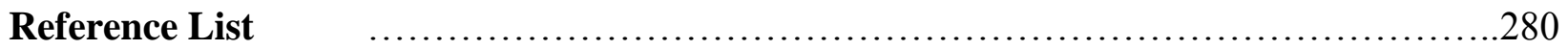




\section{List of Figures}

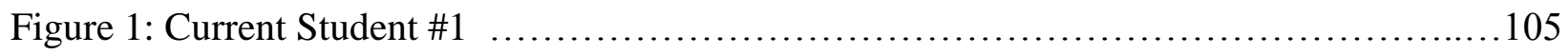

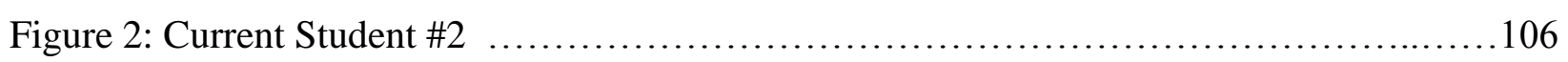

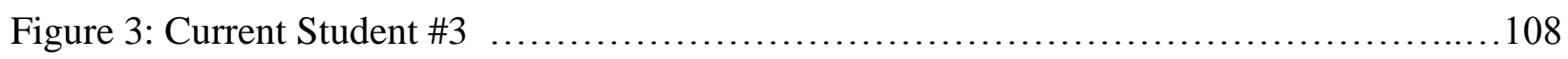

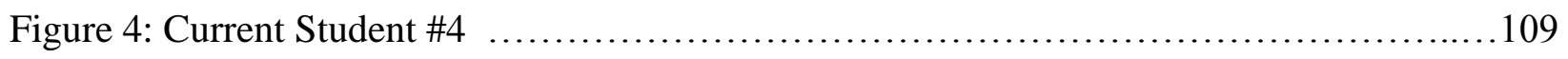

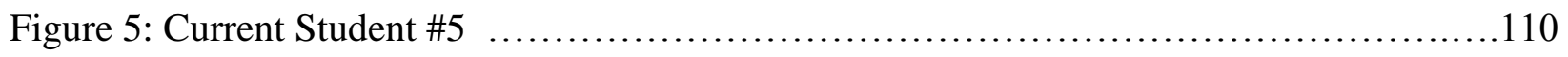

Figure 6: The process of participating in an evaluative performance.....................127

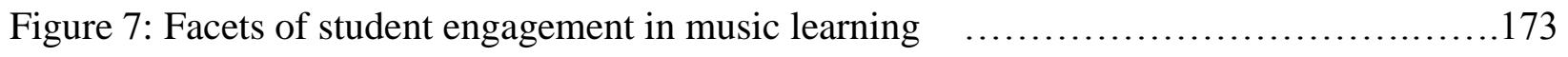

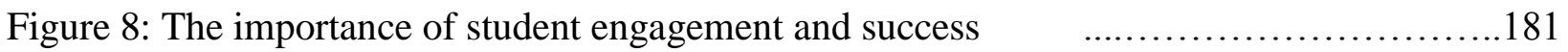

Figure 9: Personal characteristics that influence students' experiences with evaluative

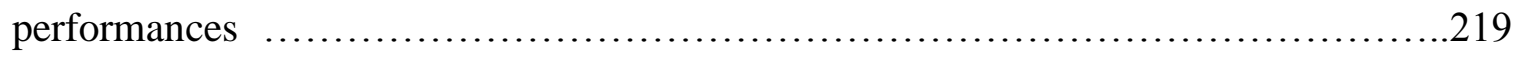

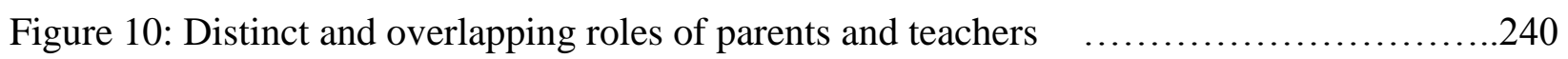

Figure 11: Conditions of a positive experience with an evaluative performance $\quad$............260 


\section{List of Appendices}

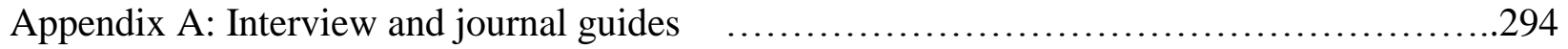

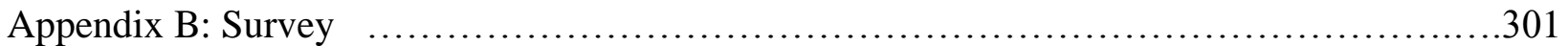

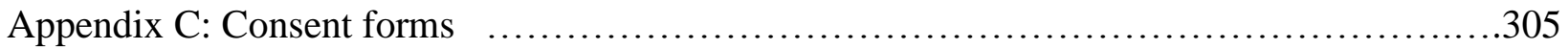




\section{Chapter 1 \\ Introduction}

\section{Beginning with Myself}

\section{Finding destiny in a box under the Christmas tree}

Just before I turned eight years old, my parents bought a special Christmas gift for the family. I was intrigued by what could possibly be contained in the long, flat box that was bigger than any of the other packages. When the present was finally opened, I saw an electric keyboard - the first musical instrument we had ever had in our home. My brother and I clambered to try the instrument. I was assigned the first turn and I tentatively played a few disconnected notes. My brother's turn was next. All of a sudden, a complex rhythm came out of the instrument. Everyone was shocked, and I was immediately upset. How was it possible that my brother, four years my junior, had managed to play something that actually sounded like real music on his first try while my efforts had sounded so terrible? We quickly realized he had pressed the button for one of the pre-recorded drum beats, and then I didn't feel so badly about what I had played.

As time went on, I gravitated towards the instrument more and more, fascinated by the buttons and the various sounds it could make. I loved trying out the different instrument sounds and drum beats. With my mother's help, I learned some simple songs and a major scale, which I then used as a template to figure out the rest of the white key major scales on my own. The patterns fascinated me and I derived great satisfaction from successfully learning another scale or song. These simple tunes and scales were even more fascinating to me than the electronic bells and whistles on the keyboard, because I could play them by myself.

When I was nine, my parents finally registered me for lessons with the pianist at our church. I had watched Karen play the hymns every Sunday, her round face set in concentration. Although I had desperately wanted to play an instrument for several years, when my mother finally told me that I would be starting lessons at the ripe old age of nine, I had some misgivings. Would it be hard? Would I like the teacher? Would I have to practice a lot? However, I soon overcame my hesitations and came back from my first lesson eager to learn the little three-finger exercises I had been assigned as homework.

Karen was not highly qualified, but my parents viewed the lessons mainly as a fun activity rather than as a future vocation. Karen had very set ideas about how I should learn to play and at what pace I should progress, based on her own experiences as a student.

Unfortunately, I was a very different student than she had been, and quickly grew impatient as I felt that she was impeding my progress. Every lesson felt the same as we painstakingly plodded through the first volume of the Leila Fletcher Piano Course. We never skipped a piece, never supplemented the method book with any other material. I was desperate to move on to more interesting music and was beginning to lose interest in practicing.

Finally, I revolted.

\section{In the presence of greatness}

Despite my frequent feelings of boredom in my lessons, I was still drawn to music and 
specifically to the piano. The prospect of learning new music excited me, particularly if the new piece was challenging and provided me with an opportunity to "show off" a little.

Sometimes, I would ask friends to show me the music that they were learning. However, my biggest burst of musical initiative ironically came about as a result of my lessons.

Karen was preparing for her Grade 8 piano examination when I was studying with her, and one day during my lesson she performed one of her pieces for me. The music, entitled "Invention No. 8 in F Major" by J. S. Bach, moved in sparkling, cascading waves with a quick tempo and short motives that repeated in ascending and descending patterns. The two hands traded the main melody back and forth, creating an unbroken energy that coursed through my body. From that moment, I loved Bach and I became determined that someday I would learn to play the piece that Karen had played.

On the way home from my lesson, I excitedly told my mother how much I loved the music Karen had performed for me in my lesson. Over the course of the following weeks, I begged Karen to play the piece again and again and she sometimes obliged. When my Aunt Margaret came to visit that summer from New York City, I told her all about the wonderful music I had recently encountered. Aunt Margaret had moved to New York to pursue a career as a painter, but she had a keen interest in all the arts, including music. Even at a young age, I sensed that she knew more about Classical music than my parents did and I was eager to share my latest musical exploits with her as she could relate easily to my fascination with music.

Aunt Margaret came for another visit at Christmas. She handed me a small, rectangular package. When I opened it, a huge grin spread over my face. It was a cassette recording of Glenn Gould performing all of Bach's two- and three-part inventions. In New York, Aunt Margaret was surrounded by an array of musical resources I could not even imagine in my rural eastern Ontario home, and from that musical bounty, she selected a recording of the very piece of music I was desperate to hear. The cassette quickly became one of my most prized possessions, not only because it contained my favourite piece of music, but also because it was the first recording I had ever owned. I listened to my music whenever I had the opportunity (not having my own cassette player sometimes impeded my listening, as I had to wait for times when other people also wanted to hear it).

Two weeks later, on my eleventh birthday, my aunt again surprised me with an incredible gift. This package was larger, and flatter than the other. I tore off the wrapping paper to reveal a book made of thick, yellowish paper with ornate decoration on the cover. My eyes focused immediately on the largest writing on the cover, the name J. S. Bach. The book's title was "Inventionen und Sinfonien," which, even with no knowledge of German, I connected to my beloved "Invention No. 8." I felt as though I had reached a new stage in my musical development, as this volume was no beginner's method book or examination collection. This was real music, complete with incomprehensible German instructions on how to perform specific ornaments, and pages and pages of dense, black notes. After frantically searching the table of contents, I located the "Invention No. 8." I was thrilled - now I could not only listen to the music I loved, but I also had the tools I needed to learn to play it myself.

Although the "Invention in F Major" was much more difficult than any of the other music I was studying at the time, I set about learning to play it. My limited technique and questionable fingering choices resulted in frequent stumbles. I would often refer to my recording of Glenn Gould, trying to achieve the same ease and vitality that was so apparent in his playing. Even though I consistently fell short, I still felt a thrill whenever I played the piece. My feelings of accomplishment grew as I was able to play longer and longer sections without stopping. With a 
determination that could perhaps be better referred to as stubbornness, I kept working on my Invention until I felt confident enough that I could play it for my teacher.

The performance day had finally arrived. I sat down on the piano bench at Karen's house and informed her that I had brought a new piece for her to hear. At that point, I launched into a rather rough performance of the "Invention in F Major." A strange expression came over her face as I played. She was utterly bewildered. This was not in the plan; I shouldn't have touched this piece for another seven or eight years according to the schedule she had laid out in her mind. When I finished, Karen mumbled something like "That was nice" and we returned to working on the repertoire for my upcoming Grade 1 examination. This incident confirmed my intuition that my teacher did not really understand me or how I would learn best.

After hearing my complaints about being bored in my lessons and seeing my motivation to practice flag, my parents began to wonder if their investment of money and time driving me to lessons was worthwhile. Shortly after my Grade 1 examination, they informed me that they had cancelled my lessons.

My interaction with the "Invention in F Major" reveals several important aspects of my involvement in music. First, it represents a time when I was motivated by enjoyment and when playing the piano was exactly that - playing. I did not learn the Invention because it was an examination requirement or because I was going to be evaluated on my performance; I learned it because something in my soul compelled me to play it. However, learning this piece, which was considerably more difficult than the music I was "supposed" to be playing, highlighted the seriousness and determination with which I approached my music studies even at that young age. As I advanced, I became increasingly goal-oriented and focused on results.

Learning the "Invention No. 8" required substantial initiative on my part. Unfortunately, in this case, my initiative was not encouraged by my teacher. Her inability to support and encourage my efforts left me feeling that she could not relate to me as a person or as a learner. My lack of connection with her impacted my diligence in following her instructions. However, I remained interested in learning the piano. I just wanted to do it my own way. 


\section{“I Can't Eat Ice Cream on a Day like This!"}

The day of my Grade 2 piano exam had arrived and, as always before any kind of performance, I was extremely nervous. The first part of the exam consisted of scales and other technical exercises. Playing the exercises first allowed me to become accustomed to the feel and sound of the piano. However, I did not adjust well to this particular instrument. It had a firmer touch than my own piano and, in my state of terror, my hands were shaking so violently that I approached the instrument very tentatively. Although I knew my scales well, a few of the notes didn't sound as my hands moved up the keyboard.

At that point, I decided that all was lost. I continued to play the rest of my technical exercises and pieces, but I could barely see the keys through the tears in my eyes. Through hours of practice, I had developed sufficient muscle memory that I was able to finish my exam program, but all sense of control over the experience or of emotional involvement in the performance was lost. I played mechanically, automatically, like a robot, overwhelmed by my desperate wish to be finished and to leave the examination room.

When the exam was over, I met my mother in the waiting room and followed her out to the car with my head hanging. She had promised to take me to the Dairy Queen for ice cream as a treat after my exam, but when we arrived at the restaurant I wouldn't leave the car. I was distraught. As far as I was concerned, I was a failure. My life was no longer worth living, even if I got ice cream. My mother tried to reassure me, saying, "I'm sure it wasn't that bad, " but I was inconsolable. Eventually, my mother gave up and took my siblings, who had been anxiously waiting for their promised ice cream, into the restaurant while I bemoaned my fate outside.

A few weeks later, the exam results arrived in the mail. My hands were shaking as I handled the envelope. I had been consumed by anxiety since the day of the exam, and now I would finally know the extent of my failure. I tore open the envelope and scanned the page for the total mark. When I found it, my jaw dropped. My mother later told me that when she saw the shocked expression on my face, she momentarily panicked, thinking that maybe I really had failed. The results showed the contrary, however. I had received a good mark after all. A wave of relief washed over me. Even though I had felt so terrible about my exam performance, I had succeeded. My judgment of my own performance had apparently been very flawed. I still was not convinced that I really deserved the mark I had obtained, but I deferred to the expert's evaluation. If the examiner was pleased with my performance, then so was I, even though at the time I had felt miserable. Now I was eager to continue working towards the next goal.

$* \quad * \quad * \quad *$

My success in my Grade 2 exam was all the more important to me because I had completed the preparations entirely on my own. After my lessons with Karen ended, my parents told me I could continue playing, and that, if I wished, they would register me for the next examination. If I completed the exam independently, they would consider finding another teacher for me. Because the lessons were expensive and they did not want to take money out of 
our limited family budget if I was not motivated, my parents wanted me to demonstrate to them that I was seriously interested in studying the piano. Working on my Grade 2 exam pieces was often extremely frustrating, as my practice strategies consisted of trying to play the piece perfectly from beginning to end with no mistakes. At this point, I remember very little enjoyment connected to playing the piano, and many, many tears of exasperation. However, I was determined that I would complete my upcoming exam and thus prove to my parents that I wanted to continue taking lessons.

Preparing for the exam without the assistance of a teacher showed me how much I could accomplish with a high level of self-discipline. From that time on, I was hooked on the exam system. I began to work diligently, spurred on by the prospect of getting to the next level. My new teacher (and the following one, whom she recommended when she felt that I had advanced too far for her to help me) stimulated my progress and encouraged me to aim high. I continued to work hard and eventually received a first class honours designation for my Grade 9 exam.

However, my confidence in my skills as a pianist was about to be profoundly shaken.

\section{My Identity Shattered...}

After some of my early successes in studying the piano, I had built up an identity for myself as a musician. By the time I was thirteen, I had decided that I wanted to study music at university so that I could have a career as a piano teacher. While I devoted considerable effort to my academic work, my main goal in doing well at school was to increase the probability that I would earn an academic scholarship to put towards my music degree. Everything progressed as I wished for the first part of my high school career, but in Grade 11 my carefully orchestrated plan began to unravel.

The Royal Conservatory of Music syllabus recommended allowing at least two years of preparation time after completing the Grade 9 exam before attempting Grade 10. However, with the omniscience granted to all sixteen-year-olds, I decided to ignore this guideline. My teacher, who may not have prepared anyone else for the Grade 10 exam, went along with my wishes. My plan might have worked had I been able to concentrate more fully on my piano studies, but the year during which I prepared for my Grade 10 exam was also the busiest year of my high school career. I struggled to find sufficient practice time, between taking a full course load, playing the oboe in the school band, serving on the band executive committee, taking driver's education 
courses, teaching piano, participating in a variety of church activities and studying music theory outside of school. As the exam approached, it became clear that I was not quite as prepared as I could have been.

The exam was an unmitigated disaster. I knew from the moment I felt myself experiencing difficulty negotiating the Bach fugue that there would not be a positive outcome to this exam. I cried most of the way home that afternoon. However, a small part of me hoped that somehow when the results arrived I would see a mark that was better than what I knew I really deserved. That was what had happened all those years ago when I completed my Grade 2 exam, was it not?

The fateful day had arrived. I held the envelope in trembling hands for a few seconds before opening it. I unfolded the form and my eyes searched for the mark, dreading what I might find. Finally I found the total: 74. My fears were confirmed. The mark was more than ten percent lower than what I had earned for my previous exam, and, perhaps even more importantly, I had barely made the required mark necessary to move on to the next level. Unlike my experience with the Grade 2 exam, this time the examiner agreed with my negative assessment of my performance. I was devastated.

I slipped into a depression that lasted for several months. Shame forced me to hide the whole incident from my friends at school. The musical identity I had so carefully crafted for myself through my piano studies and through my participation in the band program at my high school was now invalidated. Just as I had done years before, sitting in the car refusing to eat ice cream, I began to tell myself that I was a failure. However, this time I was convinced that I would be a failure forever. The university entrance auditions I had set as an objective now seemed to be an insurmountable obstacle. My goal of teaching piano was now unattainable, as I could be nothing but an imposter with such a stain on my record. However, in spite of my conviction that a career in music was now no longer an option, I was unable to think of any other field that I wanted to pursue. A feeling of hopelessness settled over me.

\section{...and Put Back Together}

Even after my disastrous exam, I kept up my lessons and practicing, although for a long time without any sense of purpose. Rationally, I knew that basing my self-worth on examination results was not healthy, but my emotions were impervious to that fact. It was only after several months of reflection and of wrestling with my emotions that I began to realize that berating myself was not producing any positive results. Other musicians had experienced bad performances as well and I needed to show myself that I could get up again after a fall. I also needed to re-evaluate the source of my self-worth and make a conscious effort to remind myself that my being valued and loved did not depend on how well I played the piano.

Eventually, my goal-orientation began to re-emerge and I began to focus more on the future. I selected a music festival in which I wanted to participate and decided to enter a category that would allow me to play Grade 10 repertoire in order to redeem myself, at least partially. I also refocused on my university entrance auditions. While I was still disappointed about the exam, I decided to concentrate on the lessons I had learned about preparation and made an effort to move forward. One day, my teacher remarked in my lesson that I seemed happier than I had been in quite some time. I knew then that I had turned a corner. My subsequent performances in university were not all resounding successes, but after my experience with the Grade 10 exam, I developed greater resiliency to deal with disappointments. 
Without my full awareness of what was happening, participating in exams had become my reason for playing the piano. The structure of the exam system motivated me to keep trying for the next level. I also used exams as a way to compare myself with other piano students and to make sure that I was not falling behind. My preoccupation with exam results was unhealthy from the beginning and only became more so as I advanced. As my identity as "musician" grew stronger, so did the connection between my self-worth and others' evaluations of my performances. Even though my teachers and parents had tried to convince me that the exam was simply one person's evaluation of one performance, for me it was the determining factor in whether my identity as a musician remained intact. In my mind, a negative evaluation had more to do with who I was than how I played.

I still have conflicting feelings about my participation in exams. On the one hand, I am glad to have developed technical skills through years of dedicated, focused practicing. However, becoming obsessed with results robbed me of much of the joy and the sense of discovery that had motivated me to start playing the piano in the first place. Now that I have finished my formal piano studies and am no longer working towards exams and recitals, I am renegotiating my musical identity so that it is no longer based only on performance results. I no longer feel the pressure to stretch my technical abilities by constantly playing more and more difficult repertoire. I can focus on maintaining the skills that I have because they are sufficient to allow me to access a wide enough variety of music that I love. While I still sometimes miss the immersion in the world of piano that I had before teaching and other academic pursuits took a more prominent place in my life, I enjoy the newfound freedom that I have to play when and what I want. 
The questions about the role and importance of exams that were raised by my own experiences as a student surfaced again as I embarked on a teaching career and encountered parents who had very decided views on the subject.

\section{But they don't want to take exams...}

I had been teaching the four siblings for about two years, during which time the older sister and brother had each completed an exam. Preparing for the exams was not an easy task. Neither student had devoted much time to practicing, nor had they heeded the detailed instructions regarding specific practice strategies that I had written in their notebooks week after week. Several times, we set goals of completing the exam in a particular session, only to realize as the application deadline was approaching that there was no way they would be readying in time. Finally, Julie completed the Grade 1 exam, and Jonathan the Introductory level. After they received their feedback from the examiner, we sat down to discuss the experience and our plans for the upcoming academic year.

I had recently started my doctoral work and was full of ideas from my graduate courses that I wanted to try out in a real teaching situation. I wanted to find out what kind of musical skills and repertoire they were interested in learning so that we could structure our program around those. I asked each of the students if they were interested in preparing for the next exam level and the answer from both was a resounding "No." They were bored by the required repertoire and were not interested in devoting many months to the kind of methodical, sometimes tedious, practicing that is required for a high level performance in an exam. Both students indicated that including a wider variety of music, particularly some popular pieces, would make their music studies more meaningful. However, when I discussed this possibility with their mother, she was adamant that we not abandon the exam system. In her view, paying for lessons was only worthwhile if her children would gain a certificate from the experience. Surprisingly, she also said that she felt that doing exams would mean that her children would continue playing for longer. I also wanted to do everything I could to ensure that music would be a meaningful part of these students' lives well into the future; however, I was not convinced that forcing them to participate in evaluations, which they found boring and stressful, was the way to accomplish that goal.

Shortly after this conversation, my relationship with this family ended. The stated reason was issues over payment, but I also knew that this mother and I had some irreconcilably different views regarding musical values and instructional approaches.

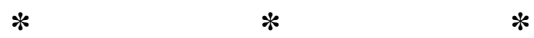

While the preceding narrative details one of the most dramatic examples of a disconnect between student interests and parental expectations that I have encountered as a teacher, I have had many students who were less than enthusiastic about participating in evaluations. Others, 
however, have enjoyed the preparations and have found the overall experience to be extremely satisfying. My research interest comes out of a desire to understand how and why evaluative performances, such as exams and festivals, can be experienced in such different ways. I hope that through this research, I can highlight some ways in which teachers can ensure that their students' experiences learning the piano are positive and meaningful regardless of whether they participate in evaluations.

\section{Rationale}

Hundreds of thousands of North American piano students participate in conservatory examinations and festivals each year (Royal Conservatory of Music Examinations, 2012). While evaluative performances are often regarded as a necessary and even inevitable part of piano study, it is far from certain that participating in these assessments is uniformly beneficial for students. The graded levels are used by students, teachers and parents as a benchmark for student progress and achievement (Davidson and Scutt, 1999). However, students' learning often progresses in very individualized and non-linear patterns that may not be reflected in a strictly graded system. Evaluative performances are also thought to motivate students to practice more than they would otherwise if they were not working towards a performance goal. While an impending evaluation can certainly provide a short-term incentive, it is highly doubtful that this kind of "carrot and stick" approach results in meaningful long-term engagement in learning (Kellaghan, Madaus and Raczek, 1997). Some teachers depend on their students' results as a way to establish and maintain their professional reputations (Davidson and Scutt, 1999).

Unfortunately, this preoccupation with results can lead to teachers neglecting to pay attention to other evidence of successful teaching. In extreme cases, teachers can identify so strongly with 
their students' performances that they can develop achievement by proxy disorder (MacArthur, 2008) with disastrous consequences for the treatment of the student.

Evaluative performances can provide excellent preparation for students who are intending to pursue careers in music; however, most children who take piano lessons end up in other fields of work (Cooper, 2001). In the latter cases, piano lessons would be more profitably aimed at preparing students for musical activities that can be pursued in leisure time (Zenker, 2004). Because the curricula used for evaluative performances is standardized, the student is expected to conform to the dictates of the evaluating body rather than following a course of study that is tailored to individual needs and interests. Even when a student achieves high results in these evaluations, he or she may still be lacking skills that could enable continued participation in music as an adult (Zenker, 2004). My research will provide insight into the participants' actual experiences with evaluative performances so that the role of these assessments in student learning can be better understood.

\section{Purpose}

This research illuminates two important aspects of student involvement in evaluative performances. First, I generate a theoretical model to explain the process of participation in evaluative performances, taking into account the various factors that influence whether a student participates and what the outcome is. However, it is not enough to simply understand what happens; for this research to be meaningful, it is necessary to have insight into students' firsthand experiences with evaluation. Many decisions regarding evaluative performances are based on the views of parents and teachers and do not necessarily take into account the student's thoughts and feelings on the issue. In this study, I give the student's experience the central place 
that it deserves. These research findings could be used to help teachers, students, and parents make decisions about student participation in evaluative performances that are based on the needs of the individual student rather than on assumptions about what music instruction should look like. It is my hope that the stories contained in this report can serve as examples of the kinds of positive experiences towards which all stakeholders in music learning should be contributing and of the negative experiences that we should all be working to avoid.

\section{Research Questions}

In order to gain a better understanding of how participating in festivals, exams, and competitions influences various aspects of student learning and engagement, this study investigates the following question:

- How do beginning and intermediate piano students experience the process of participating in evaluative performances?

- What are the defining features of a positive experience with an evaluative performance?

- What factors influence whether an evaluative performance contributes to high levels of engagement in music learning?

\section{Defining "Evaluative Performances"}

In order to examine this topic in more detail, it is first essential to have a clear definition of what is meant by the term "evaluative performances." The word "evaluative" implies a judgment of quality or placing value on particular aspects of the performance. Evaluative and competitive situations are pervasive in Western society and this preoccupation extends to 
musical pursuits. It is difficult for audience members in many musical settings to listen to a performance without making value judgments as they do so, or at the very least, depending on experts to tell them whether the performances was good or bad (Small, 1998, p.34). Even in settings such as church services, school concerts or community events, feedback is often presented in an evaluative way, for example "The choir is sounding really good these days" or "That ensemble has really improved since the last concert." While both of those comments are positive, they are focused on evaluating the performance rather than on the audience member's experience of the event.

However, there are some important differences between the kinds of evaluations that audience members make and the kinds of evaluations to which students are submitted in a festival or exam situation. The opinions of expert evaluators are given more weight by students (as well as by their teachers and parents) (Abel and Larkin, 1990; Brotons, 1993; Maroon, 2003). As a result, being assessed by an expert can contribute to higher levels of performance anxiety. For the purposes of this paper, I will focus on the evaluations that take place in a more formal setting, with an expert evaluator providing the feedback.

It could be argued that a musical performance occurs any time music is played, particularly for a live audience. Musical performances take place in a myriad of settings, many of which are quite informal (for example, families singing Christmas carols together, a sing-along at a nursing home, or a drum circle at a park). In these settings, the music-making is communal and the performer(s) and listener(s) are not segregated the way they are in more formal performance settings (Small, 1998).

More formal classical performances usually take place in a venue devoted, at least temporarily, to the event, and involve long periods of preparation on the parts of the performers. 
As a result, there is an expectation on the part of the audience (whose role is generally confined to sitting and listening rather than actively participating in the performance) that the performance will be of high quality, taking into account the ages and level of professionalism of the performers. This latter type of performance can easily turn into an evaluative occasion, as audience members assess whether the performance was worth the cost of the ticket, or how their child's performance compared to that of other children. However, the most strongly evaluative performances are those that exist solely for the purpose of giving the participants a mark, rank, rating, or other form of feedback from an adjudicator.

\section{Limitations of the Current Study}

While this research draws attention to several important factors that influence how students experience participating in evaluative performances, the study has several limitations. Many of the limitations of the study arise from the small participant pool that is also the strength of in-depth qualitative research.

While the depth of the data elicited from participants in qualitative research necessitates a small participant pool, this research could likely have benefitted from a greater diversity of student participants. Notably, there were very few male participants. This limitation in the participant poopl could have affected the scope of the findings, as previous research relating to sport (Hamm and MacLean, 2008) and graduate education (Price, 2008) has found differences in how males and females respond to competitive situations. These differences are likely the result of socialization (Frick, 2011). However, other research (Hibbard and Buhrmester, 2010) that examined competition for winning (in which there is one winner and all others must lose) and competition for excellence (in which participants compete against themselves to improve in a 
particular skill) found no differences in the incidence of the two types of competition between male and female late adolescents, but greater negative effects for females who were engaged in competition for winning. Based on this research, it could be possible that the female participants in this study were exposing themselves to greater degrees of risk to their emotional health by entering competitive music festivals.

The current students were all studying with the same teacher at the time of data collection. However, most had studied with other teachers in the past and were able to discuss differences in their experiences preparing for evaluative performances at the time of the research and with previous teachers. In addition, the former students provided valuable insights into the experience of studying with a variety of teachers.

One of the difficulties in recruiting participants was in finding current students who were having negative experiences with evaluative performances. While it is likely unrealistic (particularly based on the data collected from former students in this research) to think that every student who is currently participating in festivals and examinations is experiencing enjoyment and productivity, it is difficult to locate and engage these students in research. The necessity of going through gatekeepers such as parents and teachers effectively limits the student participant pool to those whom the adults are eager to "show off."

While the participant voices described above would undoubtedly have contributed valuable insights to this research, the existing participant pool nonetheless provided ample information upon which to base a theory of student experiences with evaluative performances. I believe that this research makes a significant contribution to the field of music pedagogy as it invites the reader to think about issues surrounding student involvement in evaluation. By taking 
the ideas presented in this document and looking for incidences of dissonance or resonance with their own experiences, readers can use this research to confirm or challenge current practices.

\section{Organization of the Thesis Document}

This thesis contains eight chapters in total, followed by three appendices. The first chapter introduces me as a former student, current teacher, and researcher and outlines the purpose of the current study.

Chapters Two and Three provide important background information necessary for understanding the insights of the participants and analysis contained in Chapters Four to Eight. Chapter Two will contain a more detailed examination of the construct of "evaluative performances," including the historical background of festivals and conservatory exams and connections to the broader social and educational context. This chapter will also discuss the existing literature related to evaluative performances in order to establish how this study contributes to the field.

Chapter Three details the methodological approach used in this study, including grounded theory and narrative research. I have also included examples of other studies that have employed similar methodology. In addition to general information about the methodologies used, this chapter contains a detailed breakdown of the specific design of this study.

Chapters Four to Seven present the participants' insights into their experiences and a gradual unpacking of the main analytical categories of the research. Chapter Four contains important background information on the participants and on the process of student participation in evaluative performances. Using descriptions from the participating students, I examine several 
important elements of participation in evaluative performances in the chronological order in which they occur.

Chapter Five describes a positive evaluation experience, answering the question "What does it look like when evaluative performances facilitate engagement in music learning?" I also employ two important theoretical perspectives to underscore the importance of positive experiences in propelling future learning.

In Chapters Six and Seven, I examine various factors that contribute to positive evaluation experiences. Chapter Six focuses on the individual characteristics of the student, including his or her understandings, values, and goals. This chapter also contains a section on students' characteristics as performers and the impact of performance anxiety on experiences with evaluative performances.

Chapter Seven focuses on the relational context in which students learn. I highlight the unique roles of parents and teachers, as well as the ways in which these important adults jointly support students' learning and participation in evaluative performances.

Chapter Eight presents the theoretical model that emerged from the data discussed in the earlier chapters. The theory is presented in both narrative and visual form, followed by several propositions. This final chapter also includes recommendations for further research and implications of this research for pedagogical practice.

Supplemental materials, including interview guides, survey questions, and informed consent letters are included in the appendices at the end of the document. 


\section{Chapter 2 \\ Examining the Central Constructs}

As discussed at the end of the previous chapter, evaluative performances are musical events that are contrived for the purpose of passing judgment on a musical performance. The person passing judgment is frequently an expert who has been hired specifically for that task, and this adds to the importance of the feedback that is provided (Abel and Larkin, 1990; Brotons, 1993; Maroon, 2003). Evaluative performances frequently act as summative evaluation events to mark the completion of various stages in a student's musical career (Kogan, 1987; Babin, 2005;

Tye, 2004; Davidson and Scutt, 1999). They may or may not be explicitly competitive events; however, even in the absence of overt rankings, students, teachers and parents can easily find ways to compare a student's results with the results of others who participated in the same evaluation. In the context of the present study, the evaluative performances in which students participated included competitive festivals and conservatory examinations. This chapter will explore the construct of evaluative performances in more detail through an examination of their historical and educational contexts and through the existing research that addresses various issues surrounding exams and festivals.

\section{Historical Background of Evaluative Performances}

The Romantic era brought about two developments that still have a profound influence on the way most piano students learn (Babin, 2005). The first was the rise of the virtuoso performer and the development of conservatories that were designed to train professional concert pianists (p.2). The second important development was the prominence of the piano as an instrument for amateurs (p.3). With the advent of printing, sheet music became readily available 
and many homes had pianos as a source of entertainment. Being able to play and sing was a requirement for any young lady who wished to be considered accomplished.

As piano skills became valued, not only for professional musicians, but also for dedicated amateurs, conservatories began to expand their offerings to include preparatory education. Geographical considerations helped to spur the development of the examination system. Students and teachers who were far away from the main centre could still access curriculum guidelines and receive feedback from visiting examiners. The first examination board to offer local music examinations was the Trinity College of Music in England, which began testing students in 1876 (Salaman, 1994). The Associated Board of the Royal Schools of Music (ABRSM) began offering exams in 1889 and has since developed into the largest music examining body in the world, attracting approximately 600,000 candidates from numerous countries on an annual basis (Ross, 2009). While the ABRSM offers examinations in a variety of practical and theoretical subjects, the piano exams are the most popular.

In Canada, the Royal Conservatory of Music (RCM) offers the most prominent musical examination system. The RCM (originally called the Toronto Conservatory of Music) was founded in 1886 and has adopted a dual mandate of training highly skilled professional musicians as well as students and amateurs. Until 1991, it was connected to the University of Toronto, but it has since become an independent school and is the largest arts education institution in Canada. The examination system run by RCM attracts over 100,000 students per year from across Canada and has recently expanded to offer examinations in the United States through the Royal Conservatory Examinations Certificate Program (Royal Conservatory of Music). Students can take practical examinations in a wide range of instruments, as well as theory and music history examinations. The RCM also offers advanced diplomas in performance 
and teacher training. Because the RCM plays an influential role in teacher development, many teachers who are regarded as highly qualified professionals have been immersed in the RCM curriculum and assessment system.

Conservatory Canada is another well-known Canadian examination system and offers a program similar to that of RCM. It was founded in 1997, when two longstanding regional examination boards, the Western Ontario Conservatory of Music (based in London, Ontario) and the Western Board of Music (based in Edmonton, Alberta), merged. In addition to evaluation by examiners, students who participate in Conservatory Canada exams also have the option of scheduling a brief clinic with the examiner. Students from remote communities can participate in electronic examinations, made possible through digital technology (Conservatory Canada).

The Canadian National Conservatory of Music (CNCM) offers a wide variety of programs to suit the needs of diverse piano students. These program offerings include a graded workshop, which is similar to the exams offered by the above institutions, but automatically includes a brief workshop, which parents and teachers are also permitted to attend; a performance examination which is conducted in the form of a recital, and a program entitled "Music for Everyone," which allows students to set their own goals and receive feedback on their work. CNCM also strives to encourage the composition and performance of Canadian music through a series of graded publications (Canadian National Conservatory of Music).

In addition to the aforementioned national examining bodies, there are also several more locally-focused music schools and conservatories throughout the country that offer their own versions of standardized curriculum and evaluation. While each examining body has a slightly different focus, all exist with the stated purpose of ensuring high quality instruction for piano students. 
Although the focus of the current research is Canadian, I will also make mention of the Associated Board of the Royal Schools of Music (ABRSM), as two of the former students who were interviewed for this study had participated in ABRSM exams as children. While originating in Britain, these exams have a wide international reach and are still extensively used in many parts of the world, particularly in former British colonies. The ABRSM offers evaluations for various solo instruments, as well as chamber groups and choirs. In addition to the graded performance examinations, students can also participate in less formal performance assessments, involving fewer repertoire selections. Young students who are not yet ready for the graded exams can also participate in introductory testing designed to be a gentle introduction to the exam system (ABRSM, 2012).

In this research, the term "festival" is used to describe a competitive festival for student musicians rather than the other common use of the word that describes a performance event (usually a series of performances highlighting a particular genre, such as chamber music or jazz) where the participants are often professional musicians. The competitive festival movement seems to have originated with band competitions in Britain, and subsequently in North America. There is also a record of fiddle competitions in Montreal in the mid-1800s. However, the first general competitive festival as we know it today likely took place in Edmonton in 1908, at the urging of Governor General Earl Grey (Canadian Encyclopedia of Music). Festival competitions for piano students are often run by community organizations (for example, the Kinsmen Club) or national or regional teachers' associations as a way to encourage the development of young musicians. Students can progress through several levels of competition, starting at local festivals and moving on to provincial or state competitions, and eventually national competitions. At the 
higher levels of competition, students often have opportunities to win monetary prizes or scholarships.

Festival participation is often closely linked to the conservatory examination system. Students are generally grouped by conservatory grade level (or sometimes by age, with a minimum conservatory level requirement) and are usually required to play one or two pieces per category. These selections are taken from the syllabi provided for conservatory exams. While some piano students participate in only festivals or only exams, many participate in both, using one performance as preparation for the next.

\section{Educational Context of Evaluative Performances}

Evaluative performances are promoted as contributors to music learning. Assessment and evaluation play an important role in all formal educational contexts. The following section discusses some issues related to standardized academic testing and the ways in which music festivals and examinations reflect school-based practices.

\section{Standardized academic testing.}

Many publicly educated students are evaluated regularly, not only by their teachers, but also by larger government-based testing bodies. Parents, administrators, school boards, and government bodies all depend on the results of these various evaluations to determine whether students are learning required material. These evaluations are significant, not only for individual students and teachers, but also as an indicator of the health of the entire education system. Supporters of standardized testing often refer to tests as a way to keep schools accountable and to maintain a high quality curriculum. These writers advocate the importance of aligning 
curriculum and assessment (Goodman and Hambleton, 2005, p. 94) and of instituting a demanding curriculum in preparation for the test (Crocker, 2005, p. 165). In the views of proponents of testing, the use of tests forces educators to implement a better quality curriculum than they would if they were not under pressure to obtain high test scores. In addition to shaping a better educational experience, tests are thought to be able to diagnose problems (Phelps, 2005, p. 56), both with educational systems and with individual students, so that these problems can then be resolved efficiently.

However, opponents of standardized testing are quick to point out that tests do not provide a complete picture of the quality of a school or of a student's achievement or potential. Hampton (2004) advocates evaluating schools in a more qualitative fashion, focusing on issues such as whether students are encouraged to engage with intellectually significant ideas (p. 257) and whether the needs and aptitudes of individual students are taken into consideration when curricular decisions are made (p. 258). In order to assess the achievement and progress of individual students and to communicate this information to parents, Decker (2004) suggests using strategies that demonstrate students' progress over time and that emphasize the ways in which the child is intelligent rather than holding one view of intelligence and using it to rank students (p. 265). Both Hampton and Decker provide valuable insight into how schools can maintain a high standard of quality and can reassure parents of that fact without relying solely on test scores, which can only provide a limited view of a school. Their views are in accordance with those of proponents of authentic assessment practices (Burke, 1992; Janesick, 2001), who also advocate for the valuing of process over product, the connection of assessment to meaningful, real-world learning, and the use of a wide variety of instructional approaches and assessment to give every student an opportunity to demonstrate his or her full potential for 
achievement.

Standardized tests are "designed to provide a level playing field" (Sireci, 2005, p. 113) in which all students are treated in the same way and are thus given the same opportunities. However, many factors impact students' potential to perform well on a test. The student's race, gender and socio-economic status can all impact his or her ability to meet the demands of a particular test (Meaghan and Cases, 2004, p. 37). Students also have different perceptions of the relevance of the material included on the test and have different preferred means of communicating what they know (Ibid.). Because only certain aspects of a curriculum are legitimized by standardized testing, tests can have a significant negative impact on curriculum. The aspects of the curriculum which are known to be on the test become the exclusive focus of instruction, and other areas of learning are neglected (Kellaghan, Madaus, and Raczek, 1997, p. 37). Moll (2004) draws attention to the disadvantages of placing the power to determine test content in the hands of large, central organizations. She argues that large-scale tests do not emphasize learning because they allow little room for addressing local needs (p. 15).

One of the most common reasons given to support the use of standardized tests is the supposed increase in motivation that occurs when students know that they will be evaluated (and likely compared to others). Phelps (2005) states unequivocally that students "work harder and learn more" (p. 61) as a result of test preparation. However, Kellaghan, Madaus, and Raczek (1997) question the assumption that students exert more effort when they know that their performance will be rewarded or punished, particularly when the rewards are distributed on a competitive basis (p.6). Rather than inspiring the kind of intrinsic motivation that leads to longterm engagement with learning, standardized tests encourage students to focus on extrinsic rewards. This emphasis in turn leads to students avoiding challenging tasks and risk taking 
(Kellaghan, Madaus, and Raczek, 1997, p. 49).

\section{Standards in music education.}

While high-stakes tests in elementary and secondary school music classes are rare, the use of standards to legitimize and advocate for music education is widespread in North America. Like in other areas of curriculum and assessment, standards in music are seen to provide accountability and quality control by setting out curriculum objectives at the national level. The knowledge reflected in the standardized curriculum becomes "musical capital" (Froelich, 2007, p. 109). In Canada, the National Symposium on Arts Education has published a document entitled Sharing the vision: A national framework for arts education in Canadian schools, which outlines the contributors views on the fundamental reasons for music education in schools and on the experiences that all students in a Canadian school music class should have (National Symposium on Arts Education, 2001, p. 3). This document is supported by the Canadian Music Educators' Association, but has not been adopted by provincial ministries of education. As a result, its influence on music education in Canadian schools has been fairly limited.

In the United States, the Consortium of National Arts Education Associations, with strong financial backing from the Music Educators' National Conference, developed the National standards for arts education in 1994. This document has attracted widespread attention and its use is required in many school settings. Because it is better known than the Canadian standards document, much more has been written about the American National Standards by various scholars in the field of music education. Some are strongly supportive of the standards, citing the threatened status of music education and the role of the standards in firmly establishing music as a subject that is important for all students (Music Educators' National Conference, 
1997, p.41). Other supporters see the standards as an opportunity to ensure that students are exposed to a broader range of musical experiences than simply performance, which has traditionally been the focus of many school music programs (Reimer, 2004, p. 34).

Both Byo (1999) and Orman (2002) see the institution of the National Standards as a positive development in music education, but found that the existing Standards are not necessarily implemented as intended. Byo (1999) examined the perceived abilities of specialist music teachers and generalist teachers (those not specifically trained to teach music) to implement the National Standards and found that generalists nearly completely rejected the standards due to limitations of time, resources and training (p. 120). This rejection could pose a significant problem for supporters of the National Standards, as many music classes, particularly at the elementary level, are taught by generalist teachers. Orman's (2002) research examined elementary teachers' use of class time in comparison with the National Standards. He found that teachers spent much more time on the standards related to performance and reading notation and less on the standards related to creative activities (p. 162). If all of the standards are to be given equal attention, music teachers need to broaden their skill base in order to feel confident in a variety of music learning scenarios.

Not all of the voices writing about the National Standards are supportive. Colwell (1995) identifies several drawbacks of implementing a system of national standards. The first is that the experiences that students bring into the classroom are far from standardized (p. 9). He also posits that being forced to adhere to standards will discourage creative, independent people from entering the teaching profession (p. 9). In response to those who would argue that standards are necessary in order to ensure quality music education, he writes, "The essential element in a strong arts program is an enthusiastic, able teacher. Those qualities are not always quantifiable 
and may not be teachable" (p. 10). Benedict (2006) is also highly critical of the standards movement in music education. She claims that, rather than improving the quality of music education, the standards serve to preserve the status quo (p. 19). In her view, the definition of a musical education that is put forward by the National Standards is limiting in that it is too focused on the technical aspects of music-making (p.27).

\section{Relating evaluative performances to standardized assessment and curriculum.}

Striving for legitimacy and increased status has led to music educators adopting many strategies that are aimed at showing that music is as "serious" a pursuit as any other academic subject. One of the most widely applied strategies has been the use of a standardized curriculum for music instruction. In the same way that government bodies try to ensure a certain quality of instruction by mandating what content will form the basis for standardized academic testing, music examining boards have always had standard curricula in order to ensure that the certificates awarded represented a certain level of achievement (Royal Conservatory of Music, 2008). Syllabi are compiled in such a way as to ensure that students cover certain repertoire and technical skills that are considered "basic" or essential in learning a particular instrument. Other skill requirements, such as sight reading and aural identification of various musical patterns, are often included as well to provide a more balanced musical education.

The unfortunate consequence of focusing on standardized curriculum and assessment practices is the limiting of students' engagement with the entirety of the content that makes up a discipline. In the case of music study based on conservatory examinations, creative aspects of music-making, such as composition and improvisation, are generally left out of exam curricula, perhaps because they are potentially more difficult to assess (Dineen and Collins, 2005, p. 44). 
The required repertoire contained in syllabi for exams and festivals tends to revolve around music from the Western classical tradition. While some examination boards offer the option of including a popular selection or even of completing an entire exam focused on more contemporary or popular music, the very nature of evaluative performances runs counter to the ways, such as listening to recordings and creating one's own version of existing music, in which accomplished popular musicians learn (Green, 2002). In this way, the evaluative performance could be said to undermine the overall experience of learning popular music.

There are several problems with the implementation of set curriculum and evaluation procedures. The first is that the testing body legitimates certain aspects of learning and evaluation (Broadfoot, 1996, pp.7-8), without taking into account the particular characteristics of individual teachers and students (Decker, 2004, pp.260-261; Moll, 2004, p. 15). Many students can feel alienated and have fewer opportunities for success if they do not see themselves reflected in the curriculum that is to be tested. Predetermined content and criteria also result in "teaching to the test," in which other aspects of the subject area are neglected in order to focus solely on what will be evaluated (Crocker, 2005, p.159). In this way, students who do not see a connection between their own strengths and interests and the contents of the test are doubly punished - not only is it more difficult for them to achieve good results on the test, but their own interests are devalued because they are not included in the curriculum.

Teaching to the test can also result in an inordinate focus on training students to answer specific types of questions (Nichols and Berliner, 2007, p.125). For example, in an academic context, students are often drilled on strategies for answering multiple choice questions. In a musical setting, teaching to the test could mean listening to and imitating recordings provided by the examination body or recordings of previous competition winners. Test concerns also impact 
the content of instruction, as teachers and students often choose repertoire that they know is "safe" for the student so that he or she will not lose marks by presenting a less than stellar performance of repertoire that may be more challenging or in a less familiar style for that particular student. When skills such as sight reading and aural recognition are tested, students often do not go beyond the specific types of exercises that will be part of the evaluation.

Standardized academic tests are designed to measure students' achievement based on clearly defined levels. One of the hallmarks of evaluative performances is the creation of many discrete levels in which students' learning and achievement are segmented. While the dividing of music learning into levels is convenient for the purposes of distributing certificates, it poses several problems. First, it requires the categorizing of repertoire in an artificial manner, as the music was generally not composed for the purpose of being put into levels. Also, having rigid levels with progressively more difficult expectations does not take into account that students' learning is often not linear or that different students struggle with different aspects of learning (Small, 1998, p. 188).

One of the most important roles of standardized academic tests is the purported increase in accountability that occurs through the generation of data regarding a school's performance. This information is conveyed to the various stakeholders who influence and are influenced by the quality of education offered at a particular school (Hampton, 2004, p. 257; Phelps, 2005, pp.5657). This increased level of accountability in turn is intended to ensure that a high level of quality is maintained in the education of all students, as having a test at the end of a year or unit of study is assumed to motivate teachers and students to produce their best work (Kellaghan, Madaus, and Raczek, 1997; Phelps, 2005). Government funding policies often reward or punish schools based on their performance on standardized tests (Nichols and Berliner, 2007, p.7). These financial 
incentives, combined with the pride or shame inherent in publicly available results, are supposed to motivate both teachers and students to produce their best work.

While evaluative performances in music do not come with the same high stakes as standardized academic tests, results from festivals and exams are still used to establish the quality and reputation of school music departments or of individual teachers. Many school music departments proudly display their trophies from various festivals. These awards are frequently used by administrators and other members of the school community not directly involved in the music program as evidence of the superiority of their school's music offerings, adding to the pressure on some music teachers to continue accumulating more and more awards regardless of whether this approach results in the most meaningful learning for a particular group of students (Austin, 1990). Private teachers often cite their students' past exam and festival results as a way to bolster their professional reputations and increase business (Davidson and Scutt, 1999). In some cases, documentation of student results is required for membership in professional associations (Ontario Registered Music Teachers’ Association, 2012). Unfortunately, many positive outcomes that occur in non-evaluative situations, such as students who find their own musical voice through composition or students who find meaning in using their music in social settings, go unrecognized.

Both academic tests and evaluative performances are based on a standardized, externally determined curricula and evaluation procedures, which are intended to ensure that the evaluation is objective (Kohn, 2000, p.4). Objectivity is highly prized in a society that values scientific evidence over subjective judgments; however, the idea of objectivity is problematic because it is impossible to have an evaluation that is not in some way influenced by the person designing or administering it (Boyle and Radocy, 1987, p. 2; Apple, 2004, p. 108). In evaluative 
performances, objectivity is supposed to be achieved by having standard training procedures for examiners and by having more than one adjudicator at some festivals. However, even when the evaluation criteria are determined ahead of time and the evaluators are given consistent training, judging a musical performance is still intensely personal and influenced by a variety of nonmusical factors (Bergee and Platt, 2003; Ryan, Wapnick, Lacaille, and Darrow, 2006).

Because many music educators feel the need to establish the legitimacy of their discipline, they often resort to strategies that have been applied in other areas of learning without examining the costs. In many learning situations, a set curriculum, a standardized evaluation process, an "objective" mark or rating and a formal recognition of achievement upon completion of a distinct level are all markers of a high quality, serious pursuit of knowledge in a particular area. Evaluative performances in music serve many of the same purposes as standardized assessments in other curriculum areas; however, they also entail many of the same drawbacks, such as limited curricular offerings, lack of recognition of students' differing learning styles and rates, and reliance on potentially unreliable data to establish the reputations of teachers and programs.

\section{Relating evaluative performances in music to competitions in other athletic and} artistic disciplines.

While music examinations are not competitive situations, music festivals have many characteristics in common with competition in certain sports and in dance. In particular, sports such as gymnastics and figure skating, which include an element of artistic judgment in addition to the measurement of technical skills or athleticism, can be experienced in similar ways to music festivals. In many cases, young athletes follow a course of progressively more demanding 
competitions in the same way that musicians do. The following discussion addresses some of the existing literature in these other disciplines.

MacArthur's (2008) study into the drive to strive present in elite gymnasts and musicians sheds important light on various factors that contribute to the development of these young artistic performers. Her research identified parental support (p. 209), knowledgeable and motivating teachers or coaches (p. 240), and the student's self-efficacy as the most significant influences on students' drive to achieve. In this study, similar experiences were reported by both gymnasts and musicians. MacArthur's findings are also consistent with studies of student performance in music examinations that have highlighted the importance of parent and teacher interactions (Davidson and Scutt, 1999) and identified self-efficacy as the main influence on student achievement (McCormick and McPherson, 2003).

LaPointe-Crump's (2007) reflective article addresses the issue of competition in dance education. With the great popularity of television shows such as Dancing with the Stars and So You Think You Can Dance, competition has taken on a significant role in the public's perception of what is involved in becoming a dancer. In addition, students regularly compete within studios for roles. However, LaPointe-Crump raises some important issues for consideration regarding the role of competition in dance education. For example, what impact does the prevalence of competition have on the creative process in dance? Is it possible for a dancer to achieve an artistic experience while performing in a competition? What happens to losers in situation in which there can only be one winner? Morris (2008) echoes some of La-Pointe-Crump's concerns in her examination of two major ballet competitions. She expresses concern that participation in competition leads to dancers focusing on technique over creativity and aesthetic performances, particularly as dancers sometimes learn their competition pieces through replication of video- 
recorded performances of previous years' winners. As will be discussed in the following section, writers in the field of music education have also highlighted issues of technique versus expressivity (Davidson, Pitts, and Correia, 2001) and what happens to music competition participants who do not win (Austin, 1990).

While competition has been the subject of controversy in dance, it has not been immune to critical examination in the field of athletics. Power's (2010) article explores the potential role of competition in the pursuit of excellence in sport and society. He posits that competition can be personally and socially beneficial provided that it takes place within a positive cultural context that places high value on playing by the rules. Other research (Hines and Groves, 1989) has shown that competition in community athletic programs for adolescents does not necessarily have a detrimental impact on the participants' self-esteem, provided that the coaches involved are supportive. Potential drawbacks of participation in competition, such as anxiety and disappointment following a loss, can be addressed when participants focus on task-oriented coping (Gaudreau and Blondin, 2004) and on rebuilding self-efficacy after a loss (Brown, Malouff, and Schutte, 2005). Supportive coaching practices also help athletes cope with anxiety during competition (Nicolas, Gaudreau, and Franche, 2011) while support from parents contributes to participants in competitive sports not dropping out (Robinson and Carron, 1982). Research in music education has also demonstrated the importance of supportive relationships with teachers and parents (Davidson and Scutt, 1999; Creech, 2010) and of students' selfefficacy (McCormick and McPherson, 2003).

Because athletic competition and dance are physically and psychologically demanding endeavours, much research has investigated the prevalence of various physical and other health problems related to participation in sports, including hypoxia in synchronized swimming 
(Davies, Donaldson, and Joels, 1995), substance use in ballet, dance sport, and synchronized swimming (Zenic, Peric, Zubcevic, Ostojic, and Ostojic, 2010), performance anxiety, eating disorders, sense of external locus of control, and substance abuse in dancers (Schnitt, 1990), and eating disorders in synchronized swimmers (Douka, Skordilis, Koutsouki, and Theodorakis, 2008). While the physical demands of musical performance are less than those of dance or sport, musicians do experience difficulties related performance anxiety (Sinden, 1999) and repetitive strain injuries (Kogan, 1988).

The stress experienced by athletes who compete in gymnastics, figure skating, and synchronized swimming and by musicians is often exacerbated by presence of a judging system that can be difficult to understand. Much research in these disciplines has focused on the factors that influence the reliability and validity of various judging systems. Gymansts' body types (Valiquette, 1997) and the order in which skaters perform (Bruine de Bruin, 2006) have been shown to affect judging results. In addition, reforms to judging formulas have not been successful in eliminating the possibility of corruption (Wu and Yang, 2004). Difficulties in establishing a reliable and valid judging system could be partially attributed to the fact that judges tend to avoid giving outlying judgments, thus calling into question the value of agreement as a criterion for validity (Lee, 2008). Many concerns have also been raised about adjudication in music competitions, including the time of day at which a musician performs (Bergee, 2007) and the potential influence of physical characteristics of musicians (Wapnick, Mazza, and Darrow, 2000). These concerns are discussed in more detail in the following section.

Evaluative performances in music share some common characteristics with competition in dance and artistic athletic events, such as gymnastics, figure skating, and synchronized swimming. The first is the importance of supportive relationships with parents and teachers in 
combination with the student's self-efficacy in ensuring positive outcomes of participation in competitive events. Concerns with the potential impact of competition on student's opportunities for engagement in creativity and artistic experiences and with the restriction of access to learning opportunities for students who do not win have been raised in both dance and music. Potential drawbacks of athletic competition (anxiety and lowered self-esteem as a result of competition losses) have also been highlighted; however, some of these potential negative aspects of participation in competition can be addressed through supportive relationships with coaches and parents and through attention to athletes' task-orientation and self-efficacy. Because competitive situations can incite people to continue engaging in activities that have become painful, the literature documents physical and emotional difficulties experienced by athletes, dancers, and musicians. The results of competitions in music and sport can have far-reaching consequences for participants, making the issue a fair adjudication a pressing one in these fields. Research in both athletics and music has identified several factors other than the quality of the performance that can influence the result of a competition.

\section{Establishing the Research Gap: Existing Literature on Evaluative Performances}

Because evaluative performances are a long-standing tradition in music education in many parts of the world, much has been written on how to help students achieve top results. Professional journals aimed at school music and private studio teachers are filled with articles offering advice on rehearsal strategies, skill development, memorization, coping with performance anxiety, and stage comportment. Many music teachers focus their reading on this professional development literature, perhaps unaware that there also exists a body of writing that examines broader issues related to evaluative performances. In this section, I examine the contributions of work based on original research or on the application of educational literature to 
the music education context. I also include a few selections from professional literature as examples of the kinds of articles that would be most likely to influence day-to-day teaching practice.

\section{Literature relating to conservatory examinations.}

This section addresses several facets of conservatory examinations. The first is the role of conservatory exams in students' musical education. While the first article is a persuasive piece, it raises important points for consideration. Following the discussion of the first article is an examination of several research studies, covering curriculum development, the impact of the examination system on pedagogical practice, and the interactions between students, parents, and teachers around examinations.

Salaman (1994) wrote a provocative piece interrogating the role of graded examinations in music. While his analysis focuses on specific requirements from the ABRSM curriculum, the differences between various examination boards are insignificant enough to make his discussion valid in various contexts. Salaman (1994) begins his critique by discussing several commonly perceived benefits of student participation in examinations, such as increased student motivation, more structured curriculum and instruction, measurement of students' musical progress, facilitation of goal-setting, and enhanced teacher reputations when students are successful (p. 210). However, he questions each of these assumptions. Perhaps students who appear motivated by examinations are motivated to achieve rather than to make music. Not all students learn in a linear and highly structured way. The measurement of musical performance that is the purpose of examinations is not actually as accurate or objective as it is often made to seem. While examinations are supposed to be non-competitive, even the drive to achieve a "personal best" 
performance makes learning music more about results than about personal significance. For teachers, having students achieve high results in evaluations is one marker of successful teaching; however, there are many other (and likely more important) aspects of teaching, such as the relationship between the teacher and student, which are not reflected in grades.

Salaman (1994) goes on to discuss various benefits of music study, such as developing performance skills and an appreciation for a variety of music (p. 212). He also cites enjoyment as one of the most significant results of a musical education. However, according to his analysis of examination requirements, participating in examinations could inhibit students' growth in some of these areas. When students are focused on a notation-based way of interacting with music, they can easily miss out on the development of aural and creative skills. Most examinations assess solo performers; therefore, a student whose musical education revolves around taking exams might not experience the joys of being part of an ensemble. A course of instruction that focuses mainly on exams also likely means that the student is developing performance skills at the expense of becoming a thoughtful listener of other performances. Salaman's analysis of a typical examination program demonstrates how the syllabus leaves many gaps in students' musical development, particularly how the technical exercises, sight reading and aural tests, all of which are pursued out of context, take up energy that could better be devoted to interacting with "real" music.

Salaman (1994) raises many important points for private studio teachers to consider, particularly given that many teachers have been content to continue using an examination system that has remained largely unchanged over many years. However, his writing is based on personal opinion and on analysis of written documents, such as conservatory syllabi, rather than on research involving the main stakeholders in the examination system. While Salaman's work 
provides a starting point for important issues and questions to be investigated, follow-up work is still needed to learn whether his views are supported by empirical evidence.

Babin's (2005) dissertation provides a historical perspective on the growth of music conservatories and examination systems in Canada. She follows the development of piano instruction in Canada from the first teachers who emigrated from England and other parts of Europe to the development of the examination system as a result of a desire to standardize instruction so that even students in rural and remote areas received high quality instruction (p. 5).

Babin (2005) provides a detailed analysis of the curriculum requirements of various examination systems. While each curriculum is unique, all have several elements in common. Students are required to demonstrate technical facility through the performance of scales and other technical exercises, to show proficiency in sight reading and aural recognition, and to perform repertoire from various periods in music history (pp. 162-163). Improvisation is not included in the examination requirements of any of the syllabi. While some conservatories allow for limited inclusion of popular music selections in the examination program, the vast majority of the required repertoire is still from the Western Classical tradition.

Babin's (2005) thesis concludes by asking if conservatory examinations should retain their central role in the education of piano students. However, she makes no attempt to answer this question. While her historical account and compilation of syllabus requirements provide a concise reference for readers interested in the workings of the conservatory examination system, it is necessary to ponder larger philosophical questions if a study of piano examinations is to result in positive changes to student experiences.

Tye's (2004) dissertation focuses on the influence of the Associated Board of the Royal Schools of Music (ABRSM) examinations on piano instruction in Malaysia. His research 
illuminates the extent to which examinations are connected to cultural values and expectations. Parents in the geographical region he studied often expect their children to participate in examinations as proof of their achievement. This emphasis on evaluation reflects a desire for concrete evidence of accomplishment in other areas, such as academics (p.30). The examination system is a remnant of colonization and could be seen as a means of oppression. However, Tye describes how many Malaysian parents want their children to be exposed to what they consider "high art" as they feel it is indicative of a high social standing and is part of the education their children will need in order to be successful later on.

Because there is no certification body for piano teachers in Malaysia (as in many parts of the world), teachers often rely on their students' examination results to establish their professional reputations (p.9). They also rely on the examination curriculum to guide their instructional practice, as there are limited opportunities available for them to pursue professional development. Most of the student of the teachers Tye surveyed learned only required examination material and found at least some aspects of the examination program uninteresting (p.97).

Tye (2005) concludes that the widespread participation in ABRSM examinations amongst Malaysian piano students had a negative impact on pedagogical practice, as teachers were unlikely to develop individualized plans of instruction to suit the needs of their students. He recommends the development of a locally designed examination system to better meet the needs of Malaysian piano students and to improve pedagogical practice (p.104).

While a locally developed examination curriculum would likely be more relevant than one coming from another country and culture, Tye does not address the larger issues that could call into question the need for an examination system in the first place. Perhaps he sees the 
societal values that result in such widespread participation in examinations as static and unchanging. However, improving pedagogical practice (and consequently, the experiences of students) would likely require a major overhaul which would include extensive training for teachers and a shift in values that would recognize that valuable learning can take place even in the absence of a numerical grade or certificate.

McCormick and McPherson (2000, 2003, 2006) conducted a series of studies to understand the factors that impact students' performance in instrumental music examinations. The first (McCormick and McPherson, 2000, also reported in McCormick and McPherson, 2003) focused on motivational factors, specifically the factors to which students attributed their successes and failures and the self-regulatory and motivational aspects which predicted student success. Participants in this study were children and adolescents who were participating in graded performance examinations. The musicians completed a questionnaire immediately before the examination in which they identified the factors they believed would influence the results they would receive and described their practice habits in the month leading up to the exam. They also identified the results that they expected to achieve. The findings indicated that most of the students had adaptive attributional beliefs, that is, they attributed success to effort rather than to ability. However, many students also attributed examination results to two less controllable factors, nervousness and luck. This study confirmed other research that has indicated that selfefficacy, or the student's belief in his or her ability to succeed in completing a particular task, is the most important predictor of achievement, even more important than the amount of time spent preparing or the student's actual ability level (2000, p. 37; 2003, p. 47).

In 2006, the same researchers undertook another study to better understand the role of self-efficacy as a variable that affects student performance in music examinations. The research 
design was very similar to the first study, and this study replicated the most important finding from the first work: that self-efficacy is the most important predictor of success (McPherson and McCormick, 2006, p. 324). However, the researchers are quick to remind the reader that selfefficacy is not the only factor that contributes to a successful performance; students must also be equipped with the requisite knowledge and skills.

McCormick and McPherson's $(2000,2003,2006)$ research attests to the importance of developing both "competence and confidence" in students. This information is valuable for anyone interested in improving student scores on music examinations. However, this research does not address the question of how self-efficacy is best encouraged, nor does it question the assumption that graded performance examinations are the best way to measure instrumental music students' learning. Because self-efficacy is very task- and context-specific (Bandura, 1977a), it is possible that students who have low self-efficacy related to performing in music examinations could have high self-efficacy (and high levels of competence) in other performance situations, such as in recitals or informal family gatherings. There is also a danger that students who do poorly in exams (and have low self-efficacy related to exams) could generalize these assessments to their overall musical ability and decide to abandon their musical pursuits.

Davidson and Scutt's (1999) study of piano and violin students focused on the interactions between students, parents, and teachers in the months leading up to and following the students' participation in an ABRSM exam. The researchers conducted interviews with all participants both before and after the examination took place in order to determine how the relationships between the various stakeholders were influenced by the examination process.

The examinations were viewed as a benchmark, allowing students to gauge their progress in relation to an external (and therefore, presumably objective) standard (p. 89). For some 
students, the objective was simply to pass the examination, to be able to say that they had achieved a particular level. Some parents did not even tell their children that different levels of passing existed in order to minimize the pressure that their children felt and increase the positive feelings of accomplishment when they received a pass, even if it did not come with a merit or distinction designation. Parents and students generally appreciated the concrete recognition of achievement afforded by the examinations. Some parents even viewed examinations as a way to get a return on their investment (p. 89).

Student motivation emerged as an important theme in this research. Using Dweck's (1986) concept of performance and learning goals, Davidson and Scutt (1999) posited that examinations could exert a positive influence on student motivation if they were approached as a learning goal (p. 93). If students were participating only to receive the certificate, rather than as a means of further developing their skills, participating in examinations could be detrimental to their long-term learning. Most of the students in Davidson and Scutt's study appeared to have learning goals in mind, which were supported by their teachers' inclusion of non-exam material in their lessons.

In Davidson and Scutt's (1999) research, the role of the teacher emerged as one of the most significant aspects of students' participation in examinations (p. 94). In all cases, the teacher initiated the student's participation in exams, by recommending or even requiring that the student be registered. Students and parents generally respected the teacher's expertise and went along with his or her plan for the student's instruction. Some of the parents mentioned selecting the teacher based on the examination results of his or her former students. It is likely that these parents were hoping for similar successes for their own children. Teachers generally felt personally invested in the outcomes of their students' examinations. As mentioned above, some 
of the teachers based their professional reputations on their students' performances in examinations. One teacher spoke of withdrawing students who were unlikely to do well from examinations so that she would not have low marks associated with her name. While this personal identification with students' results led teachers to try to find the most effective ways of structuring and pacing their students' learning, it also created considerable stress for teachers as well as for students.

Davidson and Scutt's (1999) study provides insight into several important aspects of the examination experience by following students through the entire process of preparation, performance, and receiving feedback and by seeking out the perspective of all stakeholders. However, it leaves some important questions unanswered. For instance, if teachers are largely responsible for introducing their students to the idea of examinations, how can they do this in a way that maximizes the possibility of positive student experiences? Also, what characteristics of students make them most likely to benefit from participation in examinations?

\section{Literature relating to music festivals and competitions.}

Writing on music competitions has followed two main tracks. The first group of articles consists of persuasive pieces that advocate for or against the use of competitions in music education based on research from other disciplines or from the broader field of education. While this writing is an important means of provoking thought amongst music educators, it is also important for music educators to have access to specific research addressing the impact of competition on various aspects of music student engagement. In this section, I address both the opinion and research portions of the literature. 
There are widely differing opinions on whether competition is beneficial or detrimental to student learning: some writers believe that participating in competitions results in more disciplined and motivated students, while others postulate that an emphasis on competition does nothing to increase these desirable outcomes for students and robs students of the joy that can be found in music-making when the focus is not on determining who is best.

Austin (1990) sets out to debunk several myths surrounding competition in music education. He posits that competition is not inevitable or part of human nature, but rather that emphasizing competition is a learned behavior, the maintenance of which serves the interest of those who benefit from competition (p.22). He also addresses the persistent belief that participating in competition increases students' motivation. While competitive experiences can be very motivating for students who are successful, by nature competition draws attention to one winner and many losers (p. 23). For the students who are not successful, participating in competitions can be very demoralizing. Another long-standing assumption is that participating in competition builds character. However, Austin reminds readers that some students will adopt a "win at all costs" attitude which can lead to undesirable attitudes and behaviours (p. 23).

Austin (1990) suggests some alternative practices to music educators that allow students to work towards a goal without encountering the negative aspects of competition. He advocates for involving students in regular recitals and non-competitive festivals, allowing soloists and small ensembles to perform in addition to the large ensembles that tend to be the focus of competitive events, rotating chairs rather than having students challenge for higher placements in the ensemble, and printing students' names in alphabetical order in the program (p.25).

Austin's (1990) article brings up important points for consideration, particularly in the context of a school music program in which the mandate is usually to reach the largest possible 
number of students with meaningful musical experiences. He draws attention to the negative impacts of competition on students who are less likely to be successful; however, he also acknowledges that competition can be motivating for successful students. In a private studio context, teachers can make decisions about participation in competition based on the needs of individual students. Based on this article, it is possible that for some highly talented students, participating in competition could be a positive experience. However, Austin does not provide any direction for teachers seeking to employ a competitive music event judiciously, choosing instead to discourage competition entirely.

Miller (1994) follows on Austin's work by revisiting the same concerns that emphasizing competition creates an elitist system in which many students are denied access to musical experiences. He also highlights the way in which competition discourages creativity in music teaching and performance, as music students are encouraged to offer up "safe" interpretations of works to increase their chances of winning.

Miller cites examples of programs where abolishing or revamping competitive structures has been successful, such as an Indiana middle school where students are allowed to participate in any extracurricular activity they wish, and the Little League baseball program, where the youngest players play a modified version of the game and are expected to rotate through all the positions. For school music programs, Miller advocates for non-auditioned ensembles and for not labeling students based on chair assignments. He also espouses some perhaps even more controversial reactions to competition, such as abandoning the ratings system used by most competitive festivals and evaluating applied music study at the university level using pass-fail criteria rather than marks. 
While Miller's views would certainly create a more egalitarian environment in which school music students could have maximum access to music opportunities, like Austin, he neglects to address whether competition could have a place in the development of a student who would go on to become an elite-level musician. Miller also includes in his critique situations in which students compete against a standard (for example, rated band festivals) without addressing whether the same pitfalls of ranked competition can be applied in these situations.

Gallops (2005) responds to the negative views of Austin (1990) and Hurley (1996) (who also advocates for music education practices that avoid competition entirely) by attempting to present a healthy paradigm for competition in music. He begins by examining the historical roots of music competition. While organized music competitions in the United States are a relatively recent phenomenon, Gallops provides some anecdotal evidence that musicians have been trying to prove their musical superiority throughout recorded history. He concludes that competition is not necessarily incompatible with musicianship.

Gallops (2005) also addresses the issue of whether competition is a result of nature or nurture. Because competition of various kinds can be found in many cultures, Gallops posits that competitive behaviours are likely the result of a combination of both influences (p. 18). As a result, it would be difficult to completely abandon the use of competition as some authors have suggested.

While acknowledging that competition has the potential to result in undesirable outcomes, such as students who bully their way to a victory, sore losers, or students who lose sight of musical goals, Gallops (2005) takes the view that it is unrealistic and perhaps even unhealthy to avoid competition entirely. Rather, he argues for a paradigm of competition borrowed from the work of Ruben (1980) called "autocomping." In this pattern of competition, 
the competitor focuses on internal goals and is in effect competing against him- or herself, even if there are other competitors involved. This approach to competition encourages a focus on effort and learning goals rather than on ability and performance goals. When students are focused on the attainment of their own goals, whether they win or lose becomes less important.

Gallops cites the benefit of competitive experiences in encouraging students to assess their own strengths and weaknesses, as the experience of losing can be a useful catalyst for selfexamination as long as students are not sore losers (p.20). Students who are unable to accept defeat as a result of their performance are unlikely to derive any benefit from the competition. Regardless of the results, a competition can encourage students to reflect on how much work is required to perform well, what they can do differently to prepare for future performances, how to accept winning and losing gracefully, and what can be learned from the adjudicator's report. If students are to reap these benefits, though, their teachers must address the issue of competition explicitly and encourage an approach to competition that focuses on the development of competence.

Gallops (2005) advocates for the inclusion of healthy competition as one of many motivational and instructional strategies that can be used to encourage engagement in music study. His perspective is more balanced than some of the other writing on competition in music study, which tends either to assume that competition is necessary or to push for abolishing all competitive activity from music instruction.

While Austin (1990), Miller (1994), and Gallops (2005) all present persuasive arguments for their points of view, they base their opinions on writings in the general field of educational psychology rather than on research conducted specifically in a music education context. Their articles provide an valuable starting point for teacher reflection; however, it would be beneficial 
to the body of knowledge in music education if more research examined the various issues surrounding competition and its impact on music students' engagement.

One of the concerns raised by Miller is the impact of competition on creativity in music performance. While not addressing festival performance, there is research that suggests that improvising musicians can in fact be more creative when they are part of a competition. Eisenberger and Thompson (2011) investigated the effect of competition on the creativity, motivation, and stress levels of improvising musicians. They conducted an experiment in which participants were asked to improvise based on their reactions to a selection of recorded music. The participants all had some experience playing keyboard instruments (the medium used for the improvisation). Some participants were told that the researchers were looking for the "best" improvisers; therefore, their performances would be ranked, with financial rewards given to the top three improvisations. The participants in the competitive condition were also told that their rank would be publicly posted by student or staff identification number. The participants in the non-competitive condition were told that the researchers were interested in the process of improvisation, for example what the improvisers try to convey with their music. Following the improvisation session, all participants were administered a questionnaire that measured their intrinsic motivation and stress levels. The improvisations, which had been recorded, were evaluated by a panel of expert judges for technical quality and creativity. The results of this study indicated that both intrinsic motivation and stress levels were higher in the competitive condition (p. 134). While there appeared to be no effect on the technical quality of the improvisations, the competitive condition resulted in more creative work.

Eisenberger and Thompson's (2011) research would indicate that there are advantages to having students participate in competitions. However, the researchers raise the point that perhaps 
increased motivation in competitions is related to the participants' enjoyment of competition itself, rather than of the task upon which the competition is based (p.135). Also, it is possible that these findings would not apply when looking at the performance competitions in which music students regularly participate. In these settings, it is questionable whether a more creative response would result in a higher rank.

Stollak (1996) set out to test some of the points raised in persuasive pieces, such as Austin's (1990) essay, by conducting research into how competition affected the views of choral musicians. They sent out a survey to several hundred community, church, and university/college choirs asking about the choir members motivation for joining their current and former choirs and about any experiences the choirs had had with competition. The researchers hypothesized that participation in competition would engender a "team" focus rather than a "family" focus and that more choir members would have had negative experiences in choirs in which competition was emphasized. While their findings supported the idea that creating a family-like climate in the choir is important, it did not appear that participating in competitions resulted in negative choir experiences. The choir members who spoke positively about their experiences talked about being valued as individuals, having input into the musical process, and having directors who loved music and inspired their choristers to appreciate the beauty in music, regardless of whether the choir competed. Stollak's (1996) study would indicate that the key influences on the quality of choir members experiences were the enjoyment they experienced related to the subject matter and the relationships they formed with their director and with fellow choir members. Positive interactions with music and with other people could happen regardless of the choir's involvement (or lack of involvement) in competitions. 
Earlier in this section, I referred to Austin's (1990) article, in which he argues quite strongly against the use of competition in music education. Austin also conducted two research studies $(1988,1991)$ in which he examined the effect of music contest format (either rated or non-competitive) on students' motivation, achievement, and self-concept or self-esteem as musicians. While he used different measures to operationalize the constructs in the two studies, the basic format was the same: students completed pre-test measures of their motivation to learn music and their sense of self as a musician. Teachers also submitted evaluations of students' achievement levels based on the students' prior work. Students were then told that they would be performing a solo for adjudication. Some students were told that their performance would be rated and that students would be rewarded according to their ratings. The others were told that all students who participated would be rewarded and that they should simply try to do their best. Following the performances, students' motivation, music achievement, and self-concept were measured again. They also indicated in which of the contest formats they would prefer to participate in the future.

Statistical analysis of the data revealed that the ratings condition did not have a positive influence on student motivation, achievement or musical self-esteem. Students tended to prefer the kind of performance in which they had participated, leading the researcher to believe that prior experience had a greater influence on preference than the actual characteristics of the contest. Austin $(1988,1991)$ concludes that music educators should not assume that entering students in contests will automatically result in learning or in an increased desire to learn music.

While Austin's $(1988,1991)$ research contains valuable insights into the role of music adjudication to student learning, it leaves several questions unanswered. First, Austin does not address the issue of contests in which students compete directly with others. Many music 
festivals or competitions are conducted using ratings or comments only, but others (including many in which piano students participate) rank students. Based on the concerns raised in Austin's research, it would seem that situations in which students compete directly with each other could be particularly damaging. Also, Austin used several standardized measures to operationalize his constructs of motivation and self-concept or self-esteem. These kinds of rigorously tested measurements are necessary to establish reliability and validity in quantitative research; however, they cannot provide a complete view of the complexity of students' motivational orientations and views of themselves as musicians. A follow-up study taking a more qualitative approach would provide a richer understanding of how students view competitions and the relationship between participation in competition and students' engagement in music learning.

\section{Research related to the adjudication process.}

Several researchers have tried to demystify the adjudication process by examining how adjudicators work and the various factors that impact the final rating. Ross (2009) studied the role of external examiners in various contexts. While she also looked at the role of external examiners in tertiary institutions, I will focus on her findings related to examiners working for music examination boards, as they are most relevant to the present work. Ross studied the scenario of a music examination, looking for the examiner's involvement in micro-macro social processes. While the role of the examiner could be considered a micro process, as it is limited to a few minutes on a single occasion, the ramifications of the examiner's work are much more significant. Because of the authority afforded to examiners by teachers, students, and parents, external music examiners can have a great deal of influence on the content of music instruction 
and even on whether a student continues to engage in music learning. Ross highlights the examiner's role as one that is transformative and that has the potential to influence music curriculum and instruction in a positive way (p. 481). She feels that the examiner needs to be acknowledged as having a significant role in music education.

It is doubtful that any stakeholders who are serious about their involvement in the examination system would question the influence of the examiner. Perhaps a more pressing issue, and one that is not addressed in Ross's (2009) article, is whether examiners, who usually hear a student perform only once, should be given the kind of authority that they have over the course of music students' careers. The following research studies call into question the reliability of adjudication and raise some important points for consideration regarding how the assessment of musical performance can be conducted in a way that is most useful for students.

While Ross's (2009) study focuses on the broader role of the examiner in music education, other researchers have directed their attention to the specifics of how examiners do their jobs. Winter (1993) conducted a study of how examiners differ in their use of criteria based on their levels of training and experience. He created a list of music performance criteria based on those used by several examination boards and gave it to examiners, who were divided into four groups: untrained and inexperienced, untrained and experienced, trained and inexperienced, and trained and experienced. The "trained" examiners participated in a course specifically designed for the study, which addressed topics such as the purpose of assessment, what is measured in the assessment of music performance, how results are reported, and how the assessment instrument designed for the study should be applied. The training group also had the opportunity to practice their assessment skills by evaluating a live performance. As the main intervention, all examiners listened to a recording of three piano pieces and provided an 
assessment of each. One of the recordings was put through a computer program, which generated a printout of pitch, note duration, tempo, and dynamics. This printout was then compared to the examiners' feedback to check for accuracy in the assessments. Winters found that the examiners' training appeared to influence the evaluations more than their level of experience (p. 36). Of note was the fact that the trained examiners showed more consistency in their global and specific assessments. This research has important implications for music examination boards, as it demonstrates how important it is for evaluating bodies to make explicit their criteria and how they expect the criteria to be applied.

Stanley, Brooker, and Gilbert (2002) also studied the use of criteria by examiners. In this case, the context was a conservatory that had recently amalgamated with a university and, as a result, was expected to become more transparent and systematic in its evaluation procedures. Using action research and case study methods, the researchers interviewed music examiners about their perceptions of using criteria to evaluate performance examinations with the intention of refining the criteria that would be used in the future. The findings indicated that, even with the provision of specific criteria, most examiners still start from a more holistic approach and then use the criteria to justify or sometimes challenge the overall impression. The respondents felt that having criteria helped them to focus on relevant aspects of the performance, but that constantly referring to the list also interfered with their ability to respond to the emotional or aesthetic experience created by the performance. Examiners also reported difficulties in implementing the use of criteria when a performer was inconsistent from one piece to the next during a recital (p. 52). As a result of this research, the criteria used at this particular institution were modified to include fewer specific criteria. In this way, examiners could better balance the need to offer a holistic assessment with ticking boxes on a list. 
The previous two studies reinforce Boyle and Radocy's (1987) view of the challenges inherent in making music performance assessment objective, however examining bodies might attempt to do so. The following studies demonstrate some of the specific factors that can negatively impact the reliability and validity of adjudicators' ratings.

Martin Bergee, along with several colleagues, has conducted a number of studies developing a model that explains various factors that influence the ratings school music students receive at festivals. Bergee and Platt (2003) identified time of day, school size and whether the performance was by a solo or ensemble as factors that influence how many superior ratings are awarded in a solo and small-ensemble festival competition. Competitors who came from larger schools and who performed in the afternoon were more likely to receive high ratings. For vocal entries, being part of an ensemble was beneficial, while instrumental soloists tended to be more highly rated than ensemble entries.

Bergee and McWhirter (2005) sought to replicate Bergee and Platt's (2003) study and confirmed the findings from the earlier research. They also investigated the impact of school district expenditure and found, not surprisingly, that increased spending resulted in higher festival results. Bergee and Westfall (2005) sought to develop a model that would explain the various influences on festival ratings. Bergee's (2006) final version of the model confirmed that solo performers who performed in the afternoon and who came from large, metropolitan, wellfunded schools had the highest likelihood of success.

While this research provides some valuable insight into factors which influence festival success, Bergee and his colleagues do not fully discuss the implications for pedagogy that arise from their findings. For example, how can teachers whose students do not fit the profile of successful entrants described in these studies make up for any deficiencies that might be caused 
by factors such as the time of day of the performance or the amount of funding the school receives? Crucially, this information could have an impact on adjudication, as these results could change if adjudicators were aware that they tended to award higher ratings later in the day or that they tended to reward solo performances more generously than those by ensembles.

Bergee (2007) also investigated factors that could act as sources of variability in the assessment of music performances. He used recordings of high school wind players to examine the generalizability and dependability of the ratings awarded by ten certified adjudicators. The results of this study indicate that the one-rater, one-occasion adjudication scenario, which is very common in many evaluative performance situations, is unreliable. These findings have significant implications for how evaluative performances are used in music education. While adjudicator training can likely help to eliminate some of the unreliability in music assessment, the more important implication for music educators is to encourage students to see adjudication as an opportunity to learn from another person's perspective, rather than as the definitive assessment of their musical abilities.

Joel Wapnick and his various colleagues have examined the evaluation of solo performances and the factors that contribute to how the quality of a performance is perceived by both professional adjudicators and educated audience members. The earlier studies (Wapnick, Darrow, Kovacs, and Dalrymple, 1997 and Wapnick and Ekkolm, 1997) focused on solo voice performance. The first study looked at the effect of physical attractiveness on the evaluation of vocal performance. Video-taped recordings were made of several vocal performances, which were evaluated by musicians assigned to three different conditions: visual only, audio only, and audi0visual. More attractive singers of both genders received higher ratings in the audiovisual condition; however, there was no difference between ratings of more- and less-attractive male 
singers in the audio only condition. More attractive female singers received higher ratings in both audio only and audiovisual conditions. In this research, male raters were more severe than their female counterparts and audiovisual recordings received higher ratings overall than audio only recordings.

In the same vein, Wapnick, Mazza, and Darrow (1998) conducted a study examining the effect of attractiveness, stage behavior and dress on the evaluation of violin performance. Performers who were highly rated on dress and stage behavior benefitted from the audiovisual condition. Interestingly, the performances of the more-attractive violinists were more highly rated in both the audiovisual and audio only conditions, raising the possibility that moreattractive musicians have an advantage in acquiring musical skill. Perhaps these more attractive students also have higher self-esteem, which could translate into higher self-efficacy related to performance situations.

The same researchers conducted another study to see if the same effects were seen in the evaluation of performances by sixth-grade pianists. The findings of this study also provided evidence to support the existence of bias, as non-musical factors affected expert musical evaluators' judgments of the performances (Wapnick, Mazza, and Darrow, 2000).

Ryan, Wapnick, Lacaille, and Darrow (2006) examined similar issues related to highlevel pianists. In this study, the musicians did not seem to be affected by the same attractiveness bias that had appeared in earlier research. However, there were interactions between the visual components of the performance (attractiveness, dress, and behavior) and the gender of the rater that could suggest differences in gender perceptions of these visual components.

Wapnick, Flowers, Alegant, and Jasinskas (1993) also studied the consistency of evaluation of piano performances by mimicking some of the conditions under which adjudicators 
might work. They asked their subjects to indicate which of two recorded performances they preferred under one of four conditions: no additional materials provided, musical score provided, ratings scale provided, or musical score and ratings scale provided. The use of the score and ratings scale separately and in combination did not improve the consistency of the ratings. While these tools might be useful for other aspects of musical evaluation, the preference of one performance over the other appears to be based on a "gut feeling" rather than on more objective evaluation tools.

The body of work of Bergee and Wapnick and their colleagues has important implications for the consideration of teachers and students who are hoping for high results in competitions, and also for adjudicators who are striving to make their assessments as valid and reliable as possible. However, the most crucial piece of information for everyone involved in music competitions is that the adjudication of music performance is complex and subjective. While students can work on improving in some areas that influence ratings, such as dress or stage behavior, other areas are likely beyond students' control. Therefor the practice of viewing adjudicator ratings as the ultimate authority on a student's musical proficiency must be questioned.

\section{Summary of existing research.}

The existing research related to evaluative performances brings to attention several important issues. First, the role of evaluative performances is a source of contention, as many educators assume that evaluative performances are a necessary and beneficial part of music education. However, others in the field of music education feel strongly that competition, in particular, should be avoided. Second, most of the research that has examined student 
experiences suggests that evaluative performances can be positive experiences for students, provided that evaluative performances are approached as learning opportunities. Existing research also indicates that the adjudicator or examiner is afforded a high level of authority by teachers, parents, and students. However, several factors influence the reliability of adjudicators' assessment, calling into question whether the elevated position afforded to adjudicators' ratings is justified.

\section{The research gap.}

Research into exams and festivals has investigated curriculum content and history, the interaction between evaluation and pedagogical practice, student motivation, relationships between students and important adult figures, the benefits and drawbacks of competition, and the various factors that influence the adjudication process. However, some important questions still remain regarding student participation in evaluative performances. My research will further illuminate the issue of student participation in evaluative performances in the following ways:

1. I focus on the first-hand experiences of the student. While the information from teachers and parents provides a context for the student narratives, the primary focus of my research is on students' insights into the role of evaluative performances in their musical lives.

2. While previous research has tended to focus on either examinations or competitions, I address students' experiences with both exams and festivals (competitions). Many students participate in both kinds of evaluative performance and their involvement in each intersects with their involvement in the other. While these performances have some characteristics in common, there are important differences in the ways they are 
experienced by students. This research sheds some light on the factors that contribute to some students having positive experiences with one, both or neither type of evaluative performances.

3. I include the perspectives of both current students who were immersed in active participation in evaluative performances at the time of data collection, and former students who can look back on their experiences with the benefit of several years of reflection. The current students are able to provide the most vivid accounts of the experience of participating in an evaluative performance, as the impression of their experiences has not been dimmed by the passing of time. On the other hand, the former students have been able to place their music learning within the broader context of their adult lives and can reflect on which aspects of their formal studies have had a positive or negative long-term effect.

\section{Summary}

This chapter contained an exploration of the concept of "evaluative performances," beginning with the historical development of festivals and examinations, focusing on a Canadian context. In order to better understand some of the underlying philosophical reasons for the widespread use of evaluative performances in formal music learning, I also outlined some of the similarities between evaluative performances and standardized academic tests. In order to establish the contribution of this research to the field of knowledge surrounding evaluative performances, this chapter also included a discussion of the scholarly and professional literature that deals with festivals and examinations. I concluded by listing several issues that have not been sufficiently addressed in the existing research and explaining how my research attempts to contribute to greater understanding of these aspects of music learning and evaluation. 


\section{Chapter 3 Methodology}

This chapter consists of a discussion of the qualitative methodologies used in this research: grounded theory and narrative research. Each plays an important and distinct role in helping to make clear the ideas expressed by the participants. The complementary way in which the two methodologies work together forms the basis for the next section. The latter portion of the chapter outlines the specific design of this study.

\section{Qualitative Research}

Qualitative research seeks to uncover rich data that leads to a deep understanding of a particular phenomenon. Rather than employing statistical analysis techniques using large sample sizes, qualitative researchers aim to work with smaller groups of people and to convey participants' own insights into their experiences. My research embodies several important characteristics of qualitative research, as identified by Elliot Eisner (1998). First, my research is field-focused and "non-manipulative" (Eisner, 1998, p. 33). I was interested in hearing about students' experiences as they unfolded and did not attempt to change those experiences in any way. My goal is to understand the characteristics and impact of current instructional and evaluation practices. While this leads to recommendations for pedagogical practice, the purpose of this study is not to test a particular intervention or to examine a particular method of teaching.

Second, I draw on Eisner's idea of the self as an instrument (p. 33). All of my analysis and interpretation happens through my personal lens as a former piano student and current piano teacher. Rather than trying to eliminate this bias, I have tried to embrace it and to make it explicit so that it becomes apparent to the reader how I arrived at my conclusions. My own experiences, 
as illustrated in the personal narratives contained in the first chapter of this document and in the reflections contained in Chapters Four through Eight, greatly influence my perception and understanding of the data.

My research is interpretive (p.35), with a particular emphasis on the participants' perspectives on their experiences. I wanted to hear not only what piano students experience as they participate in evaluative performances, but also how they experience those performances. In order to maximize the impact of the final research report, I use expressive language (p. 36) and draw attention to the particulars of my students' experiences (p. 37). It is my hope that employing detailed, expressive written language will enable my readers to connect with my research in a way that engages not only their intellect, but also their emotions and their appreciation for the aesthetic. In this way, my research will embody the coherence and persuasiveness that Eisner identifies as necessary in qualitative research (p. 39).

\section{Grounded theory.}

Grounded theory is the systematic investigation of a process that is not easily understood using existing theoretical understanding (Strauss and Corbin, 1998). In this approach, the researcher begins with a fairly general question, which is then narrowed through the data collection and analysis stages of the research. Data can be collected through a variety of means, such as interviews, observations, and surveys to generate a rich description of a phenomenon. Data is then analyzed through a system of coding, which helps the researcher identify important themes. Once the themes have been identified, the researcher then looks for relationships between the themes in order to generate a theory that explains the process under examination. The theory can then be explained through text and represented by a visual diagram. 
There are various types of grounded theory employing differing levels of structure. Two of the main approaches are Strauss and Corbin's (1998) systematic approach and Charmaz's (2007) constructivist approach. Each has distinct advantages, and I chose to use elements of both as I conducted my research. Strauss and Corbin's method is very structured, consisting of procedure for coding data multiple times to ensure that no important information is missed and that all possible connections between categories are explored. In the first round of coding (open coding), the researcher identifies themes through line-by-line analysis of the data (for example, interview transcripts). In axial coding, concepts are related to the central category. In order to gain perspective on the central phenomenon, the researcher includes causal conditions (factors that influence the core phenomenon), strategies (actions taken in response to the core phenomenon), contextual and intervening conditions (specific and general situational factors that influence the strategies), and consequences (outcomes from using the strategies) (Creswell, 2005, p. 398). In the final stage, selective coding, the categories are used to generate a theory to explain the central phenomenon.

Strauss and Corbin's (1998) aim in developing their approach to grounded theory was to provide a qualitative research paradigm that mirrored the systematic approach used in scientific research. In this way, they hoped to increase the legitimacy of qualitative research. While following Strauss and Corbin's procedures for analysis ensures that the data is considered carefully and systematically, it can also be difficult to ensure that the data is not forced into predetermined categories.

Charmaz's (2003) constructivist approach addresses this potential downfall of Strauss and Corbin's method. In constructivist to grounded theory, the researcher focuses on seeking the participant's meanings. While the research is of necessity a rendering of participants' 
experiences, "causality is suggestive, incomplete, and indeterminate" (p. 273). The final grounded theory in this methodology is not as neatly packaged as a theory generated through Strauss and Corbin's approach, but it allows for a more nuanced portrayal of the participants' experiences.

Both Strauss and Corbin (1998) and Charmaz (2003) include detailed descriptions of the analytical process in their writings on grounded theory research. The open, axial, and selective coding procedures advocated by Strauss and Corbin (1998) ensure that data is examined systematically. Charmaz (2003) emphasizes the emergent design of grounded theory. She describes "simultaneous collection and analysis of data" and "sampling to refine the researcher's emerging theoretical ideas" (p. 251).

Regardless of the specific approach used, grounded theory research results in the development of a theory that could be applied to understanding future instances of the phenomenon that was investigated. According to Glaser (1992), the final theory should meet several criteria. First, it must fit with the experiences of the participants. It must also work to explain variations in participant behavior. If the theory meets those two criteria, then it is relevant. Finally, the theory must be modifiable to adapt to any new information that might be uncovered through future research.

\section{Why use grounded theory?}

Grounded theory methodology is to generate broad theories and explanations for processes that cannot not thoroughly understood using existing theories (Creswell, 2005, p.396). Studies in education, nursing, social work, and clinical psychology have all made use of this methodology. Grounded theory was selected for this study because there is no existing theory 
that fully explains the process of participating in an evaluative performance. Beginning with a fairly broad question allowed me to develop a theory based on the insights from the participants. While I employed elements of Strauss and Corbin's (1998) analysis procedures when working with my data, I was also influenced by the greater flexibility encouraged by Charmaz (2003). This research reflects an emergent approach to grounded theory in the way that constant comparative data analysis was employed and in the way that the specific participants were sought out to fill in gaps in the categories after the first round of data collection. Charmaz's (2003) approach emphasizes the importance of ensuring that the voices of the participants are present. In analyzing my data, I did my best to convey the insights of the participants without forcing their experiences into predetermined categories. I also acknowledge that, while I have endeavoured to allow their voices to come through, this report is my rendering of their experiences.

\section{Narrative research.}

While understanding the process of participation in evaluative performances is important, I am also interested in how students experience that process. To illuminate these experiences, I complemented the grounded theory aspect of this study with narrative inquiry. Narrative research focuses on the first-hand knowledge of participants as told in their own stories of their experiences. Clandinin and Connelly (2000) describe a three-dimensional narrative inquiry space (p. 50) in which research into experiences takes place. The first dimension is that of interaction. Borrowing from the ideas of John Dewey, Clandinin and Connelly (2000) refer to the both the personal and social aspects of experience (p. 2). In my research, I focus on student experiences. However, these experiences do not occur in isolation, but rather through interaction with other 
people (parents, teachers, adjudicators) and with the music and curriculum requirements of the evaluative performances themselves.

The second important dimension, also borrowed from the ideas of Dewey, is that of the continuity of experiences (Clandinin and Connelly, 2000, p. 2). The past, present and future are all connected in people's lived experiences (p. 50). In following current students both before and after their evaluations, I am able to understand how their preparation influences the experience of performance and how receiving feedback affects their perspective on past events (the performance and the learning that led up to the performance). The retrospective view offered by the former students also contributes to this understanding of the continuity of experiences as these students were able to reflect on the long-reaching impact of their experiences.

The third dimension in Clandinin and Connelly's three-dimensional space is that of situation or place (2000, p. 50). It is in this dimension that the researcher considers the unique context in which the participant carries out his or her life. In my research, these places include the homes, piano studios and exam rooms in which my participants have lived out and continue to live out their experiences. In addition, our broader social and cultural contexts are also taken into account. All of these factors affect the ways in which we construct meaning from our experiences.

Narrative inquiry influenced my data collection procedures, as I strove to have participants share personally meaningful experiences during the interviews. I used various prompts in order to elicit the telling of the stories, such as having participants bring a meaningful object to one of the interviews and giving the students journals to complete and then discuss with me.

Principles of narrative inquiry also influenced the final reporting of this research, as many 
of the important themes are illustrated using narrative writing. In some cases, these narratives are based on the experiences of one student; in other cases, they are composite narratives that combine ideas from many students and serve as summaries at the end of a discussion of a particular theme.

I also make use of personal narratives to situate my work within my own lived experiences and to provide some insight into the experiences that have influenced my perspective as a researcher and teacher. Telling my own story not only made apparent my inherent biases, but also my personal investment in the research, as I hoped, when I embarked on this process, that this study would contribute to my own growth as a teacher.

Narrative inquiry employs the power of story and of descriptive writing in conveying ideas. Other art forms can be employed in narrative inquiry as well. In this study, visual art was used as a way for participants to tell part of their story. The drawings highlighted the participants' experiences with their own realities during the evaluative performance. The participants described their art-work for me, and I have used their meanings rather than attempting my own analysis of the drawings. With the permission of the participants, I have included these drawings in my thesis. The drawings make an emotional impact beyond what can be conveyed in words and help bring the participants' experiences to life.

\section{Why use narrative research?}

Narrative inquiry focuses on the experiences of the participant and the meaning that he or she derives from those experiences. Because I wanted to gain an "insider's" understanding of what it is like for students to participate in evaluative performances, narrative inquiry was an important tool. Using this methodology allowed me to focus on specific pivotal moments in 
students' musical educations and to learn from them what made these experiences significant. For example, the conversations I had with current students about the evaluative performances in which they participated during the data collection period illuminated some crucial information about what makes an examination or festival a positive experience.

\section{Rationale for using a multi-method approach.}

In this study, I believe that using multiple methods allows me to access a rich and useful understanding of students' experiences and how the stories of those experiences can shape pedagogical practice. Grounded theory, with its emphasis on understanding phenomena and processes, is invaluable in drawing attention to the commonalities of students' experiences. However, employing a narrative approach brings those experiences to life and allows the participants' own meaning to shine through. The following section provides examples of other research that has also employed multiple qualitative methods.

Burck (2005) conducted a pilot study investigating the effectiveness of various qualitative methods in used systemic research. Her comparison provides valuable insights into the respective strengths of grounded theory, discourse analysis, and narrative analysis. While she is concerned with systemic research in family therapy, her insights also have application for educational research, which is also concerned with processes and participant experiences in addition to outcomes. Her paper highlights the contributions made by different methods to an understanding of the experiences of people living life in more than one language.

For this pilot study, Burck (2005) collected data through semi-structured interviews and then analyzed the same data using the three different methodologies. She found that grounded theory allowed her to identify important categories in the experiences of participants and to show 
how the categories were related to one another. She also appreciated the reflexive aspect of grounded theory research, in which further data collection is influenced by ongoing analysis, likening this approach to the way in which a therapist constantly adapts the programming for a particular client based on new information that presents itself in therapy sessions (p. 248).

The next methodology Burck (2005) applied was discourse analysis, which focuses on the language used by participants and how this language reveals assumptions and power relationships. In her study, Burck found that this methodology was useful in showing how her participants' agency and subjectivity was affected by the language they used surrounding the learning and usage of multiple languages (p. 251).

Finally, Burck (2005) applied the principles of narrative analysis to her data. She used narrative analysis techniques, such as emplotting and poetic restorying, to understand participants" constructions of "self" and "home" (p. 256). Conducting narrative analysis allowed for a greater overall understanding of participants' experience than would have occurred with only grounded theory or discourse analysis.

While Burck (2005) does not necessarily advocate for combining different research methodologies in the same study, her concise summation of the contributions of the three methods she investigates provides a good starting point for other researchers considering what method(s) would best suit a particular research question. Several studies in various sociological fields have already effectively combined multiple qualitative methods. For example, Bolden's (2004) investigation of teacher knowledge of the teaching composing process makes use of case study, narrative inquiry, and Strauss and Corbin's (1998) approach to grounded theory. The case study and narrative components of the methodology prevent the findings from being reduced to a simple visual model, while the grounded theory component provides a coherent synthesis of the 
findings that are illustrated in more depth through the other two methodologies.

DeBlaere's (2009) investigation of the long-term impacts of parent-child verbal aggression constructed a detailed grounded theory model in which the various subcategories were illustrated with narrative data. These narrative accounts allow the reader to connect with the experiences of the participants and provide a richer understanding of the phenomenon of parentchild verbal aggression than would be possible with only a theoretical model. When dealing with an intensely personal topic, providing a venue for the voices of the participants to be heard is crucial to the reader's understanding of the issues presented.

Grosskopf (2009) employed a similar approach in conducting research into the learning motivation of preservice teachers with various achievement profiles. She also generated a theoretical model to explain "their reasons for pursuing their degree, their learning experiences in a university setting, their perceptions about meaningful learning experiences, and the nature of factors that both enhance and challenge their learning motivation." Narrative data served as a means for identifying and illustrating subcategories of the theoretical model.

Haeffele (2008) developed a grounded theory to explain why some people are successful in maintaining a significant weight loss. She also employed narratives and metaphors from the participants in an effort to help the reader better understand the factors that contribute to ongoing weight maintenance.

In the previous three studies, the researchers made use of narrative accounts as the basis for categories in the grounded theory of the phenomenon under investigation. Dey (2007) offers support for this mixing of qualitative methods (p. 184). Using narrative interviewing techniques to elicit data for grounded theory research ensures that the eventual categories emerge from a rich data source. 
Lentz (2004) used grounded theory methodology to better understand the conditions that affect the mental health of transvestites. At the end of her thesis, she employs a narrative to show the progression of the theory. Her depiction of her theory in story form allows the reader to understand the unfolding of participants' experiences over time.

Wood's (2007) investigation of teacher sensemaking employed a similar approach to that of Lentz. She used grounded theory methodology to identify the categories that are part of the core phenomenon of teacher sensemaking. She then synthesized the findings and explored the relationships amongst the categories through narrative.

In the previous two studies, the narratives used are written by the researcher to illustrate the theory in a sequential format. They do not employ the voices of the participants in the way that narrative writing in narrative inquiry would require. However, the idea of conveying information through a story influenced the design and reporting of my research. In the case of this work, I have represented my theory in the form of a narrative that is in the voice of a fictional student. The narrative draws on ideas that came up in a variety of participant interviews. My narrative provides a sequential telling of the various aspects of a positive experience with evaluative performances, beginning with the student's introduction to piano lessons and continuing to the interpretation of the feedback received from the adjudicator and the generation of future plans for music study and involvement in evaluative performances.

I have also included a visual model that shows the various factors that influence students' experiences and their decisions to continue participating in music studies without future evaluative performances, to continue participating in music studies with future evaluative performances, or to discontinue music studies altogether. Following the narrative and visual summaries of the grounded theory, I unpack the main propositions of the theory and apply the 
findings to my own experiences as a student and teacher to check for fit and relevance.

Leading up to the presentation of the final grounded theory model, I have made us of many first-person narratives and quotes from the participants to illustrate specific categories and dimensions. This is to ensure that the voices of the participants as they tell their lived experiences are ever-present.

\section{Establishing the credibility and authenticity of the research.}

In quantitative research, establishing reliability and validity are of primary concern. However, the sampling and statistical procedures that are markers of rigour in quantitative research are not applicable in qualitative methods. In qualitative research, authenticity and credibility become the primary concern of the researcher:

"For the qualitative researcher, validity must be concerned with the degree to which findings capture the reality of the situation under investigation. However, underlying ethnographic-naturalistic data collection is the assumption that reality is "holistic, multi-dimensional and every-changing; it is not a single, fixed, objective phenomenon waiting to be discovered, observed and measured.' (Merriam, 1988, 167). We are dealing with people's constructions of the world and the researcher is trying to capture this, so what seems to be true for the subjects may be more important than what is true in the researcher's frame of reference" ( Hitchcock and Hughes, 1995, p.324).

The understandings developed through the research process must be true to the realities of the participants and must resonate with the experiences of the reader if the research is to have an impact. Authenticity and credibility can be established through the collection of rich, multifaceted data. In grounded theory, researchers aim for saturation, or the point at which data collection is generating no new information (Strauss and Corbin, 1998). Constant comparative data analysis procedures (Charmaz, 2003) help the researcher to judge when enough information has been gathered. Because analysis takes place throughout the data collection process, the 
researcher is able to determine when the new data being collected is repeating the same themes that have already been uncovered.

While quantitative researchers strive for generalizability in their findings by ensuring broad sampling, qualitative researchers focus instead on what can be learned from an in-depth investigation of a smaller number of participants. While the insights gained from a few cases cannot be generalized to an entire population, the detailed understanding generated by examining fewer participants in greater depth can nevertheless provide valuable information for the reader. It is then up to the reader to take what can be learned from the research and apply it as it is suitable.

In this study, I have used member-checking of interview transcripts and triangulation (comparing interview data between participants and comparing interview data with observation data) to ensure the authenticity and credibility of the findings. I have also used the participants' voices wherever possible in order to give the reader a sense of not only the content of the interview data, but also the people who participated in the research. While my findings are not generalizable to all piano students in all contexts, this research provides a valuable starting point for reflection. When a teacher, parent, or student finds resonance with the ideas and experiences presented here, this research can have a powerful impact on teaching and learning.

\section{Design of the Study}

The following section details the specific design of this study, including the participants, recruitment processes, elicitation and recording of data, analysis procedures, and data representation. 


\section{Participants.}

Because it is necessary to have excellent participants in order to elicit excellent data (Morse, 2007, p. 230), I approached the recruitments process with great consideration. Participants in this study were selected to represent various perspectives on evaluative performances and various degrees of being stakeholders in the music learning process. There were a total of 25 participants in this study: five current piano students, five parents/guardians (one parent or guardian for each of the current piano students), twelve former students, and three piano teachers. The current students were the key group of participants in the study, as they provided the bulk of the data collected. These students were all working at a beginner or intermediate level of playing. I was interested in the experiences of the "average" piano student, who takes piano lessons as part of a host of other activities rather than the exceptional student who is planning to make a career in music. The main requirement for participation for the current students was that they be preparing for an evaluative performance during the data collection period so that I could conduct interviews in the time leading up to and following the performance.

Additional perspectives on the data collected from the current students were provided by their parents and teacher. Previous research has demonstrated how important the relationship with parents and teachers is in piano students' experiences (Davidson and Scutt, 1999). I felt I could not thoroughly understand the views of the students without also getting firsthand information from the adults who influence them.

The first teacher participant was the teacher of the current students. The two other teachers were included even though they did not have students participating because their individual experiences dealing with festivals and exams provided meaningful insight into issues 
not addressed by the other participants. While I was not able to interview any of their current students, both have had several students participate in evaluative performances in the past. As a result of their experience preparing students for festivals and exams (and also teaching students who did not participate in evaluative performances) they were able to offer valuable insights into the benefits and drawbacks of these evaluations and into the factors that influence their decisions regarding which of their students participate in evaluative performances.

The second group of student participants was brought in to complement the insights obtained from the first group. This group consisted of students who had formerly participated in exams and festivals but were no longer preparing for these kinds of evaluations. In many cases, the former students were no longer engaged in any kind of formal music learning, although some were university music students at the time of data collection. In all cases, the interview or survey questions focused on the participants' experiences as beginning and intermediate piano students. The former students had the benefit of being able to look back on their experiences and reflect on how their experiences as children influenced where they ended up as musicians and on how their perspective as adults influenced how they viewed their early experiences.

All participants were from geographical regions in which conservatory examination systems have a long history and in which these examinations are entrenched in the teaching tradition. Most of the participants were residing (or in many cases, had always resided) in Southern Ontario and had experience with the Royal Conservatory of Music examination system. Two of the former students had grown up in Asia and had participated in the Associated Board of the Royal Schools of Music Examinations. 
Throughout the text, participants are referred to with abbreviations that reflect their roles. For example, CS\#1 stands for “current student \#1," P\#1 stands for "parent \#1," T\#1 stands for "teacher \#1," and FS\#1 stands for "former student \#1."

\section{Recruitment.}

Participants were recruited through email contact with teachers, who then distributed the material to parents and students, through poster and social media advertising of the survey, and through personal connections. The first group of participants to be involved in the research were the five current students, their parents, and their teacher. This group provided the richest, most detailed data and also provided me with direction for further data collection. My contact with this group came about because their teacher responded to my email correspondence indicating that I was seeking research participants. All three teachers were personal acquaintances. Efforts to recruit potential teachers through professional organizations and through contacting various music schools did not lead to any participation in this research.

One of the issues that arose in my preliminary analysis of the first collection of data was the predominance of reports of positive experiences with evaluation. I knew anecdotally that some students have negative experiences with evaluative performances and set about trying to access some of these experiences. I was not trying to ascertain what percentage of students have had positive and negative experiences, but rather to understand the characteristics of positive and negative experiences. The former students were approached in the hopes that they would contribute to the variety of perspectives included in this research. Because they were no longer taking lessons, I expected that they would be more likely to be upfront about any negative experiences that had occurred than current students, who might feel under pressure not to speak 
out against their teacher's or parent's practices or opinions. In order to make it easier for former students to participate, I made available several options for sharing their experiences: in-person interviews, phone or email interviews, and an anonymous online survey. The former students were recruited through personal connections with the researcher and with my supervisor, through word of mouth, and through poster and social media advertising of the survey. Because of the emergent design of this research, the consent letters for the current students and their parents that are included in Appendix $\mathrm{C}$ reflect the original design of the study. The letters signed by the former students reflect any changes that were made to the participant group.

While it would certainly have enriched the data for this research if I had been able to include current students from a number of different studios, as mentioned briefly earlier in this section, repeated efforts to secure such a group of participants through contacting personal acquaintances, members of professional organizations, and directors of several private music schools were unsuccessful. The time commitment involved in participating in this research was likely prohibitive for many people. As a result, when recruiting participants beyond the first cohort, I endeavoured to minimize the amount of time required to participate in the research.

The research was approved by the Ethics Review Board at the University of Toronto. All participants were given detailed information about the study and had the opportunity to ask any questions they had regarding the research. Interview participants signed a letter of informed consent. In the cases of participants who were minors, a parent or guardian signed the informed consent letter, and the student signed an assent letter indicating an understanding of the purpose of the research and a desire to participate. The survey included information about the research and stated that participants would indicate their consent by completing the survey. All consent forms are included in an appendix at the end of this thesis. The consent forms for current 
students, teachers, and parents included in Appendix $\mathrm{C}$ reflect the originally intended design of the study (interviewing ten current students). The forms were included in their original version because this was the version that the first cohort of participants signed. The forms for former students reflect the revised participant make-up.

\section{Elicitation and Recording of Data.}

Data was collected primarily through semi-structured interviews, with video-taped lesson observations to complement the interviews. The interview guides (which are included in an appendix at the end of the thesis) were developed to address issues that I anticipated would be important based on existing literature and on my own experiences as a student and teacher. Additional probing questions or questions relating to other topics were included if the participant brought up interesting ideas that were not in the original guide. The interview guides were also modified as the data was analyzed and I realized that I wanted to follow up on it became apparent that certain ideas merited follow-up with subsequent participants or in subsequent interviews with the same participants. Semi-structured interviews were chosen because they allowed me to focus the conversation while still allowing for flexibility as the participants brought up interesting ideas that might not have occurred to me during the original question generating process.

In order to record lessons for observation, I left a video camera with the teacher for the duration of the data collection time. I periodically collected the memory cards and dropped off new ones as needed so that I could begin to view the footage before the data collection was complete. I was not present in person during the observations for two reasons. First, the distance and conflicting lesson times with my own students made it impossible for me to attend every 
lesson. Second, the teacher and I felt that it would be less disruptive for the students to have the camera alone than to have a new person present during the lessons. It appeared, from watching the footage, that the students tended to forget about the camera and went about their lessons as they normally would. I watched the footage and took field notes focused on areas that emerged as being important during the interviews.

The online survey was designed to give former student participants and easy and convenient way to participate in the research. The survey was designed following the bulk of the interview data collection. As such, the questions reflect issues that emerged as being important in the first interviews. Because at this point in the data collection I was specifically seeking out students who had perhaps had negative experiences, it was important to have a completely anonymous way for students to share their experiences. The survey also allowed for a shorter, "self-serve" version of the interview for participants who did not have the availability to participate in a full-length interview. The survey questions were structured mainly as drop-down menus and rating scales; however, each question also provided an opportunity for participants to elaborate on their responses.

\section{Current students.}

Current students were interviewed three times each, in person, with the exception of one who competed her final interview by phone. The first interview took place several weeks before the performance. For this interview, I asked students to bring or describe an artifact that was somehow related to their piano studies. This started our conversation on their backgrounds as musicians and piano students and helped to illustrate what was important to them about learning 
the piano. My goal in this interview was to establish rapport with the participants and to understand their backgrounds as musicians.

The second interview took place approximately four weeks later. During the time between the first and second interviews, students completed a lesson and practice journal in which they documented their goals, practice strategies and feelings about their upcoming performance. Students brought the journal to the second interview and it provided the catalyst for our conversations about the specific ways in which they were preparing for the upcoming performance and also the emotions that were surfacing during the preparations. After the interview, I took the journals home with me to read. This allowed me to make sure that I included the important ideas in my analysis and, perhaps more importantly, allowed me to take note of any follow-up questions I wanted to ask at the next interview. The journals were then returned to the students at the final interview.

The third interview took place after the performance. If the student had participated in a festival, at which he or she received the feedback immediately, we discussed his or her responses to the feedback; however the focus of the interview for all participants was the experience of the actual performance. At this interview, I asked students to draw a picture of whatever was significant to them about the event and to tell me about the picture. The drawings provided students with a way to communicate ideas that may not have surfaced in a simple conversation. Students were instructed that they could draw either a "realist" picture, depicting actual people and objects, or an "abstract" drawing showing emotions through the use of shapes and colours. All students chose to represent some aspect of the performance with a realistic drawing.

While some researchers conduct their own analysis of children's drawings based on artistic elements such as colour, perspective, representation of subjects (for example, whether or 
not the depiction of a person includes arms), or inclusion of underlining (Huberman, 2004), I chose to rely on the participants' interpretations of their own drawings. The drawings served as a catalyst for conversation. In some cases, the participants referred to a deliberate choice of colour or of some other artistic element in representing their experiences, but I did not make conjectures about the meaning of those artistic decisions if the participants did not provide a reason themselves.

The drawing activity provided an opportunity for students to identify one significant aspect of the evaluative performance experience. For most students, this seemed to be an enjoyable activity and enabled them to talk about the experience with greater focus than they might otherwise have been able to do. However, one of the students (CS\#2) struggled with what to draw. For this student, verbal expression came more easily and the drawing came after she had described her experience using words. This particular student was slightly older than the rest, and it is possible that she was showing evidence of the typical developmental process through which children gradually lose interest in drawing as they become more and more aware of what their drawings "should" look like (DiLeo, 1978).

The current students were video-recorded for five lessons leading up to their festival and examination performances. The teacher and students were asked not to change anything about the way they typically conduct their lessons, with the hope that the interactions I viewed on the recordings would be representative of how the lessons normally unfolded. I took field notes on the videos and included these in my analysis. Originally, I had planned to record six lessons, but the timing of the sessions allowed for only five recordings to take place before the students' performances. However, the five recordings still allowed time for students to become 
accustomed to the presence of the camera. The video data allowed for triangulation, providing a rich source of data to confirm and illustrate the ideas that were discussed in the interviews.

\section{Teachers.}

The three teachers were each interviewed once. Two of the teachers were interviewed in person and one was interviewed by phone. The interviews addressed their backgrounds as musicians and teachers, their personal experiences related to evaluative performances, their views on the benefits and drawbacks of participation in evaluative performances by their students, and their general values and goals related to teaching the piano. The first teacher was also part of the video-recording of the current students.

\section{Parents.}

Each of the five parents was interviewed once. All of the parent interviews were conducted in person. The parent interviews focused on the students` musical backgrounds, parental motivations for registering children for music lessons, and parental perceptions of the benefits and drawbacks of participation in evaluative performances.

\section{Former students.}

Twelve former students participated in this research. Five were interviewed (three in person, and two by email, with one of the email respondents following her correspondence with a phone conversation). The other seven former students completed the online survey. The survey provided rating scales so that students could describe their interest in various aspects of music study and their involvement in evaluative performances. Each question also allowed students to 
comment further and all of the participants took advantage of this opportunity to expand on their responses. I have included some of these expanded written responses as participant quotes in Chapters Five and Six.

Digital audio recordings were made of the in-person interviews, after which I typed verbatim transcripts. When possible, I returned the transcripts to the participants for member checking (no changes were requested). For the phone interviews, I relied on detailed notes taken during and immediately after the interviews rather than verbatim transcripts. I attempted to record the first phone interview (with one of the current students) and was unable to produce an intelligible recording with the small digital recorder I was using.

All of the in-person interviews took place in locations chosen by the participants. These included homes, studios, and restaurants. It was important that the participants feel as comfortable as possible from the beginning of the interview process. I also wanted to minimize the inconvenience of participating in the research by having students choose locations and times that worked best with their normal routines.

Throughout the data collection and analysis phases, I also wrote memos exploring the questions that were raised, connections between ideas, and plans for future directions in the data collection. These memos also became a source of data.

\section{Analysis.}

The interview transcripts were analyzed using Strauss and Corbin's (1998) model of open, axial and selective coding. For the open coding part of the analysis, I used NVivo 9. This program allowed me to highlight phrases or sections from the transcript that would be stored in a separate file related to a particular node, or category. The same text could be part of multiple 
categories. I took the files related to each category and copied them into Word so that it would then be easy to copy and paste any relevant quotations into my final thesis.

The next steps in the coding process were done manually. After reading through the documents I created in NVivo 9, I began to group the categories, deciding on a few key categories, or axes, around which other categories seemed to cluster. The final result is the model included at the end of the thesis, which shows how the various categories interact to explain the phenomenon of participation in evaluative performances. While it is impossible to approach research data free from expectations (Kelle, 2007, p. 197), I endeavoured to be open to whatever I discovered in the texts and to verify my provisional categories by looking for support in existing literature and in other data sources (for example, the lesson videos and transcripts from other participants).

As I went through the coding process, memo writing became a very important tool for me to organize my thoughts and to explore connections between ideas that emerged from the data and insights gleaned from other participants, existing literature, and personal experience. Writing memos led to further questioning and helped me to maintain a record of my thoughts as they occurred, so that I could return to them at a later date. Memo writing was integral to the reflexive nature of the data collection and analysis process, as I was able to adapt future interviews based on insights from earlier conversations. The informal "thinking in writing" process also helped me to organize the thesis document.

While the bulk of the analysis included in the thesis document is based on verbatim quotes or restoried narratives of the participants' actual experiences, I also make use of composite narratives. These serve as summaries at the ends of sections, but are written in the first person in order to make the writing more powerful and to make the main ideas stand out from the 
rest of the text. While these passages are not typical narratives as employed by narrative inquiry (not being based on the experiences of only one participant), they are based on the idea that writing that engages the reader at more than an intellectual level is powerful. Employing a more literary voice in those passages emphasizes the potential emotional impact of the material. I have titled these passages "composite narratives," as they are made up of actual experiences of many participants, woven together to highlight the most significant aspects of a particular category.

Geelan (2003) also makes use of this kind of fictionalized narrative in his work on implementing innovative science teaching methods in a secondary school. In his writing, he uses narrative accounts to convey the significant events that occurred throughout his year of participant observation in the school. While his narratives read like depictions of actual events, the characters are composites of several teachers with whom he interacted, and the incidents described weave together experiences that took place at different times.

The composite narratives in this thesis include the most important elements of both a positive and negative experience with evaluative performances in each thematic category. For example, in the discussion of student engagement in learning in Chapter Five, the first composite narrative makes use of various positive emotions described by students who had positive and negative experiences with evaluative performances. While every student who had a positive or negative experience did not necessarily refer to each emotion mentioned in the composite narrative, every emotion was described by at least one participant. The other composite narratives are put together in a similar manner: each characteristic referenced was mentioned by at least one actual participant, but any one participant did not necessarily exhibit all of the characteristics contained in the composite narrative. 


\section{Data Representation.}

I strove to include several modes of data representation in order to maximize the impact of the participants' ideas. These include direct quotes from the participants, re-storied narratives, composite narratives that draw on ideas from multiple participants, and visual representations (both the students' drawings and my own graphics, which are used to summarize the ideas in Chapters 4 to 7 and to convey the theoretical model in the final chapter). Through these multiple modes of representation, the findings speak to both the intellect and emotion. While my analysis provides some interpretation of the findings, my hope is also that readers will be able to make their own connections through interacting with the participants' voices.

The organization of the thesis reflects a gradual unpacking of the analysis. Chapter Four contains largely descriptive information regarding the participants and the process of

participating in an evaluative performance. While this chapter contains some analytical elements, the main focus of the chapter is to give the reader a foundational understanding of the people and the experiences that are the basis for this exploration.

Chapter Five delineates what is meant by a positive experience with an evaluative performance. Building on the descriptions provided in Chapter Four, I delve into facets of an evaluative experience that results in students wanting to continue engaging in music learning through participation in evaluative performances.

Once we have established the definition of a positive experience with an evaluative performance and why positive experiences are so crucial to student engagement, it is important to understand what factors influence the quality of students' experiences with evaluative performances. Chapter Six outlines the personal characteristics of the student that influence whether he or she experiences high levels of engagement in music learning through participation 
in evaluative performances. When the personal characteristics explored in Chapter Six align with the demands described in Chapter Four, the student is more likely to have a positive experience.

Chapter Seven provides the final layer in the analytical process, as it explores the broader relational context in which students' learning and performing takes place. The relational context is so influential that a student's negative experiences in this area can outweigh any personal characteristics that might have predisposed the student to having a positive overall experience participating in evaluative performances.

The theoretical model and propositions that are presented in Chapter Eight reflect the gradual layering that takes place through Chapters Four to Seven. The visual diagram shows the central phenomenon of the evaluative performance, surrounded by concentric circles representing the various contextual factors that influence how students experience the process of the performance.

\section{Summary}

This research employs a qualitative, multi-method approach that emphasizes grounded theory and narrative inquiry. Using a multi-method approach allows this research to embrace a thorough investigation of the process of participating in an evaluative performance while giving a central role to the lived experiences of the student participants. The primary participants in this research are the current and former students who provided rich interview and observational data regarding positive and negative experiences with festivals, competitions, and conservatory examinations. Parents and teachers were also interviewed to provide a broader contextual understanding of students' experiences. The thesis document employs visual data representation 
to convey clearly the ideas generated in the grounded theory portion of the research, while narrative writing brings to life the individual and shared experiences of the participants. 


\section{Chapter 4 \\ Setting the Stage: Introducing the Participants and the Process of Participating in an Evaluative Performance}

This chapter provides some important background information that will help the reader understand and contextualize the discussion that follows in later chapters. In the first section, I introduce the participants, who are grouped into the following categories: current students (those who were in the midst of preparing for an evaluative performance during the data collection period), parents (parents and/or guardians of the current students), teachers, and former students (participants who were reflecting on past experiences with evaluative performances). The second section of the chapter outlines the process of participating in an evaluative performance, based on the descriptions provided by the participants. The general process, from initial introduction to music study to receiving feedback from the adjudicator, was very similar for all participants, regardless of when or where their performances took place. The chapter concludes with a discussion of the participants' perceptions of the benefits and drawbacks of participating in evaluative performances.

\section{Introducing the Participants}

\section{Current students.}

The five current students were girls ranging in age from 11 to 14 . Their levels playing at the time of the data collection ranged from Royal Conservatory of Music Preparatory B to Grade 6. They were all studying with the same teacher at the time, although four of them had started their piano studies with other teachers. All of the current students had been studying with their current teacher for at least a year at the time of data collection. Three of the students used their experiences preparing for and performing in a festival as the basis for their participation in this 
research. For one of the students, the festival in which she participated during the data collection period was her first. The other four students had previous experiences participating in festivals. All of the students had participated in conservatory examinations in the past. All of the students were planning future conservatory examinations, and two of them used their exam preparation and performance as the basis for their interviews.

\section{Parents.}

Three mothers, one father, and one grandmother participated in this research (one adult for each of the current students). For the sake of simplicity and to protect the confidentiality of the participants, I will refer to all of the adult family members as "parent" and will use feminine pronouns. Some of the parents had some musical training themselves, while others did not. All saw evaluative performances as contributing to their children`s musical educations.

\section{Teachers.}

Three teachers participated in the research. All were female their teaching experience ranged from 15 to 30 years. The first teacher to participate in the research was the teacher of the five current students. Both she and the second teacher were in the process of training to become Royal Conservatory of Music examiners at the time of data collection. The first two teachers had completed advanced degrees in piano performance and pedagogy. The third teacher had been teaching the longest and had relied largely on her own reading and experimentation to shape her

teaching practice. She had tried to pursue advanced examinations many years ago, but had had to stop when a physical disability prevented her from using the pedal (an exam requirement). Her 
less conventional relationship with the traditional teacher training paradigm allowed her to offer important insights in the purpose and value of examinations.

\section{Former Students.}

Twelve former students participated in this research. Five participated in interviews and seven completed an online survey. Two of the online participants were male; all the other former students were female. The ages of the former students ranged from thirteen to midthirties. All had started taking lessons as children and had participated in conservatory examinations (Canadian participants through the Royal Conservatory of Music and others through the Associated Board of the Royal Schools of Music). Some had also participated in festivals. Although five of the former students went on to study music at the university level, for the purposes of this research, they discussed their experiences as children, when they were playing at a beginning or intermediate level. None of the former students had gone on to careers as performing musicians, although many still played the piano for their own enjoyment.

\section{The Process of Participating in an Evaluative Performance}

This section summarizes students' participation in evaluative performances and outlines the common process encountered by all the participants. The process of participating in an evaluation is divided into several steps, beginning with students' initiation to piano study and culminating in the students' plans regarding future music learning following the evaluative performance. 


\section{The beginning: reasons for initiating piano study.}

The students described a variety of responses to their introduction to piano lessons.

Several students described being registered for lessons as very young children without being consulted. While they did not necessarily have any negative feelings about learning the piano at the time, they had not really considered it until their parents initiated the registration process. In these cases, the lessons were generally started for extra-musical reasons, such as cultural expectations that children would learn music, parental desires for children to develop skills that would transfer to an academic milieu, parental eagerness to offer their children opportunities that they had not had in their own childhoods, or simply the need for an activity to occupy time productively. Parents who desire to register their children for piano lessons generally have high expectations for their children's overall achievement in a variety of areas and strive to give their children many opportunities for learning and personal growth (Cooper, 2001; Duke, Flowers, and Wolfe, 1997). Many of the extra-musical reasons for starting piano lessons (for example, character-building and life skills) that were listed by the parent participants in this research have also been cited by students as giving meaning to music study (Campbell, Connell, and Beegle, 2007).

One of the parents (P\#1) described registering her daughters for piano lessons when they were young, as it was a way to pass time before they entered full-time schooling. This mother had regretted that she had not had the opportunity to learn to play the piano as a child and wanted her children to have every opportunity to become competent pianists. She hoped that her daughters would continue their studies until they had completed their Grade 8 conservatory examinations as she viewed the Grade 8 certificate as a significant accomplishment, one that could open up the possibility of part-time employment through teaching beginners. While one 
daughter planned to continue working towards that goal at the time of data collection, the other had decided to pursue other musical interests. However, it appeared that, for both daughters, their time spent in piano lessons was paying dividends in long-term music-making.

One of the former students described her introduction to piano lessons in this way: "I was 4 years-old when I first started taking piano lessons. I don't remember there being a discussion about it; just that one day, I was told that I'd be going to piano lessons" (FS\#5). This student ended up developing a deep love for music; however, at the young age that she was when she began lessons, it had not occurred to her to want to study the piano.

While in some cases, students had not expressed any desire to learn music until they began lessons, others were keenly motivated. In these cases, the students came from family environments in which informal music-making was very important (Borthwick and Davidson, 2002). As a result of immersion in a musical environment, some students developed the desire to learn to play music themselves. One former student described how she was "dying to take music lessons" (FS\#3) as a child and sought out every opportunity she could to play the piano at relatives' houses before she was registered for lessons. Her grandparents, seeing her passion for music, gave her their piano so that she could begin taking lessons.

Another former student described how she had envied her brother's music lessons. While he quit soon after he began, she was so eager to study that she practiced diligently on her own for a period of time, keeping a log of her practicing to convince her now skeptical parents that investing in piano lessons for her would not be the same fruitless venture it had been with the older brother. 
Siblings who were taking music lessons often served as important role models for aspiring young musicians. One of the parents described his daughter's initiation to the piano and the influence of an older sister:

P\#4: She [CS\#4] always ... liked music... we could tell ... that she really responded to it, always, to music. So we just thought when we got [older sister] involved with piano lessons and we got a little, just a small keyboard and whenever [older sister] was playing it, [current student] was excited and would sort of join in, so then we just, when she was old enough, we just got her into lessons as well.

In this case, the student had an opportunity to watch her older sister learn the piano and also to engage in music-making in a very playful way before being registered for more formal music study. The parents' decision to register their younger daughter for lessons was a direct response to the child's interest in music.

The second current student told of how she had learned to play a few simple songs by rote with one of her relatives. Her great aunt would give instructions to play "this note, then that note" (CS\#2) and eventually, the child would realize that she was playing "Twinkle, Twinkle, Little Star" or another familiar tune. Because her introduction to the piano took place in the context of a warm, playful relationship, she embraced her more formal music lessons eagerly when they began a few years later.

The reasons cited by the participants for beginning piano study are consistent with what I have experienced as a student and as a teacher. In the case of my own initiation to piano study, I had a high level of motivation to learn music and had been asking my parents for music lessons for a number of years before I began formal music study. I also enjoyed a musical environment at home and the support of my extended family (for example, the aunt who bought me a recording of Glenn Gould when I mentioned my interest in Bach). I have seen this kind of motivation on occasion in my students; however, in most cases, piano study has been initiated by the parents. In some cases, parents have been interested in having their children develop musical 
skills, often so that the children can participate in musical activities with other family members. In other cases, the parents have been more concerned with potential extra-musical benefits, such as relaxation, the development of discipline, or the transferring of skills developed through music lessons to other academic disciplines.

A few students had started their musical studies with group classes before taking private lessons. The group classes were generally favourably viewed, because they were fun, provided opportunities for social interaction, involved singing and movement, and often made use of some sort of token economy system, such as sticker rewards. The group context appeared to be an effective way to spark students' interest in music learning and to develop some basic musical skills that could be used as a foundation for the more advanced studies undertaken later in a private lesson context. Students enjoyed the social aspect of learning music in a group. Woody (2001) emphasized the importance of friendly early music learning environments on students' musical development. When students encounter a welcoming environment in their first exposure to music study, they are more likely to develop a positive overall attitude toward learning music. Some of the students who had started their formal music education in a group setting remarked that they missed the interaction with other students when they later began private lessons.

\section{Music study becomes more serious: participants' introduction to evaluative performances.}

Participants described how their teachers generally introduced the idea of participating in evaluative performances and recommended the events which they felt would be appropriate for their students. This finding is consistent with Tye (2004) and Davidson and Scutt (1999), who also noted that most students who participate in examinations do so at the recommendation of 
their teachers. The teacher of the current students "strongly encourages" (T\#1) all of her students to participate in examinations, although she does not require reluctant students (particularly older ones) to participate. She also encourages her students to participate in festivals and often uses these performances as a way to increase preparedness for an upcoming exam. She feels that the exam curriculum ensures that her students continue making progress and that they cover a wide range of skills. While she values the examinations system, she also ensures that her students learn a variety of music that is tailored to their individual tastes and schedules regular recitals and other performance opportunities in order to keep her students engaged in learning.

The other two teachers tended to reserve exams for particularly keen students and encouraged festival participation as a more manageable way to encourage students to set goals for learning and performance. However, they felt that the time commitment involved in preparing an entire examination program (versus the one or two pieces generally required for a festival entry) was too costly for many students. While some of their students were able to prepare for an exam in the context of a broader musical education, these highly capable and motivated students were the exception rather than the rule. For example, the second teacher said that out of her studio of approximately 16 at the time of data collection, perhaps two or three would take an exam.

There are a number of factors that could contribute to the teachers' differences in opinion regarding which students should take exams, including personal experiences with exams and the characteristics of the students in a particular studio. However, it appears clear from my conversations with them that all three teachers value both the structure provided by evaluative performances and the freedom of tailoring learning to students' individual interests. 
The teachers who participated in this research encourage student input in decisions regarding participation in festivals and exams. Their approach is in line with Pitts' (2004) recommendation that students' experiences with their own learning should be at the heart of any music education endeavor. However, many of the former students were not given a choice about whether or not they would participate in evaluations. For their teachers, it was simply a given that taking piano lessons meant participating in evaluative performances, particularly conservatory examinations. Parents tended to go along with the teacher's recommendation unless something dramatic happened to make them question having their children participate in evaluative performances.

One former student said that, as a child, she had never heard of someone deciding that they were going to "learn and not take an exam" (FS\#4). The exams were the main focus of music study amongst her peer group. She also described how, where she grew up, students would take school exams twice a year in every grade. Because regular, standardized evaluation was so important in all educational settings in her location, it made sense to her and to her family that studying music would also involve testing.

Another (FS\#5) described how her teacher regularly registered her for festivals and exams even though she did not want to participate. Her parents accepted the teacher's recommendation without question, as they also valued the documentation of achievement that was part of the festival and exam system. Eventually, as a teenager, this student simply did not attend one of her scheduled festival appearances. After this, she was allowed to stop participating.

Yet another former student (FS\#3) had actually initiated her own involvement in exams, although she had previously participated in several festivals at the suggestion of her teacher. She 
had enjoyed successes in her festival performances and thought that it would be worthwhile to do an exam, as she was considering pursuing a career in music. Unfortunately, her decision to take an exam coincided with a change in teachers, and the lack of support she received from her new teacher resulted in a very negative experience with her first and only exam.

One of the parents (P\#2) described how her daughter originally had been extremely reluctant to participate in exams. However, both the parent and teacher felt that the student could be successful and would benefit from the boost in self-confidence that could come as a result of success. In this case, the parent and teacher presented the examination as something the student could try once to "see what it's all about" $(\mathrm{P} \# 2)$ and then decide if she wanted to do again. Doing one exam seemed like a manageable commitment for the student, who agreed to participate. She received an excellent grade and was eager to continue her involvement in the exam system after that.

The parent of another current student (P\#4) had studied the piano herself, as a child, and had participated in conservatory examinations as part of her music studies. In this way, she was already familiar with the exam system when her daughter's teacher broached the idea. She valued the thorough musical training she had received as a result of participating in exams and wanted the same for her daughter.

My own introduction to evaluative performances happened even before I began taking piano lessons, as I was aware that my mother had taken violin exams as a child. As a result of hearing about her experiences, I entered my formal music studies with the assumption that taking exams was part of learning how to play an instrument. Because my first two teachers were students themselves at the time that they were teaching me, I heard about their own exam preparations in my lessons. My initial motivation to participate in examinations myself grew out 
of a desire to be like my teachers. While they definitely supported the idea of my taking exams, I was eager to follow the same path as my teachers and did not need much encouragement to participate.

As a teacher, I have never required my students to participate in exams. My approach has generally been to wait until a student is already at a level at which they could take their first exam and then present exam participation as an option. In some cases, the student (in consultation with the parent(s)) decides to go ahead with the evaluation; however, I always make clear to the families with which I work that taking exams is optional and that we will be engaging in meaningful learning activities regardless of their decision concerning examinations. In most situations, this approach has worked well: the students who have chosen to participate in examinations have found the experience to be satisfying, while the ones who have chosen not to participate have found other ways to further their music learning. However, as described in the Introduction, I have also encountered challenging situations in which the students' voice has been overpowered by the parent's decision that the child must take exams.

\section{Practice makes perfect: participants' preparations for evaluative performances.}

Being well-prepared for an evaluative performance requires a considerable investment of time and effort on the parts of teachers and students. Performances were planned months in advance so that weekly lessons and independent practicing could be structured to maximize students' likelihood of success.

It was obvious from the lesson observations that the teacher of the current students approaches preparation for evaluation in a systematic way, helping students break down complex material into simple, achievable steps and giving students specific strategies for tackling 
challenges such as fingering problems or memorization. She also conveyed information in different ways, such as writing reminders in a notebook and recording musical examples on a $\mathrm{CD}$, which the students took home with them each week. In this way, students were more likely to understand and remember what they were expected to work on between lessons. Several students mentioned that they found the multiple ways of presenting information helpful in ensuring their understanding of what was expected of them. This teacher was also careful to frame all of her feedback in a constructive and encouraging manner, thus ensuring that even sensitive students would receive the greatest possible benefit from their lessons (Atlas, Taggart, and Goodell, 2004).

Because this teacher was very experienced and was being trained to become an examiner herself, she was able to give students very specific instructions regarding what the examiners would expect to hear. Her familiarity with the curriculum and her knowledge of her students as individual learners allowed her to pace the festival and exam preparations so that her students were well-prepared without becoming bored with their required repertoire.

Regardless of the competence of the teacher, students cannot achieve excellent results in evaluative performances unless they expend a significant amount of effort themselves. The current students all described very detailed practice strategies, such as practicing slowly, saying finger numbers out loud, practicing hands separately, breaking the music down into small sections, using specific practice materials (such as ear training CDs) to work on technical skills, and playing along with the metronome or the sample CD. Students also described using imagery to help them convey the character of the music they were learning. The students who had positive experiences with evaluative performances enjoyed the kind of detailed, systematic practicing that is required to be well-prepared for a performance and felt satisfied when they 
knew they could play a piece well. The experiences of these students confirm Miksza's (2006) findings that strategic practicing results in higher performance achievement. With guidance and coaching from their teacher, these students had also developed good planning and task management skills, behaviours that Martin (2007) identified as being adaptive for engagement in learning.

In order for independent practice sessions to be effective, students must be able to reflect on and assess their own performances (Lebler, 2007). All of the participating teachers regularly ask their students to listen attentively to their own playing and give them specific criteria by which they can judge their own playing. The students described varying degrees of ability to assess the quality of their own playing. Some looked at specific criteria, such as "when I have everything memorized" (CS\#2) or "if I can play it once through and I have all the dynamics" (CS\#4). These students were generally confident in the accuracy of their own assessment and knew when their playing was sufficiently polished and when they still had significant work left to be done before they could perform. Others felt less confident in their self-assessments and relied more on the teacher's assessment of their readiness to perform.

In addition to developing a thorough knowledge of the music to be performed, the current students also described strategies for practicing the performance itself. These students were offered the opportunity to play in studio masterclasses, where they would perform in front of a group (determined by playing level) of other students from their teacher's studio. The teacher would then offer feedback so that the students could learn from each other's performances as well as their own. Many students also participated in mock exams, in which they would play for a colleague of their teacher's who was also an examiner. Playing in a mock exam several weeks before the actual performance helped students to see how they reacted under pressure and gave 
them an indication of which aspects of their exam program required the most work before the actual performance.

Boredom was a common issue raised by some of the former students when discussing their preparations for evaluative performances. In cases in which evaluative performances were the sole focus of music study, students frequently lost interest in practicing the same pieces for several months at a time. Particularly if students do not have a repertoire of appropriate and efficient practice strategies, it is easy for them to feel that they are not making progress and lose interest in their studies. Cziksentmihalyi (1991) described this phenomenon when he drew attention to the importance of aligning challenge and skill in preventing boredom and frustration. The students who complained the least about boredom were those whose musical educations included a variety of styles and genres of music and a variety of performance opportunities, as well as a repertoire of effective practice strategies to ensure that they continued to make noticeable progress each week.

My most significant memories of my own exam preparation periods are of stress and frustration. I was an intense perfectionist and prone to outbursts when I was unable to play a piece the way I wanted to, particularly as a younger musician. When I resumed lessons after my fateful Grade 2 exam and started making plans to take the Grade 4 exam, my brother asked with trepidation "Is Nancy going to get frustrated again?” As I matured, personally and musically, I developed more effective and efficient practice strategies (for example, practicing small sections rather than trying to play the whole piece from beginning to end without errors). However, I always struggled when my expectations of myself did not match my actual performance.

While the preparation process certainly included negative elements, above all I remember the satisfaction of mastering musical challenges, of knowing that I could now play well 
something that a few months prior I could not play at all. As I advanced in my studies and adopted more effective practice strategies, I took pleasure in documenting my progress and in seeing improvement from one week to the next. I felt a sense of accomplishment, as I took the advice my teachers gave me during my lessons and then managed my practice sessions myself as I worked toward my goals.

When helping my students prepare for their evaluative performances, I have tried to help them practice as systematically and efficiently as possible. I encourage them to isolate problem areas and give them strategies for surmounting specific challenges, such as playing an Alberti bass pattern as solid chords when first learning the piece, or applying different rhythms and articulations to fast running passages to avoid the fingers becoming jumbled. Because I remember my own frustration and anxiety, I try to pace students' learning so that they are able to achieve their goals within the prescribed time frame.

\section{The big day: participants' performance experiences.}

This section contains a general description of festival and exam performances with specific illustrations provided by the five current students. All of the students described very similar performance conditions, regardless of how long it had been since they last performed, indicating that festival and examination practices have changed little in the last three decades and that the examination process is similar across evaluating bodies. This fact illustrates the power of evaluating bodies, who feel little obligation to respond to local need or to modify their practices based on changes in the student population. While many conservatories have recently made efforts to update their curricula, the basic structure of the examination is the same. In many cases, the festival or examining body in a particular location is the only option for students who 
wish to participate in some sort of evaluative performance. Tye (2004) expressed concern in his research that the ABRSM curriculum, which is the predominant system used in Malaysia, as in many other former British colonies, was not well-suited to local needs. In recent years, several conservatories have made an effort to challenge the position of primacy occupied by the Royal Conservatory of Music. As a result of this competition, all of the conservatories have begun to offer a wider range of options to appeal to the interests and needs of students (Conservatory Canada, 2012; Canadian National Conservatory of Music, 2011). However, it is difficult to determine how many teachers would feel comfortable embracing new, unfamiliar approaches, choosing instead to enter their students in performances that echo the ones in which they participated as part of their own training.

Students who participated in conservatory examinations had to prepare several pieces from different historical periods, studies, and technical exercises. These students were also required to perform sight reading and aural tasks as part of the evaluation. The evaluation requirements were outlined in a syllabus published by the conservatory administering the exam. During the performance, only the student and the examiner were allowed in the examination room, although in some cases students and their parents could hear the muffled sounds of other candidates' performances from the waiting room. Feedback was mailed to the students or made available online several weeks after the performance, and the examiners maintained a neutral demeanor so as not to give any indication of how they felt about the students' performances. Communication between the examiner and student was generally limited to a greeting and instructions regarding what the student should play next.

Descriptions of festivals were also consistent amongst the participants. Because festivals often generate their syllabi based on those from examining bodies, festival requirements have 
remained fairly constant as well. As part of a class of other pianists of a similar age and/or level of playing, festival participants performed one or two pieces for a live audience and an adjudicator. Requirements for the various classes were generally designed to align with those outlined in examination syllabi. The feedback from the adjudicator was received immediately after all of the participants in a particular class had played. While some festivals include noncompetitive categories, all of the participants in this research who had performed in festivals had played in competitive festivals in which they received both a mark and a rank. The top three students in each class generally received special recognition. In some cases, students who performed particularly well might be invited to play at a gala performance at the conclusion of the festival.

Some of the students who participated in this research had played regularly in both festivals and examinations. In many of these cases, performances were scheduled so that the festival could act as preparation for the exam. The feedback received from the festival adjudicator and the student's and teacher's reflections on the festival performance served as formative assessment that influenced the course of the preparations leading up to the exam. Exams were generally viewed as more important performances, as they provided the summative evaluation for a particular grade level. Students generally did not move on to working on repertoire at the next level until after they had passed the exam.

All students described some level of nervousness related to the performance. For some, the anxiety was manageable and did not detract from the quality of the performance. However, for other students, performance anxiety was so debilitating that it was the main reason they stopped participating in evaluative performances or even stopped playing the piano altogether. 
Performance anxiety and its influence on students' experiences with evaluative performances is discussed in more detail in Chapter Six.

\section{Participant voices.}

As part of the data collection with the current students, each student drew a picture representing some aspect of her experience performing in a festival or examination. I provided blank white paper and a set of coloured pencils for students to use to create their drawings. Students were instructed to draw whatever they felt was important about the experience, using either representative drawings to show people, objects, etc. or abstract colours and shapes to convey emotion. All students chose some level of representation in their drawings; however, some also made use of colour and perspective to convey ideas. With the participants' permission, I have included the drawings in the thesis document, along with the descriptions and the students provided to explain their drawings. 


\section{Current student \#1.}

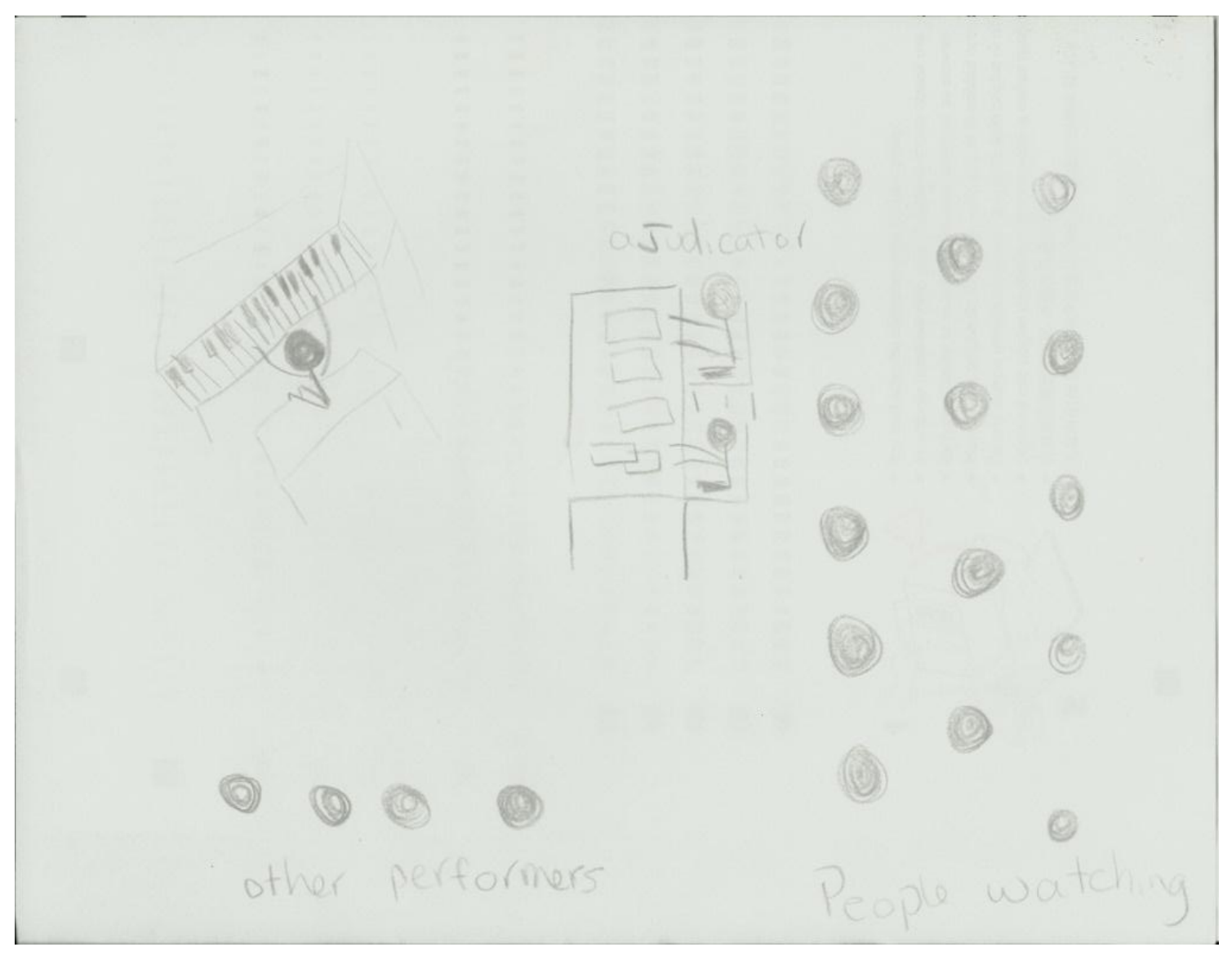

Figure 1 Current Student \#1

The first student drew herself performing in a competitive festival organized by the professional association to which her teacher belongs. Her drawing depicts herself sitting at the piano, with the adjudicators seated at the table listening to her play. The other performers (bottom left) and audience members (right-hand side) are represented by circles. The most notable feature of this drawing is the monochromatic colour scheme. When asked to explain her drawing, this student made apparent the fact that her choice of colour had been very deliberate. She had chosen the grey pencil as the only colour used because she felt that the overall atmosphere at the festival was "dull," uninteresting compared to other performances (such as recitals) in which she had been involved in the past. The festival took place at her teacher's 
home, a familiar environment. However, she was struck by the fact that a space that was normally warm and inspiring could become so filled with tension and restraint. She could sense the anxiety in both the other performers and in the audience. The overall atmosphere contributed to her feeling unexcited about the performance, even though she generally enjoys performing in public. Her mother also mentioned that the atmosphere had been very tense and that no one (neither the performers nor the audience members) seemed to be enjoying the experience. In spite of her feelings about the overall atmosphere, though, the student was successful. She valued the outcome of the performance highly enough that she wanted to participate in future festivals.

\section{Current student \#2.}

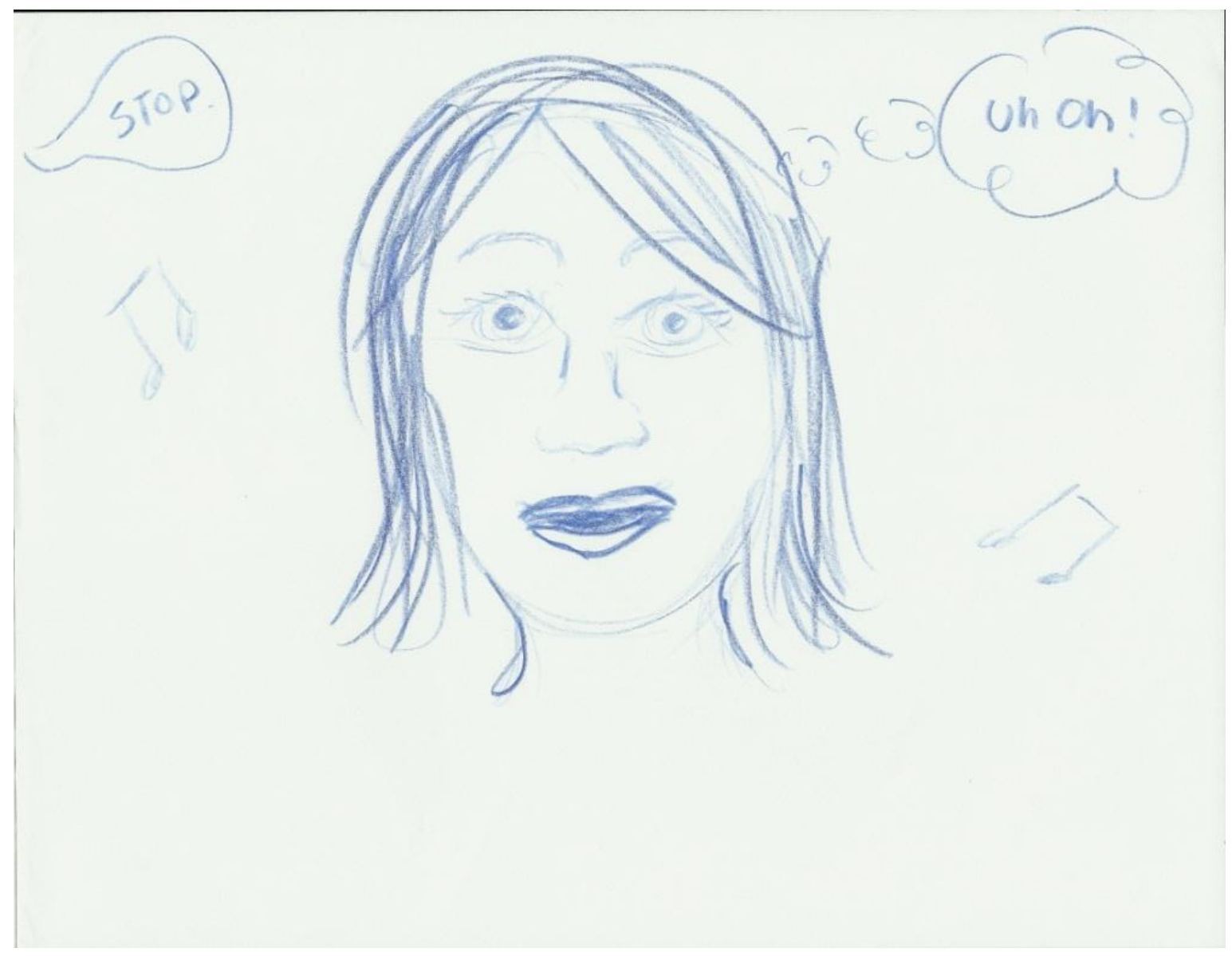


The second student focused on one particular moment in her exam that elicited a strong emotional reaction, choosing to depict in her drawing the expression on her own face at the instant when she was asked to stop playing before reaching the end of one of her pieces. She immediately worried that the examiner's request was an indication that her performance was deficient in some way. Her drawing shows the extreme concern and anxiety she felt when she was asked to stop. Fortunately, she asked for clarification ("Is that a bad thing?") and received reassurance from the examiner that the request was simply related to the need to stay on schedule. The examiner even provided some encouragement when she asked the student how long it had taken her to learn this particular piece. The examiner was impressed that the student had been able to learn the music as quickly as she had. While having to stop her performance part-way through the piece was initially unsettling, the whole conversation with the examiner ended up boosting the student's confidence in her abilities. It is interesting to note, though, that the most memorable part of the exam, which was a positive experience overall, was this momentary sense of panic. 


\section{Current student \#3.}

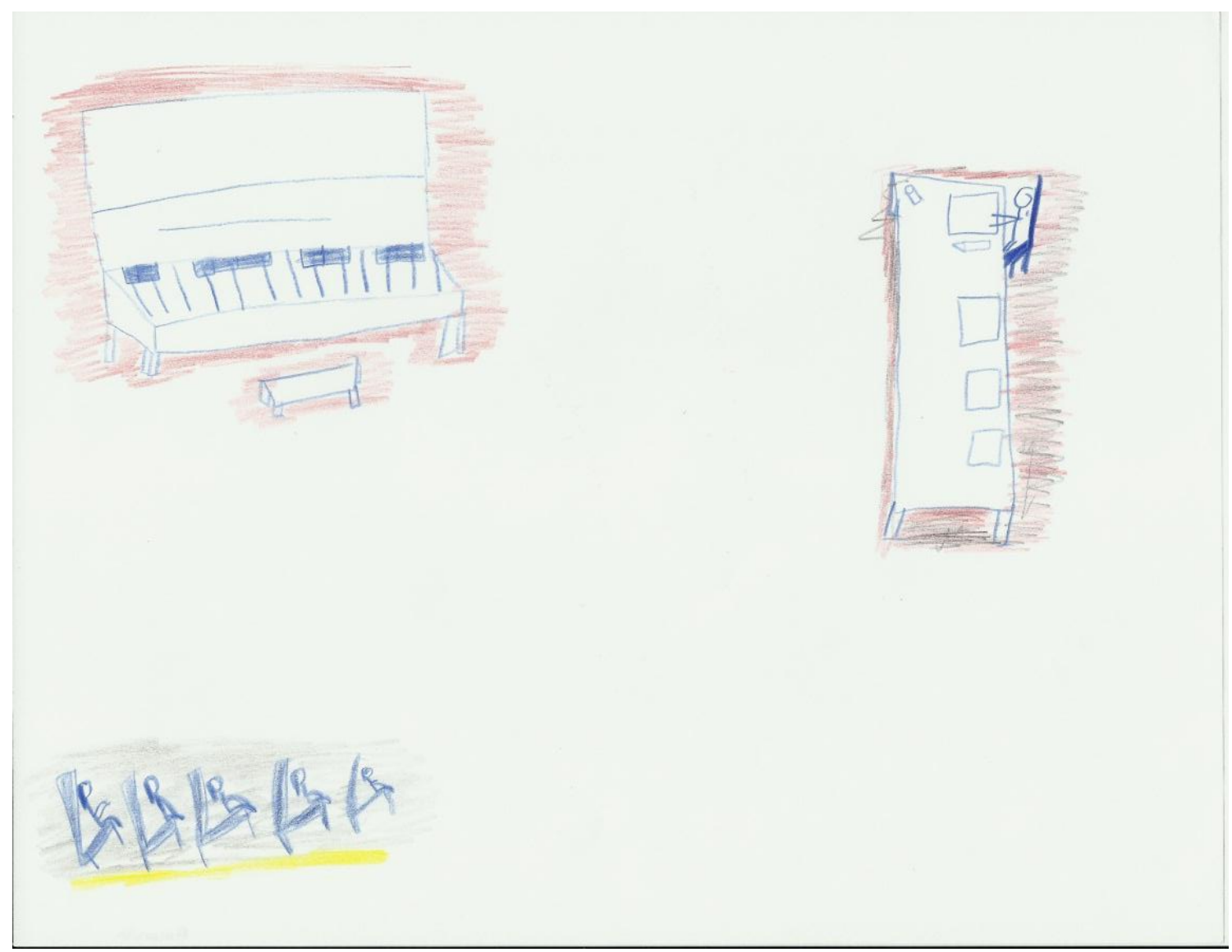

Figure 3 Current Student \#3

The third student drew her festival performance as well, showing the piano, the adjudicator, and the other performers. In this case, she used the scale of the drawing to convey the extreme performance anxiety she felt before she was called to play. In her drawing, she is represented by the figure the farthest to the right in the group of blue people in the bottom left corner. She is the smallest of all the performers, her head barely half the size of the others'. This student described feeling "like a little mouse" when faced with the adjudicator and the other competitors. Her performance anxiety was so intense that she felt dizzy and lightheaded. However, once she started to play, the anxiety receded, and she was able to play so convincingly that she was awarded the first place for her category. The positive reinforcement of her 
performance outweighed the negative experience of the anxiety, and her overall impression of the festival experience was a positive one. She felt a strong sense of accomplishment and was eager to enter more festivals in the future. However, like the previous student, when asked to choose one particularly memorable moment, she chose a strong, negative emotional memory.

\section{Current student \#4.}

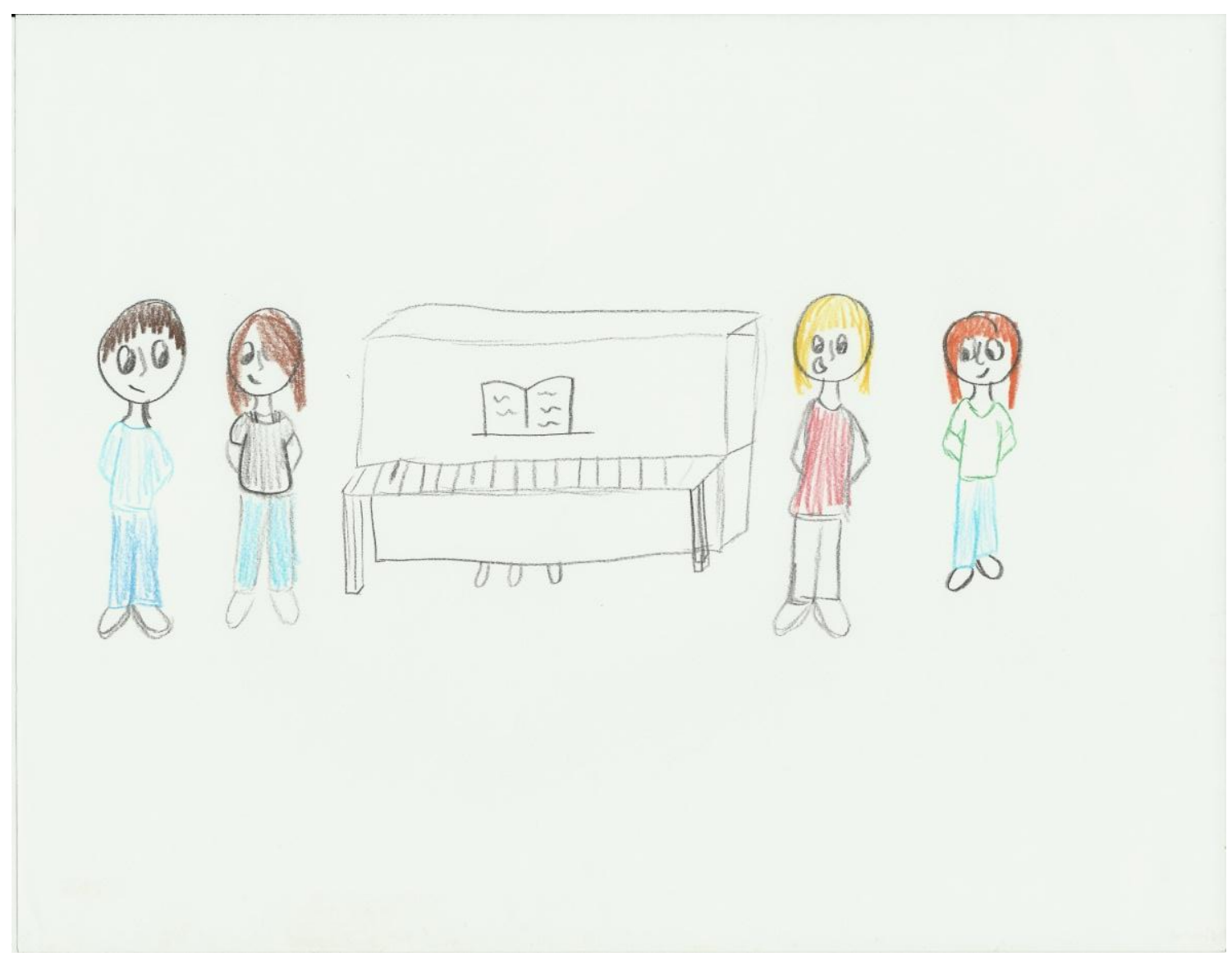

Figure 4 Current Student \#4

The fourth student drew all of the students at the festival performance, enjoying the opportunity to share a musical experience. This student had the most positive overall impression of the experience. In her interviews during the preparation period leading up to the festival, she expressed a desire to place in the top three performers. However, she was determined that the festival experience would be a positive one regardless of the outcome, as she was excited to have 
an opportunity to perform in front of an audience and to hear other students play. In the end, she was awarded first place. Receiving that recognition from the adjudicator simply added an extra positive dimension to an already positive experience. In her picture, all of the festival participants are smiling and seem to be enjoying the day. She referred to the experience as one that was positive for all involved, stating that all of the performers had played well. Interestingly, this student's drawing is the only one that does not include some reference to the adjudicator, either pictorially or in thought bubbles. For her, the primary purpose of participating in the festival was performing and hearing other students perform and she thoroughly enjoyed both of those aspects.

\section{Current student \#5.}

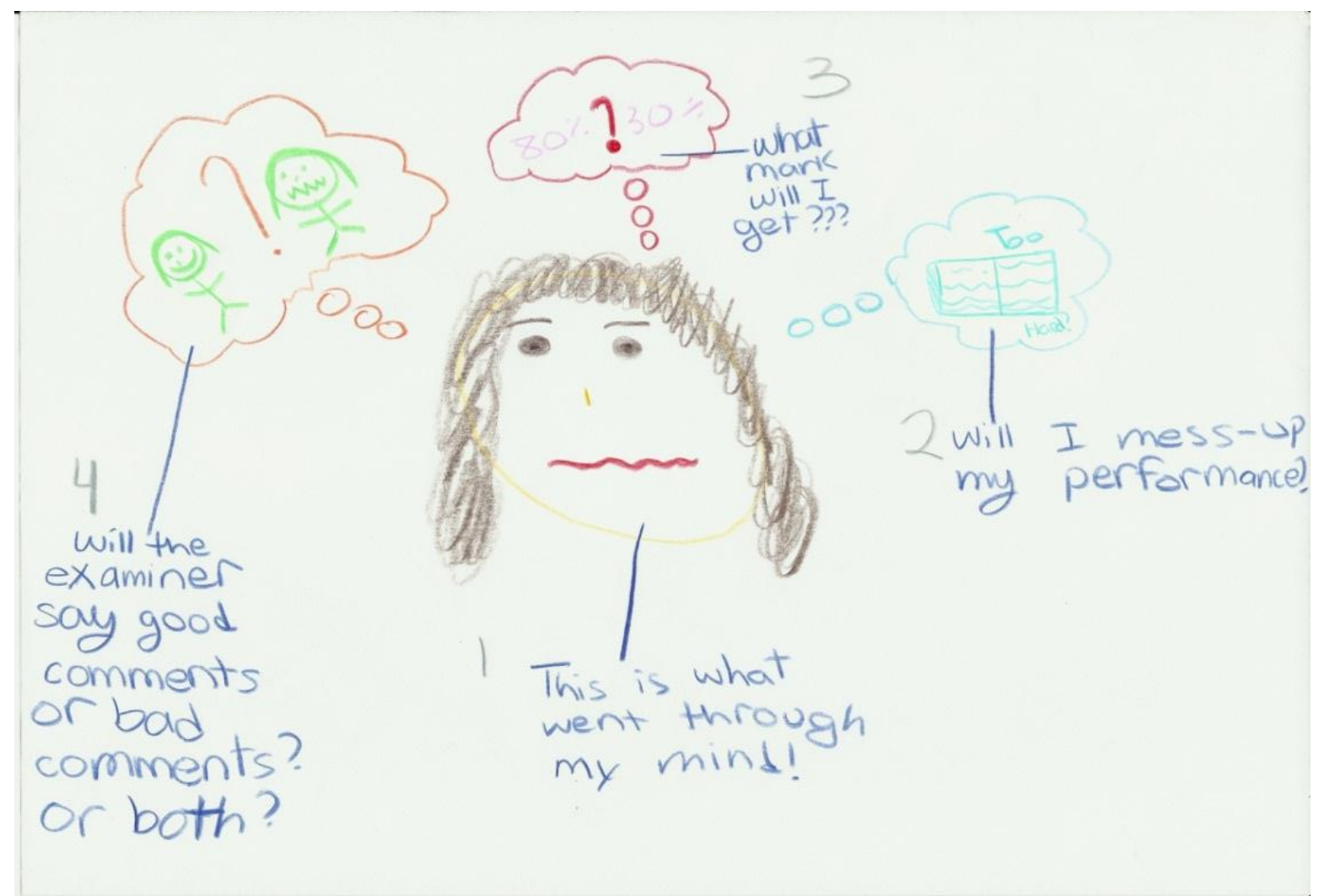

Figure 5 Current Student \#5 
The final current student drew herself surrounded by thought bubbles to depict the questioning that went through her mind leading up to the performance. It is evident from her drawing that she experienced considerable anxiety. The anxiety was related to her own performance, over which she had some control, but even more strongly, to the examiner's opinions of the performance. The examiner's assessment of the performance is an aspect of the experience that is beyond the student's control. For a student who places a high value on achievement (as did this student, who proudly showed off her exam certificates when asked to bring an object connected to her piano studies), marks and comments are extremely important. Her use of "good" and "bad" to describe potential comments from the adjudicator might reflect her interpretation of the exam experience as a value judgment. The comments are not simply an explanation of the mark or suggestions for future learning, but represent her "goodness" as a musician.

In all cases, the students highlighted some aspect of the emotional or psychological experience of participating in a festival or examination. For all, except the fourth student (who seemed to feel unflaggingly confident), these experiences involved some measure of anxiety or self-doubt. Students described anxiety both leading up to and during the performance. However, in the end, each of the students felt satisfied with her performance and felt empowered that she had been able to succeed in a task that at some point in the process had seemed daunting. All of the students responded positively when asked if they would want to participate in another similar performance in the future, in spite of the stress that most of them experienced at some point in the process.

Not all of my examination experiences were memorable; however, the performances I remember were those (such as the two described in the first chapter of this thesis) that involved 
the highest levels of anxiety. In common with most of the participants who completed drawings, I also was very focused on the adjudicator. I have very little memory of most of the adjudicators who heard me play, but I had developed a very intimidating (and likely unjustified, based on my actual experiences) mental construct of an adjudicator who was eagerly awaiting every error, ready to tear apart my performance and my self-concept at the same time. The adjudicator presented the great unknown in the examination experience, as I never entered an exam feeling confident that I knew what the adjudicator was expecting to hear. I certainly never felt confident that I could deliver a solid performance on the day it was required.

\section{The experts: participants' perceptions of adjudicators and examiners.}

In most cases, students had neutral or positive feelings about adjudicators and examiners, who were perceived as friendly, if somewhat distant, and fair. None of the participants described difficult experiences with unfriendly or excessively harsh evaluators. Participants'strongest memories of adjudicators and examiners related to times when they received high praise for a particularly strong performance.

In order to maintain the impression of objectivity, adjudicators and examiners were brought in from outside the community and were unfamiliar to the students. The evaluators likely had never heard the students play before and would never hear them again. They also had no vested interest in whether or not the students succeeded.

The lack of relationship between student and evaluator served to dehumanize the adjudicators and examiners and to reinforce the idea that they were experts who cared only about how well the student played. One student (FS\#4) described the anxiety she experienced as a child performing for examiners who had been brought in from a different country. While the 
examiners were friendly, she always worried that their unfamiliar accent might result in her failing to understand their instructions. Other students described how they found the lack of immediate feedback in the exam unsettling and wished that they had been able gauge what the examiner was thinking.

Adjudicators and examiners were perceived as authority figures by all of the participants in this study. Participating in a festival or examination requires an intense preparation involving sacrifices of time, energy, and money. The only way that investment is worthwhile is if one values the feedback from the adjudicator, which cannot be obtained any other way. During the lesson observations, I noted several conversations in which the teacher and students discussed what the examiner would be expecting to hear in a certain component of the exam. Two of the teacher participants ( $\mathrm{T} \# 1$ and $\mathrm{T} \# 2$ ) were training to become examiners during the data collection and were putting to use their insider knowledge of the examination system as they prepared their students for evaluation. The idea of the adjudicator or examiner as an authority figure is a key facet of the whole experience of evaluative performances. If that person's evaluation were not worth more than the appraisal that a student could receive from a teacher, parent, audience member, or self-assessment, it likely would not be worthwhile to invest everything that is required to prepare to play excellently in that one performance that the evaluator hears.

Maroon (2003) and Brotons (1993) emphasized the authoritative role of the adjudicator. Knowing that they will have to play for an expert has a profound effect on students' anxiety levels and performance quality. While the idea that a stranger who has only heard a student perform once can provide a more accurate assessment of musical achievement than a teacher who has a long-standing relationship with the student is questionable, many teachers, parents, 
and students are willing to accept the adjudicator or examiner as an authority figure in the same way that many accept the authority of standardized academic tests.

In the previous section, I described having very few specific memories of the examiners who evaluated me. They were friendly, but maintained the expected distance and formality, giving little indication of their perception of my performance on the day of the exam. My students have described similar experiences. While the lack of communication is likely necessary in order to stay on schedule and to allow the conservatory to audit examiners' reports before the student has been informed of the result, it can also have a negative impact on students' levels of comfort and on the potential enjoyment of the performance experience, as there is no immediate positive reinforcement after the student plays. More importantly, the time lapse interferes with the utility of the examiner's feedback, as will be discussed in more detail in the following section.

\section{Judgment day: participants' responses to feedback from adjudicators and examiners.}

The current students had all experienced a great deal of success in their evaluations. They remembered the marks that they had received in previous festivals and exams and had specific goals related to the marks or ranks they hoped to receive for their upcoming performances. While the students who had been successful enjoyed the recognition they received in the form of marks and ranks, the ones who had not enjoyed the same success often took the negative feedback very personally. One of the current students (CS\#2), who had previously been very successful in evaluations, had recently had a disappointing result at a festival. She and her teacher had a 
lengthy discussion during one of her lessons as they worked through her feelings of disappointment and frustration at not receiving the result she had anticipated.

The comments from adjudicators and examiners were generally perceived to be not very useful, as they were either repetitions of information the student already knew, or were so specific to a particular piece of music that they provided no guidance that could be applied to future learning. In the case of conservatory examinations, the feedback was received so far after the actual performance that it was difficult for students to remember exactly how they had played. It would appear from the conversations with the students in this study that the comments serve as a means to explain or justify the mark given, rather than as a significant means of furthering students' development as musicians. One of the current students described her exam comments in this way:

CS\#5: Um, well, no cause it was kind of like wrong notes and stuff, cause it was almost perfect, just like "You had a little bit of trouble in this line" but he didn't say what trouble, just said trouble.

In this case, the student received a description of her exam performance, but no particular guidance that could help her avoid similar mistakes in future performances. This lack of direction for future learning is a characteristic of weak feedback (William, 2011, p. 7).

This finding regarding the lack of utility of examiner feedback is somewhat surprising, given that teachers and parents often talk about the usefulness of the feedback as one of the main benefits of students' participation in evaluative performances. The marks seemed to be more useful in shaping future learning than the comments. The teacher of the current students described how she would modify her instruction for the following grade based on where students received low marks (for example, starting sight reading practice earlier or placing more emphasis on technique). 
As a student, my main focus was on the marks I received, although I appreciated any general comments that contained positive overall assessments of my musical potential (for example, a comment such as "Best wishes for your future musical studies" implied that the examiner thought it was worthwhile for me to continue studying). I don't remember ever changing the way I prepared for future exams as a result of the comments I received on a prior evaluation.

As a teacher, my experiences interpreting and trying to use the feedback from examiners and adjudicators has echoed what was described by the participants in this study. While the marks have been a helpful indication of how well a student is progressing in a particular area and some of the comments provide general insight about the student as a performer (particularly if a student receives similar comments from different adjudicators on different occasions), many of the comments are either too specific to be relevant to future studies or too difficult to interpret without having heard the performance upon which they were based.

\section{What next? The influence of students' experiences with evaluative performances on their future plans.}

After receiving their feedback, students had an opportunity to reflect on their experiences and to make plans for future involvement in music study and evaluative performances. For students who had positive experiences participating in festivals and exams, goals for future music study usually involved more evaluation. Many students had specific goals regarding the level they hoped to reach, such as completing their Grade 8 exam, finishing the exam curriculum, or being able to play as well as their teacher. 
Students who had had negative experiences with evaluation hoped to avoid future negative experiences. Unfortunately, some of these students were forced to continue participating in evaluative performances against their wills as a result of parental and teacher expectations. In many cases, evaluative performances had been such an integral part of their formal instruction that avoiding future evaluative performances meant discontinuing lessons. For students who had never really wanted to learn the piano in the first place, stopping formal instruction came as a relief. However, when a student had at some point been enthusiastic about piano studies, stopping lessons because of a negative experience with evaluation represented a dramatic change in plans. This relinquishing of a previously valued goal was an emotionally difficult experience.

Many students who stopped taking lessons continued to play the piano at least occasionally for their own pleasure; however, their goals for future improvement or skill development tended to be very modest compared to those of the students who were still pursuing formal instruction and evaluative performances. The students who were planning on participating in future festivals and examinations envisioned themselves reaching levels of skill much beyond their current attainments. However, the students who had stopped participating in evaluative performances were focused on using the skills they had already developed to play "for fun" (FS\#7, FS\#8) or in community settings, such as in church (FS\#6, FS\#7).

It would appear from the responses regarding future (or current) involvement in music study that, for most students, evaluative performances are an integral part of focused skill development. Students who are no longer taking exams do not necessarily substitute other achievement or mastery goals (Dweck, 1986) beyond learning specific pieces of music. This insight would lend credence to the perspective of parents who are determined that their child 
must reach a certain level in the examination system, hoping that this achievement will lead to a greater likelihood that the child will be able to play a wide range of music independently. However, I have seen in my own teaching practice that many students can continue to grow as musicians without the externally imposed structure of an evaluation system and that other students, when finally freed from the constraints of the exam system, could not be more eager to abandon the piano.

\section{Why Participate in Evaluative Performances?}

Participating in an evaluative performance requires a significant investment of time, energy and money on the parts of all stakeholders. As a result, students, parents, and teachers weighed the benefits and risks of student participation when deciding to pursue a festival or examination. This section outlines the participants' perceptions of the benefits and drawbacks of student participation in evaluative performances.

\section{Perceived benefits of evaluative performances.}

Evaluative performances were viewed as a way to ensure thorough skill development, to increase student motivation, to structure the academic year, to increase self-confidence, to hear other students, to learn from expert feedback, to mark achievement, and to receive credentials. One of the former students described her perception of conservatory examinations in this way:

FS\#8: Although I did not particularly enjoy taking piano exams, I think they were necessary in improving my piano playing skills and also, instilling discipline. I was certainly too busy with music (and other school work) to get myself into any trouble during school days!

For this student, participating in exams ensured not only a high quality music education, but also contributed to overall character development. 
The importance of having a goal to work towards was addressed by several participants. One teacher said that she felt her students had a tendency to "drift" (T\#1) when they were not preparing for a performance. Another described how she structures her teaching year around a festival. Several students described a rhythm in their practicing in which they worked harder as the evaluation date approached. Many alluded to the idea that having a goal to work towards helped them be more consistent and focused in their practicing, particularly when they were working on aspects of their musical development that they found less interesting, such as technique, sight reading, or ear training. According to Costa-Giomi's (2005) findings, their persistence in practicing might even have been related to their persistence in taking piano lessons.

Several students used the word "accomplishment" (CS\#1, CS\#2, CS\#4) to describe how they felt upon completing a festival or exam. This sense of satisfaction with their achievement was a source of confidence and acted as an incentive to continue pursuing their musical endeavors. In some cases, the drive to achieve appeared to be just as important to these students as the musical learning outcomes of being involved in evaluative performances. For some students, the mark or rank assigned by the adjudicator was of prime importance. In the case of festival performances, some students were focused mainly on being able to show the audience what they were capable of doing. They were proud of the progress they had made and were looking forward to the appreciation they would receive for a strong performance.

Teachers also took pride in their students' successes and appreciated the reassurance that they were doing a good job. It was obvious in the tone of voice used by all three teachers when talking about their students' participation in evaluative performances that they were invested in their students' results and that they celebrated with their successful students. The teacher of the 
current students had a bulletin board in her studio devoted to celebrating the achievements of her students in festivals and examinations. The second teacher described how she appreciated the validation of her abilities as a teacher when her students did well in evaluative performances. The third teacher described in detail and with great enthusiasm some of her former students, who had achieved particularly high results in a festival several years prior. Even after several years, she still exuded pride over the recognition that these students had earned. As much as these teachers enjoyed their students' successes, though, they did not put pressure on their students to achieve or make students feel that they had let down the teacher in the case of a disappointing result.

All parents were happy to see their children learning, enjoying themselves, and taking pride in their achievements. Some also saw successful outcomes in evaluative performances as evidence of receiving a good return on the money they had invested in their children's lessons and valued the potential of examinations, in particular, to provide a credential that could be placed on a student's resume. The following quote is from a parent who had given careful consideration to the level of achievement she hoped her children would reach:

P\#1: Uh, well, in the back of my mind I'd always kind of hoped that if they had this piano, and I believe I always told the girls, well you can quit when you get your Grade 8, cause then you can go in for music. I was thinking [local arts high school] at the back of my mind, and they would have to have a minimum of Grade 8 to get in. Um, but at the same time I know that that's probably not where they're going to go. I just thought if they had that, it's something that they can fall back on, maybe they could teach little kids a couple of lessons here or there and you know maybe if they wanted to later on pick it up.

For this parent, the documentation of achievement was of primary importance, as it would open up opportunities for future musical involvement.

Other parents emphasized the confidence that they felt came from their children's exposure to performance situations. One described what she felt was the purpose of performing in festivals and examinations: "So that festivals and things like that bring a little bit of comfort, 
make them comfortable playing in front of a group. Because you know, art is all about showing, isn't it?” (P\#5) In her view, her daughter's piano lessons would be a waste of time if her daughter was not able to share her music with other people. Festivals and exams were worthwhile pursuits because they provided an opportunity to practice performing with poise and confidence.

In most cases, parents emphasized non-musical outcomes of music study and of participation in evaluative performances over musical outcomes. This emphasis makes sense when we consider that none of the current students expressed a desire to pursue music as a career.

While both festivals and examinations provided the opportunity for students to hear the opinion of an adjudicator, festivals provided a unique opportunity in that students could hear other students perform. Several students mentioned enjoying hearing new music and other interpretations of the music that they were learning themselves. When students felt well-prepared for their own performances, they were able to see others' performances as an opportunity for learning and enjoyment and did not feel insecure.

One parent (P\#2) described how beneficial it had been for her daughter (CS\#2), whom the parent described as a perfectionist, to hear that there could be many ways of performing in an artistically satisfying manner. She described how playing in festivals (and hearing another student play the same piece) had changed her daughter's perspective on what makes a good performance: “[F]or her what's interesting, ... and I guess this is what being an artist is all about, is that there is no right or wrong, it's just different." Being exposed to a variety of performances freed this student from the feeling that she had to master one "correct" way of playing her pieces. 
Another parent (P\#4) and her daughter (CS\#4) described an eye-opening experience in which they heard another performer, who was much younger than the other musicians in her class, play extremely well. This experience forced the student to evaluate her own playing and the amount of time and energy she was willing to invest in pushing herself to achieve. In the end, she decided that she was content with her level of progress (which was still very good) and did not want to experience the kind of pressure that she imagined would be involved in aiming for the same level of achievement as this other musician.

In summary, the perceived benefits of participation in evaluative performances included increased motivation to practice (particularly aspects of the curriculum which might be less appealing for students), greater and more consistent progress as a result of structured learning and concrete goals, a sense of accomplishment for students, formal documentation of achievement, increased confidence in performance situations, and exposure to a variety of musical perspectives from adjudicators and other students.

\section{Perceived drawbacks of evaluative performances.}

While the participants identified several benefits to participation in evaluative performances, they also referred to several drawbacks. These included boredom when the festival or examination curriculum became the sole focus of music study, limited musical development as a result of the narrow scope of the curriculum, anxiety leading up to and during performances, feelings of disappointment and disillusionment in the case of failure, and strained relationships with parents and teachers when the students' attitudes or achievement did not align with the adults' expectations. 
Participating in evaluative performances can easily become the sole focus of music study, as both students and teachers feel strongly motivated to do everything possible to ensure a successful outcome. Several former students expressed regret that they did not have the opportunity to pursue musical interests that were not part of the required curriculum. Boredom was a frequent complaint amongst these students, who wished that they had had the opportunity to develop a wider variety of skills and to explore repertoire outside of the Western Classical canon.

As previously mentioned, the teachers who participated in this study all mentioned the value that they place on their students' engagement in learning outside of the examination curriculum. Because these teachers have prioritized offering a balanced and individualized course of study, their students are able to enjoy a wide range of musical activities that do not come with the stress inherent in preparing for evaluative performances. Several students described playing popular music or composing their own music in their spare time. These activities were intensely satisfying, as they allowed students to engage in music in ways that were personally and socially meaningful. In some cases (for example, FS\#1), pursuing an interest in popular music virtually replaced playing classical music after the students stopped formal piano instruction.

Not only did students who had limited musical diets during their formal music studies find their studies to be less interesting, they also expressed regret that they missed out on developing some important musical skills. For example, one of the former students described how she depended on a friend's transcription skills when, as a university student, she wanted to learn popular songs she had heard on the radio. I experienced similar feelings of regret when I 
realized that my years of formal piano study had done little to prepare me for playing from lead sheets at church or improvising accompaniments for my elementary recorder students.

While boredom with the required curriculum can lead to students' having lower levels of interest in their music studies, the anxiety related to participation in evaluative performances was the main emotional drawback described by the participations. I will discuss performance anxiety in more detail in Chapter Six, but it is worth mentioning here that anxiety was mentioned by all of the student participants, even those who had positive overall experiences with evaluative performances. For some students, performance anxiety was manageable and perhaps even beneficial, as it motivated them to practice on days on which they did not feel like working and gave them extra energy when performing (Sinden, 1999). However, for other students, performance anxiety was debilitating and was the main reason they decided to discontinue their participation in evaluative performances.

While students who had been successful in evaluative situations described how they felt a sense of accomplishment and increased self-confidence after their participation, students who were not successful often had markedly different views. One student (FS\#3), who had failed her first and only examination, took several years off from her piano studies after her performance and still does not feel comfortable playing the piano in front of other people. Another student (FS\#2) described a performance which, while not evaluative, did not go well and influenced her decision to avoid performing in public in the future.

Participating in evaluative performances could also result in strained relationships between the student and his or her parents and teacher, particularly if the student was reluctant to participate or felt pressured to achieve in order to maintain the teacher's reputation. The 
relational context of students' learning and participation in evaluative performances is so important that I have devoted Chapter 7 to this topic.

When parents and teachers recommend that students participate in evaluative performances, the recommendation is generally made under the assumption that the student will benefit from the experience. However, all of the students experienced some drawbacks to participating in festivals and exams. For some, the drawbacks were minor and did not come close to outweighing the positive aspects of the experience. However, other students experienced significant negative effects from their participation in evaluative performances. Unfortunately, for these students, experiences with boredom, anxiety, frustration, disappointment, or tension in relationships extended beyond the experience of participating in evaluative performances and coloured their overall impressions of formal music study.

\section{Summary}

This chapter provided an introduction to the participants in this research and an initial exploration of the process of student participation in evaluative performances. This process, which is outlined in the diagram below, consists of many stages, beginning with students' introduction to formal music education. Students' initial involvement in music study is influenced by several factors, including their own desire to learn music, which often grows out of exposure to an environment rich in informal music-making, and their parents' involvement in determining extra-curricular activities.

The idea of participating in evaluative performances is generally introduced by the teacher, although some students and parents have prior knowledge of the festival or exam system as a result of their relationships with other people who have participated in these types of events. 
Students prepare for evaluative performances through weekly lessons, which are usually focused mainly on preparation for the evaluation, and through regular independent practice sessions between lessons. Teachers give specific guidance related to what the adjudicator or examiner will expect to hear and how the student can practice most effectively in order to achieve a high result. Preparations also sometimes include practicing the act of performing, for example, though a mock examination.

The performance itself is generally at least somewhat stressful, although some students reported enjoying performing and (in the case of festivals) appreciated the opportunity to hear other students. Other students find it very difficult to enjoy any performance, particularly a performance that involves evaluation, and experience extreme levels of anxiety.

The students who participated in this study described adjudicators and examiners as being friendly, if somewhat distant. The evaluators are trained to maintain strict professional boundaries in order to maintain the authority and perceived objectivity of their role. While successful students appreciated receiving high marks and certificates, the comments from the adjudicators or examiners were generally not viewed as being particularly useful in shaping the direction of future learning.

Students who had positive experiences with evaluative performances generally wanted to participate in more of them and structured their goals for future music study in terms of evaluation levels. On the other hand, students who had negative experiences with evaluation sometimes altered their future plans to eliminate not only more evaluative performances, but also formal piano study in general.

Perceived benefits of participating in evaluative performances included increased motivation and discipline in students, the opportunity to learn a balanced musical curriculum, 
and the opportunity to benefit from feedback. Many participants valued the structure provided by the exam and festival systems and appreciated the formal recognition of achievement afforded by evaluative performances.

Perceived drawbacks of participating in evaluative performances included the omission of potentially meaningful learning that was not related to the evaluation, feelings of frustration or disappointment in the face of a low result, experiences with performance anxiety both leading up to and during the performance, and strained relationships with parents and teachers.

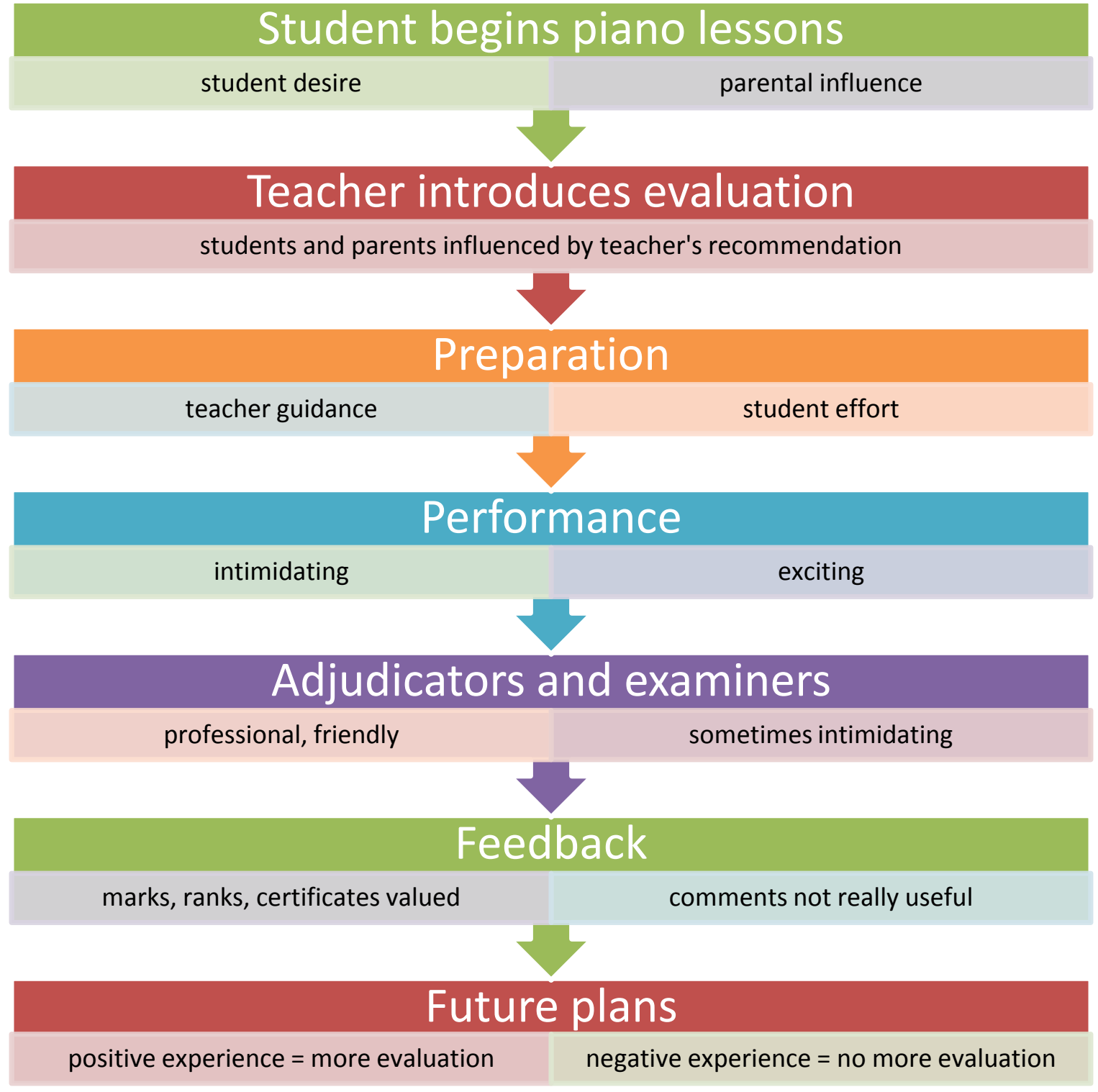

Figure 6 The Process of Participating in Evaluative Performances 


\section{Chapter 5 \\ Engagement in Music Learning Through Participation in Evaluative Performances}

One of the main goals of this research is to highlight some of the factors that contribute to students' having a positive experience with evaluative performances. Chapters 6 and 7 will discuss in detail the personal and relational characteristics that influence the quality of students' experiences. However, first, I will examine more closely exactly what constitutes a positive evaluation experience. To define a positive experience most simply, a student who had a positive experience with evaluative performances had to say something to the effect of "I liked it and I want to do it again." Conversely, a student who had negative experiences participating in evaluative performances disliked the experience and wanted to avoid future participation (even if they were forced to continue participating for a time before they were allowed to stop). The category of "positive evaluation experiences" has three main properties: the quality of emotional responses, the meaningfulness of music learning, and the development of a sense of the self as a musician. All three of these properties is affected by the students' success or failure and by the degree of ownership exercised by the student over his or her learning and evaluation experiences. Positive evaluation experiences are important because they determine the degree to which participation in evaluative performances contributes to overall engagement in music learning.

\section{Quality of Emotional Responses}

Many of the participants in this study described strong emotional responses to their involvement in evaluative performances. Emotional memories are very powerful and have farreaching influence (Cameron and Carlisle, 2004). As a result, it is crucial not to underestimate the effects of students' emotional experiences on both present learning and on the desire to 
engage in future learning. Students who had positive views on evaluative performances described a variety of positive emotional outcomes. These students experienced happiness, enjoyment, pride, and a sense of being supported by others. These students spoke of loving music and found great enjoyment in playing music for themselves and for others. Learning a variety of music allowed them to explore various forms of musical expression and to find their own musical voices. In the following section, I examine some of the participants' descriptions of their emotional responses to learning the piano and to participating in evaluative performances. Some students had very positive memories of their earliest experiences learning to play the piano. One student described her introduction to the piano with the support of a relative:

CS\#2: Well, I enjoy listening to music and stuff and when - actually my great aunt, she had a piano and when I was really tiny, she would sit me down and just sort of let me play along with her and she, she used to play. So she'd be like "okay, push this note, push this note" and we'd end up playing a song or something, like "Twinkle, Twinkle Little Star" and it sort of like turned out really fun.

For this student, the warmth and connection she felt with her great aunt contributed to a very positive introduction to the piano. Equally important in this case was the introduction of familiar repertoire. The student enjoyed great satisfaction in being able to play a song that she had known for a long time.

Another student also described an environment in which she was immersed in music from a very young age. Her interest in music was developed through listening and through interacting with other musically interested family members.

CS\#3: [M]y mom used to play CD's all the time when I was little ... my grandmother would be playing the piano up here and my mom would be playing CD's downstairs, so like I'd be hearing music all over the house.... I couldn't stop listening to music. And then when I got older and got my own CD player, as soon as I walk in my room, even if it's just to grab socks or something, I'll turn on my radio. Like I'll flip it on, grab it, turn it off, go. 
For this student, learning to play an instrument was a natural extension of the musical interest that had played such a large role in her life from her earliest memories.

Siblings also played an important role in some students' development as musicians. One student described her sister's involvement in this way:

CS\#4: Well, I really like music and singing and stuff, and whenever she'd play, I always wanted to learn how to play and it really looked interesting. I'm like "Oh, I want to learn that" so I would try and learn pieces and so I think I just really thought it was interesting.

Several students mentioned being inspired by older siblings' piano studies. Interestingly, many of the younger siblings ended up pursuing their musical educations with more enthusiasm and persistence than evidenced by their older siblings.

Once students began taking formal lessons, the biggest attraction for many was the enjoyment they experienced from learning new music. One of the current students identified this satisfaction as her favourite part of learning to play the piano.

CS\#2: The pieces, because whenever I get a really fun piece, I'm so focused on finishing it and when I finish it, I feel so accomplished, like I feel so proud that I finished it and it sounds good, 'cause some of the pieces have CD's that go along with them, so you can hear what it sounds like, so when I play and it sounds like that, I feel really accomplished that I achieved that.

This student appreciated both the final musical product ("it sounds good") and the sense of accomplishment that she experienced when she knew that she had conquered a challenging task. Her sentiments were echoed by one of the survey respondents, who described her feelings on the exam curriculum thus:

FS\#7: I did not find there was any music I disliked. I think what I enjoyed most about learning music was the sense of accomplishment after mastering a particularly challenging piece. The best part about music lessons was receiving the new scores for the year because it becomes an unofficial assessment of how much the teacher trusted in my potential/abilities/skills to master a more challenging piece. 
For this student, being assigned new pieces was not only an opportunity to experience new music but also a signal that she had met her teacher's expectations for improvement. Another student referred to enjoying learning new songs, emphasizing the importance of novelty and of advancing to progressively more challenging music over time. For these students, mastering a wide and varied repertoire was an important part of music study. They not only enjoyed learning the music but also felt great satisfaction as their skills developed and as they received recognition from their teachers for this improvement. Their experiences confirm the findings of Rife, Scnek, Lauby, and Lapidus (2001), who identified children's enjoyment of music learning and dedication to practicing as important contributors to overall satisfaction with music lessons.

The musical materials with which students interacted were also a source of positive emotional responses to learning. Some students were very articulate in describing specific aspects of the music that they enjoyed.

CS\#3: Well, I'm crazy about staccato, because I'm really good at it - I love it. It's like really quick and I don't have to hold it down for very long. So that's mostly why I like Clockwork. And Lady Moon - it's just like very calming and very haunting, kinda, and I'm big on that kind of stuff. It's just very calm, but spooky at the same time. So I love it.

$N$ : Are there particular kinds of music that you like better than others?

CS\#4: I like jazz and I like kind of the minor things, like a minor and things like that. So really subtle, nice pieces that are kind of beautiful.

$N$ : So what kind of moods are you creating when you're playing those pieces?

CS\#4: Well, like subtle moods, kind of like wind and stuff, I've done a couple pieces like that - happy moods, and sometimes even sad. I don't know, like any mood is really fun.

FS\#9: Depends on the individual piece, but I much prefer practicing interpretation/phrasing/shaping, etc. than learning notes, and so it takes me longer to enjoy a contemporary piece than a classical/romantic piece.

These students particularly enjoyed experiencing the emotional, expressive aspects of music. The first two students quoted were very outgoing and enthusiastic in their interviews and it would 
appear that for all of them, music is very much a form of personal expression and communication. They relished the variety of feelings that could be experienced and conveyed through music. Their views echo the findings of Davidson, Pitts, and Correia (2001), who emphasize the importance of not neglecting the study of expressive aspects of music in favour of focusing solely on technical concerns. When students are given opportunities to explore the personal expressive potential of music, they are more likely to be highly engaged.

In addition to creating positive emotions, music could also be used to assuage negative emotions. One current student (CS\#3) described how she would play favourite pieces as a form of stress relief when she encountered frustration in her practicing. The enjoyment she experienced when playing familiar, well-loved music brought her back to a place of calm and focus so that she could continue working on her more challenging repertoire.

Positive emotions related to music learning in general are a crucial foundation for students' experiences with evaluative performances. If a student enjoys learning music and has a desire to continue developing his or her skills, he or she will be likely to embrace an opportunity to pursue further learning (Martin, 2007). The festival or exam itself could also result in positive emotional outcomes. In this excerpt, a parent describes how her daughter felt about performing in festivals:

P\#4: For [current student 4], it's because she likes to be the centre of attention and she likes to be challenged and...And I think she just enjoys playing the piano as well. And then you get - [teacher] runs it quite nicely, you know, everyone gets dressed up and take a bow and whatever and actually the formality of it is kind of nice for her, too.

This quote captures the student's eagerness to perform and share her music with other people, as well as the importance of festival participation in this student's musical life. For this student, festivals provided an opportunity to demonstrate what she could do to an appreciative audience. 
The formality (dressing up, bowing) afforded a sense of occasion to the performance, making the experience all the more exciting and memorable.

In order to experience positive emotions, such as enjoyment, while performing, students needed to feel very well-prepared for their evaluation. One former student described her early experiences in this way:

FS\#3: The first few competitions...were really easy and ... I had progressed really quickly, so it was never a problem in terms of the challenge.

At this point in the interview, the student's tone was warm and positive, as she was recalling pleasant memories of successful performances. She felt confident on stage and enjoyed the thrill of performing for an audience.

While the performance itself was enjoyable for some students, for others, the main positive emotional response came as a reaction to the results.

CS\#4: Well, I think because then you know that, like, you made, you've finished this grade and you just have the pride - you're just proud because you made it through the grade and it was fun. I don't know, it's just kind of important to me, because, yeah, it's just an accomplishment.

CS\#2: I just started doing festivals last year and same with exams, because I'm not really a competitive person, but [my teacher] has always encouraged me to try, just to get some good feedback and stuff, so she got me into my first festival and my first exam, and we did really well, so I did 2 exams in one year last year. So I got really good marks on those ones. I sort of felt confident and proud that I'm such a good piano player and stuff.

All of the students who had positive experiences with evaluative performances had very detailed memories of their prior achievements in evaluative performances. They could remember the ranks they had been awarded in festivals and could often recite specific exam marks. When asked to bring an object that represented their piano studies to the first interview, several students brought some sort of award or certificate, indicating that receiving recognition was an important 
element in their positive view of music learning and performance. These students experienced a "high" when they earned a high mark or received praise from an adjudicator and sought out opportunities to experience that sense of pride again. The word "accomplishment" was used by several participants to describe how they felt about their participation in evaluative performances.

For the students who viewed their participation in evaluative performances in a positive light, participating in festivals and exams encouraged the love of music that was already present. Preparing for the performance gave students a reason to polish pieces to a very high level. In the time that the students were practicing their festival and exam pieces, they became immersed in that music. Because they loved the music, they enjoyed the process of integrating this repertoire into their own musical make-up. Their pieces became like old friends. Participating in evaluative performances also afforded students an opportunity to share their music-making with other people. For all of the students who had positive evaluation experiences, sharing musical ideas with others was an important part of learning. Although the sharing that occurs during an exam is limited (as the audience generally consists only of one examiner), the students often performed their exam repertoire in festivals and recitals as part of their exam preparation. Most importantly, participating in evaluative performances afforded students an opportunity to experience success. The resultant feelings of pride and accomplishment propelled them toward future learning. I experienced many of these positive emotions as a result of my own participation in evaluative performances. I loved music and appreciated the new world that opened up to me each time I learned to play a new piece. I also took great satisfaction in developing a greater understanding of the theoretical aspects of music. Participating in evaluative performances provided a structure for learning the music that I loved and encouraged me to be dedicated in my 
practicing. When I experienced success, I also experienced a great deal of satisfaction and pride. I believe that these positive emotions played a large role in my continued involvement in evaluative performances over the course of many years.

The students who had positive emotional outcomes related to their music learning and participation in evaluative performances experienced deep levels of satisfaction that motivated them to continue pursuing their musical growth even when they encountered challenges. In his exploration of "flow," Cziksentmihalyi (1991) discusses the way in which "optimal experiences" encourage personal growth. Flow occurs when the student's level of skill and the difficulty of the task are well-matched (p.97). When students achieve success in a challenging task, they experience a deep satisfaction that motivates them to continue engaging in the activity. Student ownership over the learning process is also a crucial component of flow experiences (Custodero, 2002). As a result of these rewarding experiences, students' desire to continue engaging in music learning is reinforced.

The students who had positive experiences with festivals and exams described several experiences that could be characterized as "flow." For the sake of simplifying the concept for younger participants, I asked them to describe any times when they were practicing when they became so involved in the task at hand that they lost track of time. All of the students who had positive experiences with evaluative performances had experienced flow at some point during their preparations. One of the parents described how, in spite of her daughter's occasional reluctance to practice, "she gets in there and if she gets into it, she'll go for an hour and enjoy it" (P\#1). Beginning the practice session was challenging, but once this student was immersed in playing, she could easily continue for a long time without the work feeling onerous. 
For many students, these episodes of total immersion in their practicing occurred when they were working hard at mastering a particularly difficult section. They became so caught up in playing the same small section over and over that they were surprised to find out that they had been practicing for a long time. The student whose parent is quoted in the above paragraph described her experiences with flow in this way:

CS\#1: I'11 just be like working on something and I'll be practicing it for a while and realize that I've been practicing for over 45 minutes or an hour.

$N$ : And you didn't even sense the time passing.

CS\#1: No.

$N$ : So what do you think it is that makes that happen sometimes?

CS\#1: Well, if I'm like improving a lot or working on a section that's like a hard part that I'm overcoming.

Another student described similar experiences when she was engaged in very systematic practicing:

CS\#2: Yeah, sometimes, I just find myself just stopping and going, fixing all the mistakes, that I find myself going "whoa, how long was I on there? How long have I been practicing?" cause me and Jen don't usually record how long I am, it's just the fact that I get it done, so I'm not recording how long it is, but if I was, sometimes I might be on longer than other times. Sometimes I go practice a few pieces and then I'm done, but sometimes, if I do everything from start to finish like a little mini exam by myself, it's sort of like "whoa, that's a long time"

These experiences are consistent with Cziksentmihalyi's (1991) description of flow experiences that require a high level of focus (p. 31). The students who described this kind of systematic practicing felt highly satisfied when they were able to play fluently a passage that previously had caused them to stumble.

Other students described how they would become lost in the music as they played familiar pieces. One student described a specific incident when she lost track of time while she was practicing at her grandmother's house: 
CS\#3: Yeah, one time I practiced for a long time and my dad was taking me home cause my grandma had to sleep and he told me that I had five more minutes and then he - when he came back he said "it's been 10 minutes" and it was just like "that was only one" so it's kinda - get distracted sometimes, but not all the time.

N: So what do you think - when it is just so absorbing - what do you think it is that lets you get so into it that you kind of forget about everything else?

CS\#3: I think it's the fact that it's fun and even if I mess up it's not that big of a deal right now, cause I'm just practicing at my grandma's house and I'm just having fun and it's just me blowing off steam and calming myself down.

In this example, rather than focusing on a specific technical aspect of the performance, the student was immersed in the expressive qualities of the music. Manipulating elements such as tempo or dynamics provided enough challenge to maintain her interest, while her mastery of the technical demands of the piece provided her with a great deal of satisfaction.

According to Cziksentmihalyi (1997), flow experiences are not only enjoyable and satisfying at the time but also contribute to personal growth (p. 131). The students who experienced flow experiences while they were preparing for their evaluative performances were passionate about music learning and were motivated to continue pursuing musical development because they experienced flow experiences while engaged in music-making. These students also experienced personal growth in a more general way as they became more confident in their abilities to solve musical problems and to perform with accuracy and conviction.

Sadly, some students experienced very negative emotions related to their participation in evaluative performances. Several students described fear, disappointment, humiliation, isolation, and resentment (directed towards parents and teachers who had forced them to participate in evaluative performances against their wills). Other students experienced less intense responses, such as boredom, to music learning and evaluation practices that did not fit with their interests or personalities. 
All of the student participants in this research were interested in some form of musicmaking and music learning. However, for several students, the musical materials they were required to learn for festival and exam participation left them feeling cold.

FS\#1: Well, I like, since I was maybe 7 I didn't want to do piano anymore since I just kind of lost interest and I didn't really like it, but my mom wanted me to keep going until I got my Grade 8 exam done and then she finally let me quit. I just didn't like practicing and I wasn't interested in the music.

This student continued to pursue other musical interests after discontinuing her piano lessons. She also occasionally played some of her favourite popular music on the piano. However, the combination of repertoire and practice demands that were involved in formal piano lessons were uninspiring for her. This student's experience echoes Zenker's (2004) concern that students can achieve success in evaluative performances without developing skills that will enable them to integrate music into their daily lives.

Another former student, when asked if she continued to play the pieces she had studied on her own after she stopped taking lessons, also mentioned the importance of popular music.

FS\#4: Um, no, no, because when I was - for the ABRSM it was a lot of classical pieces, I think out of every 3 pieces, one would be something more contemporary ...But no, I would just find things that were maybe more popular music type things and off the internet

She further clarified her musical tastes by singling out the music of Bach as one particular aspect of the curriculum that she had not enjoyed as a student. However, because preparing for ABRSM exams had featured so prominently in this student's course of learning, she had not been given a choice in the music she learned. When she moved away from home for college and stopped taking piano lessons, she was able to focus her efforts entirely on the music that she found interesting and enjoyable. She expressed regret that her formal music education had not included 
a broader range of repertoire, as she felt that including popular music, as per Senyshyn's (2004)

recommendation, would have made her studies much more interesting.

While some students showed lack of interest in the musical materials that were part of their piano lessons, for other students, problems arose not with the curriculum but with the expectation of public performance that was integral to formal piano studies.

FS\#2: I LOATHED [emphasis in the participant's original email interview] playing in front of people. My parents used to complain that I didn't practice enough but in fact it was just because I waited until everyone was out of the house before I would practice. My father used to force me to play for family/guests when they came over. If my parents hosted dinner parties or during holidays like Christmas and thanksgiving when lots of family was around, my father would force me to sit at the piano and play all night. I can't even describe how angry I was at him for that. I hated it with a passion. The only reason I did it was because it was his money paying for my lessons.

In this case, the student's desire to learn music was used against her to force her into a public display that made her deeply uncomfortable. Although these events occurred many years before our interview took place, it was evident that the student still experienced strong negative emotions when thinking about how she had been manipulated. Her feelings stand in sharp contrast to some of the other students who enjoyed performing and basked in the positive attention they received from the audience.

For many students, evaluative performances were particularly stressful. One of the former students who completed the survey mentioned that he would be particularly nervous if he knew the adjudicator, or if he was aware that a particular adjudicator was known to have very high expectations.

While hearing other students play was cited as a positive aspect of festival participation by some students and parents, for others, being part of the audience could also be a source of stress. One former student described how "in the competitions, too, you'd see a lot of kids just crash and burn. That was always a bit scary" (FS\#3). In keeping with Bandura's (1977b) social 
learning theory, the vicarious experience of watching another student struggle emphasized the possibility of her own failure. She was likely also feeling some level of empathy for the student who was struggling, and these feelings of concern would have been a distraction from the focus she hoped to bring to her own performance.

Some of the students described earlier in this section had experienced a deep sense of pride and accomplishment as a result of their successes in festivals and examinations. For students who did not experience success, the shame and frustration could be overwhelming. The same former student who described her nervousness at hearing other students struggle during festival performances recounted dramatically the profound impact of failing a conservatory examination:

FS\#3: It was horrendous. And I walked out of there and said "I am never touching the piano again." This was going to be my career, I thought I was going to be a musician, and I'm never touching the piano again. I did not touch the piano for years... And I can't play in front of anybody now. I can barely play in front of my husband. It's really bad.... I wish I could play for a group of people. I still can't, because of that panic attack I had. I could never play for you, by the way. I can play for my kids. I could not play for somebody that I didn't know or that I thought was evaluating me in some way, couldn't do it at all. It's a very sad story.

Previously, this student had enjoyed great success in her festival performances and was a confident and ambitious musician; however, one devastating failure was enough to completely undermine her confidence in herself as a pianist. Although she occasionally plays now for her own enjoyment, the emotional trauma she experienced at this event resulted in an abandonment of the goals she had previously held.

For other students, negative emotions surrounding evaluative performances were less intense, but no less influential in the long-term. Repeated experiences with performance anxiety sometimes led to students dreading their participation in festivals and exams. 
FS\#2: My parents and piano teachers influenced (forced) me to play in festivals. I was more willing to do exams because I wanted to be a teacher one day....Festivals made me want to quit. ... I wanted to quit simply so that I wouldn't have to perform.

For this participant, any benefit that could have been derived from festival performance was overshadowed by her intense dislike of public performance. While this student had originally taken the initiative to ask her parents for piano lessons and had demonstrated high levels of dedication to her studies, her extreme dislike of performing in festivals even made her question whether she wanted to continue taking lessons.

Another former student also described how being forced to participate in festivals and exams cast a shadow over what was otherwise a very positive relationship with the piano.

FS\#4: There was nothing really that I didn't like about my lessons apart from the festivals and exams that I was told I had to do... I was a pretty reserved kid, so I didn't enjoy the stage whatsoever, not even at age 4. I'm sure that it had an effect on my performance - i.e. I'd go into it (a performance) with the sole end goal of getting it done, with total lack of regard of how I was going to do it. I resented having to do it, so I didn't care how I did it, rather that I just did it.

From a very early age, this student was able to see that performing in public ran against her more reserved personality and that it was unlikely that she would ever enjoy the process. However, her teacher and parents believed that she would be able to overcome her nervousness through repeated exposure to stressful situations. It is possible that some sort of Cognitive Behaviour Therapy or other program could have been helpful for this student in dealing with her anxiety (Sinden, 1999). However, this student did not receive any systematic help in overcoming her anxiety and continued to suffer through repeated attempts to make her more comfortable performing. The negative experience was not worth what she perceived to be minimal possible benefits from participating in evaluative performances. Eventually, as a teenager, she asserted herself by simply not attending a festival performance for which she had been registered against 
her will. After that incident, her parents and teacher agreed to stop forcing her to participate in evaluative performances.

The students who were required to engage in musical activities that were not in line with their own desires often expressed anger and resentment toward the adults whose influence was the source of these students' stressful musical experiences. Whether the activity that was forced on students was participation in evaluative performances or piano studies in general, students disliked having to engage in a pursuit that seemed like a waste of time or that was fraught with negative emotions. These students experienced a great sense of relief when they were finally allowed to stop formal piano studies and pursue their own musical interests.

Students' negative emotional experiences related to their participation with evaluative performances or other aspects of music learning often had long-term consequences for their future involvement in music-making. All of the students interviewed started their piano journeys with positive, or at least neutral, emotions. Their experiences confirmed Rife, Scnek, Lauby, and Lapidus' (2001) finding that most children are generally satisfied with their music lessons. Many were enthusiastic about the music they were learning and some loved the performance aspect of learning to play the piano. However, that enthusiasm could be easily snuffed out, either by one significant negative event, or by the wearing down of several lesser events. Students whose experiences with evaluative performances involved fear, disappointment, a sense of failure, humiliation, anger, or resentment were often extremely reluctant to participate in any further evaluations. For many of these students, evaluative performances were so entwined with music study in general, that the end of participation in evaluative performances also spelled the end of formal piano study. While nearly every student eventually stops taking lessons (Cooper, 2001), many former students look back on their piano studies as being positive experiences. In the cases 
of students whose years of piano study were coloured by negative emotional responses to evaluative performances, there were many expressions of regret or frustration that their time as piano students had had adverse effects on their emotional states.

\section{Composite narratives.}

The following narratives integrate ideas from various participants interviews to illustrate the importance of students' emotional responses to music learning and evaluation experiences.

I've always loved music, ever since I can remember. It just speaks to my soul. I had wanted to learn the piano for a long time and I was very excited when my parents told me they had found a teacher for me. Now I get to learn more and more about music every week. Each piece is a new experience - a new world opening up to me.

I love learning all kinds of music. It's such a great feeling when I've really mastered a new piece and I know it sounds the way it's supposed to sound. The process is fun, too. Sometimes I get so caught up in my practicing that I lose track of time.

I'm excited to be playing in the festival coming up because I enjoy performing. It's fun to hear the other students play and to hear the audience's applause. I always feel really proud of myself when I do well in a performance. Last year, I did an exam and got 90 percent. I still remember it, because it was a big accomplishment.

Put simply, playing the piano makes me happy.

I like a lot of music, but piano lessons are pretty boring. I have to spend months and months working on the same three pieces - pieces I didn't even like to begin with! Bach just doesn't speak to me; I'm more interested in popular music, or music from movies. My teacher wants me to focus on serious music, though - no fluff.

The worst part about learning the piano is the performing. I get so nervous whenever I have to perform in front of people. It's bad enough playing for my family or my classmates, but playing in situations where I know I'll be evaluated is terrifying. I often don't do very well, and then I feel embarrassed. I try not to care too much about the results, though, otherwise playing in festivals and exams would become really unbearable. I tell myself "You just have to get up and do it and then it will be over" and then I kind of go on automatic pilot to get through the performance.

Ifeel angry that my parents and teacher are still forcing me to play in festivals and exams. It seems more important to them that I follow their set ideas about what learning the piano should look like than that I be happy. It's really too bad, because I still think that learning music could be so wonderful, but so far that hasn't been my experience.

These composite narratives illustrate some of the emotional reactions students experience in relation to their involvement in music study and in evaluative performances. The following 
section explores one of the reasons for students' emotional responses: the degree to which their learning is personally relevant and meaningful.

\section{Meaningful Learning Experiences}

Many participants had strong emotional responses to their music learning, whether they experienced enjoyment and pride, or boredom and frustration. The root of many of these emotional reactions was the degree to which the learning and evaluation practices in which the student was involved were personally relevant and meaningful. Participants in this study described the importance of several aspects of music learning that contributed to the meaningfulness of their music learning, including personally relevant musical materials, nonevaluative performances (such as recitals), and social opportunities for music-making.

For students who participate regularly in evaluative performances, these kinds of events have a great influence on the content of musical learning and on the way in which the student's learning is structured over the course of a calendar year. Preparation for an evaluative performance is designed to lead to specific musical outcomes. Students become familiar with a range of repertoire and performance practices that are considered "essential" for the mastery of their particular instrument (Babin, 2005). Because festivals and examinations generally value replication over highly original interpretation (Davidson and Scutt, 1999; Tye, 2004), students develop an attitude of reverence for the score and for our best estimation of the composer's original intentions. If students are preparing for an examination, they also develop some measure of proficiency in technique, sight reading, and aural recognition, although the relevance of the examination exercises to performance in "real" musical contexts is perhaps not as great as the examining bodies would have students believe (Zenker, 2004). At higher levels, examination 
candidates also complement their practical studies with courses in theory and music history in an effort to develop a deeper level of understanding of the mechanics and the social and historical context of the repertoire they are performing.

Many of the participants in this research endorsed the examination curriculum, as they enjoyed the repertoire and valued the skills that they were developing. One former student described how, in her lessons, she learned "almost entirely music from the Western canon (my choice)" (FS\#4). In her case, the examination syllabus and her own tastes were very much in line, although she also pursued interests in composition and popular music independently.

Other students particularly enjoyed certain aspects of the curriculum, such as the more contemporary pieces or the optional popular selections, but were able to appreciate the other aspects of their examination programs enough to make the overall pursuit worthwhile. Not surprisingly, the least liked aspects of the exam curriculum were technique, sight reading, and ear training. Students often found these areas to be very challenging and the kind and amount of practicing necessary to master these skills to be tedious and uninspiring. However, the students who were highly engaged in music learning through participation in evaluative performances were able to see how their attention to these aspects of the curriculum would benefit them in the long run. One of the current students gave her views on the importance of technique, sight reading, and ear training:

CS\#4: Well, because I think it helps when you're on the piano to kind of know how to move your hands and the different scales and what you can like, what you can actually do on the piano and the different keys and notes and everything - it helps with that. And then the ear training, it probably helps a lot with listening in piano. I think something like that. And then sight reading, I think you need to be able to look at a page and kind of know how to play it, like you should be able to kind of almost play it, but not quite get it down perfectly, but you should be able to do that. 
For her, these aspects of the exam curriculum were relevant not only because she needed to be able to earn marks in certain categories for her exam, but because they were skills that would contribute to her future musicianship.

While enjoying the required repertoire was an important factor in whether a student had positive overall experiences with evaluative performances, equally important were opportunities to engage in musical activities outside of festivals and exams. Several students spoke of learning music with which they felt a strong personal connection. Popular music played an especially important role in many students' musical lives outside of their formal piano studies. One parent described how she and her daughters appreciated that their new teacher, in contrast to their first teacher, encouraged the study of popular music in addition to the examination repertoire.

P\#1: [N]ow they're really enjoying playing stuff that they really like to play. A friend of mine gave [my daughters] a Taylor Swift songbook and it was guitar, vocal, and piano, and you couldn't have given them a better gift. They absolutely love it. They just got it at Christmas and it's well-worn, because they've played the stuff over, and over, and over. [T] hey're drawn to that sort of genre of music and that's fun for them and that motivates them to go to the piano and play.... I see that change in them, where before when they were playing all the Classical stuff, I mean they liked it, but they used to complain, you know, they'd play it at school and nobody ever knew what they were playing....[T] here was no connection. No, now it's just the fun stuff. And ultimately, that's what I wanted for them, is to be able to sit there and play and play for yourself or play for your family, that kind of thing.

Although this parent encouraged her daughters to pursue exams and valued the certificates and formal recognition of achievement that went along with participation in the conservatory system, she was also starting to see broader applications for her daughters' piano studies. One of her daughters elected to stop taking lessons so that she could focus on other musical pursuits, but even the daughter who chose to continue found a new level of enthusiasm for her piano studies now that she was encouraged to embrace her interest in popular music. Being able to play songs 
that her peers recognized made her piano studies relevant to her life outside of the studio, as she received encouragement and validation from admiring friends and family (Regelski, 2006). The experiences of these students highlight the concerns raised by Temmerman (2005) regarding the lack of connection between the various cultural contexts in which music learning takes place. For the first daughter (FS\#1), piano lessons became irrelevant because she could not relate what she was learning to the community-based music learning that was more interesting for her. However, for the second sister (CS\#1), formal piano studies took on a new level of meaning when she could see how the skills she was developing would allow her access to other musicmaking opportunities at school and in informal contexts. The experiences of these two students are in accordance with Popovich's (2006) recommendation that arts curriculum content should reflect students' interests.

The students described above were teenagers at the time of data collection and placed a typically high value on their relationships with their friends. However, playing relevant and interesting music was important for students of all ages. One current student described her excitement when, as a young beginning student, she learned a song from "Winnie-the-Pooh."

CS\#2: I'm a big Pooh fan and whenever, when I started playing that's how I got really hooked on it, I played it over and over and over again. That was really why I liked piano when I was a little person, because I just kept playing that song.

She described this piece as being her first "not from the method book," indicating that, while the method book might not have been objectionable, it was not "real" music in the eyes of this particular student. Being encouraged to learn music that appealed to her as part of her lessons added legitimacy to her existing musical tastes. For this student, an early experience with a familiar and well-loved piece of music cemented a strong relationship with the piano. Later in her interview, she emphasized the importance of familiarity in learning new music: 
CS\#2: Well, my family and I are really Disney freaks, so whenever I see a Disney song I'd be like "I love that song!" and sort of like 'cause I know how it goes, I don't have to sort of listen to it beforehand because I already know how it sounds, like I know how it flows and stuff, sort of like for example, like Chim-Chimeree - that's one of the songs I'm playing for my exam. I know how it's like "da da-da-da" instead of, like, a different sound and stuff, so I'm usually comfortable with that, with those pieces, because I already know how they sound.

Learning a familiar piece of music provides students with a sense of security and confidence, as they already feel a degree of expertise even from the earliest stages of learning the piece.

Additionally, they are able to rely on multiple senses as they are learning the music in a way that might not be possible if their only exposure to a piece of music has been through the printed score. Like the popular musicians who participated in Green's (2002) study, this student was able to experience the value of employing aural skills to learn new music. In her case, because she also had strong music reading skills, she was able to make use of both senses as she mastered her new piece.

For another one of the current students, personal connections with her repertoire were also extremely important.

CS\#3: [M]y favourite songs out of this book would have to be this one "Gypsy Band" because I have family from Hungary and there's lots of gypsies there.... And then I'm playing "Sixteenth Century March" in here and I love this song cause I love history... And this, too - I'm playing "Leap Frog." I'm big about animals so I wrote, like, little things about each frog.

In contrast to some students whose musical tastes preceded learning specific music, this student seemed open to a wide variety of music and made a conscious effort to find ways to connect whatever she was learning to her own life, whether the music related to her interest in animals or to her cultural heritage. In fact, the only music she claimed to dislike was "songs that are sung about, like, really weird stuff, like alcohol and stuff. Unless it's by Ke\$ha. Then I love it, no matter what." Her widely varied tastes and general enthusiasm about music meant that she 
approached all her music learning with great gusto. In keeping with Regelski’s (2006)

encouragement to make music education relevant in students' lives, this student was able to connect her music learning to many areas of her life.

The student who described having learned a song from Winnie-the-Pooh also explained how having the freedom to explore music outside of the exam curriculum was important in providing a challenge and in pushing her skills to their limits.

CS\#2: It [performing in recitals] allows me to get another few songs in instead of just working on exam pieces. It allows me to do something maybe a little harder or different from what I would do for exams.

This student set very high expectations for herself regarding the results she hoped to achieve at her exam performances. If her learning had been solely focused on learning exam material, she might have chosen to learn only "safe" music that she was confident she could perform to her (and the examiner's) exacting standards. However, with multiple performance opportunities throughout the year, she was able to take risks and learn music that provided her with significant challenges without worrying about any impact on her examination results. Her approach is consistent with Atkinson's (1964) findings regarding the relationship between students' need for achievement and the kinds of tasks students choose. Because this particular student had a high need to achieve, she chose moderately challenging tasks when she was facing the prospect of evaluation. However, she appreciated having an opportunity to explore other music for the sake of enjoyment and variety (as well as additional skill development that would help her in future exam pursuits).

Not only do students need to have opportunities to practice relevant musical skills, they also need to develop metacognitive skills that will enable them to transfer what they are able to do in one piece of music to others. The second teacher described her main goal as "teaching 
[her]self out of a job" (T\#2). By this, she meant that by encouraging students to understand how and why they were able to play certain music, she was encouraging their development as autonomous musicians. She made a point of ensuring that her students were comfortable reading music and had a good technical foundation so that when they eventually stopped taking lessons, they would be able to teach themselves the music they wanted to learn.

Several of the current students described how they had come to value technique, sight reading, and ear training as means to become more independent learners. They described wanting to be able to use the piano as a leisure activity when they became adults and recognized that being adept at sight reading, having fluent technique, and having acute aural skills would ensure that a wide range of repertoire would be accessible to them. In particular, they recognized that, with adult responsibilities, the time they would be able to devote to their piano studies could be limited. As a result, they valued skills that they expected would help them learn new music quickly and efficiently.

One of the former students provided an illustration of how the skills acquired through her years of lessons found application when she turned to the piano as a form of stress relief when she moved to another country to attend university:

FS\#4: I have to say, though, after I left, stopped lessons altogether, and then when I was studying, was in the US and I was doing my bachelor's degree, there was a grand piano in the dorm and ... every now and then I would just go down, I would get some scores and just go down and play what I liked. And it was actually only after I stopped lessons that I really enjoyed playing, which - and it was pretty much a kind of stress relief for me, as well as - I was away from home for the first time and about 16,17 , so that was my - just for myself, I would just play. Um, and also it was also a good way to meet friends as well, cause it was in the living room of the dorm and there would be people who would come by and stop and chat or we would play together and stuff.

The development of relevant skills is integrally connected to students' learning of relevant music. This student's classical training had given her the reading skills to access music on her 
own. However, her musical preferences leaned more toward popular music. While she was able to learn some new songs through reading scores, in other cases she relied on a friend to transcribe songs from the radio. If her education had included a greater emphasis on aural development, she would have been able to learn whatever she wanted independently.

Another former student described how she now applies the skills she developed through her time as a piano student, when she participated in numerous exams and festivals.

FS\#7:I would often play just for fun. Now I can pick up most any music and learn them [sic] on my own (mastering them, however, is a whole other matter...). Sometimes I will play if a friend or family has an event they'd like me to play at, typically in church settings.

While this student was no longer taking lessons at the time of data collection, the skills she developed during her many years of study had equipped her to learn music independently. Because she was able to teach herself new repertoire, she was able to use her musical skills in her everyday life.

The discussion of the importance of relevant musical materials touched on the importance of situating music learning within the student's family and peer relationships. Not only is learning familiar music enjoyable for the individual student, it also reinforces the student's membership in family and social groups. The students who had positive experiences with evaluative performances had participated in festivals and exams as one part of a much broader musical education. For these students, the social aspects of music learning were also reinforced through non-evaluated performances and through involvement in group music-making (on the piano and on other instruments).

One of the current students described how she would engage in a variety of musical activities, in both formal and informal ways. 
CS\#4: Yeah, because a lot of the time I like to just learn pieces for the fun of it and other times, like, I think last year I did a competition and it was playing piano and I also sang, and then sometimes there's talent shows at school and sometimes it's just for the fun of it. So I like to play different pieces.

Participating in more serious musical pursuits, such as competitions, as well as other performance opportunities, such as school talent shows, that focused on sharing musical ideas in a fun environment helped this student achieve a balance between reaping the benefits of a more structured, formal music education and of finding her own unique ways of expressing herself musically. Her varied performance experience will likely help her to find ways to incorporate music into her life as she grows up.

All of the current students described performing in recitals as being enjoyable and as something that they anticipated eagerly. Performing in recitals was a way to share what they had been learning, to "show off' a little to a supportive audience of family and friends, and to hear other students perform in a non-competitive atmosphere. The requirements for recital performance were often more relaxed than for an evaluative performance. For example, the teacher of the current students said that she does not require her students to memorize their recital repertoire. This teacher structured her recitals as celebrations, often incorporating food and socializing into the event as a way to reinforce the enjoyable and communal aspects of music learning.

Although one of the former students described very negative experiences performing in even informal settings (such as for family or at school), for many students playing for friends and family was a positive and rewarding aspect of learning to play the piano. One of the parents saw this kind of sharing as one of the main reasons for her daughter's involvement in music:

P\#5: Because you know, art is all about showing, isn't it? You know, soothing our soul, too, but at some point when we are together with our friends and family, if someone is capable of playing, we want her to be comfortable to play for us. 
For this parent, the development of comfort in performance was the main benefit she saw in her daughter's participation in festivals. Becoming a more confident performer enabled her daughter to share her musical gifts with her community.

While I enjoyed my formal music studies, my piano skills became most relevant to my life when I applied them in other settings, for example, in playing for my family or in church. I enjoyed learning the repertoire that was part of the exam system, but never harboured any illusions that I might be able to earn a living as a classical pianist. My music learning was relevant in allowing me to play a particular role in my community and in opening up the possibility of teaching, which has been an interest since I was a young child.

This study has focused mainly on the development of piano students, who have the misfortune of spending much of their training in solitude. While other musicians regularly participate in a variety of ensembles, young pianists are almost always soloists. Austin, Renwick, and McPherson (2006) point out that young musicians who are engaged in solitary practice are less likely to enjoy the social rewards that go along with playing music in a group. Thus, it is important for piano students to find other sources of motivation to sustain the kind of prolonged effort that is necessary for success.

Some of the students who participated in this research began their music studies in group classes, which allow beginning students to develop foundational musical skills in a fun, social environment. All of the former group participants had very positive experiences in their group classes, citing enjoyable musical material, fun instructional strategies, and social interaction as aspects they particularly appreciated. However, as soon as these students reached a certain age or level of playing, they progressed to private lessons and left the group context behind. In some 
cases, students found learning the piano to be much less interesting and enjoyable after that transition.

Participating in evaluative performances tends to reinforce a solitary pursuit of music. While some festivals have chamber music categories, all of the students who participated in this study competed as soloists. Examinations are nearly always solo performances. Social interaction through music-making is an important part of making music learning meaningful for students (Campbell, Connell, and Beegle, 2007). Some of the piano students who participated in this study played with duet partners. Others participated in musical activities outside of piano lessons, such as musical theatre classes, band classes at school, or rock band camps that allowed them to make music in a social setting and to connect with other people (particularly peers) through music. Students appreciated these other venues for music-making and enjoyed their overall musical educations more as a result of this interaction with fellow musicians.

The pursuit of meaningful experiences affects every aspect of the music learning process, including repertoire selection, performance opportunities, and the development of skills, such as reading, improvising, composing, and playing by ear. Students are generally eager to invest their time, energy, and effort in developing skills they see as worthwhile. Unfortunately, for some students, participating in evaluative performances was perceived to be a huge waste of time. These students could not relate to the repertoire they were expected to learn and resented the fact that they were forced to devote their lessons and practice time to music that they did not enjoy. For example, one of the former students (FS\#1) described how exam preparations became progressively more onerous as she advanced through the levels. Eventually, she stopped taking lessons because she was not willing to expend so much time and energy on music that was "not 
[her] thing” (FS\#1). Because music-making is profoundly personal, students need to feel that they are being equipped with the tools they need to express their own musical ideas.

The students who had positive experiences with evaluative performances were engaged in widely varied music-making in a social context. Not only did they experience enjoyment from their broader musical educations, but they were able to derive more meaning from their participation in evaluative performances because they could connect the material upon which they would be evaluated to the knowledge and skills necessary to play the music they found most enjoyable. In contrast, the students whose music learning revolved completely around evaluative performances sometimes had difficulty seeing any purpose for the effort they were expending, as there was no connection between their formal piano studies and their musical interests outside of piano lessons. Not only do students need to experience music learning that they find enjoyable or interesting, they also need to experience the richer meaning that comes from engaging in musicmaking in a social context. For piano students, special effort needs to be taken to ensure that students are given opportunities to collaborate with other musicians.

While the students who had positive experiences with evaluative performances enjoyed much of the required repertoire and performances, it was clear from all of the participants that the presence or absence of musical experiences outside of preparation for evaluation were crucial to students' overall impressions of music study. Students who have had the opportunity to learn music that resonates with them, who have developed the skills to learn new music easily, and who have had opportunities to experience music-making in a social context experience the greatest possible joy from their interactions with music (Davidson, 1999). They will be more likely to want to continue their formal music educations and will also want to continue engaging in music learning and music-making in informal contexts after their formal education comes to 
an end (Campbell, Connell, and Beegle, 2007). The positive emotions that these students

experience as a result of the connections between their music learning and the rest of their lives

help to reinforce the importance of music. When music-making has an important place in

students' lives, they will likely choose to continue engaging in musical practices that strengthen

their sense of the self as musician.

\section{Composite narratives.}

The following composite narratives explore some of the factors that contribute to

students' perceptions of the relevance of their music learning.

I think the main reason that I enjoy learning the piano so much is that I get to play music that connects with the rest of my life. I've played pieces from my favourite movies, Christmas carols, and pop songs. I find it easier to learn this music because I already know how it's supposed to sound. That makes the learning process go more quickly, so it doesn't take very long before I can play the pieces well and really enjoy them. Another reason it's great learning this music is that my family and friends all recognize it. When I play my exam pieces, the reaction is usually "That's nice," but they don't really appreciate the classical pieces as much. When I can play something they know, they get really excited and they think what I do is really cool.

Even if I don't already know a piece when I first learn it, I still try to find a way to connect it to my own life. Sometimes I recognize something I can do really well, like staccato, and that makes the piece fun. Or it just creates a really interesting mood. I also like music that relates to my culture and family because it helps me understand myself better.

Even though I probably prefer my "fun" music, I'm still glad I do the exam program, because it helps me learn a lot of important skills. I probably wouldn't be as disciplined with practicing technique or sight reading or ear training if I weren't going to be evaluated on those things. I know those skills will help me learn new music on my own later, though, so I think they're important to have even if practicing scales isn't my favourite thing to do.

Learning the piano wouldn't be as much fun as it is if I only ever did festival and exam music. For one thing, the performances can be pretty stressful. I'm really glad I get to play in recitals because there is a lot less pressure. I don't have to memorize, and I get to play for my family and friends. I feel proud when I can show them what I've been learning, and they're proud of me as well!

Sometimes I get a bit lonely practicing my exam pieces by myself day after day, so I really enjoy being able to make music in a group as well. I play the clarinet in the school band and I also take musical theatre classes. I find my music classes at school really easy because of the training I've had in my piano lessons. It's nice to have activities that allow me to have fun with other people who also like music. We have a strong bond because of our shared interests. 
I really didn't enjoy my piano lessons because, at the end of the day, they weren't really about me. My parents signed me up for lessons because that's what all the parents in our neighbourhood did. I found the music boring because it had nothing to do with the music that my friends and I listened to for fun. When I would play for my friends, their eyes would glaze over because they found the music so boring.

The worst part was the festivals and exams that I had to do every year. No one seemed to care that I hated these evaluations; it was just a required part of learning the piano that every year I had to perform. I think my parents liked them because they wanted to see some sort of concrete return on all the time and money they put into my lessons. They thought that if I earned enough certificates, I'd be able to mention my piano studies on my resume. My teacher wanted me to do well so that she could brag about her students' high marks when other parents called to inquire about lessons. I didn't care about any of that, though. I just wanted to learn how to play the music that I liked.

I used to get lonely practicing by myself hour after hour. Some of my friends used to play in garage bands and it sounded like so much fun, hanging out with friends and making music at the same time. Exam preparation is a lot more "serious" and it was pretty isolating.

When I got older and I was finally allowed to stop taking lessons, I started playing more of the music that I wish I could have played when I was younger. I did appreciate some of the skills that I had developed during my time taking lessons, such as reading music, but I wish I could do other things more easily. For instance, I wish I could listen to a song on the radio and just play it, but I can't - I have to track down a score before I can learn it.

When students had the opportunity to engage in meaningful music learning, they

developed a strong musical identity. The following section outlines contributors to musical identity and why having a sense of the self as a musician is important for students' current and future musical pursuits.

\section{Musical Identity Development}

Evidence from research with infants suggests that humans are born with the innate capacity to engage in music-making and to develop a musical identity (Trevarthen, 2002). Unfortunately, for some students, formal music education has a hindering effect on the development of a strong musical identity. When music learning is enjoyable and provides a means for students to develop personally meaningful skills and understandings, being a musician becomes an important part of students' sense of self (Hargreaves, Miell, and MacDonald, 2002). 
A student who has positive experiences participating in evaluative performances and who is highly engaged in his or her music studies is more likely to have a strong musical identity. Musical identity has two facets: the individual's identity as a musician, and the shaping of the identity through music (Hargreaves, Miell, and MacDonald, 2002, p. 12). For the purposes of this chapter, I will focus mainly on the first aspect by exploring how participation in various aspects of music learning affected the participants' musical identities. In particular, I will examine the role of evaluative performances in determining how students identify themselves as musicians.

Many of the students who participated in this research described how music was an important part of their lives. Their sense of self had developed so that music was an integral part of their personal identities (Davidson, 1999). Regardless of their experiences with evaluative performances, all of the students had something positive to say about some type of musical pursuit. This finding is consistent with DeNora (2000), who describe the pervasiveness of music in all facets of life. However, not all of the participating students felt that they were good at music, or specifically, at playing the piano. The ones who were confident in their abilities were the ones who had had positive experiences with evaluative performances. The following exchange with one of the current students demonstrates her self-assurance as she describes an upcoming audition for a school talent show and its potential impact on her musical self-concept:

$N$ : Do you think it's going to be really competitive to get into the coffee house at your school?

CS\#3: Um, I don't know. I'm playing the piano and I feel confident that I'll be able to cause I've done really good so far in music at my school, so I think I'll get in, but if I don't I'll just go hang out with my friends and forget that I tried out and stuff, be like "oh whatever."

N: So it wouldn't be a huge disappointment.

CS\#3: No, cause there's a lot of great piano players at my school. I'm just one of them. 
This student felt confident in her abilities to do well in the audition. However, she also recognized that the very nature of an audition process would mean that some people would not have the opportunity to perform. Her confidence in her own abilities was not based solely on comparisons with other students, but she placed herself firmly in the group of "great piano players at my school." I did not have an opportunity to find out if this student made it into her school coffeehouse, but based on this conversation, it would not appear that her confidence in herself as a musician would be adversely affected if she didn't. Being a musician (and a confident one, at that) was so much a part of her self-perception that her confidence could withstand a possible rejection.

The conversation in the preceding paragraph did not investigate the source of this particular student's self-confidence. However, another of the current students was more direct in attributing her confidence in her musical abilities to previous successful experiences in evaluative performances.

CS\#2: I just started doing festivals last year and same with exams, because I'm not really a competitive person, but Jen has always encouraged me to try, just to get some good feedback and stuff, so she got me into my first festival and my first exam, and we did really well, so I did 2 exams in one year last year. So I got really good marks on those ones. I sort of felt confident and proud that I'm such a good piano player and stuff.

For this student, festivals and exams provided some concrete evidence of her level of competence that other musical pursuits, such as playing in recitals, had not done for her (Davidson and Scutt, 1999). Because of the authority she invested in the feedback from the adjudicators and examiners, the high marks were an important confidence booster.

As described in Chapter 1, my musical self-concept was almost entirely based on my examination marks. I did not give any particular consideration to the potential pitfalls of this perspective until I experienced a disappointing result and had to consider other sources of 
musical identity. While I was able to regain some of my musical self-concept as a result of simply continuing to pursue my interest in music, I still regarded my formal achievement as a significant indicator that I was a musician.

While students' achievement and performance experience play an important role in establishing their sense of musical identity, other factors are also important if a student is to feel confident in his or her musical self. In particular, student ownership over the learning process plays an important role in the shaping of musical identity (Pitts, 2004). The previous chapter explored the varied impetuses for students' first forays into learning the piano. Some students were highly motivated to begin and had a long-standing desire to learn to play the piano. These students were very excited when they were provided with the support they needed to pursue their musical interests. Their passion for music was already an important part of their sense of self and taking lessons was a way to become part of the world of competent musicians. For some of these students, choosing to participate in festivals and examinations was another way to increase their learning and to confirm and strengthen their musical identities.

A student taking initiative in his or her own musical learning is an indication of a strong musical identity. One of the current students described how she enjoyed being able to take ownership over some of the material that she learned.

CS\#4: I normally choose my own music because I like to go to [the music store] sometimes and just look at music and just try and do it. Sometimes I just really like music so I just try and learn it myself.

This student had an insatiable appetite for learning music and showed a great deal of confidence in her own abilities to access and learn new music. The more she learned through her formal music studies, the better able she was to apply her skills to learning the music that she wanted to learn. Her experience stands in contrast to the experiences of some of the former students, who 
had to wait until they had stopped taking lessons before they were able to experience the kind of autonomy she describes in choosing and learning her own music.

One of the parents was the mother of a current student and a former student who both participated in this study. While our conversation focused mainly on her views of participation in festivals and exams related to the current student, she also discussed some of her other daughter's musical pursuits.

P\#1: Yeah, so what I mean like [former student] is saying, you know she's asking me now all of a sudden about this going to [local arts high school] for music. She's now seriously thinking maybe music is the way I should go, where she's the one I thought, well this is now really just a hobby for her.

Initially, this parent thought that her daughter was abandoning her musical pursuits because she had stopped taking piano lessons. However, in reality she had simply replaced a musical activity that she found boring and stressful with one that gave her a great deal of joy. Because she had found a music-making context that was meaningful to her and that built up her musical identity, this student was now seeking out opportunities to further her skills and to become part of a social setting in which music was valued (Cameron and Carlisle, 2004). Her sister, in contrast, while still pursuing a more "serious" musical education, was less enthusiastic about music learning and was focused more on the extraneous benefits of participation in evaluative performances, such as the accumulation of certificates.

In contrast, the students who were forced to participate in festivals and exams against their wills had weaker musical identities or musical identities that were in conflict with the concept of musician that is perpetuated through evaluative performances. While performing in festivals and exams was a required part of their formal musical educations, their musical selfconcepts were based on other aspects of music-making, such as playing with a rock band (FS\#1) or mastering classical pieces for their own enjoyment (FS\#5). 
In my own experiences as a student and teacher, I have seen how important student ownership over the learning process can be in motivating students to pursue particular goals. I was very self-directed as a student and took pride in the fact that I did not have to be reminded to practice. While I have never taught a student who was required to be as self-directed as I was when preparing for my Grade 2 exam, I have had several who were actively involved in choosing their own musical goals. These students displayed a level of enthusiasm and confidence that stands in stark contrast to the apathy and reluctance of some students who have been forced to pursue goals that did not have meaning for them. The students who were pursuing their own musical goals developed a strong sense of their own musical identities and had strong convictions regarding the role of music in their lives.

The teacher of the current students encouraged a balanced musical education by incorporating musical materials that were not part of the exam curriculum into each student's lessons. One of the parents (P\#5) described how, when her daughter was showing signs of boredom after working at perfecting her exam pieces for several months, the teacher suggested learning "Let It Be" for fun. The student had been getting "bored of [her] songs" (CS\#5) and was relieved to be given the opportunity for a change of pace. She enjoyed learning the new music and was also inspired to buy a few other pieces that she hoped to learn after finishing the selection recommended by her teacher. Incorporating the study of popular music into lessons legitimizes students' musical interests and encourages students and parents to view a wide variety of musical pursuits as being worthwhile. Students are more likely to have a positive musical identity if their own musical preferences are validated and if the music program in which they are involved in inclusive rather than exclusive (Lamont, 2002, p.55). 
However, it is important that teachers are careful in the way they approach "fun" music so that students can benefit from the greater freedom they can experience when working on music from outside of the examination requirements. For instance, the teacher of the current students does not require her students to memorize their recital pieces, which are usually chosen from outside the exam curriculum. In this way, the students avoid experiencing the stress and anxiety that come from having to perform from memory and are also able to learn a greater quantity of music, as they do not need to invest the time required for memorization for all of their pieces. When students learn popular music, they also have flexibility in adapting arrangements by ear; they are not bound to the printed score in the way that they are when learning music from the Western classical tradition.

While my own training focused almost entirely on music from the Western classical tradition, I have developed a strong conviction that I need to be able to offer other options to my students. One of my favourite parts of teaching is developing a personalized program of study in collaboration with the student. For some students, an individualized approach includes participation in evaluative performances; however, I have grown to appreciate the value of including many diverse styles and genres of music along with the importance of encouraging students' personal expression through music.

Because festivals and exams provide concrete evidence of achievement, students who participate in these evaluations are often easily recognized as musicians in their social circles. Even people who are not musicians and who would not necessarily be able to assess a student's actual musical skill can relate to the grade levels, marks, and certificates that are part of the exam curriculum. When others view them as musicians, students' identity as musician (and specifically as "pianist") is reinforced (Borthwick and McPherson, 2002, p. 76). Importantly, when students 
can demonstrate their musical achievements concretely, their music learning is also legitimized in other educational contexts, for example, by schools that grant high school credit for achievement in advanced piano examinations.

The learning that results from students' participation in evaluative performances can also contribute to success in other musical pursuits. In particular, the music reading and theory skills that are necessary for success in evaluative performances also contribute to success in meeting many school music curriculum requirements. One parent (P\#1) described how her daughters (both of whom participated in this research, one as current student and one as a former student) had experienced positive outcomes in their school music courses that they attributed to their piano studies: “[B]oth girls excelled in music in school, like they’ve been rewarded for their musical knowledge. Um, they feel good - they reap the benefits of that" (P\#1). Other students and parents also described how they have seen a transferring of skill from piano lessons to school music courses resulting in students' being able to earn high marks at school with relative ease. When students are successful in a variety of musical contexts, their overall musical identities are reinforced.

The school environment could also be an important venue for social recognition of musical ability and identity. One of the current students described how she appreciated having her musical abilities reinforced by her teacher and classmates:

CS\#5: Yeah, at school, sometimes our teacher, she gives us a play day, we can bring musical stuff in. And every time I bring in a piece that I've learned last year or this year and I always play and then a few times I've played they asked me to play again since it was really good.

Not only did this student enjoy the initial offer to perform, she especially appreciated being invited for an "encore" performance, as it was a special privilege not afforded to all her classmates. She had been singled out as having musical talent. 
Gagné (2003, cited in McPherson and Williamson, 2006) differentiates between "giftedness" and "talent." According to her definitions, giftedness refers to an individual who has a distinctly above average potential for achievement in a particular area. A talented individual, on the other hand, is someone who demonstrates superior performance (p. 241). Talent only emerges "when a child's natural abilities are mediated, not only through the support of intrapersonal and environmental catalysts, but also through systematic learning and extensive practice" (McPherson and Williamson, 2006, p. 241). The current students in this study were likely musically gifted, although I made no attempt to assess that particular characteristic. However, their success in festivals and examinations would point to significant musical talent that has been developed through formal and informal musical practices, including making music with family members, attending weekly lessons with a qualified teacher, and practicing consistently and systematically between lessons.

The connection between the sense of self as a musician and results from evaluative performances can become a dangerous one (MacArthur, 2008). Students who have been successful in their performances can easily see themselves as competent and skilled musicians. Their overall musical self-concept and their self-efficacy related to performance in festivals and exams are high as a result of the success they have had in previous evaluative performances. As I learned from my own experiences after a disappointing exam, it can be very difficult for students who are accustomed to success to negotiate failure without profound changes to their selfconcept and even self-worth. The age at which many students participate in evaluative performances also affects their perceptions of the relationship between marks and ability. Prior to grade 4, most students see ability as being susceptible to improvement through effort (FreedmanDoan, Wigfield, Eccles, Blumenfeld, Arbreton, and Harold, 2000). However, students tend to 
develop more fixed concepts of ability as they get older. If an older student sees a low result as representative of his or her musical ability, he or she could give up hope of being able to improve. In Chapter Six, we will examine in more detail some theories of motivation that help to explain how students' goals and values affect their self-concepts and engagement in learning.

One of the current students (CS\#2), who had previously been very successful in all of her solo festival and exam performances, had to deal with a disappointing experience when she and her duet partner came second in a local festival during the data collection period. Although the stakes attached to the performance were low, and the responsibility for the disappointing result did not rest entirely on her shoulders, she experienced difficulty accepting the result and its possible ramifications for her musical self-concept. At her next lesson (which was captured on video), she and her teacher spent a considerable amount of time debriefing this experience. By the end of their discussion, the teacher had been able to encourage the student to get back on her feet and continue working toward her upcoming exam. One can only wonder, though, if an event like this (which would be relatively minor in importance, compared to an examination) could result in such an emotional struggle, how devastating a more significant disappointment could be.

One of the former students provided a vivid example of how a single negative experience with evaluative performances can result in a profound rearranging of an individual's musical self-concept. As described earlier, the former student who experienced a panic attack during her first exam performance abandoned her ambitions to pursue a career in music and even avoided playing the piano in non-evaluative contexts after that negative experience. She described the impact of her negative exam experience thus: 
FS\#3: [I]t was always a reference point, it was always that monumental failure, and yeah, my career had changed. My career plans, and hopes and dreams, everything changed after that day.

It was obvious from her tone when she was recounting this part of her experience that, even years later, she felt a great deal of regret and disappointment that her piano studies had ended the way they did. There was a sense of longing in her voice when she described how she wished she could play the piano in public. Her experience was so traumatic that she went through a grieving process as she tried to make sense of life without the piano and to ascertain how she should view herself and her relationship with music. Eventually, she found other means, such as musical theatre, to reconnect with the musician and performer aspects of herself, but her self-concept as a pianist was obliterated.

When students experience disappointing results, it can challenge their self-perceptions of their musical ability. In particular, if a student has an entity or fixed concept of musical ability (in which ability is viewed as an innate quality, not subject to change), he or she can be devastated if the feedback received from an adjudicator or examiner does not support a strong self-perception of ability. In these cases, a failure could be particularly dangerous, as a student with an entity view of ability could take the adjudicator's low rating as the final word on his or her musical talent. Austin, Renwick, and McPherson (2006) point out that the maladaptive responses to failure that result from an entity view of ability end up resulting in lower student achievement (p.219). In contrast, students who have a malleable, or incremental, concept of ability see ability as something that can change over time as the result of effort. If a student with an incremental view of ability encounters failure, he or she is likely to seek help, continue expending effort, and ultimately reach higher levels of achievement and learning than a student with an entity view (Austin, Renwick, and McPherson, 2006). 
The development of musical identity is deeply intertwined with the two topics discussed earlier in this chapter: students' emotional experiences and the meaningfulness of music learning. The development of musical identity is related to students' emotions, as students experience positive emotions when their experiences as performers align with the expectations they hold for themselves based on their musical self-concepts. Playing the piano had become an important part of their personal make-up because it brought joy to their lives.

Students' musical identities are also influenced by the relevance of the music learning in which they are involved. The students who described positive experiences with evaluative performances enjoyed and related to the music they were required to learn. They were also engaged in a wide range of musical activities that included non-evaluated performances and repertoire that was not part of the festival and exam syllabi. As a result, they were able to see themselves as musicians in a much broader sense than if they had been focused solely on their preparations for evaluative performances. In this way, meaningful music learning contributes to the development of a strong musical identity.

\section{Composite narratives.}

Music is such an important part of my life; I really can't imagine myself without some kind of involvement in music. Learning the piano has given me an opportunity to develop a lot of skills so that I can learn all kinds of music that appeal to me. While I don't always enjoy all the aspects of the exam curriculum, I appreciate the skills that I've developed.

When I do well in a festival or exam, it makes me feel confident that I'm good at music. My family and the people at my school recognize that I'm a good piano player, so they often ask me to play for different events. I'm happy to play for my relatives or in class because it gives me a chance to show what I can do and to share the music I love with other people. I'm known as one of the more musical students at my school, because I always do really well in my music classes. I'm also involved in all the concerts.

I can't imagine music ever not being part of my life. I might not always have time to take lessons and do exams, because I know adults have a lot of other responsibilities, but I definitely want to have a piano so that I can play for fun after I get home from work. I think I'll play all kinds of music. Probably some of the pieces I learned for my exams, and some pop songs, and 
who knows what else. We don't know what the music of the future will be, but I'm excited to find out. I want to get as good at the piano as I possibly can before my life gets too crowded with other things so that I can play any kind of music I want when I get older.

There were aspects of learning the piano that I liked, and I still play sometimes for fun, but the approach that I had to follow when I was younger didn't speak to me at all. My parents wanted me to take lessons and my teacher insisted that I play in festivals and exams, but none of that was really important to me or to how I see myself. Now that I can play music on my own terms, I just choose the pieces I like and I avoid performing.

I don't really consider myself a musician, because real musicians like to play classical music and they are able to perform without completely panicking. I wish I were more confident in my musical abilities, but my past experiences have shown me that I'm just not cut out to be a classical pianist. I usually didn't do very well in my festival and exam performances - whatever musicality I might have had wasn't what the adjudicators were looking for. Mostly I'm just glad that that part of my life is over and I can focus on doing things that make me happy rather than trying to please my parents and teachers.

\section{Success and Failure}

The above conditions (positive emotional outcomes, meaningful music learning, and the development of a strong musical identity) are most likely to be met if the student encounters success in his or her endeavours. Success brings with it immediate positive emotions. If the curriculum aligns with the student's interests, the learning that brought about a high result in the evaluation will also have resulted in the development of meaningful skills and understandings. When students associate their participation in evaluative performances with positive emotions and with meaningful learning, their experiences performing in festivals and exams will contribute to their valuing of music learning and their sense of self as a musician.

Research into education in general has demonstrated how important it is for students to experience success (Bandura, 1977a). Academic self-concept and achievement exist in a reciprocal relationship (Snowman, McCown, and Biehler, 2009). That is, students who have high self-concepts are more likely to achieve high results. In turn, achieving high results increases 
students' self-concepts. Best practices in assessment recommend ensuring that students receive a variety of formative feedback in addition to summative evaluations (William, 2011). Formative feedback provides students with the information they need to improve their performance on subsequent tasks. Students should also be offered many different opportunities to demonstrate their learning. In this way, the greatest possible number of students achieve success.

In contrast to the assessment practices that are described above, evaluative performances function in much the same way as standardized academic tests, i.e., they measure students' achievement in a narrow series of set curriculum expectations. Students must demonstrate their achievement in one way, on one occasion. Their exam or festival results are not necessarily representative of the learning that took place during the preparation period. In Chapter 2, I discussed some of the concerns regarding standardized academic testing and the similarities and differences between evaluative performances in music and standardized tests that are administered in schools. The widespread use of evaluative performances is problematic, because these types of evaluations are designed to rank students and to highlight those who have particularly strong talents. For students who will go on to have careers as professional musicians, having the opportunity to learn the standard repertoire for their instrument and to perform regularly under pressure is good preparation for the kinds of performances they will be expected to put on in the future (Kogan, 1987). However, the majority of beginning and intermediate piano students will not become professional musicians. For these students, the primary benefit of music lessons is to prepare students to engage in music-making as a leisure activity later in life (Cooper, 2001). In order to develop a desire to continue their active participation in musicmaking, students need to have a strong musical identity (Davidson, 1999). While participation in evaluative performances can contribute to students' musical identities, students who struggle to 
achieve success in festivals and exams are likely to become discouraged and to doubt their potential as musicians. Because of the relatively narrow scope of the curriculum used for festivals and examinations, it is very possible for students to see themselves as "unmusical" when in fact they have high levels of musical skill that are simply not part of the material covered in evaluative performances. Rather than contributing to wider engagement in music learning, evaluative performances can instead serve to weed out students who do not measure up. While teachers and students hope for and work towards success in evaluative performances, most students experience a disappointing result at some point in their musical careers. Whether the student did not meet a minimum passing mark established by the examining body or simply fell short of achieving his or her personal standard, a student's experiences with failure can inspire serious doubts regarding the personal value of music study in general and evaluative performances in particular. The immediate aftermath of a disappointing performance can be a difficult area to navigate. Students are likely to be dealing with intense negative emotions, such as shame (if they feel responsible for the failure themselves), anger (if they feel that the result was unfair), or confusion (if they do not understand what they could have done differently) (Weiner, 1986). If the failure was due to a lack of preparation, the student likely did not derive the full benefit of mastering the new skills and concepts that were part of the curriculum for that grade; therefore, he or she might not be ready to move on to the next grade level (Davidson and Scutt, 1999). Having to spend more time than originally planned on a particular level can be extremely disappointing for an ambitious student who had a strict timeline for his or her studies. It is also likely that the student will struggle to apply the learning in a personally relevant way if he or she has not achieved a high degree of mastery. 
In spite of all the difficulties that occur when students experience failure, a disappointing performance can provide an opportunity for learning, reflection, and ultimately a greater degree of clarity and focus in the student's musical pursuits. Teachers and parents have an important role to play in minimizing the potentially damaging effects of failure and in helping students derive the most benefit from a potentially difficult experience.

One of the ways in which adults can support student learning even in the face of disappointing results is through encouraging breadth in music learning. When students see their participation in evaluative performances as one aspect of music learning rather than as the only important indication of their ability, each individual result becomes less important (Davidson and Scutt, 1999). Students who have developed a variety of knowledge and skills outside of the examination curriculum can also maintain their identities as church musicians, members of a rock band, etc. even if their confidence as classical pianists is temporarily shaken. Fostering students' enjoyment of music learning also minimizes the likelihood of future performance difficulties as the result of a failure, as students who have positive affective states while learning experience fewer declines in performance following a low result (O’Neill and Sloboda, 1997).

With the right support from parents and teachers, students can bounce back from a disappointing performance and can become more determined and resilient as a result of their challenging experiences. This support includes acknowledging and validating the student's feelings, reflecting on the reasons for the failure, and creating a plan that encourages the student's self-efficacy and creates optimism around future music engagement in music learning, whether that means continuing formal piano lessons or focusing more on some other aspect of music-making. Above all, a student who has experienced a disappointing performance needs to be reassured that he or she is valued unconditionally by the important adults in his or her life. 
The diagram below shows the interaction between the three main factors that influence student engagement, within the context of students' experiences with success. When students are successful in their evaluative performances, they experience positive emotional outcomes, meaningful learning, and the development of musical identity. Each of these three factors influences and is influenced by the other two to produce high levels of engagement. In the final part of this chapter, we will examine why student engagement is so important by looking at students' experiences through the lenses of two important theoretical perspectives: self-efficacy and self-determination.

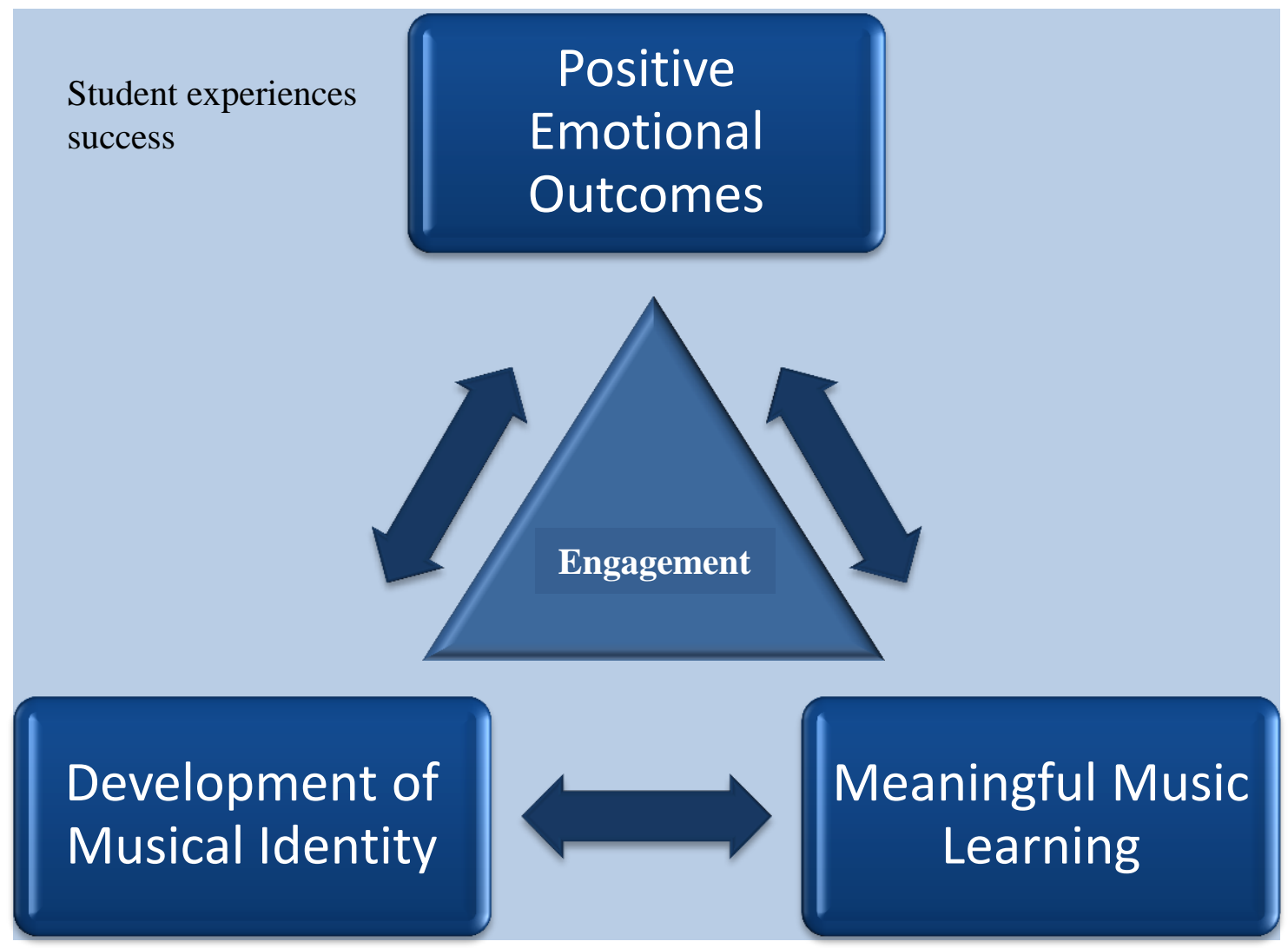

Figure 7 Facets of Student Engagement in Music Learning Through Participation in Evaluative Performances 


\section{The Importance of Positive Experiences: Self-Efficacy and Self-Determination}

So far in this chapter, we have explored three important facets of engagement in music study through participation in evaluative performances. Students who have positive views of evaluative performances experience positive emotional outcomes related to their involvement in festivals and exams, find their involvement in evaluative performances to be supportive of personally meaningful musical goals, and develop a strong musical identity through their participation in evaluative performances. Experiencing success is crucial to all three of these aspects, as failure tends to be connected to negative emotions, lack of depth in learning, and a weak musical identity. This definition of engagement is consistent with Austin, Renwick, and McPherson's (2006) view of motivation as "a dynamic process involving the self-system (perceptions, thoughts, beliefs, emotions), the social system (e.g., teachers, peers, parents and siblings), actions (motivated behaviours including learning investment and regulation), and outcomes (learning, achievement)" (p.213). In this view of motivation, or engagement, it is impossible to separate the various factors which influence students' pursuit of their musical goals.

Student engagement in music learning through evaluative performances is an important topic for consideration, as students who are highly engaged through the process of participating in one evaluative performance are more likely to want to continue their studies and their engagement in evaluative performances. All of the current students stated definitively that they planned to participate in future evaluative performances. I reconnected with their teacher at a workshop approximately a year-and-a-half after the original data collection period, and she was happy to report that all of the students who had participated in this research were still taking lessons and were still involved in festivals and examinations. 
Two important theoretical perspectives illuminate why students' high levels of engagement in music learning through participation in evaluative performances result in future engagement. The first is Bandura's (1977) concept of self-efficacy and the second is Ryan and Deci's (2000) self-determination theory.

Self-efficacy is an individual's confidence that he or she can succeed in a particular task. It plays a crucial role in learning of all kinds, as students who have high levels of self-efficacy are more likely to embrace challenges and to continue pursuing deep levels of learning (Pierson, 2005, p. 4). Self-efficacy is influenced by four main factors: past experiences, vicarious experiences, feedback from others, and emotional responses (Bandura, 1977a). The students who demonstrated high levels of engagement in music learning through participation in evaluative performances had previous experiences of success that inspired their confidence in their abilities to succeed in future evaluations. They deliberately reflected on their past evaluation experiences and used these as benchmarks for goal-setting. Often, students selected goals that were equivalent or incrementally higher than their previous achievement. They felt confident that they could match (or slightly exceed) their prior results in similar tasks. Previous successes in evaluative performances were particularly influential in increasing students' self-efficacy as these events were generally perceived to be challenging (Pierson, 2005, p. 50). Achieving success was then viewed as a considerable accomplishment.

Successful students' exposure to other, similar music students also reinforced their sense of capability. For example, the teacher of the current students highlighted their successes by posting student achievements on a bulletin board in the studio. In this way, students could see that their peers had been able to achieve strong results and felt inspired to continue the tradition of excellence established in their studio. Students also had opportunities to hear their peers 
perform in recitals, studio classes, and festivals. While hearing another student do poorly could be unsettling, hearing other students play well could be inspiring and could open up the students ears to various possibilities. One of the parents described how her daughter, who tended to be a perfectionist, had learned to see the value in a variety of interpretations through her participation in festivals. By developing a broader personal definition of musical success, this student was able to increase her self-efficacy.

In addition to personal and vicarious experiences, feedback from others also plays an important role in building students' self-efficacy. Students received feedback on their musical abilities from a number of important people in their lives, such as family members, friends, and teachers. However, the most influential feedback came from adjudicators and examiners. The students who had positive experiences with evaluative performances felt strongly validated when they received affirmation from evaluators. Conversely, low marks or criticism from an adjudicator could seriously undermine a student's self-confidence. This finding confirms the findings of Maroon (2003), who emphasized the importance of the examiner's authority and the effect of being judged on students' experiences with performance anxiety.

The final factor that influences students' self-efficacy is the student's emotional and physiological state. The current and former students in this research described a variety of emotional and physiological responses to their involvement in evaluative performances. These reactions were related to their motivational characteristics and tendency towards performance anxiety, which will be discussed in more detail in the next chapter; however, a few examples are pertinent here. If students placed high value on the recognition afforded by a positive result, receiving affirming feedback from the examiner can result in intensely positive emotions. For students who experienced extremely intense performance anxiety, the negative emotions and 
physiological symptoms associated with the anxiety created lasting negative memories that were often enough to make a student want to stop participating in evaluative performances or even in music lessons altogether.

Self-efficacy is an extremely important factor in student learning, as it affects numerous aspects of the learning process. Nielsen (2004) found that university music students with higher self-efficacy were more likely to be cognitively and metacognitively aware during their practice sessions. Because this kind of awareness is crucial to students' being able to learn music autonomously, students who have high self-efficacy are more likely to be able to make significant progress between lessons and to be able and eager to continue learning music after they have stopped formal instruction. Self-efficacy is also the single biggest predictor of actual performance on music examinations (McCormick and McPherson, 2003). Not only does prior success support the development of high self-efficacy, but self-efficacy also contributes to future success (thus establishing a reciprocal relationship between the two).

The second important theoretical perspective that ties together the findings of this chapter is self-determination theory (Ryan and Deci, 2000). Self-determination theory posits that people have three basic psychological needs: autonomy, competence, and relatedness. When these needs are met, an individual will act in a self-determined way, which is characterized by high levels of intrinsic motivation.

In the view of self-determination theorists, people are most motivated to engage in a particular activity when their needs for autonomy, competence, and relatedness are met while doing so. Autonomy refers to the degree to which individuals are able to control their own activities. A sense of ownership has been demonstrated to be extremely important in fostering student engagement in learning (Custodero, 2002). Students who are allowed to choose the 
activities in which they participate and the way in which they engage with specific material are more likely to want to continue learning. In contrast, students who are forced to engage in activities that hold little interest for them will look for opportunities to stop participating in those activities and may harbor resentment against the people who required their participation in the first place.

People also have a need to feel competent and will choose to engage in activities that allow them to experience success (Atkinson, 1964). Students' perceptions of their own abilities are important, as "children who perceive themselves as highly competent are more likely to engage in learning tasks, utilize the skills and strategies they possess, persist when they confront difficulties, and achieve success" (Austin, Renwick, and McPherson, 2006, p. 220). Zeidner and Matthews (2005) differentiate between achievement and competence motivation. While achievement (for example, in testing situations) can be one indication of competence, "competence motivation is ubiquitous in daily life, it has a substantial impact on emotion and well-being, it is operative across the lifespan, and it is evident in all individuals across cultural boundaries" (p. 6). Given the preceding description of the importance of competence motivation, it is little wonder that the students in this research who felt competent as a result of their participation in evaluative performances were keen to engage in further music learning.

Finally, people are more likely to engage in activities that foster a sense of connection (relatedness) with other people (Cameron and Carlisle, 2004; John, 2004). When participation in an activity takes place within a social context that is supportive, students experience the activity in a positive way. Students are also motivated to participate in activities which bolster connections with other people who also engage in that activity. 
The students who had positive experiences with evaluative performances had all three of these needs met through their participation in festivals and exams. They were not forced to participate in these events, even if they might have been acting at the suggestion of a teacher or parent. All of them were enthusiastic about the idea of participating in future evaluations. These students had a strong sense of ownership over their musical development, as they were given opportunities to pursue personally relevant goals.

Because these students had experienced success, participating in evaluative performances helped to bolster their sense of competence as musicians. Feeling competent led the successful students to identify more strongly as musicians and as performers, increasing the likelihood that they would want to continue engaging in music learning and in festival and exam performances. They were invested in their own learning and felt proud of their previous accomplishments and optimistic about their future potential.

These students also had positive relationships with significant adults (their teacher and parents or guardians) surrounding their participation in evaluative performances. The practical and emotional support the students received from their parents and teachers was crucial to their success and to their continued engagement in learning.

In contrast, the experiences of students who had negative views of their festival and exam participation show a marked neglect of these three crucial needs. Students who were registered for evaluative performances against their wills had negative experiences at the time of the performance, and often harbored long-term resentment toward the adults who were seemingly oblivious to their needs and interests. For this group of students, participating in evaluative performances led to a diminished sense of competence. In some cases, low marks made these students feel unskilled as musicians. Even when the results of the performance were adequate, 
students' experiences with high levels of performance anxiety often made them question their overall potential as practitioners of a performing art. In many cases, the students' relationships with parents and teachers were not supportive. Negative relationship experiences described by the participants in this research ranged from a lack of involvement to physical and emotional abuse. The relational context of music learning and of participation in evaluative performances is so important that a subsequent chapter of this thesis is devoted to a further discussion of this issue.

Experiencing high levels of engagement in music study is important for both short-term and long-term involvement in music-making. In this study, the students who had positive experiences with evaluative performances also had positive views on their piano studies in general. While it is impossible to establish a causal relationship between experiences with evaluative performances and attitudes towards music study based on this research, it appears from the experiences of these participants that there is a cyclical relationship in which a desire to learn music prompts them to participate in evaluative performances as a means to develop their skills. Their love of music and desire to improve their skills inspires thorough preparation, which generally results in success. When students succeed in evaluative performances, the resultant sense of accomplishment contributes to their overall positive experiences with learning the piano. In other words, participating in evaluative performances contributes to a deeper level of engagement in music learning. 


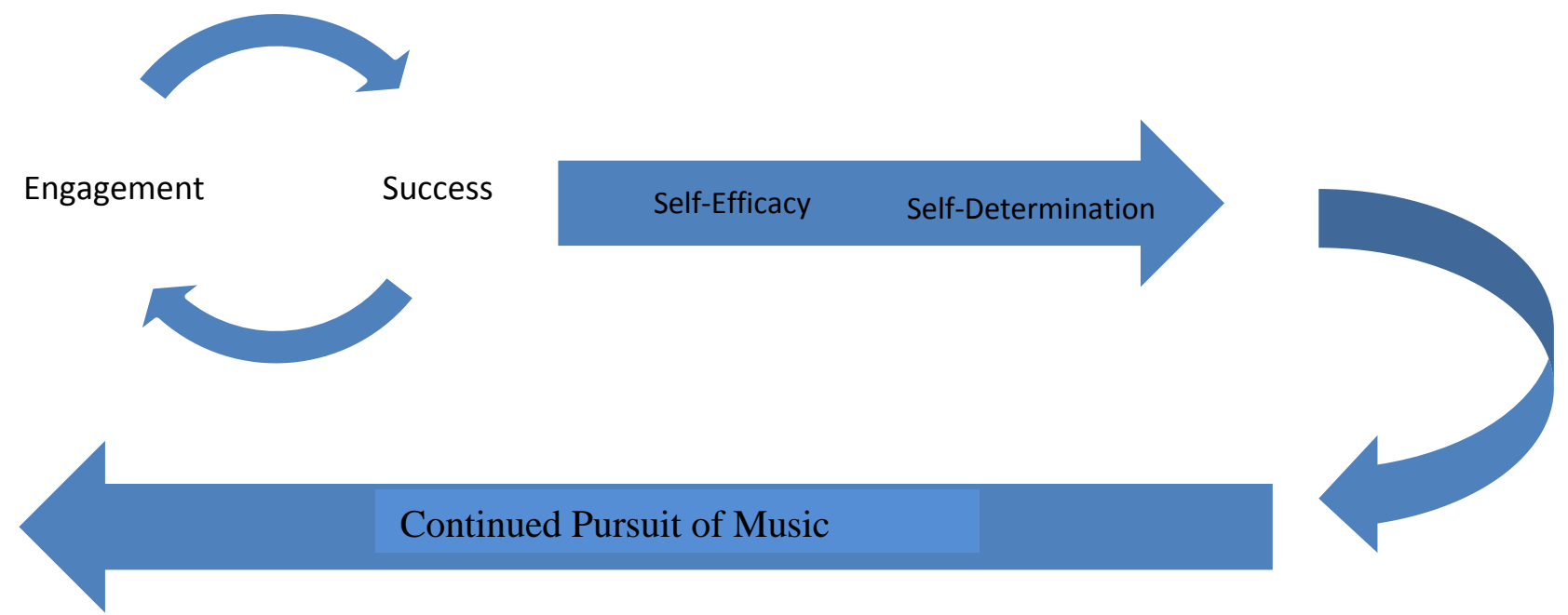

Figure 8 The Importance of Student Engagement and Success

When students have negative experiences with evaluative performances, they can develop a corresponding negative impression of the entire music learning venture. While many of the former students were able to find their own musical voices as adults (perhaps even employing skills that were developed as they were preparing for evaluative performances), their reflections on their years of formal music study were tinged with regret.

\section{Summary}

This chapter explored the characteristics of a positive experience with an evaluative performance. Students who had positive experiences with festivals and exams were highly engaged in music learning through participation in evaluative performances. Their engagement in learning was characterized by positive emotional responses to learning, perceptions that their music learning was meaningful and relevant, and a strong musical identity. Students were most likely to experience these facets of engagement when they were successful in their evaluations. There appeared to be a reciprocal relationship between engagement and success, with highly engaged students being set up for successful outcomes and successful students experiencing the 
three facets of engagement discussed at the beginning of the chapter. Positive experiences with evaluative performances (or high levels of engagement in music learning through participation in evaluative performances) are important because they contribute to students' sense of selfefficacy and self-determination. Students who have high self-efficacy and who are selfdetermined are more likely to want to continue engaging in music learning. The self-efficacy and self-determination of the current student participants was evident in the fact that all of them stated, without hesitation, that they planned to participate in more festivals and examinations in the future. The following chapter will unpack in greater detail some of the personal characteristics that contribute to the likelihood of students' experiencing this kind of engagement in learning. 


\section{Chapter 6 \\ Personal Characteristics that Influence Student Engagement in Evaluative Performances}

In the two previous chapters, we explored the demands of evaluative performances and the characteristics of a positive experience participating in these kinds of events. To sum up, evaluative performances generally require an accurate, musical, stylistically correct performance (for pianists, usually from memory) of repertoire that comes mainly from the Western classical tradition. Preparing for the high level of performance that is expected by adjudicators and examiners generally requires a long period of diligent practicing under the guidance of a qualified teacher. Students who have positive experiences participating in evaluative performances experience positive emotional responses to music learning in general and to participation in evaluative performances specifically, view their music learning and participation in evaluative performances as meaningful, and have a strong musical identity that is in line with the concept of musician perpetuated by evaluative performances. All three of these factors influence each other and are the result of students' experiencing success. There are several personal and relational influences that contribute to whether students can have positive experiences participating in evaluative performances. In this chapter, I will outline how the student's characteristics as a music learner and as a performer contribute to success and to engagement in music learning through participation in evaluative performances.

\section{Student as a Music Learner: Understandings, Values, and Goals}

The student's characteristics as a music learner greatly influence whether he or she has positive experiences with evaluative performances. When the students' characteristics are in line with the demands of the evaluative performance, he or she is more likely to experience the kind 
of engagement described in the previous chapter. Students who had positive experiences with evaluative performances enjoyed most of the required repertoire and were able to appreciate the value of the parts of the program they found less inspiring. These students were meticulous in their preparations, following their teacher's instructions closely and practicing diligently. In this way, they were able to achieve the kind of highly polished performance that leads to success in evaluative performances. While none of the students who participated in this study enjoyed every single aspect of preparing for festivals and exams, the students who had positive experiences with these events were able to focus on the ways in which participating in festivals and exams was consistent with their own musical values and goals.

This section will employ several theoretical perspectives to illuminate how students' characteristics as music learners contribute to their experiences with evaluative performances. The first is organismic integration theory (Ryan and Deci, 2000), which is a component of the self-determination theory described in the previous chapter. This theory explains how people motivate themselves to persist in activities that are not necessarily immediately enjoyable in the pursuit of larger goals. Attribution theory (Weiner, 1986), which offers insight into how students understand the causes of their successes and failures and the impact of these understandings on future engagement in learning, provides an important perspective in understanding why students would continue to work hard in the pursuit of success. Expectancy-value theory (Wigfield and Eccles, 2000 )demonstrates the importance of two facets of motivation in influencing students' willingness to engage in a particular activity: expectations of success and the value they placed on the potential outcomes of an activity. Students' values are closely linked to their goals, which, according to goal orientation theory (Dweck, 1986), can be categorized as mastery, performanceapproach, or performance-avoidance. 
While enjoying the required repertoire is indeed important for students to experience high levels of engagement, the students who had positive experiences with evaluative performances had also found ways to incorporate less enjoyable aspects of learning into an overall positive view of music learning. Self-determination theory offers an interesting perspective on students' motivation to pursue activities for which they are not necessarily intrinsically motivated. Rather than presenting intrinsic and extrinsic motivation as opposing poles, proponents of selfdetermination theory use a spectrum (referred to as organismic integration theory) to show a progression from extrinsic motivation, or externally regulated behavior, to intrinsic motivation, or self-determined behavior (Ryan and Deci, 2000). As discussed in the previous chapter, when an individual is functioning at the self-determined end of the spectrum, his or her psychological needs for autonomy, competence, and relatedness are being met through participation in a particular activity.

When a person's behaviour is externally regulated, he or she is engaging in an activity purely for the prospect of receiving some sort of reward (Ryan and Deci, 2000). An example of external regulation would be a student who participates in an exam simply to meet her parents' expectations for her to accumulate certificates. When the achievement of the reward is tied to a person's sense of self-worth, he or she is said to have introjected regulation of behaviour. In this case, the student would base her self-worth on the achievement of grades and certificates. Her motivation to succeed in an evaluative performance would be based on a desire to maintain her self-worth. A person whose behaviour is regulated through identification is still governed by the pursuit of external reward, but is pursuing a goal that has been consciously decided upon as being personally important. For example, a student might not enjoy the process of participating in an evaluative performance, but participates because she wants to develop certain musical skills 
that are part of the exam curriculum. In integrated regulation, the individual's goals have become part of his or her sense of self. While this type of motivation shares some characteristics with intrinsic motivation, intrinsic motivation focuses on the pursuit of an activity purely for enjoyment, while integrated regulation still involves a concern for external reward. In this case, the student would identify as a musician and would participate in evaluative performances as a means to reinforce that musical identity. The final point on the spectrum is intrinsic motivation, in which an individual is pursuing an activity purely because he or she finds that activity to be enjoyable or fulfilling, without concern for external rewards. An intrinsically motivated student would learn to play the piano for the sheer joy of learning and performing and of expressing herself through music.

This spectrum is useful from a theoretical point of view, although it can be difficult to distinguish the various levels of integration in practice. The participants in this study represented various points on the spectrum, in some cases exhibiting evidence of different levels of integration at different times. For example, some students only participated in evaluative performances because they were forced to by parents or teachers. One former student described how she enjoyed everything about learning the piano except "the festivals and exams I was told I had to do" (FS\#5). In this case, the students' behaviour was regulated entirely externally, as she could see no reason to participate in evaluative performances beyond others' expectations.

Other students viewed their sense of self-worth as being tied to their achievement in evaluative performances, thus displaying evidence of introjected regulation. For these students, the results they achieved in their evaluative performances were an indication of their personal value. In particular, negative results could have a devastating effect on students' self-esteem. For example, one of the current students (CS\#2) who experienced a disappointing festival result 
found it difficult to deal with the fact that she had not achieved what she had been hoping. A former student described her unsuccessful exam attempt as a "monumental failure" (FS\#3) after which she never felt confident in her skills as a pianist again.

Most of the current students showed evidence of either identified or integrated motivation for participation in evaluative performances. They were involved in evaluative performances because they valued the potential outcomes of participation (for example, increased skills and the achievement of certificates). Previously, I mentioned how several of the students used the word "accomplishment" in reference to getting good marks on exams and being able to move on to the next level. In addition, for many students, achieving the goal of increasing their musical skill played an important role in developing their self-concept. One student described how she was one of "lots of great piano players" (CS\#3) at her school. She viewed herself as a musician and sought out activities, such as playing in festivals and exams, that would increase her sense of musical identity.

While intrinsic motivation is the most adaptive motivational orientation for learning, it is difficult to engage in an evaluative performance without some level of external regulation. The students who had positive feelings about evaluation invariably spoke of the sense of accomplishment they felt after placing in the festival or receiving a high mark on the exam. The prospect of experiencing that pride and excitement again played a large role in influencing their decision to participate in future evaluative performances. Several students (both those who had positive and negative experiences with festivals and exams) described high levels of intrinsic motivation to learn music, but none described a truly intrinsic motivation to participate in evaluative performances. It is quite likely that it is nearly impossible to have purely intrinsic 
motivation to participate in an evaluation, as so much of the focus of the event is on the external reward.

As a student, I had intrinsic motivation to play music; however, my involvement in evaluative performances was characterized by introjection and integration. I participated in evaluative performances because I saw myself as a musician and wanted to participate in an activity that I expected would further my musical skill development. I also saw successful participation in evaluative performances as an essential part of being a competent musician and did not want to leave out this important component of my "ideal” musician.

Chapter 4 described the kind of rigorous preparation that is necessary for successful performances in festivals and exams. Students' diligence and attention to detail in their lessons and practicing are evidence of a considerable amount of effort. Their reasons for putting forth this effort can be partly explained through an examination of attribution theory. Attribution theory explains how people understand their successes and failures (Weiner, 1986). There are a number of factors to which the outcome of a particular activity can be attributed. These factors can be classified as internal or external, stable or unstable, and controllable or uncontrollable. Examples of specific attributions are ability (internal, stable, uncontrollable), effort (internal, unstable, controllable), task difficulty (external, stable, uncontrollable), and luck (external, unstable, uncontrollable). In general, people are more motivated to continue engaging in an activity if they attribute their successes and failures to factors that they can control. Successful students tend to attribute their successes to a combination of effort and ability and their failures to lack of effort (Snowman, McCown, and Biehler, 2009). The emphasis on effort (particularly in cases of disappointing results) allows these students to foresee a different outcome if they were dissatisfied the first time or to feel confident that they can replicate a successful outcome. 
In this study, the current students (who had had largely positive experiences with evaluative performances) were asked to explain why a student might do well or do poorly in an evaluative performance. In all cases, the students attributed success to hard work and the use of effective strategies. One of the current students said that successful students achieved high marks as a result of "constantly practicing what they needed to work on" (CS\#1). Her ideas were echoed by another student who cited "preparedness" (CS\#2) as the most likely explanation for success. The ability to stay calm and focused was also an important contributor to success, as described by CS\#3, who said that "staying steady and staying calm, and not freaking out in the middle "cause they missed one note" would ensure a good outcome. The other two current students had very similar ideas, emphasizing both the need for hard work and the need for attentiveness to the teacher's instructions. The following description captures the importance of consistent and effective practicing:

CS\#4: I think they probably practiced a lot - really hard and also they listened to what their teacher was telling them to kind of work on and they used that advice to kind of keep going and to work on those specific things. And then they probably yeah, they pretty much worked hard and they didn't just let, like stop doing it and be all lazy and say "I'll practice another day"

None of these students attributed successful outcomes to luck or to the easiness of the task. This finding would confirm that all of these students viewed evaluative performances as challenging endeavours that required dedicated, serious preparation in order for a successful outcome to occur. The views of these students are in agreement with those expressed by the participants in Legette's (1998) study, which found that public school music students tended to attribute success to a combination of ability and effort.

All of these students were diligent in their own practicing and were able to describe specific strategies that they used to improve their playing and to deal with particularly 
challenging aspects of their music. For instance, students referred to practicing small sections, playing slowly, using verbal cues to remind themselves of important fingering changes, taking note of patterns to help with memorization, and paying close attention to their teacher's verbal and written instructions. The teacher of the current students praised their hard work and attributed their progress to the efforts they had made. This kind of attributional feedback has been demonstrated to be beneficial in helping students develop self-regulation (Schunk, 2001, p. 138).

One of the students described how she makes the best use of her practice time by prioritizing the pieces that she finds more challenging:

CS\#2: [W]hen I practice, I focus - mostly focus on the pieces that I'm not strong on. Like say, like if I really like this piece, I practice it a few times and then I get comfortable with it and then I would go to work on the stuff that I'm struggling with. Like if there's a section in a song, I would sort of go over that a few times and I find that that works, that I have something good to show [my teacher] ... when I go to my lesson.

Spending time on the more difficult parts of her exam program ensured that she continued to make progress. This student emphasized that feeling well-prepared was extremely important to her in dealing with performance anxiety; therefore, it was important to her to be disciplined in her practicing so that she could feel confident and achieve success.

Another student discussed the importance of establishing a practice routine. When asked how challenging it was to schedule practice sessions, she replied:

CS\#3: Well, it's kinda easy cause my grandma and I have a routine. On Mondays, Tuesdays and Thursdays I come here, and then Fridays, that's when my favourite vampire show comes on, so I stay over at my house and I bring my keyboard into my basement and practice there, and same on Saturdays and Sundays, except I come to church on Sundays, and sometimes I come here to practice even on Sundays. And Wednesdays I have my class, so I don't practice then. So it's kinda like a routine, so I don't really think about it anymore. 
For this student, the support she received from her grandmother helped her to be consistent in her practicing. She did not struggle to discipline herself to practice regularly, because her piano practice was such an established part of her routine.

The descriptions they provided of their own practicing would indicate that these students were applying their attributional beliefs to their own learning. Their practicing was consistent, focused, and strategic. Because these students believed that being well-prepared would help them achieve success in their upcoming evaluations, they were willing to discipline themselves to practice even when they did not necessarily feel like working on a particular day.

When asked to explain why a student might not be successful, the current students hinted at a lack of effort and attentiveness, but focused on the root cause of this lack of engagement by emphasizing the belief that students who don't succeed don't value the pursuit of achievement. One of the students gave the following explanation for why a student might be unsuccessful in an evaluative performance:

CS\#4: [T] hey were lazy about it, or they just didn't really listen to what, like what their teacher was saying, yeah, they didn't really care about the festival, they just thought “oh, it's another thing, it's fine if I don't place" like they just had no goals to set or anything.

Other students also echoed her statement that unsuccessful students "don't care" about the evaluation or its outcome. Because being thoroughly prepared for a festival or exam involves a considerable amount of work, a student who is not highly invested in the process is unlikely to want to expend the necessary effort.

Another of the current students described a lack of attention to detail as a possible explanation for a student's failure. Specifically, she felt that a lack of accuracy in following the markings on the score could lead to a student receiving a low mark: 
CS\#2: I know one thing that gets me is looking at the dynamics that they give you instead of what you think should be happening, like, same with pedaling, like maybe they didn't do what the book says and did what they think. That's probably one thing that would go through my head because [my teacher] and I always talk about that sort of thing. So that's probably what would go through my head first.

In this case, the student drew on her own experiences as a potential explanation for why a student might not be successful. While she had received excellent marks for her own festival and exam performances, it would appear that she and her teacher had had some discussions about the possible ramification of being too adventurous with the interpretation of her pieces. In her case, she valued achieving high marks enough that she was willing to sacrifice her own interpretive ideas to meet the examiner's expectations.

While the current students, all of whom had been successful in their previous performances, could speculate on why a student might fail, one of the former students was able to provide some insight into the actual process of attribution through which she and her parents attempted to make sense of her disastrous exam experience:

FS\#3: We were blaming everyone after that exam. We were blaming my current teacher for not having prepared me well enough and for letting me sit the exam when I probably wasn't ready. We were blaming my other teacher for not teaching me enough sight music and not teaching me any ear training. Um, so yeah, everyone was at blame except for me, really. I know that my parents were giving me a break. So yeah, there was nothing like this exam. It's just being tested on stuff that you don't know how to do, that was it for me. Like, why was I doing this? Why was I sitting an ear training section when I didn't know how to do it? Why would anybody do that? I don't know. I don't know. I actually, in retrospect, do blame that teacher, because she - how could she think that I could do that? Did she think that I was going to do so well on the other parts of the exam that maybe if I failed the ear and sight that I could still pass?

In this case, the main attributions for her failure were external. The task was too difficult because she had been inadequately prepared for it. The main responsibility for that lack of preparation lay with her teachers, the first of whom should have ensured that she covered a balanced curriculum from her earliest lessons and the second of whom should have been able to predict how much 
time she would need to become familiar with the required material. Interestingly, she states that she knows that her parents were "giving [her] a break." Her parents likely understood that, as devastating as the poor exam result was when understood in terms of the teachers' failings, the experience would have had an even stronger negative impact had the student been encouraged to see it as resulting from an internal cause. Perhaps her parents were hoping that by emphasizing the role of the teacher they could help their daughter preserve her musical self-concept so that she would be willing to continue pursuing an activity about which she had previously been so passionate. However, it is possible that attributing the failure to external factors also contributed to the student's viewing any future performance results as being beyond her control. It is also quite likely that in spite of all the efforts to blame her failure on the shortcomings of others, this student still came away from the experience doubting her own abilities. If she truly believed that the bad exam experience was the result of the teacher's failure to offer adequate guidance, she might have remained confident in her own abilities in spite of one bad experience and sought out a new teacher who would help her fill the gaps she had exposed in her learning that had been exposed through the exam process.

When I reflect on my own experiences as a student, I am convinced that my attributional beliefs played a large role in the level of anxiety I felt regarding my participation in evaluative performances. In contrast to the stable concept of ability that is assumed by attribution theory, I viewed my ability level as subject to change. If my last evaluation had resulted in a good mark, then perhaps I had talent; however, I could not rely on ability to predict future performances. While I worked hard and did not believe that it was possible to be successful without diligent practice, I never felt that hard work was enough to justify any measure of confidence in the outcome of an examination. All I could do was prepare to the best of my ability and then hope 
that all of the external, unstable, uncontrollable factors (such as the preferences of the examiner, the condition and responsiveness of the piano, the physical characteristics of the room) would align to allow me success. Most importantly, I believe, I felt I had very little control over my own mental state on the day of the performance. Not only did I experience anxiety about the performance itself, but also about the anxiety I expected to feel and the impact this uncontrollable stress might have on the quality of my playing.

Students' attributions have a profound impact on their persistence in engaging in a particular activity. Research has shown that successful students tend to attribute their successes to effort and ability (internal factors) and their failures to a lack of effort (Schmidt, 2005). These students persist in the face of challenges because they view their achievement as something that they can control. In particular, they are convinced that increasing their level of effort will result in improved results, thus framing failures as temporary disappointments. In contrast, less successful students tend to attribute their successes to external factors, such as an easy task or luck, and their failures to a lack of ability. Because they view ability as a stable characteristic, students who are convinced that they have failed at a particular task due to a lack of ability are unlikely to want to attempt it again.

These prior research findings are largely confirmed by the findings of this study. The students who were successful cited effort and the use of effective strategies as the reasons for their success. These students also felt confident in their abilities because they felt in control of the effort they were expending and the strategies they were employing to ensure thorough preparation for the performances. Their speculations that a student might fail as a result of "not caring" point to another important perspective on motivation: expectancy-value theory. 
Expectancy-value theory defines motivation as the degree to which an individual expects to succeed in a particular task combined with the value placed on the activity (Wigfield and Eccles, 2000). Expectations of success are closely tied with self-efficacy, which was discussed in some detail in the previous chapter. In this study, the students who had positive experiences with evaluative performances expected to succeed, as they felt confident that they were well-prepared for their evaluations. The students who had positive views of evaluative performances had participated in these kinds of events before and had achieved good results. This fact helped to bolster their confidence.

One of these students (CS\#1) was preparing for her first festival performance during the study period. Because she did not know exactly what to expect, she was feeling uncertain about her prospects of success. Her lack of specific experience and knowledge related to festivals increased her level of anxiety related to the performance. However, her previous successes in exam situations reassured her that she had the potential to compare favourably with the other students competing in the festival. Between the first and second interviews, she worked hard in her practice sessions and had the opportunity to play on the piano on which she would have to perform, both strategies that helped her to feel more confident. She also received support from her teacher, who expressed that she was confident the student would do well. Stipek (2002) highlights the importance of students' confidence in their ability to succeed as a key to allaying evaluation-related anxiety. Because this student had been able to bolster her sense of selfefficacy related to the upcoming performance, she could respond affirmatively when asked if she was looking forward to performing.

While students' expectations of success play a crucial role in determining their engagement in learning through participation in evaluative performances and in influencing their 
results, the other component of expectancy-value theory is just as important. Individuals are more likely to engage in an activity when they value the potential outcome. This value is influenced by several perceptions: attainment value (for example, receiving rewards for participating in the activity), utility value (for example, finding uses in daily life for a particular skill), intrinsic interest (the enjoyment derived from participating in a particular activity), and the perceived cost (for example, the time, money, effort, and/or neglect of other activities that is required to engage in a particular activity (Austin, Renwick, and McPherson, 2006).

The students who had positive experiences with evaluative performances showed evidence of valuing their participating in festivals and examinations for all four of the above reasons. These students placed a high degree of importance on formal recognition of achievement, such as the marks, ranks, and certificates they were awarded as a result of their participation in evaluative performances. They also found ways to use the skills they were developing in their daily lives and had musical goals that necessitated a conscious effort to become more skilled. As discussed in the previous chapter, these students had high levels of intrinsic motivation to learn music; therefore, they enjoyed many aspects of the preparation process of participation in evaluative performances. Finally, these students acknowledged the costs associated with participation in evaluative performances and decided that the benefits of participation were more significant. Because these students placed high value on their music learning and achievement, they were willing to engage in volitional processes that would ensure the self-regulation necessary for continued success (Corno, 2001, p. 194).

Students who had positive experiences with evaluative performances viewed festivals and exams as a way to improve their skills as musicians and as performers. Sometimes the 
pursuit of increased skill involved dedicating themselves to less exciting aspects of music study, such as technique or sight reading, as described by one of the current students:

CS\#1: Cause before, I didn't really - it was just sort of like, "Okay, scales, whatever, it doesn't matter. Theory, whatever" Now I know that, like, now when I go to exams I know that it's actually important instead of just there.

For this student, knowing that she would be evaluated added to the importance of some of the aspects of the curriculum she might otherwise have been inclined to neglect. She was willing to do whatever she needed to do to ensure a high mark, even in scales and theory.

However, the students who placed high value on evaluative performances were concerned not only with what they would learn through the preparations, but also with the formal recognition they would receive for their achievements. All of the students who had positive experiences could remember previous results and were proud of these accomplishments. It was also very important to the current students to maintain or improve upon their previous records at their upcoming performances.

The teacher of the current students also recognized the importance of students' values in their engagement in learning. She described with a bit of frustration a former student who had not taken her musical development seriously:

T\#1: [S] he was a kid who, no matter what I did, she just never cared. She couldn't care less. ... [S]ome kids just don't care and no matter what you do you can't get them to care. But I find exams and festivals are one way to get them to care about taking music to another level.

Although she was not able to succeed in motivating this particular student, this teacher had found in the past that evaluative performances were effective in helping students to value their music studies more. The sense of pride and accomplishment that these students felt when they received a good mark was enough to make all of the hard work worthwhile. 
When asked to describe why some students are unsuccessful in evaluative performances, some students mentioned that those students likely "didn't care" (CS\#1, CS\#5). Presumably, this low esteem for evaluative performances would translate into reduced effort, less attention to detail, and less effective strategy use when practicing. However, it is very interesting to note the students' choice of words. The main attribution for lack of success was not a specific action (or lack of action), but an attitude. Some of the former students reinforced this idea of values being important. They described being forced to participate in festivals and examinations because it was just assumed that these events were an essential part of learning to play the piano. However, these students did not see the evaluative performances as having any real value and were not motivated to do any more than the bare minimum in preparing for them.

One former student described festivals and exams as being "extraneous" (FS\#5) to her primary goal of developing her musical skills. While she was very interested in becoming a more competent musician, grades and certificates held little meaning for her. This student enjoyed the music that she learned as part of her preparation for festivals and examinations, assigning both utility value and intrinsic interest to her musical pursuits. However, her lack of interest in the opinion of the adjudicator (coupled with very intense performance anxiety) meant that engaging in evaluative performances was too costly.

For other students, the actual learning that had to take place in order to assure success in the evaluative performance was of little value. Students who found the required repertoire boring or irrelevant were unlikely to see the intense preparations as worthwhile. For example, one of the former students described how she was content to participate in conservatory examinations as a younger student, when it was possible to do well without having to invest significant amounts of time in preparation. However, as she got older and the examination requirements became more 
demanding, she began to resent the amount of time that was required in order to be successful. This student cared about the marks she received and was unwilling to enter an examination if she was likely to receive a low mark. However, she could see no utility value to learning the required music and derived little enjoyment from her preparations. As a result, for her, examinations were more trouble than they were worth.

As a young music student, I valued the skill development and exposure to new music that resulted from my involvement in evaluative performances. However, I also placed very high value on the formal recognition of achievement that was an integral part of the examination system. I took great pride in accumulating the examiners' assessment forms and certificates, even taking them with me when I left home for university. Because I cared so deeply about progressing quickly from one examination level to the next, I purposefully neglected some other areas of music study that might have been beneficial for my overall musical development. For example, the teacher with whom I studied when I was a high school student was a very proficient improviser. He offered to help me learn how to improvise, but I was so preoccupied with getting through my next exam that I did not take him up on his offer. At the time, the cost to my exam preparations seemed too great; however, I later regretted not trying to develop this important musical skill.

When considering the experiences of the participants in this study, those who had positive experiences with evaluative performances had confidence in their potential to succeed in festivals and examinations. Not only did they expect to succeed, but they also valued the potential outcomes of participation in evaluative performances. They saw the preparation period as an opportunity to develop their musical skills. Equally importantly, they valued the formal recognition of achievement that is part of the evaluation process. In many cases, it was the desire 
to earn the rewards of marks and certificates that made the hard work worthwhile. Even the students who were enthusiastic about their overall music studies and their participation in festivals and exams generally had some aspect of the exam curriculum (for example, technique or sight reading) that they found less enjoyable. For these students, the desire to do well provided sufficient motivation to master these less intrinsically interesting parts of the curriculum.

The values of the students who had positive experiences were reflected in their goals, both immediate and long-term. Goal-orientation theory strives to explain how an individual's goals influence his or her motivation to engage in an activity (Dweck, 1986). Goals can be characterized as mastery (or task or learning) and performance (or ego) goals. Mastery goals focus on the development of a deep level of understanding with less emphasis on results and on learning on a particular timeline. Performance goals can be divided into two categories: approach (in which the focus is on achieving a particular result) and avoidance (in which an individual avoids engaging in the activity in order to avoid the possibility of failure).

The students who viewed their experiences with evaluative performances in a positive light tended to exhibit a combination of mastery and performance approach goals. Some of the mastery goals cited by students included aspects of performance such as being able to play from memory without mistakes or remembering to follow the dynamic markings. One of the current students stated that, even if she did not place in the upcoming festival that "if I can achieve any personal goals, or something I was struggling with then, yeah, I'd be happy with it [my performance]" (CS\#1). Having personal learning goals could provide a means for decreasing anxiety about the outcome of the performance, as students could likely more easily predict being able to master a particular musical challenge than to foresee the mark or rank that might be assigned to them based on their performance. 
However, these students also had very specific goals regarding achievement. The desire to do well influenced the dedication with which they approached their preparations. The quest for grades could motivate students to work hard, as described by one of the current students: "Um, well I'm just practicing 'cause I really want to do well in this festival and I think it prepares me for exams" (CS \#1). This student valued achievement highly enough that it provided reason to practice consistently and intentionally, even though in another part of her interview she described experiencing frequent boredom while practicing. Many students had very specific performance approach goals, including placing in the top three at the festival, or achieving a mark of at least 80 or 90 percent at an exam. Previous performances informed specific achievement goals, as students generally wanted to maintain or improve upon their previous results. All of the current students who participated achieved (or in some cases, surpassed) their goals for the performances that took place during the data collection for this research and were very satisfied with their performances as a result.

The current students also showed a mix of mastery and performance approach goals when discussing their long-term goals. Many of the students framed their goals in terms of the specific grade level they wished to achieve. One of the current students had particularly detailed plans regarding her future progress through the exam curriculum:

CS\#2: [My teacher], my mom and I, we were discussing that. [My teacher] said that I could actually be in Grade 10 piano by the time I'm in Grade 12 [in school], so that's probably where I might like stop, because Grade 10 is pretty achieving for a lot of people, so it's sort of like Grade 10, there's not much more you can do, well, there is, but exams aren't that necessary when you get into the higher grades sometimes, and I think that if I keep doing the schedule, cause she gave me this sort of idea of like what exams I would have to complete in one year, so it would be like two this year, one, one, one or two another year, and then two this year, and then just one, so yeah, that Grade 10 is probably the goal overall for Grade 12, which would be in four years. 
When asked to elaborate on why reaching the Grade 10 level would be important to her, this student referred to both the sense of accomplishment she would feel and also the level of skill she would have developed in order to be able to play at that level.

This combination of reasons for wanting to reach a particular examination level was also echoed by other current students. While they expected that they would stop taking lessons at some point, as nearly all piano students do (Costa-Giomi, Flowers and Sasaki, 2005, p.234), all of them envisioned continuing to play the piano as a leisure activity when they became adults. They recognized that in order to be able to learn new music independently and efficiently, they would need a high level of skill that they hoped to develop through pursuing advanced exams. However, they also wanted to be able to say that they had reached a certain level of achievement. In my own experience as a student, both of these goal orientations were heightened, as I knew from a young age that I wanted to pursue a career in music teaching. My career ambition required not only the development of a high level of skill, but also the documentation of that skill development through regular participation in examinations.

There is some inconsistency in research findings relating to goal orientation and engagement in learning. Some research has demonstrated that adopting learning goals is beneficial for younger students who have limited ability or low self-concept, while either learning or performance approach goals can work well for older students with higher skills levels and self-concept (Austin, Renwick, and McPherson, 2006). Another study identified mastery goals as being adaptive cognitions for engagement in learning (Martin, 2007). However, other research found that mastery goals had no impact on performance and emotional outcomes, but that intrinsic goals were associated with positive outcomes in both areas. The same study found 
that both types of performance goals had adverse effects on performance and emotional outcomes (Lacaille, Koestner, and Gaudrea, 2007).

While having specific performance approach goals can be a helpful indicator for students of their progress, it can also set them up for feelings of disappointment when they do not achieve their goals. Average examination marks generally decline in higher grades (RCM, 2012). While some students continue to do well as they move through the levels, there are many others who, at some point, see their marks drop. If a student is faced with a drop in marks, he or she must then decide whether to adjust his or her standards and expectations or to discontinue the pursuit of a goal that is now likely unattainable.

Not only can a drop in marks result in disappointment, but a change in the rate at which a student progresses through the examination levels can also pose challenges for students. One of the former students (FS\#1) had stopped taking lessons shortly after beginning to study with a new teacher. This student had lost interest in working towards examinations, but could not really imaging taking piano lessons without having the structure of constant exam goals. Her teacher, in an effort to find a course of study that would meet the needs of this particular student, suggested registering for a popular music exam. However, because the requirements differ so much from those of the classically-based examinations, this student would have had to start over at Grade 1 in order to feel adequately prepared for her exam. While she was not interested in pursuing further classical exams, this student still took pride in having achieved a certain level of study (she was working on Grade 6 level repertoire at the time she stopped lessons). She could not imagine going back so far in the grade levels and, as a result, did not see the popular music exam as a viable option. 
I experienced first-hand the perils of adhering to too fixed a schedule in my own progression through the examination system. My disappointing result on my Grade 10 exam was the direct result of my performance approach goal orientation taking over. I had decided that I had to take the exam at a certain time and paid for it with a sub-par performance due to lack of adequate preparation. While the experience was difficult at the time, I learned a valuable lesson regarding the importance of mastery over efficiency that I have been able to apply in my own learning and in the approach I take to scheduling students' evaluative performances.

The goal orientations of the students who had negative experiences with evaluative performances varied. Performance avoidance goals were evident in students who had experienced difficulty in evaluative performances at some point in the past. For example, one former student described how she left a disappointing exam convinced that she would "never touch the piano again" (FS\#3). This student had previously held strong performance approach and mastery goals, which when not realized, left her doubting her musical potential. She never again entered an exam, too afraid to risk another failure.

Some students had strong mastery goals and were very interested in developing a deep understanding of music and a high level of skill even if they did not have achievement related goals attached to their music learning. As a result, they saw evaluative performances as largely irrelevant. One of the former students described how she viewed festivals and exams as making no real contribution to her music learning.

FS\#5: They seemed like important pursuits in the sense that I was expected to work hard and practice extra for the "big day". But I don't think it ever really sunk in for me - that is, I never felt that it was that important for my musical studies. It seemed like an extraneous pursuit, a rite of passage - something that I had to get done, but that it didn't really matter in the long run....I didn't feel personally invested in them either; so whether I did well or poorly, it didn't seem to motivate or discourage me from my musical studies. 
This student had a strong mastery goal orientation and was passionate about learning music. She eventually went on to study music at an advanced level. However, she saw no direct benefit to her learning as a result of her participation in festivals and exams. In fact, her experiences with severe performance anxiety resulted in an overall negative view of evaluative performances. While she was forced to participate for much longer than she would have liked, she stopped performing in these kinds of events as soon as she became old enough to assert her own opinion. The preceding theoretical perspectives offer useful insight into students' understandings, values, and goals and how these characteristics relate to experiences with evaluative performances. In order for a student to have positive experiences with evaluative performances, he or she needs to have some level of intrinsic motivation related to music learning as outlined in Organismic Integration Theory. While intrinsic motivation to participate in evaluative performances is likely impossible (due to the unavoidable focus on results), students who feel positively about their participation in festivals and exams are generally functioning at the level of identification or integration. These students are willing to delay gratification when working on the aspects of the curriculum they find less appealing. Students who have positive experiences with evaluative performances are motivated to expend effort and to practice strategically because they see these two factors as the main reasons for success. Because they can control their efforts, they expect to be able to succeed when they perform. They value the potential outcomes of participating in evaluative performances; namely, enhanced music learning and formal recognition of achievement. These two values point to the combination of mastery goals (the development of deep levels of understanding and high levels of skill) and performance approach goals (the achievement of a specific result). 
In contrast, students who have had negative experiences with evaluative performance can lack intrinsic motivation for the kind of music learning that is required for participation in evaluative performances and are often externally regulated when participating in evaluative performances. They may attribute the outcome of their evaluation to external factors that are outside of their control, such as the whim of the adjudicator or a lack of ability. Because of this lack of control over the outcome of the performance, these students can lack confidence leading up to the evaluation and do not expect to succeed. In some cases, students who had negative experiences with evaluative performances did not value the formal recognition of achievement that is one of the main features of participation in festivals and exams. These students sometimes set performance avoidance goals for themselves, seeking to avoid future participation in evaluative performances in order to avoid the possibility of a negative result.

\section{Composite narratives.}

The following narratives summarize some of the motivational characteristics that influence the quality of experience students have with evaluative performances.

\section{Why I play in festivals and exams}

I like playing in festivals and exams because it gives me a goal to work towards. There are some parts of the exam program (like scales and sight reading and ear training) that I find kind of boring, but I know it's important to work on those areas so that I'll have strong fingers and be able to learn new music more quickly. Knowing that I'll have to play those parts for the exam just gives me a little bit of extra motivation to stay focused and practice those parts even when I don't feel like it.

Practicing my pieces isn't much of a chore, because I really love the music. I'm excited to be able to show the adjudicator what I can do. I especially like working on things like dynamics and expression - telling a story through the music.

I've done really well in festivals and exams so far. I think it's because I work hard and I pay attention to the instructions my teacher gives me. I think the students who don't do well probably don't care and that's why they don't do as well. I guess they don't work as hard because they don't really care about how they do on the exam. I feel really good when I know that I'm playing my pieces well. It's exciting when I can listen to the CD and recognize that my 
playing sounds a lot like the recording! I also have a certain mark that I want to get. I'd really like to place in the top three in the festival and get at least 80 or maybe even 90 on the exam. Getting a good mark is a nice accomplishment and it makes all the hard work seem worthwhile. I want to keep going until I get to the end of the exam system. I think it would be a great accomplishment to get the last certificate. Finishing the exams would also mean that I would be able to play just about anything. I want to be able to play like my teacher does. She can just sit down and play anything. There is so much great music out there and I would really like to be able to enjoy it for myself. If I get to the last exam level, I will have developed my skills so that I'll be able to learn things quickly. Being able to learn new music easily will be important because I probably won't have as much time for piano when I'm an adult and have a job and family and stuff like that.

I don't really understand why I have to play in festivals and exams. They just don't seem that important to me. I really enjoy learning music, especially pop songs and movie music, but the music I have to learn for the festivals and exams doesn't really interest me. A lot of the classical pieces seem kind of boring. My friends aren 't interested in hearing them, because they don't know them at all. But the parts I really hate are the sight reading and ear training and all the scales!

Even when I come across a piece that's not bad, it still seems like a lot of work for no reason. I'm not sure how playing in festivals and exams actually helps me learn to play better. I think my parents and my teacher want me to get as many certificates as possible, but I don't really care about the marks. I usually get okay marks - not fabulous, but not terrible. I think I would have to work a lot harder than I'm willing to if I wanted to improve my marks. Even then, I don't know if I would be able to do better. I just don't think I'm cut out to do well in festivals and exams. I get so nervous on the day of the performance that I usually don't play very well, so the marks don't really represent what I can do. Even if they did, I would gladly give up getting certificates if it meant I didn't have to play in any more festivals or exams.

\section{Student as Performer: The thrill of the stage and the throes of anxiety}

The degree to which a student's understandings, values, and goals as a music learner are in line with the demands of the evaluative performance contributes to whether or not the student will have a positive experience with evaluative performances. Equally important are the student's characteristics as a performer. The following section will discuss two aspects of students' performances experiences: the excitement of being on stage and the challenge of dealing with anxiety. 
Evaluative performances can be extremely stressful events, as they represent the culmination of months of hard work. Many students attach very strong emotions to the outcomes of evaluative performances and want to avoid disappointment at all costs. For some students, the actual performance is simply a means to an end; however, other students relish the opportunity to play for an audience and to share their musical ideas. Students who enjoy performing and who can do so confidently are much more likely to feel positively about their experiences participating in festivals and exams, while those who battle with crippling performance anxiety often dread participating in evaluations.

Several of the students interviewed described the thrill of being up on stage, sharing their musical ideas with others. The students who enjoyed performing felt proud of their music and wanted to show their family and friends what they could do. One current student (CS\#4) described with great enthusiasm her varied involvement in the performing arts (in addition to piano lessons, she was also studying voice and musical theatre). Her outgoing, bubbly personality was evident in our interviews, and I could easily imagine her enjoying being in front of an audience. When asked to tell me about her upcoming festival performance, she said she was "excited" (CS\#4) because she would have an opportunity to "play for an audience." Her parent also described how this student loves to be the "centre of attention" (P\#4) Another student (CS\#1) described how her love of performing was what she most enjoyed about learning the piano. For her, being able to "show other people" what she could do was a highlight of music study. Her intense enjoyment of performance could be characterized as a flow experience (Cziksentmihalyi, 1991).

Other students would do anything to avoid being in the spotlight. One former student described how, as a young child, she realized that she was not cut out to be a performer: 
FS\#5: [B]ecause I'd been a nervous performer ever since I was a little kid, they [my teachers] felt that the more that they pushed me into participating [in evaluative performances], the more that it'd help my nerves. It never did. 25+ years later, I feel no different than I did at age 4 (re: nerves), and I'm okay with that. I've been okay with not performing in public; this is something that I accepted a long time ago, like when I was 7 years-old (when I realized what kind of a performer I was and I was okay with that). It just took my teachers a lot longer to be convinced that I'd probably never change.

This student is introverted and reflective and, for her, making music is an intensely personal process. Sharing that process with others involves too much vulnerability. While she experiences some anxiety in other situations, musical performance is more stressful than any of these other events, such as school presentations. Later in her interview, she described how coping strategies, such as breathing exercises and visualization, were not very effective in managing her anxiety and she has simply tried to avoid performance situations that make her uncomfortable. Unfortunately, she endured many years of painful performances because her early teachers did not understand the severity of her performance anxiety.

Interestingly, students had differing views on the level of stress involved in participating in recital, festival and examination performances. For many students, recitals were especially enjoyable, as they provided an opportunity to perform and share musical experiences with others without the added stress of being judged (FS\#4). The teachers reinforced the idea that recitals served as celebrations of what the students had learned over a period of time. The absence of an adjudicator meant that the focus was simply on having fun and enjoying music. The expectations were generally less stringent than those of an evaluative performance. For example, the teacher of the current students said that she does not require her students to memorize their recital repertoire. Students would generally perform fewer selections for a recital than they would for an exam. Interestingly, some the students who described being the most anxious about festival and exam participation did not have the opportunity to play in regular recitals. These less stressful 
performance opportunities could play an important role in building students' resilience to the stress of performing in situations in which the stakes are higher.

For some students, the same kind of enthusiasm evident in their recital participation carried over into performing in festivals. While playing in a festival was still more stressful than playing in a recital for family and friends, the common element of having an audience made the experience exciting for many students. One former student (FS\#3) described the thrill of being up on stage, performing for a crowd. She was very successful in her festival performances, and this helped to build her confidence for each successive event. The students who felt confident in their own abilities also appreciated the opportunity to hear other festival participants' performances and did not feel threatened by possible comparisons. For example, CS\#4 described enjoying the social aspect of festival performances.

In contrast, the students who experienced higher levels of anxiety and who felt less confident in their ability to succeed dreaded the possibility of public humiliation when performing for a larger audience. One of the former students stated vehemently that festivals made her "want to quit" (FS\#2). The anxiety she felt in any performance situation was particularly heightened when there was an audience to witness her potential struggles.

For the students who enjoyed performing, exams were sometimes uninspiring. One student (CS\#4) described how preparing for an exam was so much work for an audience of one person. Particularly because examiners are trained to remain very neutral during the examination process and not to give immediate feedback to students, there is very little reward for the student who enjoys basking in applause at the end of a performance. However, the students who found public performances more stressful often preferred performing in exams. For these students, an exam presented a less risky scenario, as the possibility of humiliation was less when there was 
only one person to hear the performance For example, one former student (FS\#2), although adamant that she would never play in a festival again, stated that she might consider participating in an exam in order to gain qualifications for teaching beginning students.

I could identify with the latter group of students, as I did not enjoy any kind of public performance. Performing for an examiner was particularly stressful; however, I felt that in this setting, I at least had the solace of knowing that if I played very poorly no one but the examiner would know. I generally avoided festival performances, as I could not face the stress of potentially being humiliated in front of a larger audience and, worst of all, in front of fellow students and competitors.

All of the participating students described some level of performance anxiety. The extent to which they experienced this phenomenon had a significant impact on how they experienced the evaluative performance. Their experiences ranged from manageable to completely overwhelming. Many students described physical symptoms of anxiety, such as shaking hands, dry mouth, nausea, lightheadedness, and difficulty seeing, in addition to emotional reactions, such as overwhelming fear and feeling threatened. While some students felt that they were able to manage their levels of anxiety so that it did not interfere with the quality of their performance, others felt that they were never able to perform at their potential because of anxiety. I also have vivid memories of experiencing a variety of physiological symptoms over which I felt I had no control and feeling as though I could never recover from the negative effects of a poor performance.

For some students, the majority of their experience with performance anxiety was isolated to the day of the performance and provided a heightened sense of alertness that helped their performance. The nervousness that they might feel leading up to the performance served to 
motivate them to be dedicated in their practicing on days when they might not otherwise want to work hard. For example, CS\#4 described some nervousness while performing, but no major stress leading up to the event. In these cases, performance anxiety was not a negative experience, and was outweighed by many other positive aspects of the performing experience, such as having the opportunity to share their musical ideas with a live audience.

For other students, performance anxiety was a very unpleasant part of participating in evaluative performances. There were a number of conditions that contributed to increase performance anxiety. One of the survey participants eloquently described some of the factors that influenced her experiences with performance anxiety:

FS\#11:I experienced the most anxiety in exam situations. I found it very intimidating, but I think part of the problem was that I was not always prepared, and yet because I had paid for the exam months in advance, my teacher still made me take it. I also found I was more anxious at the beginning of my exams because I had to get used to the piano I was playing on - I think it would be better if we were able to play on the piano first (just very briefly) to get used to the touch - this would have prevented some anxiety). I also found exams intimidating because I knew that my adjudicators from year to year had not always been consistent. I would play something (I thought) very well, and get a bad mark, and then play poorly and get a good mark. It depended on the adjudicator, so I had anxiety just wondering what exactly I'd have to do to impress THIS adjudicator. There was anxiety because you never knew what exactly they were looking for, just that you had to play it "right."

All of these situations point to a lack of control on the part of the student. In cases in which she was unprepared, she was forced to participate in the evaluation in spite of the fact that she felt unready to do so. In the other cases she describes, she was faced with an unknown, either an unfamiliar instrument or an examiner with unknown expectations. Her perception of examiners' assessments as being quite arbitrary could point to a lack of expertise on the part of her teacher or a difficulty with her own self-assessment of her performances. 
One of the current students gave a vivid description of her experience with performance anxiety during her festival performance. She describes how her anxiety altered her perspective of the whole room:

CS\#3: I felt small at the beginning, like really tiny. Everything was getting bigger and I was just like "I don't want to do this." And it was kind of like, you know how sometimes when you get scared, it's like everything, everybody else is evil and your just like a little tiny mouse that's about to be squished or something.

This student's intense experience exemplifies the irrational aspect of performance anxiety. While there was no real threat to her safety even in the event of a poor performance, her anxiety resulted in a perception that she was in danger.

Several students described how the importance of the performance increased their levels of anxiety. For most, exams were the most significant (and therefore, most anxiety-inducing) performances. One of the survey respondents offered the following description of her experiences with performance anxiety:

FS\#7:I would feel most anxious in the performances I felt were really important, like exams and rated competitions. Performances such as end-of-year recitals and private performances for family members were often more relaxing. Any performances in which I could play with the music score in front of me did not produce any feelings of anxiety.

For this student, an unsuccessful outcome in an exam or competition was a much more frightening prospect than a poor performance in a less formal setting. Playing from memory was particularly intimidating, as not having the music in front of her as a kind of security blanket made the outcome of the performance seem much less certain. This student's experience is consistent with research that has shown a strong link between perfectionism and performance anxiety (Sinden, 1999, p. 33). Students who care deeply about achieving a particular result are more likely to experience high levels of anxiety, as they perceive the consequences of not meeting their goals to be devastating. 
Performance anxiety had far-reaching negative consequences for some students. In some cases, extreme anxiety was a contributing factor in the student's decision to stop taking lessons or to stop playing the piano entirely. One former student described feeling obligated to play in front of her school mates, who were less than appreciative of her performance:

FS\#2: I once had to perform in front of my music class at school and at the very last minute my audience went from 11 people to 500 people (long story short, the entire student body showed up in the cafeteria at the wrong time). I started crying on stage because I was so nervous. My music teacher gave me the option to back-out of the performance but I knew I wouldn't be able to live with myself if I chickened out. I performed and during the performance someone yelled "get off the stage". He was suspended for three days. It was an awful experience. As an adult, my fear of playing in front of people hasn't improved. I recently played at a recital and my fingers were shaking so badly and I felt so weak, light-headed and dizzy that it was hard to play forte as I simply didn't have the strength in my hands to press the keys harder.

Even years later, this student remembers vividly how traumatized she felt when she was exposed to a very stressful performance situation. She still finds public performance difficult and tries to avoid performance situations whenever possible.

Several students described the impact of one particularly traumatic experience on future anxiety levels. As previously described, the former student who had a panic attack and failed her first conservatory exam still experiences intense performance anxiety related to the piano. Although she plays sometimes for her own enjoyment or for her immediate family, she avoids playing in public and stated emphatically that she would never be able to play for someone who was knowledgeable about music or who might be perceived to be judging her performance. Another former student, who completed the survey, described how an experience with a memory slip during one performance had resulted in ongoing difficulties with anxiety. When asked to elaborate on experiences with anxiety, she wrote:

FS\#10:Was fine through all evaluations until RCM 7 - experienced bad memory lapse during a performance, causing me to skip half a page. Experienced horrible stage fright ever since (including shaky hands) and made noticeable mistakes in 
almost every performance/evaluation (particularly in regards to memory blanks) until my university audition (during which I told myself that I absolutely cannot afford to mess up). But even now, almost every performance (big or small) makes my hands shake and fogs my brain until I can no longer concentrate fully on the music.

For this student, one significant mistake led to a perpetual cycle of worrying about having a memory lapse, experiencing physiological and psychological symptoms of anxiety, and having more memory lapses as a result. While her difficulties with performance anxiety did not stop her from pursuing advanced music studies, they did rob her of any joy that might have previously been connected with performing. Her description emphasizes the sense of lack of control that many sufferers of performance anxiety experience, as the anxiety seems to take over regardless of the desires of the musician.

There are differing theoretical understandings of performance anxiety (Elliot and Dweck, p. 151), including the performance deficit theory and self-regulatory theories. The first perspective holds that students experience anxiety as a result of negative self-referent cognitions and that anxiety influences motivational and cognitive processes that affect performance. In the second way of understanding anxiety, students' anxieties are brought on by thoughts of failure (Sinden, 1999, p. 21). These two perspectives are complimentary, as a student could easily have a negative self-concept, engage in self-handicapping behaviours, and also be worried about the ramifications of failure.

Performance anxiety appears to be debilitating for two main reasons. First, it manifests as physiological and psychological symptoms that are highly unpleasant in themselves. Participants described shaking hands, dry mouth, nausea, vision disturbances, and lightheadedness, among other physical symptoms. Feelings of fear and hopelessness were also common, as students often feel out of control when they are experiencing high levels of anxiety. It is understandable that a 
student who has experienced these negative symptoms would want to avoid any future experiences.

Additionally, performance anxiety can have a negative effect on the outcome of the performance (Sinden, 1999, p. 7). When a student's symptoms are severe enough to interfere with concentration or with the physical ability to play the instrument, he or she is more likely to make mistakes, have memory lapses, or perform in a way that does not convey the full expressive aspects of the music. If students receive lower marks as a result of these difficulties, they could begin to doubt their abilities as musicians.

The participating students who were able to manage their performance anxiety had several characteristics in common. They were generally confident and enjoyed aspects of performing and being on stage. For some of these students, anxiety produced extra energy that resulted in a higher quality performance (Sinden, 199, p. 8). Returning to the ideas explored in the previous section, they also valued the potential positive outcomes of participating in the performance. As a result, they were willing to experience some of the negative aspects of performance anxiety if it meant accessing the benefits of having completed the performance. These students were also able to mitigate their anxiety by ensuring that they were well-prepared for their performances. Preparation gave them a sense of control over the experience and the outcome of the performance. In addition, these students had supportive parents and teachers who provided security and reassurance that the student would be valued regardless of the outcome of the performance. 


\section{Composite narratives.}

The following composite narratives illustrate some of the varied perspectives the

participants held regarding the experience of performing for an audience, in both evaluative and non-evaluative settings.

\section{Two views on performing}

I've always loved to be on stage. I take musical theatre classes and voice lessons as well as piano because I think you can never have enough music in your life. Performing gives me a chance to share the music I love with other people. It makes all the hard work I put into learning my music worthwhile. It's so rewarding to see the audience enjoying my music and it feels really great when people come up to me after the performance and tell me how well I played.

I really enjoy recitals and festivals because they give you the chance to play for an audience. Recitals are the most fun because there isn't as much pressure. It's just about showing your family and friends what you can do. Festivals are a little more nerve-wracking, but I still like playing for an audience and getting the applause when I'm finished. Exams are more about getting the certificate and being able to move on to the next level. Playing for one person isn't very exciting.

I get nervous right before I perform, but I usually feel okay once I start playing. I don't think the nerves affect how I play. I'm still able to play well even when I'm nervous. In fact, sometimes I think I play better because I'm a bit nervous - it makes me more focused. The nerves are part of the thrill of performing. It's really exciting to get to the end of the performance and think "I did it - and everyone liked it!"

Performance and anxiety were always connected when I was studying the piano. I can't remember a time when I had to play for an audience when I didn't feel nervous. My hands would shake, the room would spin, my mouth would go dry, and my stomach would be filled with butterflies.

For me, music is a very private experience. I feel very deeply when I play music, and I don't like to share that with other people. I tend to be pretty reserved, so any kind of public performance, even oral presentations for school, is challenging for me. There is something unique about the vulnerability involved in playing music, though. Sharing my music is too risky. What if the audience doesn't like my playing? It's almost as if they're saying they don't like me.

My teacher and parents used to sign me up for festivals and exams every year. Nobody seemed to care that I didn't want to perform. Festivals and exams were just part of learning the piano. Eventually, I got old enough that I was able to stop. I've never felt such relief. I think my parents and teacher expected that if I kept performing, I would become more confident, but that just didn't happen. I don't think it was worth the torture of the nerves to get a few certificates. Most of the time, I didn't even do that well. Even if I was well-prepared, I was much too nervous at the performance to get top marks.

I still love music, but any future studies would have to be on my own terms. I would want to take lessons to improve my skills, but not perform in public. Sometimes, I've considered trying 
to upgrade my qualifications so that I could teach a few beginning students, so I might do an exam if I had to, but no more recitals and no more festivals. I'm old enough now to stand up for myself and not be pushed into doing something that makes me so uncomfortable.

\section{Issues for Further Consideration}

The preceding discussion outlines some of the personal characteristics that appear to be related to students' experiences participating in evaluative performances. However, it is impossible to say from this research if there is a causal link between these characteristics and how students experience festivals and exams. It is quite likely that there is a circular relationship in which certain characteristics make students more willing to attempt an evaluative performance and which may also contribute to students' experiencing success. For example, a student who is internally regulated, attributes success to effort and ability, expects to succeed, values learning and formal recognition, and sets mastery and performance approach goals is setting him- or herself up for an enjoyable and successful experience, particularly if he or she enjoys performing in public. A confident, well-prepared student playing music that he or she loves is likely to be successful and to feel positively about his or her experience participating in an evaluative performance. The positive reaction to the experience would reinforce the understandings, values, goals, and performance skills that contributed to the student's success. 


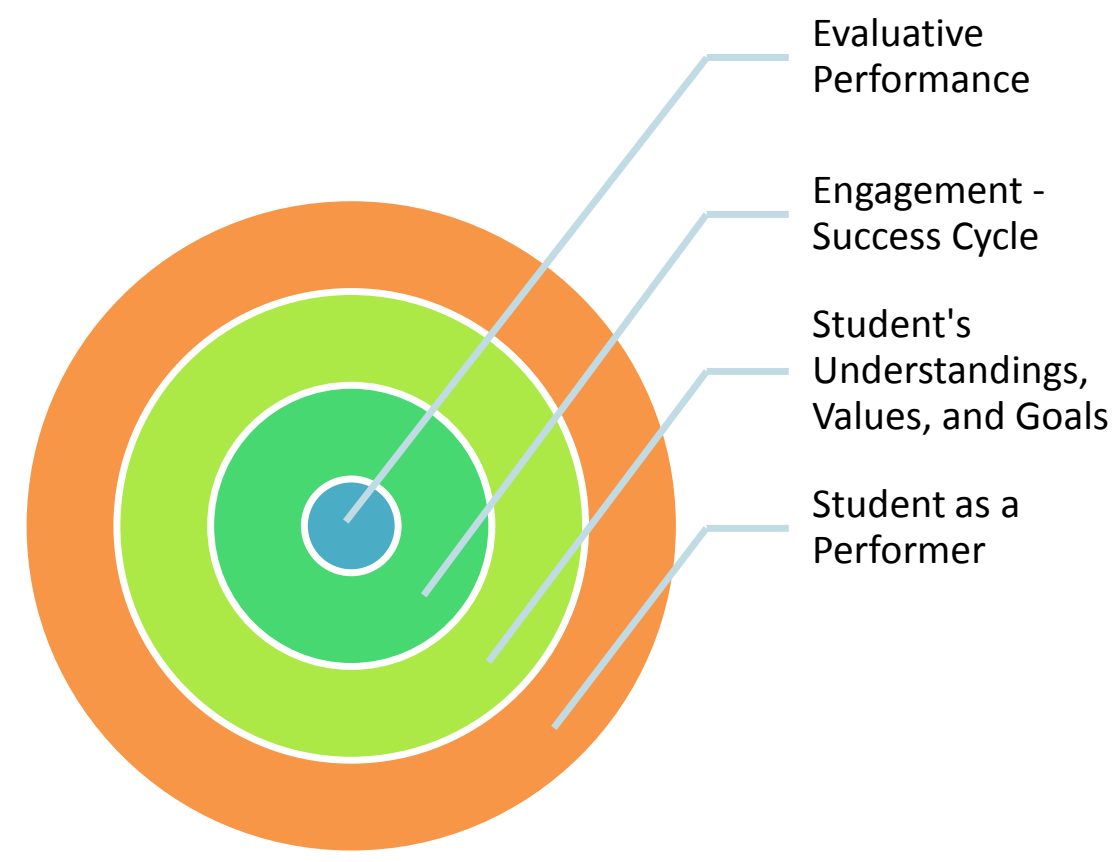

Figure 9 Personal Characteristics that Influence Experiences with Evaluative Performances

An important consideration for teachers is whether and to what extent these personal characteristics can be changed. Can teachers help students develop in ways that will make it more likely that students will be engaged in evaluative performances, or should teachers focus on assessing the characteristics that are already present in the student so that a decision can be made about whether an evaluative performance would be an appropriate choice for that particular student?

While involving students in decisions regarding their own learning is essential to maintaining student engagement (Custodero, 2002), it is also possible that teachers and parents can make recommendations, based on their experience and knowledge, which might not have occurred to a particular student. Should teachers and parents accept whatever the student verbalizes regarding his or her preferences for participation in evaluative performances or try to influence students' decisions if they believe that a student would benefit from a particular course 
of action? For example, the second current student was initially very reluctant to take an exam; however, she consented to try one at the urging of her parents and teacher, who believed that she had the potential to be successful and that the experience would contribute to her learning. At the time of data collection, she was eagerly planning her future involvement in evaluative performances, hoping to reach Grade 10 by the end of her high school career. Had the adults accepted her initial refusal, she might have missed out on what has turned out to be a very satisfying experience.

A flexible approach to instruction and assessment allows for optimal alignment of students' diverse characteristics and the demands of evaluative performances. Some students, such as the one described in the above paragraph, might benefit from the encouragement of their parents and teachers to attempt an evaluative performance that they might not otherwise feel confident enough to try. Other students need to be afforded the opportunity to change their minds after pursuing evaluative performances for a period of time. One former student (FS\#1) described how, as she progressed through the exam levels, the amount of work that was required to be successful became too burdensome. She found the required repertoire dull and the practicing tedious and decided that the investment of time and energy that would be required to complete the next exam was simply not worthwhile. While this student was not forced to participate in evaluative performances in her earlier years of study, her mother strongly wished for her to complete a Grade 8 exam. When the preparation process became too onerous, her parents, albeit reluctantly at first, went along with her decision to discontinue lessons and exams. With their support, at the time of data collection, she was happily engaged in a variety of enjoyable and personally relevant musical pursuits. 


\section{Summary}

The student's characteristics are the first determining factor in whether participation in an evaluative performance will be a positive experience. These characteristics include the student's understandings, values, and goals related to music study and his or her abilities and inclinations as a performer. While some of these characteristics can change over time, many are likely so ingrained in the student's personality that it is better for teachers and parents to focus on finding instructional strategies that are well-suited to the student's current state than to attempt to change the student to meet the demands of the evaluation. Giving students an opportunity to voice their opinions regarding their own participation is crucial. Teachers and parents must also be flexible in their expectations, as students' views can change based on their prior experiences or changes in the demands of potential future evaluative performances. The last section of this chapter hints at the importance of the relationship triad formed by the student, the parent(s)/guardian(s) and the teacher. This dynamic set of relationships is so important to the student's overall experience that it forms the subject of the following chapter. 


\section{Chapter 7 The Importance of the Relational Context of Learning}

The previous chapter concluded with the statement that, while there are a number of personal characteristics that influence whether or not a student will experience participating in evaluative performances in a positive way, parents and teachers play an important role in assessing whether the student's characteristics are a good match for the demands of the evaluation. Indeed, the relational context in which the student is undertaking his or her learning and participation in evaluation has a profound influence on whether the student has a positive experience. All of the students who described negative experiences with evaluative performances also described some level of relational difficulties with their parents, teachers or both. These difficulties ranged from adults who seemed disconnected from the student and unable to assess how best to support the student's learning to emotional and physical abuse. Conversely, the students who had had positive experiences with evaluative performances described several ways in which their parents and teachers supported enjoyable, meaningful music learning. To begin, I will highlight the unique roles of parents and teachers, followed by a discussion of the shared contributions of these important adults. Following a general discussion of the roles of parents and teachers, I include several participant narratives to illustrate positive and negative relational contexts. The chapter also includes a brief discussion of the roles of the extended family and peer groups, as these relationships also influence students' engagement in learning.

For the sake of simplicity, I use the term "parent" in reference to any adult who has a parental role with regards to the student's music lessons, even if that person is not necessarily the student's main care-giver in other areas of life. This chapter is written with the assumption that the student is a minor, as all of the students who participated in this study were either minors at the time of data collection or were discussing experiences that occurred when they were minors. 


\section{The Unique Role of the Parent}

Parents have an extremely important role to play in the musical education of their children. In fact, parental support is a determining factor in whether or not students continue to pursue music lessons (Davidson, Howe, Moore, and Sloboda, 1996). While some students have a strong desire to learn music even before they begin lessons, as young children, they require the permission and support of their parents (and sometimes other family members) to begin formal instruction. In previous chapters, I have described several students (for example, CS\#2, CS\#4, FS\#2, FS\#3) who were very eager to begin lessons, often because they had an older sibling or other relative who played the piano and who served as a source of inspiration for their own musical interests. In these cases, the parent's role was to be attentive and responsive to the child's desire to learn music.

My own introduction to music study was a response to my environment and to my intrinsic motivation to interact with music. My parents provided musical stimuli in my home environment through singing for me, playing recorded music and providing an instrument (the keyboard that appeared one Christmas). I was also exposed to music through my involvement in a church community. While my parents valued music enough to include it my daily life, they did not have any specific ambitions regarding my future musical education. When I was eventually registered for lessons, it was after several years of requests on my part for more formal musical training.

While some of the participating students' lessons began as a result of their own desires to learn, other students' lessons were initiated entirely by their parents. If the students were enrolled in a program (whether group classes or private lessons) that was interesting, engaging, and led by 
a caring and supportive teacher (Woody, 2001), they tended to want to continue learning music even if the idea originated with their parents. However, when students were enrolled in programs that did not meet their individual needs or with teachers who were not a good fit, the overall experience of learning the piano was much less positive. For example, in some cases (such as FS\#4 and FS\#5), students were forced (or at least strongly encouraged) to continue participating in evaluative performances because their parents felt that their children's participation was an indication of money well-spent on lessons. While it is understandable that parents do not want to feel that the time, money, and effort they have invested in their child's musical education has gone to waste, parental expectations can put pressure on a child that ultimately makes learning the piano less enjoyable (Yun Dai and Schader, 2001, p. 25).

Whether the idea of music study originates with the child or the parent, one of the first ways in which parents demonstrate their support for their children's musical education is in choosing a teacher for their child. In most cases, choosing a teacher seemed to be a matter of convenience. Parents generally chose teachers who were located close to them or who had been recommended by a friend or acquaintance. In some cases, the students' families had met the teacher in some other context, such as a church. My own experience is also reflective of this phenomenon. My first teacher was selected because of a prior acquaintance through our church; however, in spite of a prior acquaintance, she was not the best fit for my learning needs. My second teacher was also selected through personal acquaintance; this time, I studied with the daughter of my father's mechanic. While, in the end, she was very well-suited to meet my musical needs at that stage, the good working relationship I had with her and the resultant learning that took place were thanks to fortune or providence rather than to an intentional search for the best possible teacher for my needs. 
It would appear, based on this research, that few families conduct a systematic search for a piano teacher. Perhaps parents may not know what they should look for in a teacher or are unaware of resources, such as professional association directories, which can provide assistance in this area. However, given the importance of the child's relationship with the piano teacher, it would seem that it would be important for parents to give careful consideration to the selection of a teacher (Duke, Flowers, and Wolfe, 1997). Finding the right teacher for a particular student can make the difference between a student who is highly engaged, enjoying music learning, and experiencing positive effects on their self-concept, and one who is bored, frustrated, anxious, or feeling badly about him- or herself.

Once a child is registered for lessons, parents provide essential practical support, such as paying lesson tuition, driving students to lessons and providing an instrument on which students can practice. Parents also play an important role in helping students develop a consistent practice routine, whether that means sitting down with the student or simply providing opportunities for the student to initiate his or her practice sessions. Without this financial and logistical support, students would be unlikely to achieve success. The parents in this study were dedicated and provided consistent support that allowed students to derive the most benefit from their lessons.

Parents also contribute valuable expertise to their children's educations, as they know their children well and can provide teachers with information on their child's unique interests, motivations, and learning style. This knowledge of the student as a person and as a learner is one half of the puzzle of matching the student's characteristics with the demands of the evaluative performance. The parents and guardians who were interviewed for this research all seemed to be very in tune with their children's personalities, interests, and learning styles and were able to talk about how these characteristics influenced how the student experienced her musical education. 
For example, one parent (P\#4) described how her daughter loves to be the centre of attention and enjoys all kinds of public performances as a result (P\#4). Another described her daughter's perfectionist tendencies and the impact that this characteristics has had on the student's involvement in evaluative performances $(\mathrm{P \# 2})$. All of the participating parents were very appreciative of how their children's teacher also responded to their children's interests and learning styles.

Unfortunately, some of the former students described parents who were less in tune with or less responsive to their individual needs. In previous chapters, I described a student (FS\#2) who was regularly forced to play for her extended family, in spite of the fact that she experienced a great deal of anxiety in any kind of public performance. She felt manipulated by her father, who controlled the financial resources that made her lessons possible. Other students were expected to participate in festivals and exams, even though they found these events to be stressful or found the preparations to be boring and tedious.

Children need their parents' practical support in order to have a successful music learning experience. They also depend on their parents to act as intermediaries when relationships with other adults (such as teachers) become challenging (Macmillan, 2004, p.308). For example, one of the former students (FS\#4) described how she wished her parents had stood up for her when she was being intimidated and physically abused by her piano teacher. When she described the abuse, her parents believed her teacher's assertions that she was doing fine but needed to practice more. By simply accepting the teacher's dismissal of the accusations, the parents allowed the hitting to continue. Another former student (FS\#5) had a teacher who insisted that she perform regularly in festivals and exams, even though she experienced a great deal of anxiety related to her performances. Her parents did not question the teacher's perspective that these evaluative 
performances were necessary, thus allowing the student to continue in a stressful situation for many years. Yet another former student (FS\#3), who was sent into an exam unprepared, wished that her parents had been more aware of her progress in her lessons so that they could have helped her avoid a negative situation that she did not feel she could have foreseen herself at such a young age.

In the cases described above, perhaps the parents felt that they lacked the requisite knowledge to question a teacher's practices or wanted to ensure that they respected the teacher's authority (and that the child did the same). While a parent who constantly questions a teacher's practices could easily make the working relationship untenable, the findings from this research indicate that it is important for parents to be aware of what their children are studying, whether or not the current course of study is interesting and at an appropriate level of difficulty for the student, how their children are feeling about their music studies, and how their children are relating to their teacher. In particular, parents need to act quickly in any instance of suspected abuse.

Because the parent-child relationship is so close, parents have the potential to offer a level of emotional support that cannot be received from anyone else (Creech, 2010). Children who know that they are loved unconditionally by their parents are able to approach their lives with confidence. These parents provide a soft place to land when their children encounter difficulties and disappointments. The parents interviewed for this study exuded warmth and love for their children, and the students were confident and happy.

Parents also play an important role in encouraging students to approach their music studies in a disciplined way (Creech, 2010). Some students need more reminders to practice or need more assistance from parents to navigate their practice assignments. However, other 
students work more effectively when they are allowed to work independently with minimal parental interference. One of the parents $(\mathrm{P \# 2})$ described how she did not respond to nagging as a child and had decided not to use this strategy as a way to motivate her children to practice, as she felt it would eventually result in them losing interest. Both of her children (a daughter who participated in this research and younger son, who also played the piano, but was not part of this study) were enthusiastic in their practicing, reinforcing this mother's intuition that giving her children ownership over their practicing was the best approach.

My parents were similarly "hands-off” with regards to my practicing. In fact, I was motivated to practice in an effort to show them that I was serious about my music studies. I had learned, following my flagging motivation while preparing for my Grade 1 exam, that if I did not show sufficient initiative my lessons could be cut off at any time. Viewing my music studies as a privilege rather than as a right or an obligation provided me with an impetus to continue being diligent, to show that I was worthy of the continued investment in my musical education.

As described by the participants in this research, parents play a pivotal role in all facets of piano students' development. They are involved in the earliest decisions about student enrolment in music lessons and make music study possible through practical, financial, and logistical support. Some of the students who participated in this research described parents who were unaware of difficulties they were experiencing or who were too caught up with their own expectations of what their child's involvement in music lessons should entail to notice that their child was unhappy. However, most students had parents who were astute in ensuring that their children's activities corresponded with their needs and interests. These parents provided emotional support and helped their children negotiate their relationships with their teachers so 
that music learning and participating in evaluative performances was an enriching and enjoyable experience.

\section{The Unique Role of the Teacher}

The teacher is the subject area expert in the relationship (Davidson and Scutt, 1999). Competent teachers bring a wealth of knowledge related to repertoire and skill development. They are able to demonstrate high-quality performances as a result of their own musical skill. The teacher is an important figure in student's lives, providing inspiration and acting as a role model (Cameron and Carlisle, 2004). Students' concepts of what it means to be a musician and pianist are profoundly shaped by their interactions with their teachers. One of the former students (FS\#3) described with great enthusiasm how her first teacher regularly played for her. This opportunity to bask in personal performances each week was one of the highlights of her lessons and an aspect that she missed when she transferred to another teacher who did not perform for her. Several of the current students described how their teacher could easily sit down and play anything. These students held up their teacher as a model whom they wished to emulate. She was the embodiment of their own long-term musical goals.

I also experienced the power of the teacher as a role-model when I began my musical studies. While my first teachers were not highly trained, they provided insider knowledge regarding more advanced piano studies. I related easily to them and saw their achievements as being attainable for myself. As they described the music they were learning, and sometimes played for me, I developed a desire to follow in their footsteps, assuming that if they could do it, so could I. My subsequent teachers, who had higher levels of training were also important sources of inspiration, as they regularly played for me. One teacher in particular would often 
practice immediately before my lesson time. If I arrived early, I would stand on the doorstep and listen to him practice for a few minutes before knocking on the door. When I began my university music studies, I was immersed in a new world in which music was ever-present. My teachers provided immense support as I adjusted to a new environment and supported my goals for future studies. All of my teachers helped me develop my concept of what it means to be a musician and a music teacher.

The teacher's content knowledge is crucial if students are to be successful in evaluative performances (Davidson and Scutt, 1999; Tye, 2004). In addition to knowing about aspects of the music, such as technique and stylistic concerns, teachers must also be familiar with the requirements and expectations of the evaluative performance in which the student will participate. Two of the teachers who participated in this research (T\#1 and $\mathrm{T} \# 2)$ were in training to become examiners at the time of data collection. Their training gave them a thorough understanding of what would be expected of their students who chose to enter examinations. Their students had confidence in the fact that they would be well-prepared for their evaluations because of their teachers' insider knowledge of the process. Several of the current students and their parents mentioned their confidence in their teacher's knowledge and guidance. One of the parents referred to her as "an amazing teacher" (P\#2) who knew how to reach each student effectively.

Not only do excellent teachers know how the final musical product should sound, they are also aware of the incremental steps by which students achieve competence. An ability to break down complex concepts and skills into manageable "bites" for students is an invaluable skill for teachers (Custodero, 2002). In order for teachers to reach a variety of students, they must also be able to explain ideas in a variety of ways according to how the student learns best 
(Pitts, 2004). Part of breaking down goals into small, achievable steps is providing students with specific practice strategies that will enable the student to make progress between lessons (Miksa, 2006). These strategies must be tailored to both the task and the abilities and interests of the student. While inexperienced teachers may experience difficulty connecting specific teaching behaviours with specific learning outcomes (Frederickson, 2007), more experienced teachers gain the ability to refine their practice in direct response to a student's grasp of a particular concept.

The lesson observations provided me with an opportunity to see this kind of pedagogical skill in action. The teacher who was part of the observation employed many different strategies to keep her students engaged and to ensure that they would be well-equipped for successful practicing at home. For instance, she encouraged students to play slowly if they were experiencing frequent stumbles. She pointed out patterns in the music that would aid students in memorization. Students who were having trouble maintaining a steady pulse were encouraged to use the metronome or to play along with the sample CD in order to become accustomed to playing without speeding up and slowing down. The teacher also provided specific strategies, such as saying finger numbers out loud while playing scales, to help students with particular technical challenges they encountered in the music. To ensure that her students knew exactly what they needed to practice following their lessons, the teacher recorded detailed instructions in students' notebooks. She also made a CD recording of her directions for the week, including musical examples. In this way, the students did not have to rely solely on verbal descriptions, but could also listen to their teacher playing what they were expected to play.

While the teacher employed a variety of strategies to help her students achieve accurate performances, she also ensured that her students presented a convincing and captivating 
interpretation of their music (Davidson, Pitts, and Correia, 2001). She maintained a constant focus on the quality of sound her students produced and cited this aspect of her teaching as a particular strength. She also encouraged her students to reflect on the images and emotions that were conveyed in their music. Her students received many commendations from adjudicators and examiners regarding the musicality of their performances. They also appeared to have internalized her emphasis on musicality, as many of her students referred to expressing emotions and exploring different moods through music as their favourite part of learning the piano.

Because excellent teachers have extensive knowledge of curriculum and evaluation, they are well-equipped to help students set appropriately challenging goals for themselves (Custodero, 2002). The teachers in this study helped students select the level of the evaluation as well as the timing of the performance in order to maximize the chances of success for the student. In line with Cziksentmihalyi's (1991) ideas regarding the importance of matching challenge and skill, choosing the appropriate evaluation at the right time also ensures that students remain engaged in the learning process, without feeling bored or overwhelmed. Achieving this delicate balance requires careful guidance from the teacher. All of the current students were confident that they were well-prepared for their upcoming performances, but they had not yet reached the point of losing interest in their required pieces. With years of experience upon which to draw, their teacher was able to judge the timing of exam and festival preparations with great accuracy. Some of the students who had had negative evaluation experiences described entering evaluations unprepared and experiencing failure and high levels of anxiety as a result. More commonly, students worked on the same few pieces for a very long period of time in an effort to ensure that they would be ready for the exam. One former student (FS\#4) described how she found her lessons to be extremely boring because she would work on the same three pieces for 
months on end. Her experience is in line with Tye's (2004) concern that students who spend too much time working on exam repertoire become bored as a result of their limited musical diets. While helping the student set appropriate goals is important in any context, it can be challenging when the teacher does not yet know the student well. The teacher of the current students described how she avoids exams altogether for the first year of working with transfer students. In this way, she and the student able to become acquainted, and the teacher has the opportunity to help the student catch up in any areas that might be lacking without the pressure of an impending evaluation. Taking the focus off exam preparation also helps to mitigate any disappointment the student might feel if he or she has to spend time focusing on weaker areas or relearning certain skills that might have been missed or incorrectly learned with a previous teacher.

The teacher's role is crucial in inspiring students to become interested in evaluative performances and in ensuring that students are well-prepared for their evaluations. Teachers also provide important support as students interpret and reflect upon the results and comments they receive from adjudication. It is crucial for students to have opportunities to reflect on their performance and to engage in self-assessment, as these activities increase students' autonomy and self-efficacy (Lebler, 2007). However, students can benefit from teachers' providing time, space, and prompting for reflection following evaluative performances. The teacher of the current students provided an example of this kind of reflection when she helped CS\#2 debrief after a disappointing festival performance.

Previously, we have examined the authority that is afforded adjudicators and examiners and have discussed the weight that evaluations carry with many students. The current students who participated in this study remembered specific comments from the adjudicators and had 
analyzed their interactions with their adjudicators and examiners in great detail. Their teacher provided a sounding board for interpreting the results and for helping to allay any confusion the students might have. Because they knew that their teacher was also highly qualified and understood the exam and festival process, these students were willing to accept their teacher's explanations of a result that perhaps they did not fully understand. She celebrated their successes with them (for example, by posting a list of student achievements in her studio) and provided consolation if they were disappointed with their performance or with the adjudicator's reaction. Because she could describe personal experiences in which she had had to move past a disappointing result in order to continue her musical career, she was able to offer her students convincing assurance that they still had musical potential even after a disappointment. This kind of support likely could not be offered by a parent who did not have a similar personal experience upon which to base their assertions that "everything will be fine, you're still a good musician," etc.

While knowledge of curriculum and pedagogy is essential if teachers are to engage their students in meaningful learning, perhaps the teacher's most important role is in establishing the social-emotional climate of the lesson (Cameron and Carlisle, 2004). If the music studio is a safe, inviting, inspiring, and caring space, students will look forward to attending their lessons each week (John, 2004). The positive associations with weekly lessons will then carry over into students' independent practicing and overall impressions of the piano. One of the current students included her teacher in her enthusiastic list of what she liked about learning the piano, stating "my teacher's awesome" (CS\#3) when asked to describe her favourite part of piano lessons. For this student, learning the piano was just as much about the relationship she had with her teacher as it was about learning the musical content. By encouraging warm, positive feelings 
in association with the piano, her teacher was making an investment in this student's lifelong desire to engage in music-making.

I have always been profoundly grateful that all of my teachers were warm, kind, and supportive. As a result, I always looked forward to my lessons and had a positive overall impression of music learning. I cringe when I hear other students' experiences of enduring various forms of abuse from their teachers, as I know that for many people music learning has been the source of a great deal of pain. When these experiences are contrasted against those of students who have studied with caring, compassionate teachers, it becomes even more apparent how much the students of abusive or negligent teachers miss.

The relationship a student has with his or her teacher has a profound impact, not only on how students experience their participation in evaluative performances, but also on their impressions of music study in general. Teachers have a unique role that encompasses many different aspects of the learning process. They serve as role-models, providing students with a concept of what it means to be a musician and a teacher. Competent teachers have extensive knowledge of the content and evaluation standards that are used for festivals and examinations, giving them a clear sense of the goals towards which their students are working. Not only do teachers know how the final product should sound, they can break down the learning process into manageable steps. Because experienced teachers are likely familiar with the demands of a given evaluative performance, they are equipped to help students decide if and when a festival or exam is an appropriate goal. Following the evaluation, teachers facilitate students' reflections on their experiences and on the feedback they received from the adjudicator or examiner. Most importantly, teachers control the social-emotional climate of the lesson. A teacher who is warm 
and caring and who supports student ownership in the learning process is likely fostering a love of music and of music learning in his or her students.

\section{The Shared Roles of the Parent and Teacher}

Parents and teachers have distinct, unique roles to fulfill if a student is to have the best possible experience learning the piano and participating in evaluative performances. However, their roles also overlap in some important ways. These include communication with each other and with the student, providing emotional support for the student, and helping the student develop autonomy as a musician and learner.

Because the parent and teacher have different areas of expertise, it is crucial that they develop effective communication strategies to share the information that might be useful for the other party (Pierson, 2005; Melnick, 1991). Many teachers make use of some sort of communication book in which they make note of anything they want to communicate with the student and parents. The time immediately before and after lessons can be an important time for the teacher and parents to touch base, although these conversations tend to be rushed if there are other lessons scheduled around the one in question. Phone calls and emails can also be convenient ways of conducting more involved conversations. One of the keys to effective parent/teacher communication is to ensure that any concerns are brought up quickly before the issue develops into something more serious. In addition, it is crucial that both teacher and parent approach the conversation with a spirit of collaboration. The parents of the current students in this research described how they appreciated the multiple forms of communication offered by their teacher. In the lesson footage, the teacher made reference to the students' communication books and reminded them to bring their blank CDs so that she could record instructions and 
musical models to guide their practicing. She offered incentives for students who remembered all of their supplies, reinforcing the importance of remembering what was discussed in the lesson. Prioritizing effective communication with students and parents ensured that her students derived the most possible benefit from their weekly lessons.

The parent and teacher both play important roles in providing emotional support for the student, especially in potentially stressful situations, such as the time leading up to an evaluative performance (Sinden, 1999, p. 49). Both adults need to provide the student with assurance that he or she is valued regardless of his or her performance. This assurance will help the student to be resilient in the event of a disappointing performance. Parents and teachers also play an important role in helping students maintain perspective on evaluative performances. It is very easy for children or young people to become so focused on the results of one evaluation that they lose sight of how insignificant that event could become later in life. When adults downplay the importance of one-time events in establishing students' worth as people and as musicians and help students focus on enjoyment and on long-term learning (Lacaille, Koestner, and Gaudreau, 2007), students will be more likely to approach their evaluative performances with confidence, knowing that their self-worth and self-concept as musicians can remain intact regardless of the outcome. When a student is successful, the positive emotions that he or she experiences as a result are heightened when parents and teachers celebrate the achievement as well. Parents and teachers also provide an important role in listening to and commiserating with the student in the event of a disappointing result. Encouragement from these important adults can sometimes be enough to help the student "get back on the horse."

Both parents and teachers can play a crucial role in fostering the development of student autonomy and self-regulation. In Chapter Five, we examined the impact of students' having 
ownership over various aspects of their engagement in learning. Skill development is an important aspect of preparing students for independent musical pursuits. One of the teachers who participated in this study described one of her main teaching goals as being "to teach myself out of a job" (T\#2). By this, she meant that she wanted her students to develop the reading, technical, and interpretive skills they would need to learn music on their own. The current students were also aware of the kinds of skills that would be required in order for them to learn new music on their own when they someday stopped taking lessons. Because their teacher presented the future benefits of what they were learning in their lessons, they were willing to invest their time and energy in developing a solid foundation in music reading and technique. Several of the former students described how they now put their skills to use playing the music that interests them. While these students had not necessarily enjoyed every aspect of the exam curriculum, they were grateful that they had developed the necessary skills to learn new music independently.

Students also appreciated being given choices regarding the repertoire they would learn. Several students described going to the music store to select new music that they wanted to learn. While the possible choices for exam repertoire were much more limited, the current students described appreciating the fact that their teacher encouraged their input in building their exam programs. In most cases, she would play a number of pieces for the student who would then make the final choice.

Parents' role in developing students' autonomy revolves around the fostering of selfdiscipline and in encouraging students' positive attitudes towards music study (Davidson, Howe, Moore, and Sloboda, 1996). While parents play an important role in encouraging regular practice and in providing the necessary environment in which students can work on their music learning, their involvement can result in students' becoming too dependent on external regulation. Self- 
regulation is a crucial skill for students who hope to enjoy future successes. It is developed through self-esteem and self-efficacy. Students who are self-regulated have the confidence to pursue goals that are important to them. They are able to delay gratification in the pursuit of a highly-valued goal. The current students were generally quite enthusiastic about their piano studies and, as a result, did not require much parental prodding to maintain a consistent practice routine. One of the parents described how she purposely avoided "nagging" her daughter to practice, as she knew that this approach would result in her daughter resenting having to practice.

The following Venn diagram illustrates the distinct and overlapping roles of parents and teachers, as described by the participants. The teacher`s unique role is to convey knowledge relating to the content and practices of the evaluative performance in a way that is well-suited to the particular student. The parent's unique role is to provide practical and logistical support for the student's musical pursuits and to act as an advocate for the student's needs in conversations with the teacher based on the parent`s expertise regarding the personality, temperament, learning style, and other characteristics. Both important adults contribute to student learning through offering encouragement and emotional support and through providing students with opportunities to develop autonomy and self-regulation. 


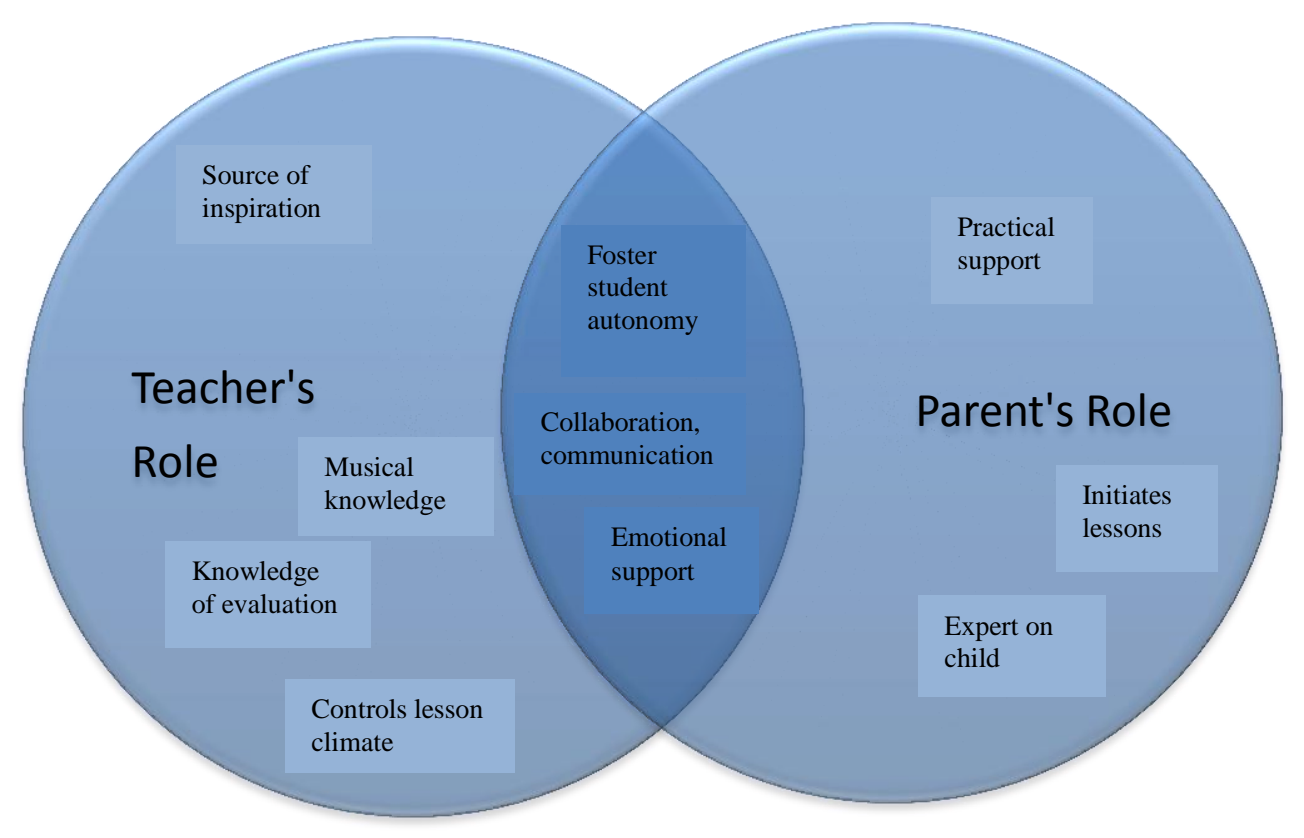

Figure 10 Distinct and Overlapping Roles of Parents and Teachers

\section{Other Important Relationships}

This chapter has focused mainly on the crucial role played by parents/guardians and teachers, as these are the relationships that have the most impact on the student's experiences with music learning and with evaluative performances. However, students also experience many other important relationships that contribute to positive learning experiences. Jorgensen (1997) recognizes the extended family as an important "sphere of musical validity" (p. 45), or a setting in which particular musical values and practices are perpetuated. Several of the students who participated in this study described how they received much-appreciated support from extended family members. One of the current students (CS\#2) described how she learned how to play simple melodies with her great-aunt long before she began taking formal lessons. She continued to benefit from her great aunt's love of music when her family was able to purchase a piano as a 
result of her great aunt's financial legacy. A former student's (FS\#3) interest in the piano was sparked when, as a very young child, she would play her grandparents' piano. Her grandparents took note of her fascination with the instrument and ended up giving it to her so that she could pursue music lessons. Another current student (CS\#3) would go to her grandmother's house to practice. In these cases, support from extended family members allowed students to enjoy learning opportunities that may have been out of their reach had they been solely dependent on the resources of their immediate families.

In the first chapter, I describe the role my aunt played in encouraging my interest in Bach. As a life-long classical music enthusiast and a resident of a large urban centre, she was able to access the specific resources I needed to further my musical studies at that time. My grandfather, who also loved Bach, also played an important role in encouraging my developing music skills. Each time he came to visit, he would ask me to play and always had encouraging words for me. Because he had grown up in a musical family and had a brother who was an accomplished pianist, his praise carried more weight than any I might have received from less knowledgeable listeners. Most importantly, I appreciated the sense of connectedness to my extended family that developed as I pursued my interest in music.

The presence or absence of supportive peer relationships was also cited by several students as influencing their overall impression of music study. For example, one of the current students (CS\#3), who had recently changed schools, described how the friends from her first school would offer her encouragement whenever she was feeling stressed about an upcoming performance. However, her peers at her new school had been less supportive, expressing annoyance when she would bring up the anxiety she was feeling about her approaching festival. One of the former students (FS\#1)was very enthusiastic in describing how she has joined a rock 
band since discontinuing her piano lessons. She is now enjoying her music learning much more than when she was learning by herself, not only because of the change in the musical content but also because of the social aspect that was now part of her music learning. Another former student described how she initiated peer relationships through music by playing the piano in her university residence.

\section{Why Is the Relational Context So Important?}

Students' relationships with adults have a profound effect on their overall self-esteem and ability to focus on learning. When a student receives unconditional respect and support from parents and teachers, he or she will be confident and willing to take risks, such as performing in public (Sinden, 1999). Supportive relationships encourage students to become self-regulated learners (Creech, 2010), not only preparing students for success in the immediate task at hand but also fostering the development of skills that will lead to success in future learning endeavors.

Students who do not experience the kind of support described earlier in this chapter are more likely to feel insecure in both their relationships and their learning efforts. If students are left to negotiate their music studies without support from their parents and teachers, they can feel abandoned and stressed, unsure of how to manage responsibility that should have been shared with an adult. On the other hand, if students are coerced into participating in activities that are not suitable for their individual interests, needs, or temperament, they can experience profound levels of emotional pain and can harbor resentment towards the adults whom they regard as responsible for that pain. 


\section{Relationship narratives.}

The following narratives, each based on the experiences of a particular student, provide illustrations of the impact of both positive and negative relationships in the student-parentteacher triad.

\section{Former Student \#4: Waiting for the Next Blow}

I can feel a knot forming in my stomach as I wait for my sister's lesson to finish. Soon it will be my turn. My mind churns with all kinds of different thoughts. I probably didn't practice enough this week. I know that I'm still fumbling in the second line of my Bach. I can already feel the sting of the pencil on my knuckles that I know will come with the first wrong note.

I had hoped that maybe things would change after I talked to my mother about Mrs. Chen's propensity to impart musical knowledge with physical force. Mother actually called her to talk about it, but Mrs. Chen was quick to assure her that everything was fine. Apparently, I just need to practice more. I suppose if I never made any mistakes, Mrs. Chen would have no reason to hit me. I wish mother had realized how terrified I am, but I suppose it's not surprising that she trusts the teacher. After all, why would my story be more believable than an adult's?

My sister's lesson is over now. I sit down at the piano and start to play. Out of the corner of my eye, I see Mrs. Chen's hand go up. I flinch and stop playing, waiting for the blow.

It doesn't come. She was just brushing a stray hair off her face.

Her expression is quizzical.

"What is wrong with you?" she asks.

In this account, a former student describes the physical abuse she suffered at the hand of her teacher. While this teacher is certainly not unique in her use of hitting as an instructional strategy (Bartel and Cameron, 2000), this narrative demonstrates just how damaging corporal punishment can be to the relationship between student and teacher. Instead of helping this student improve her playing, being hit had the opposite effect. Because she was constantly looking out for the next blow, the student was unable to focus fully on the music she was playing. The fear not only kept her from enjoying her lessons but also likely led to more mistakes.

This narrative illustrates damaging relationships with both teacher and parents. While the teacher's behaviour was overtly inappropriate, the parents were complicit in the abuse by not 
taking seriously their child's concerns. While the student did not express anger toward her parents for their willingness to accept the teacher's version of events, she did wish that they had offered her more support and had been better advocates for her. When asked if there was anything that she would change about her lessons as a child, this participant immediately replied that she wished she had studied with a different teacher. However, at the time, the choice of teacher was out of her control.

Because relationships between adults and children have an unequal power dynamic, children are vulnerable to abuse at the hand of an unethical or simply ignorant teacher or parent (Bartel and Cameron). The welfare of a child should be the primary concern for both parents and teachers and any indication of abuse on the part of either should be taken seriously by other adults who have contact with the child.

Even in cases in which the child is not being abused, parents have an important role to play in making sure that the teacher and the lesson content are meeting the needs of their child. Parents are the experts on their children's personalities, temperaments, and interests and can provide invaluable information that teachers can use when designing a course of study for a particular student. If the lessons are not meeting the student's needs, parents might need to advocate for some modifications, or, in some cases, change teachers in order to find one whose teaching style is a better fit for their child. In turn, excellent teachers are able to tailor their teaching to the needs of their students and employ a variety of effective instructional techniques that help students achieve their full potential in a safe and supportive environment.

\section{Former Student\#2: Forcible performance}

I love playing the piano. Ever since the piano first came into the house, I've been so excited to learn to play. Music is my outlet, my passion - when I play, I can lose myself in something magical. 
My parents were wary when I told them I wanted to take lessons. After all, they had been burned once already. My brother, for whom they had originally bought the piano, took lessons for a short time and then quit. If they were going to invest in lessons again, it would not be without a good return. So, I worked away on my own, proving to them that I really wanted to do this.

In my father's eyes, my lessons are not only for my own enjoyment. While he was reluctant to register me for lessons at first, now he has found a way to benefit from my musical pursuits, as all our relatives compliment him on his talented daughter.

"Come sit," he says to his guests. "Elizabeth will entertain us. Elizabeth, go play your pieces for our guests."

I have no choice. After all, if I refuse, he will cut off my lessons. The family concerts are torture, though. I can feel the knot in my stomach start to grow as soon as the guests arrive. By the time I've been ordered to the piano, I am acutely aware of all the eyes boring into my back.

As I start to play, my hands shake. The sweat makes my fingers slip on the keys. Why must every family gathering turn into a concert? Can't my father see how miserable I am? I hate him for putting me through this. Finally, he motions for me to get down from the piano bench. The relatives gush for a few minutes, and then move on to other, more interesting topics of conversation. I'm free now - at least, until the next time the relatives come calling.

This narrative demonstrates the effect of an unhealthy kind of parental involvement. In the case of this former student's experiences, the practical support offered by her parents came as part of a transaction. Because they provided the financial resources necessary for her muchdesired lessons, she was expected to ensure that her lessons benefitted the parents as well. Her parents enjoyed the accolades of their relatives when they showed off their talented daughter. The fact that these performances humiliated her was of secondary importance. She owed them this.

The father's insistence that she perform went against her personality, which was much more reserved. In fact, she described elsewhere in her interview how she often waited to practice until everyone was out of the house so that no one would hear her play. Her father's blatant disregard for her discomfort and the manipulation that ensured that she would continue performing in spite of her fear could be considered a form of emotional abuse. He took something that was of great value to her (piano lessons) and set conditions for her to receive it that made her life miserable. Although this student is now an adult, living on her own, and 
pursuing her interest in the piano on her own terms, she still feels resentment toward her father

for his role in making her early years of learning more stressful than they should have been.

\section{Current Student \#2: Lessons as therapy}

I was feeling kind of down after my festival duet performance didn't go very well. We came second, which was disappointing, because usually when I play in a festival I come first. I was playing with my friend who doesn't take lessons anymore, and I think maybe she didn't take the whole thing as seriously as I did.

When I arrived at my lesson today, my teacher could tell that I wasn't my usual self. My teacher and I had a long talk about how festivals work and how it can be so hard to predict the outcome. I can't control how much my duet partner works or what the adjudicator thinks of the performance. After that disappointing experience, I was feeling kind of unsure about the festival and exam that were coming up, but my teacher encouraged me to keep going. She reminded me that one bad experience doesn't mean I'm not a good musician. She said that everyone - even professional musicians - have performances they're not happy with. The real test of how good a musician you are is how you're able to bounce back after a performance that doesn't go well.

It really helped that she took the time to talk about what was bothering me. I was so upset when I arrived for my lesson that I couldn't concentrate on any of my new work, but after we talked about it, I felt a lot better and I was able to put the bad experience behind me and focus on what I needed to do to get a really good mark on my exam in a few weeks. My teacher is demanding and doesn't let me get away with anything in my playing, but she is also really warm and friendly. I feel safe with her and I like that she sees me as a person and that she cares enough about me to help me when I'm having a hard time.

It was obvious in talking to the teacher of the current students and in watching the video footage of her lessons that she cares deeply about her students. Her warm demeanor and enthusiasm for working with children are evident. She is also a very perceptive teacher who takes time to get to know her students, who responds to their unique personalities and interests, and who takes the time to understand what is going on in her students' lives outside of their lessons. In order to have a positive, productive relationship with their students, teachers need to be concerned with the whole person, not only the subject matter (Cameron and Carlisle, 2004).

In this case, the student (who generally achieves excellent results and who sets very high standards for herself), was feeling disappointment at her most recent festival performance. She was also feeling frustrated at the injustice of being "dragged down" by a duet partner who, while 
being a good friend of the participant, was not as serious a music student. Rather than dismissing the student's feelings or downplaying the importance of the performance, the teacher took time to acknowledge the disappointment. The teacher empathized with the student by sharing some of her own experiences with performances that did not go as well as she had hoped and how she was able to bounce back. Her perspective helped the student to see that the occasional disappointment is part of being a musician and that the real test of her competence was in how she would be able to persevere.

The student was in the midst of intense exam preparations at the time that this lesson took place. It would have been easy for the teacher to avoid "wasting" precious lesson time dealing with the student's emotional state, but her investment in her student's well-being and in their relationship was worthwhile, as the student was able to focus and to approach her upcoming performance goal with enthusiasm.

Not only was the student enthusiastic in her praise for her teacher, her mother was also very pleased that they had found a teacher who was supportive and nurturing. The mother viewed the teacher's musical knowledge and her ability to relate to students as part of her professional expertise. When teachers are warm and supportive, both students and parents respond with appreciation and loyalty.

\section{Current Student \#3: Grandma is my biggest fan}

I don't know what I would do without my grandmother supporting me. I've always loved music, but she's the one who made it possible for me to take lessons. She found a voice teacher for me and then when he couldn't teach me anymore, he suggested my piano teacher. I love working with my teacher - she's a lot of fun and she really knows how to help me play better.

I come over to my grandmother's house to practice because she has a piano and I don't have one at home. The routine really helps me stay on top of my practicing - it's hard to forget when my grandmother picks me up from school so that I can practice at her house! I know someday she probably won't be able to pay for my lessons anymore, so I'm trying to learn as 
much as I can now and make the most of the opportunities that I have. Her support means so much to me. I wouldn't be able to do this without her!

All of the current students had support from family members that allowed them to begin and continue their involvement in piano studies. In this case, the student's grandmother took the primary role in encouraging her granddaughter's musical interests and development. While the student was extremely enthusiastic about music in general and about learning the piano specifically, she needed the practical support provided by her grandmother in order to make progress. This student seemed particularly aware of the fact that her grandmother went to great effort to ensure that she had lessons and access to a piano for practicing and appreciated the support that she received.

This example shows an ideal situation in which the student's interests and the family member's ability and willingness to offer support coincided. Piano lessons had been a very positive outlet for this student. They provided her with great enjoyment and allowed her to experience a sense of accomplishment that she sometimes missed out on in other situations, as she found some of her academic work quite challenging. I was struck by how bubbly and enthusiastic this student was in describing the various pieces she was learning and how she looked forward to sharing her musical pursuits with friends and family at her recital performances. Her grandmother's perception and understanding resulted in this student being able to pursue an activity that was a perfect match for her interests and personality.

\section{Former Student \#3: My teacher is my inspiration}

If I had to sum up my first teacher in a word, it would be "inspiring. " I look forward to my lessons every week and I always leave excited about what I'm learning and what I'm going to work on before the next lesson. I love that she plays for me. I could listen to her forever. She plays the most beautiful music-Beethoven, Chopin. Her performances are so moving. I really relate to the strong emotions in the music. Listening to my teacher play makes me want to learn all the more, so that someday I can be like her. 
My teacher is very warm and friendly. I felt safe the moment I met her. She really cares about me and I know she sees me as more than just another weekly appointment. She takes the time to get to know me and to understand how I'm feeling on a particular day. I look forward to seeing her each week because she has become like a friend or a mentor to me.

She is so encouraging when I play for her. She says things like "Beautiful!" and "Well done!" and it makes me feel that I can do anything. I never feel very nervous before I go into a festival, because she makes me feel so confident. The last few times I've performed, I've done really well. I think it's just because I know that what I'm doing sounds good and that I am musical. I find performing in festivals really fun because I'm able to share my music with an audience.

\section{Current Student \#3: On my own}

As much as I loved my original teacher, it was getting to be too difficult to get to lessons at her new house. Since she has had children, she has also become more preoccupied with her family obligations and has less to offer to her students. I'm pretty serious about my piano studies now, so I asked for recommendations for a teacher who could prepare me for conservatory exams and maybe, eventually, studying music at university. My new teacher was highly recommended, but I'm not sure why. I keep comparing her to my old teacher, and it seems in every way she falls short.

She is very reserved and emotionally flat. My lessons are purely business-like; she doesn't really seem interested in me as anything more than one of many students. I really miss the strong personal connection I had with my first teacher. There is no warmth in my lessons now, no sense of welcome and safety. My old teacher was always telling me what a wonderful musician I was. Now all I hear about are the things I can't do and don't know. There is such a negative tone to my lessons, especially since so many of the exam requirements are unfamiliar to me. I am feeling much less secure about my abilities these days.

My new teacher never plays for me. I guess she figures it would be a waste of time, that my lessons should focus on brushing up on my (mediocre) skills. In the past, my lessons were like mini concerts. I looked forward to those intimate performances so much because they brought the music alive for me. Now, learning the piano is all about drills and repetition and fulfilling the requirements in the syllabus.

I learned lots of wonderful music with my first teacher, but never took an exam. There are parts of the exam curriculum that are completely new to me, but my teacher acts as if it is my fault that I'm not proficient in these areas, as if I'm somehow deficient because I can't sight ready or play back melodies. She leaves me to do a lot of the preparation on my own - in fact, she just told me that for two months before my exam, she'll be on vacation.

I really want to do well on this exam, as I feel that my future as a pianist rests on being able to get these certificates. I don't feel as confident or as excited about this performance as I have about previous performances, though. I'm just hoping that somehow I'll get through.

These narratives illustrate how powerful the relationship between the student and teacher can be. The difference in tone was apparent when this former student talked about her experiences with two very different teachers. Even many years later, she lit up when talking 
about the first teacher. The warmth in her voice indicated that she was talking about very pleasant memories. She began her lessons with great enthusiasm, as she had wanted to learn the piano for a long time before starting formal studies. Her first teacher was everything that she could have wanted, and under the guidance of this extraordinary teacher, her skills blossomed and her enthusiasm for learning the piano increased. The encouragement she received from her teacher, coupled with some early successes in local festivals, prompted her to consider approaching her musical studies in a more serious light with the possibility of pursuing a career in music. Her experiences are consistent with Duke, Flowers, and Wolfe's (1997) finding that the quality students valued most in their first teachers was warmth and caring.

A series of events, including the personal circumstances of her first teacher and her own desire to pursue a more rigorous level of instruction led to change in teachers which proved to be disastrous. The second teacher failed to connect with this student in every way. The personal relationship that was so vital to the positive experience the student had with her first teacher was absent. The second teacher also neglected to take into consideration the student's needs as a learner, assigning work that was beyond her current level and not offering the necessary support. Unfortunately, the ending to this story was the previously described disastrous failure at the exam that led to the student quitting her lessons and having long-term anxiety related to her piano abilities.

Students' need for a personal connection with their teacher varies. Another former student (FS\#5) described how she did not enjoy working with more "motherly" teachers, and instead preferred a completely professional relationship in which the focus was on helping her become the best possible musician. Her experience is consistent with Duke, Flowers, and Wolfe's (1997) finding that, as students mature and begin to take their music studies more 
seriously, they begin to value their teacher's skills and competence more highly than personal characteristics, such as warmth and approachability. However, all students need to feel safe and need to feel that the teacher has their best interests in mind.

\section{Parent \#5: Encouraging independence}

I always thought that I would want my child to participate in some kind of artistic activity, in addition to academics and sports. When my daughter was six years old, I looked through a community newsletter for music classes. I didn't know anything about what kind of lessons would be appropriate for her, but we ended up registering for a group piano class with a really nice teacher. My daughter enjoyed it a lot, even though she wasn't necessarily the strongest student in the class. It was expected that the parents attend the class and then work with their children between lessons. I sat with her at every practice session and made sure that she completed her assignments. I don't have any music training myself, so I would take notes in the classes to remember what she would need to work on.

She really came into her own after the first year of studying and her teacher told me that she had a lot of potential. The group class is only for beginners, so when my daughter graduated, we looked for a teacher for private lessons. I continued going to the lessons and helping her with her practicing because I thought that was what was expected. I wanted her to get the most out of her lessons. Sometimes, I think she rushes through her practicing and doesn't spend enough time mastering each step before she wants to move on to the next step.

A while ago, I had a really busy time at work. I had to work late most nights and, by the time I would get home, it was too late to sit down at the piano. I was worried that, without my being able to supervise her practicing, she would not make much progress. She surprised me, though. She took responsibility for her own practicing and continued working hard even without having me beside her at each practice session. Her teacher gives very detailed instructions and she was careful to follow them.

She did so well practicing on her own that I've stopped being so involved even though I'm less busy at work now. She takes a lot of pride in knowing that she is managing her own practicing. She really loves the piano and wants to do well, so I don't have to motivate her to work hard. I think it helped her develop good habits to have me involved at the beginning, but now she doesn't need that support. I'm proud of how independent she has become.

This parent exemplifies many of the traits that are important in ensuring that students have positive experiences learning the piano and participating in evaluative performances. She provides practical and logistical support for her daughter's lessons, ensuring that her daughter is able to attend weekly lessons and has the resources she needs to practice effectively at home. 
While the original impetus for starting lessons came from the mother, the decision to continue was based on the daughter's interests and abilities.

The mother's involvement in her daughter's practicing was also tailored to her daughter's needs. At the beginning, when her daughter was very young, the mother's direct involvement was necessary for her daughter to establish an effective practice routine. The mother made sure that the daughter knew exactly what she needed to work on each week and monitored her progress in each practice session. However, with time, her daughter developed the maturity to manage her own practicing. The parent's approach reflects McPherson and Williamson's (2006) finding that parental involvement in music lessons tends to be most intense at the beginning of the learning process and tapers off as students mature and take over more responsibility for their own learning (p. 247-248).

In the case of this family, the daughter showed high levels of intrinsic motivation to learn music and also strong achievement motivation to do well in her evaluative performances. This combination of mastery and performance approach goals helped her to stay focused and to exercise self-discipline in her learning. She showed many aspects of self-regulation, such as planning, organization, and metacognition (Zimmerman, 2001, p. 1). She used her teacher's guidance to plan her practice sessions, employing effective strategies to maximize the depth of learning and the efficiency of the learning process.

The daughter's self-regulation became evident when the mother withdrew some of the direct support she had previously given. Although, initially, the mother planned to resume her involvement when her schedule became more flexible, the daughter's evidence of independence made this unnecessary. The daughter was now ready to manage her own practicing and felt even more invested in her music learning now that she was responsible for her own success. 
Determining the degree of support a child needs can be difficult for parents. If parents offer less support to a child who is not equipped to self-regulate, the child's progress will likely be impeded. If the student senses that his or her learning has stagnated, doubts about musical ability or potential could set it. When a student has determined that he or she is "not musical" it is very difficult to reignite interest in learning the piano.

On the other hand, a student whose parents are overly involved, who micromanage each step of the learning process, can start to feel smothered. Students take pride in accomplishments they feel they have earned, and it is important for parents to be aware of the possibility of robbing students of that satisfaction by not allowing them to exercise responsibility to the extent that they are able. Students thrive on a sense of personal agency, which occurs when they "take responsibility for their actions and ascribe success and failure to the goals they choose, the resources they mobilize, and the effort they expend" (Paris, Byrnes, and Paris, 2001, p. 167). When students feel that they are in control of their own learning, they are more likely to persist and to experience a sense of pride when they achieve success.

\section{Summary}

Even if the student's personal characteristics align perfectly with the demands of an evaluative performance, supportive relationships with parents and teachers are essential if the student is to have a positive experience. Parents and teachers each play a unique role in empowering students to learn. Students rely on their parents for practical support and for help mediating any difficulties that could arise with the teacher. Teachers are a source of inspiration, subject matter knowledge, and knowledge related to the evaluative performance. They also control the social-emotional climate of the lesson. Parents and teachers work together to provide 
students with emotional support, including celebration of achievements and commiseration in the event of a disappointment. Both parents and teachers also play an important role in fostering students' autonomy and self-regulation. Students also benefit from receiving support for their musical pursuits from peers and extended family members. 


\section{Chapter 8 \\ Discussion and Conclusion}

This chapter brings to a close the discussion in the previous chapters. First, I present a grounded theory to explain student engagement in music learning through evaluative performances. The theory is presented in narrative form, as well as in a visual diagram followed by several propositions that outline the conditions under which students are most likely to have a positive experience participating in evaluative performances. The chapter concludes with recommendations for further research and implications for pedagogical practice.

\section{A Grounded Theory of Student Engagement in Music Learning through Evaluative Performances}

The preceding chapters outlined the various steps in student participation in evaluative performances, characteristics of a positive experience, and the personal and relational factors that contribute to students' having a positive experiences with evaluative performances. In this chapter, I will present a theory of student engagement in music learning through evaluative performances. The theory is explored first as a fictional first-person narrative, drawing on the experiences of many participants in the study who fit the characteristics of high levels of engagement in music learning through participation in evaluative performances. At the end of the narrative account, the theory is presented through the use of a visual model and through an unpacking of several propositions.

\section{Narrative representation of the theory.}

My name is Stella. I'm 10 years old and I love music. I've been taking piano lessons with Lisa for three years now. Before that, my grandmother showed me how to play "Twinkle, Twinkle" and "Mary Had a Little Lamb" on her piano. That was a lot of fun, but we don't get to 
see my grandmother very often, so I was really excited when my mom told me that we'd be getting our own piano and that I would take lessons every week.

We met Lisa through my friend who started lessons a couple of months before me. She's great! She's really friendly and fun, and she pushes me to play my best. I've really learned a lot since I started studying with her. Sometimes she plays for me and that is one of my favourite parts of my lessons. She plays really well-I just get lost in the music as I listen to her. If I keep working hard, I hope that someday I'll be able to play the way she does.

Did I mention that I love music? All of it-folk songs, music from Disney movies, classical pieces, Christmas carols. I want to play it all. My teacher lets me choose a lot of the music that we learn and she also suggests things she thinks I will like. Right now, I'm getting ready for my Grade 2 exam. I like all the pieces I'm playing, but the scales and sight reading and ear training are kind of boring. I know I need to work on them, though, because being able to do those exercises will help me learn new music more quickly. Right now, I'm focusing on my exam pieces, but earlier this year we learned some pop music. After my exam, we 're planning on starting some pieces from my favourite movie. I like learning music that I already know and that my friends know. They think it's pretty cool that I can play some songs that they listen to.

Having a goal to work towards helps me discipline myself on the days I don't feel like practicing. I'm pretty good at practicing every day. Sometimes my mom has to remind me, but mostly I remember myself. Lisa gives me lots of instructions so that I know what to practice and what my pieces should sound like. When I'm working on challenging music, I usually practice one bar at a time, or play slowly, or practice one hand at a time. Sometimes, when I'm really focused on working on a challenging part, I lose track of time. I always feel really proud when I know that I can play a piece well.

Last year, I did my Grade 1 exam. It was a lot of work to get ready for it, but the hard work paid off. I was kind of nervous when I had to play, but I still had fun. I was proud to show the examiner what I could do. I knew I was ready for the exam because I could play all my pieces by heart without making many mistakes. Lisa sent me to one of her friends who is also a piano teacher so that I could do a mock exam a couple of weeks before the real exam and that helped me feel more prepared, too. Lisa said that she expected that I would be able to do well, and that helped me feel confident. She has been teaching for a long time and she knows what the examiners expect, so I trust her to tell me when she thinks I'm ready to perform.

I felt really proud of myself when I got my results. I got 88. Lisa said that's a really good mark. I got a certificate, too. It's hanging on the wall in my room now. I liked doing the exam because it's a nice accomplishment to know that I finished that level and now I'm ready to move on to the next one. I want to finish all the levels so that I can play the music that Lisa can play. She's amazing - she can just sit down and play anything you can think of.

I like exams because I get a certificate and mark, but performing for a bigger audience is more fun. Now that I've been taking lessons for a while, I'm kind of the musical one in my class at school. Sometimes my teacher asks me to play for the class, or I play for my family when we have relatives over. Performing for people is fun. I enjoy sharing the music that I like, and it's always nice to have people clap for me. Sometimes, I feel a bit shaky, but the nerves don't really affect the performance. Most of all, I like being able to show my family what I can do, thanks to their support.

I really appreciate what my parents have done to help me with my music lessons. I know music lessons and instruments are expensive, but they've paid for everything happily. They remind me if I forget to practice, but they don't nag. They always come to hear me play in 
recitals and festivals. It really helps me manage the nerves when I know that I can play for them and that they'll love me no matter what.

My teacher helps me work through the nerves as well. She's able to give me lots of good suggestions for helping me relax because she's had to use them herself over the years. I've had a couple of performances that didn't go as well as I hoped, but she helped me to see that I'm still a good musician and that I just need to keep working hard. Everyone has a bad performance now and then, but it doesn't mean that I can't continue making music.

I think I'll keep playing the piano and keep taking lessons for a long time, probably until I'm an adult. Adults have lots of other responsibilities, so it might be hard for me to keep doing all the practicing once I have a job and a family of my own, but I think I'll always play as a leisure activity. Music will always be part of my life!

\section{Explanation of the visual model.}

The following model explains the conditions of a positive experience with evaluative performances. The core phenomenon, indicated by the blue circle in the centre of the diagram is the student's participation in an evaluative performance, including all aspects of the process as described in Chapter Four. The other components of the diagram indicate the causal and contextual categories that influence the quality of the student's experience with the process of participating in an evaluative performance.

The arrow on the left-hand side of the diagram represents a causal condition for participation in evaluative performances and indicates the intrinsic motivation to learn music that serves as the initial impetus for music study in students who have positive experiences with festivals and examinations. For these students, a love of music motivates them to want to become more skillful and evaluative performances are perceived to be a way to increase their skill levels.

Surrounding the core category are several contextual conditions, each of which influence the way in which the student experiences the phenomenon of the evaluative performance. The first layer outside of the core phenomenon, shown in dark green, is the engagement-success cycle. Students who have positive experiences with evaluative performances are highly engaged in music learning through participation in evaluative performances. This engagement is 
evidenced by positive emotional outcomes, perceptions of the relevance and meaningfulness of music learning, and the development of a strong musical identity. Students who are highly engaged have generally experienced success in previous evaluative performances (or have had other experiences, such as recital performances, that have given them confidence to attempt an evaluative performance in the case of students entering a first evaluation). Their success contributes to the three factors that are part of engagement, while their high levels of engagement motivate them to engage in activities that will likely result in future successes.

The next circle, shown in light green, represents students' understandings, values, and goals. This category includes aspects such as the student's attributions for success and failure, the value the student places on various aspects of music learning and on the formal recognition of achievement, and the kinds of goals the student has related to learning and achievement. Students who had positive experiences with evaluative performances held adaptive attributions, expected to succeed, valued the potential outcomes of participation in evaluative performances, and held both mastery and performance approach goals.

The outside layer of the circle, shown in orange, represents students' characteristics as performers. In order for a student to have a positive experience participating in evaluative performances, he or she needs to feel confident in performance. Some students described how they enjoyed performing and found the experience of being on stage to be exciting and satisfying. While these students also often described some level of nervousness related to performing, their levels of anxiety were manageable and did not detract from the overall experience of performing.

When all of the conditions described above work together to contribute to a positive experience with evaluative performances, students experience high levels of self-efficacy and 
self-determination. Students who have high self-efficacy feel confident in their ability to be successful in future evaluative performances. Students who experience self-determination in relation to their participation in evaluative performances have their needs for competence, autonomy, and relatedness met through their participation. Self-efficacy and self-determination are important because they are strong predictors of future engagement in learning. Students who have strong self-efficacy and self-determination exhibit a desire to continue engaging in music learning and in participation in evaluative performances.

Finally, students who have positive experiences with evaluative performances experience the whole process of preparation, performance, and reflection within the context of positive relationships with important adults. Parents and teachers have distinct roles, but also share responsibility for some aspects of the student's musical education. When a student receives support from his or her parent(s)/guardian(s) and teacher, music learning and participation in evaluative performances can be an enjoyable and satisfying endeavor. 


\section{Conditions of a Positive Experience with an Evaluative Performance}

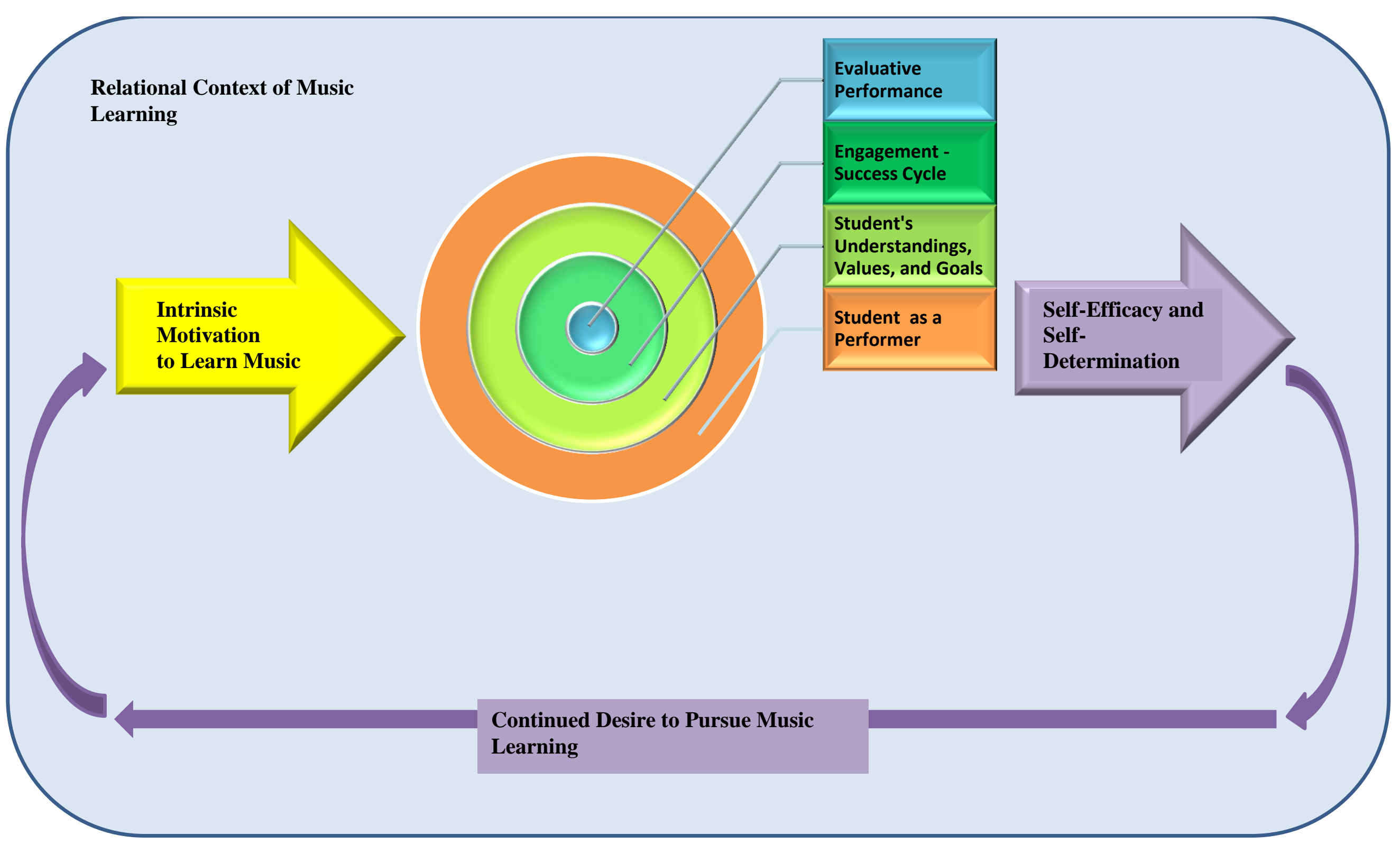




\section{Propositions.}

Positive experiences with evaluative performances occur when:

\section{Students have high levels of intrinsic motivation related to music learning.}

Intrinsic motivation is key to maintaining interest in a particular activity

and to achievement and deep levels of learning (Lacaille, Koestner, and Gaudreau, 2007). The students who had positive experiences with evaluative performances enjoyed music learning and found satisfaction in learning music apart from their participation in evaluative performances. Regardless of whether music instruction was initiated by the parent or by the student's expressed interest, the students who had positive experiences with evaluative performances developed a deep love for music. These students could not imagine their lives without active participation in music-making. As a result, participation in evaluative performances was a means to continue pursuing an activity about which they were passionate, rather than an end to itself.

\section{Students' learning takes place in the context of supportive relationships with} parents and teachers.

The importance of relationships with influential adults cannot be overstated (Bartel and Cameron, 2000). The students who had the strongest negative reactions to their participation in evaluative performances all described extremely negative interactions with parents and teachers who were out of touch with the student's needs, neglectful, or even abusive. In contrast, the students who had positive experiences recounted a variety of ways in which their parents and teachers provided practical and emotional support for their music learning and for 
their participation in evaluative performances. Parents provided practical, financial, and logistical support for the students' lessons and practicing and acted as advocates for their children's needs. Teachers provided subject-matter expertise and wisdom gleaned from years of preparing other students for evaluative performances and also served as role models for students' emulation. Both parents and teachers offered encouragement and emotional support so that students felt secure in their self-worth regardless of the actual results of the performance. While parents and teachers provided important guidance, students also benefitted greatly from being given a sense of ownership over their own learning, specifically with regards to whether or not they would participate in evaluative performances. Many students also experienced significant benefits from relationships with siblings, friends, and extended family members who served as role models and who offered support.

\section{Students' musical preferences align with the required syllabus.}

While none of the students was completely enthusiastic about all aspects of the syllabus, all of the students who had positive overall experiences with evaluative performances described the enjoyment they experienced learning at least some of the required repertoire. The less preferred elements in the exam program, such as technical tests, sight reading, and ear tests were viewed as tools that would help students develop the skills they would need to become proficient in playing the music they loved. Students who found the required music generally boring or uninspiring often resented having to devote significant amounts of time to learning irrelevant music. 


\section{Students' characteristics as learners align with the demands of preparing for and performing in an evaluation.}

Preparing for an evaluative performance requires a high level of discipline and attention to detail (Davidson and Scutt, 1999). The evaluation criteria used in festivals and examinations set high standards for accuracy and musicality in students' playing and demand that students have a very thorough knowledge of their pieces and exercises. Students are also generally expected to perform from memory. Even very talented students generally have to work hard to achieve this level of performance. Particularly in cases in which the students have high expectations regarding the mark or rank they hope to achieve, intense preparation is necessary. Preparation for evaluative performances involves consistent attendance at private lessons, careful attention to the teacher's instructions, and many hours of dedicated, meticulous practicing.

In order to pursue such a monumental goal, students must be highly motivated. Those who described positive experiences with evaluative performances had both mastery and performance goals, expected to be able to succeed, and valued the formal recognition afforded by festivals and exams. They also attributed their successes to a combination of ability, effort, and effective use of strategies.

\section{Students' are able to perform with confidence.}

The students who were most enthusiastic about their participation in festivals and exams enjoyed performing. They were students who craved the limelight, who appreciated the applause of the audience. For these students, music 
had an important expressive and communicative role that could not be fully realized unless they were playing for a room full of people. While all of the students described some level of nervousness related to their festival and exam performances, for those who felt positively about their participation, performance anxiety was not debilitating.

In contrast, some students viewed their musical pursuits as a more personal, private endeavor. The stress that these students felt when performing for other people made any kind of performance unappealing; however, the added pressure of being evaluated was often overwhelming. Performance anxiety was experienced in a particularly acute fashion when students felt unprepared for the performance.

\section{Students experience success.}

The students who had positive experiences with evaluative performances had all been successful in their previous endeavors. As a result, the marks and feedback they received from adjudicators (and later from teachers and parents in reaction to the adjudicator's feedback) were affirming of their musical skill. While some of the students who had negative experiences with evaluative performances had also been successful, other aspects of the experience sometimes cancelled out any satisfaction these students might have found in their achievement. Importantly, none of the participants described a situation in which they received a low result and still felt good about their overall experience participating in evaluative performances. While failure in an evaluative performance does not necessarily preclude a positive overall impression of music 
study, a disappointing result can be difficult for students to process. This is particularly true because the students who are the most eager to enter evaluative performances are often the same students who will be the most devastated by a failure. In contrast, students who place less value on formal recognition of achievement are less likely to be distraught when they receive a low mark and are also less likely to be motivated by the prospect of success.

\section{Students experience positive emotions when engaging in music learning and} in participation in evaluative performances.

Music learning was a source of great enjoyment for many students. It allowed students to express a variety of emotions and served as stress relief. Participation (and success) in evaluative performances allowed students to feel a great sense of accomplishment. Students also felt satisfaction in seeing their skills develop as they mastered new music.

In contrast, for students who had negative experiences with evaluative performances, learning music was sometimes boring or stressful. Evaluative performances in particular could be the source of much anxiety and shame.

\section{Students view their music learning as relevant and meaningful.}

For students who had positive experiences with evaluative performances, participating in these events was one component in a larger musical education that was focused on meeting their individual needs (Pitts, 2004). Students appreciated learning music that was relevant to their lives outside of exam preparation. While the repertoire required for festivals and exams was sometimes engaging enough to be meaningful for some students, students all needed an opportunity to learn a 
greater variety of popular music or to explore other facets of music making (for example, taking voice lessons or playing in the school band). The students whose learning had centred solely on festival and exam preparation found their formal music studies boring and irrelevant.

The students who had positive experiences with evaluative performances all envisioned themselves continuing some level of musical engagement into adulthood. Interestingly, many of the students who had profoundly negative experiences with evaluative performances still found a way to incorporate the piano into their daily lives, although the music they chose to play often had very little to do with what they had learned during their formal musical education.

\section{Students develop a strong musical identity that aligns with the concept of} "musician" that is perpetuated through evaluative performances.

The musical identities of students who were successful in their festival and examination performances were strengthened (MacDonald, Hargreaves, and Miell, 2002), as these students could look back on previous experiences to bolster their confidence. While positive feedback from adjudicators and examiners played an important role in cementing students' musical self-concepts, the skill development that occurred through the preparation process was equally important. When students had a wide range of musical skills upon which to draw in a variety of situations, their role (and others' perceptions of their role) as musician was confirmed. Students who experienced positive emotions as a result of their participation in evaluative performances viewed music as something that contributed to their sense of self. 
Students who had negative experiences with evaluative performances sometimes had weaker musical identities, as a result of receiving feedback from adjudicators and examiners that called into question their musical ability or of experiencing a lack of interest in their music studies. Other students had strong musical identities that were in conflict with their participation in evaluative performances (for example, an identity that centred around playing popular music).

\section{Students experience high levels of self-efficacy in relation to their participation in evaluative performances.}

Students who have strong self-efficacy feel confident in their abilities to succeed in a particular task (Bandura, 1977). Self-efficacy is a predictor of both achievement and future engagement in an activity. A student who has had successful prior experiences, has received positive feedback from others (particularly influential others, such as adjudicators and examiners), is surrounded by models who have been successful in similar situations, and experiences positive emotional and physiological responses in performance situations is likely to feel confident in his or her ability to succeed in future tasks. In this study, the students who had positive experiences with evaluative performances had achieved high results in previous festivals and examinations, received supportive feedback from adjudicators and examiners, saw other students (for example, other competitors at festivals, or other members of the same studio) succeed in evaluative performances, and experienced enjoyment and satisfaction as a result of their participation. 
In contrast, students who had negative experiences with evaluative performances had experiences that worked against the development of strong selfefficacy. Some of these students had experienced low results or had received negative feedback from adjudicators. Others had watched peers struggle. However, the most important factor that contributed to students' low self-efficacy related to participation in evaluative performances appeared to be the students' own experiences with negative emotional and physiological responses as a result of extreme anxiety.

\section{Students experience self-determination as a result of their participation in evaluative performances.}

Students who had positive experiences with evaluative performances had the three psychological needs identified by self-determination theory met through their participation in evaluative performances (Ryan and Deci, 2000). First, their participation in evaluative performances allowed them to feel competent. Students who did well in festivals and examinations had positive views of their competence as musicians and performers. Also, students who had positive experiences with evaluative performances were afforded an opportunity to exercise agency in the process, thus allowing the experience to contribute to their sense of autonomy. While their participation in festivals and examinations might have been initiated by a teacher or parent, the final decision regarding their participation was theirs to make. Finally, the students who had positive experiences with evaluative performances experienced relatedness with parents, teachers, peers, and extended family through their participation in evaluative performances and through the 
skills that developed as a result of their preparations for festivals and examinations.

In contrast, students who had negative experiences with evaluative performances felt less confident in their musical abilities as a result of their participation. They were sometimes forced to participate and resented the lack of autonomy that they had over the course of their music studies, particularly if they found participation in evaluative performances to be stressful or otherwise unpleasant. Many of these students also had strained relationships with parents and teachers as a result of conflicting views on their participation in evaluative performances.

\section{Students have a resultant desire to continue participating in evaluative performances.}

The students who had positive experiences participating in evaluative performances all expressed a desire to continue participating. Interestingly, none of these students was planning a career in music, but all still felt that pursuing evaluative performances was worthwhile for the time being. They felt that working towards progressively higher festival and examination levels would ensure that they would develop a high level of skill that they could then apply later in life, when music became a leisure activity. Students' goals for skill development were based on two desires: to have access to a wide variety of music and to be able to learn new music efficiently (an important skill in adult life, when students assumed that many other responsibilities could easily crowd out time for serious piano practice). 


\section{Students' positive experiences continue to be reinforced.}

As students continued to engage in more evaluative performances (and the learning that occurred in preparation for those performances), their sense of the self as musician continued to be reinforced. Even amongst students who had negative experiences with evaluative performances, many participants still felt some connection to music-making after all of the time and energy they had invested in pursuing their craft. The fact that their interest in music was not completely destroyed by a negative experience speaks to the power of encountering music at a young age. However, the strongest sense of musical selfconcept was found in the students who had positive experiences with evaluative performances. These students felt that they could "take on the world" and could not imagine music ever ceasing to be part of their lives.

\section{Recommendations for Further Research}

Because of the limitations of the participant pool previously described in the introduction, it would be extremely valuable for follow-up work to this study to include a wider representation of piano students and teachers and to include the impact of various demographic factors in the analysis. For example, all of the students who completed interviews for this research were female (there was some male participation in the survey). Previous research has shown gender differences in students' engagement and motivation (Freedman-Doan, Wigfield, Eccles, Blumenfeld, Arbreton, and Harold, 2000), and it would be worthwhile to examine whether the insights of the participants in this research also hold true for male students. 
One of the former participants raised the issue of the influence of cultural factors on evaluation practices. A more detailed examination of the intersection of culture and music education values and practices would shed light on how evaluative performances could be relevant in different contexts. For example, in a cultural context in which standardized assessment is part of most learning endeavours, are evaluative performances taken for granted? What options would be effective in this context for students who do not respond well to participation in evaluative performances?

Cultural factors can also have a profound impact on expectations surrounding relationships amongst students, parents, and teachers. Comparative research could be useful in examining the impact of differing relational dynamics on students' learning and on students' experiences with evaluative performances.

A study that focused specifically on students who are engaged in music study, but who have chosen not to participate in evaluative performances, would also be very valuable. Examining the reasons cited for not participating in evaluative performances, the kind of learning that takes place without the structure and pressure of preparing for evaluative performances, and the level of engagement in music learning that is evidenced by students who are not participating in evaluative performances would help to shed some light on the actual impact of evaluative performances on student learning. For example, how do students who are not preparing for evaluative performances set goals and assess their level of learning or achievement in relation to those goals? Do students who participate in evaluative performances end up reaching greater skill levels?

The scope of this research was limited to students who at some point had participated in formal music lessons. While students who were registered for piano 
lessons had varying experiences with evaluative performances, there are likely potential students who are put off from even beginning piano lessons because they associate piano lessons with having to participate in evaluative performances. This study did not address the issue of the impact of widespread use of evaluative performances on who registers for piano lessons in the first place. While it would be difficult to access the necessary participants, research into the role of evaluative performances in determining who embarks on formal music education would be very valuable in shaping the direction of pedagogical approaches.

This study focused on the experiences of pianists because evaluative performances are a very entrenched part of formal piano study in many parts of the world. However, music students in other areas (particularly strings and voice) also participate regularly in festivals and examinations. Research into the experiences of these musicians would provide a more complete understanding of the role of evaluative performances in the broader field of music education..

Additionally, many students participate in festivals and competitions as part of ensembles. It is likely that being part of a group would change the experience of participating in an evaluative performance; however, it is also possible that some of the issues raised in this study (for example, students experiencing boredom as a result of very limited curricular offerings while preparing for an evaluative performance) would hold true in an ensemble context as well as for individual students.

While logistically challenging, a longitudinal study in the area of evaluation and piano study would be extremely valuable. This kind of research could uncover if and how students perceptions of their involvement in evaluative performances change over time. 
All students stop participating in evaluative performances at some point, either because they have reached the highest level in the curriculum, or because they have decided they no longer wish to participate. Research that focused on students' experiences around the time of terminating participation would provide valuable insight into the factors that influence the decision to stop and whether perceptions of previous experiences change with the reflection that occurs after a change in the course of action.

While the present research provides examples of positive and negative evaluation experiences and illuminates some of the factors that contribute to the quality of experiences students have, it cannot provide the basis for any statistical analysis of what percentage students view their participation in evaluative performances positively or negatively. A widespread survey (perhaps conducted in the form of an exit survey following festival or exam performances) would generate very useful data related to the role evaluative performances play in music learning. This information would be useful for examining bodies and festival organizers as they strive to meet the needs of the student population, as well as for teachers and parents trying to decide if festivals and exams would contribute to a particular student's musical education.

A larger sample size would also provide a means for examining the various categories and relationships identified in this research in more detail. For example, students could complete measures of anxiety, self-concept, and various motivational orientations that could be used for statistical analysis to further illuminate the incidence of various characteristics and the relationships amongst various factors. 


\section{Implications for Teaching and Learning}

This research has several implications for teaching and learning, including challenging assumptions upon which teaching practices are based, sparking reflection, and encouraging the use of adaptive pedagogical approaches. Jorgensen (2003) presents a compelling plea for the importance of challenging assumptions regarding what music education must entail:

Among the symptoms of transforming music education, music educators and those interested in their work need to break out of the little boxes of restrictive thought and practice and reach across the real and imagined borders of narrow and rigid concepts, classifications, theories, and paradigms to embrace a broad and inclusive view of diverse music educational perspectives and practices (p.119).

One of the main goals of this research is to challenge aspects of teaching practice: in particular, the assumption that all piano students should participate in evaluative performances and that evaluative performances are the best indicator of the quality of teaching and learning. It is my hope that the findings of this research will be useful to teachers (and the parents and students with whom they interact) in several ways.

First, the questions and issues raised in this research can help spark reflection on the part of teachers. Without engaging in reflection and questioning, teachers often replicate their own experiences as students (Tye, 2004). In order to become qualified to teach, piano teachers nearly always follow a course of study that involves participation in numerous evaluative performances. However, the kind of training that is necessary for preparation for music teaching is not necessarily the best education for a student who is not planning a career in music. It is my hope that this research will encourage teachers to reflect on the assumptions regarding quality music education that they might have based 
on their own musical backgrounds and to consider other possibilities that could be of benefit to their students.

Parents and students can also benefit from reflecting on the reasons for which a particular student is participating in piano lessons, and specifically in evaluative performances. The more knowledge parents and students have of the student's characteristics and musical interests, the more likely they will be able to present their needs to the teacher in a coherent way or to seek out a teacher who will be a good match for the student's learning needs.

This research also provides some indicators that teachers can use when considering the benefits and risks of having a particular student participate in an evaluative performance. In cases where a student has already performed in a festival or exam, this research can provide insight into the factors that might have influenced the outcome of that performance and the student's reaction to the overall experience. If the performance was not a positive experience, the teacher can then assess, along with the student and parent, if the factors that influenced the negative outcome can be changed (for example, allowing the student extra opportunities to perform in various contexts leading up to the evaluation in order to address performance anxiety) or are likely to remain stable (for example, a student's lack of interest in learning the music that is part of the syllabus).

The participants' experiences with evaluative performances, both positive and negative, highlight the importance of the evaluation in influencing students' musical selfefficacy. The role of the adjudicator and examiner is particularly important, as students tend to view the comments from the evaluator as having more weight than comments 
they might receive from their teachers or from other people. While the participants in this research tended to view the specific comments from adjudicators and examiners as having minimal impact on future learning, the impact of adjudicator feedback on selfefficacy was powerful and could certainly influence a student's desire to continue learning the piano. The findings regarding the limitations of the traditional model of delaying examiner feedback would also lend support to the initiatives of some examining bodies to include mini-lessons or workshops as part of the exam.

This research also contains some valuable insights for examining bodies. The students whose music learning consisted entirely of preparing for and performing in festivals and exams were the least likely to feel positively about their participation in these events. In contrast, the students who participated in a wide range of relevant musical activities were able to connect the learning that was part of exam preparation to larger, more personally meaningful goals. In any testing situation, there can be a temptation to focus entirely on test preparation (Kohn, 2000). However, if students were required to present some sort of documentation (such as a portfolio) to the examining body outlining the music learning in which they were involved outside of their practical exams (similar to theory and history co-requisites, but involving composition, improvisation, ensemble playing, playing a variety of styles and genres, etc.) perhaps this would encourage teachers, students, and parents to give this "extracurricular" music learning the attention that it deserves.

This research challenges teachers, students, and parents to expand their views of what can constitute meaningful and worthwhile music learning. Some students experience high levels of engagement in music learning when they are involved in 
evaluative performances. The current student participants in this research provided many inspiring examples of the contribution of festivals and exams to meaningful music learning. However, other students are best served by pursuing musical goals that lie outside the provenance of conservatories and festival organizations. These goals are no less worthwhile than those of students who spend the bulk of their studies preparing for evaluative performances.

In order to embrace the multiplicity of music learning that can enrich students' lives, teachers, students, and parents need to take a long-term view of music study. The former students who participated in this research had vivid memories of the highs and lows of their experiences learning the piano. Because evaluative performances were frequently emotionally charged events (whether positive or negative), the memories attached to participation were strong even years later. This study serves as a reminder that the interactions children have with teachers and with their learning environments are powerful and have long-term effects.

Most importantly, this research underscores the primary importance of the relational context in which students learn. Regardless of whether or not a student participates in evaluative performances, he or she is entitled to a safe and supportive relationship with both parents and teachers. It is never worthwhile to inflict damage on a child for the sake of achievement (Bartel and Cameron, 2000). Students' agency must be respected in all decision-making. None of the participants in this study who were forced to participate in evaluative performances had positive overall comments about the experience. It is of primary importance that parents and teachers be willing to set aside their assumptions about the goals of piano lessons and focus instead on meeting the 
musical and relational needs of the particular student. Flexible views of music education can transform piano lessons from an endeavor that is less than engaging for many students to one that meets many diverse musical needs (Jorgensen, 2003).

\section{Conclusion}

Any investigation of student experiences learning music must raise some broad questions regarding why music study is important and why students engage in music study in the first place. Children take piano lessons for a myriad of reasons: to develop musical skills, to foster an appreciation of music, to develop discipline through practicing, to achieve certificates and credentials, or to gain social status through exposure to so-called "great works." However, the most powerful motivation for music study is reflected in the words of one of the former student participants in this study: "I just think it's [music is] like drinking water; it's a necessity for life. Being able to play an instrument is just the most satisfying thing. I love it." (FS\#3)

Decisions about whether a student should participate in evaluative performances should take into consideration the ultimate goals of the student's music education. The varied experiences of the participants in this study showed that evaluative performances can contribute to high levels of engagement in music learning. Students who had favourable views of their participation in evaluative performances experienced positive emotions as a result of their participation, viewed the music learning that occurred during the preparations as being relevant and meaningful, and developed a stronger musical identity through their participation in evaluative performances. While these outcomes are very desirable, not all students who participated in evaluative performances had similar 
experiences. Unfortunately, for some students participating in evaluative performances can lead to boredom, frustration, and anxiety. Many personal and relational factors must be taken into consideration when a student is exploring the possibility of participating in a festival or examination. Students whose understandings, values, and goals align with the requirements for the evaluation and who are confident performers are more likely to find satisfaction in participating in festivals and exams. Importantly, students' learning must also take place within the context of supportive relationships with parents and teachers.

Evaluative performances can enhance the experiences of some music students, but care must be taken to ensure that the student is participating because the experience will be beneficial for that individual and not because of assumptions on the part of the parents or teacher that evaluative performances are a necessary or universally beneficial component of music learning. When students are engaged in music learning that is enjoyable, relevant, and that takes place in the context of supportive relationships (regardless of whether the learning includes participation in evaluative performances), they become unable to imagine life without active music-making. 


\section{Reference List}

Apple, M.W. (2004). Ideology and curriculum, third ed. New York: Routledge Falmer.

Associated Board of the Royal Schools of Music. (2012). ABRSM history. Retrieved from http://www.abrsm.org/en/about/beginning/.

Atkinson, J.W. (1964). An introduction to motivation. New York: Van Nostrand Reinhold.

Atlas, G. D., Taggart, T., and Goodell, D. J. (2004). The effects of sensitivity to criticism on motivation and performance in music students. British Journal of Music Education, 21 (1), 81-87.

Babin, A. (2005). Music conservatories in Canada and the piano examination system for the preparatory student: A historical survey and comparative analysis. Unpublished M.A. thesis, University of Ottawa, Ottawa, Ontario Canada.

Bandura, A. (1977a). Self-efficacy: Toward a unifying theory of behavioural change. Psychological Review, 84(2), 191-215.

Bandura, A. (1977b). Social learning theory. Englewood Cliffs, N.J.: Prentice-Hall.

Bartel, L. (2004). Music making for everyone. In L. Bartel (Ed.) Questioning the Music Education Paradigm, (pp. 228-243). Waterloo, Ontario: Canadian Music Educators Association.

Bartel, L. and Cameron, L. (2004). From dilemmas to experience: Shaping the conditions of learning. In L. Bartel (Ed.) Questioning the Music Education Paradigm, (pp. 39-61). Waterloo, Ontario: Canadian Music Educators Association.

Bartel, L. and Cameron, L. (2000). Engage or disengage: An inquiry into lasting response to music teaching. Orbit 3l(1), 22-25.

Benedict, C. (2006). Chasing legitimacy: The US national music standards viewed through a critical theorist framework. Music Education Research, 8(1), 3-16.

Bergee, M. (2007). Performer, rater, occasion, and sequence as sources of variability in music performance assessment. Journal of Research in Music Education, 55 (4), 344-358.

Bergee, M. (2006). Validation of a model of extramusical influences on solo and smallensemble festival ratings. Journal of Research in Music Education, 54 (3), 244256. 
Bergee, M. and McWhirter, (2005). Selected influences on solo and small-ensemble festival ratings: Replication and extension. Journal of Research in Music Education, 53 (2), 177-190.

Bergee, M. J. and Platt, M. C. (2003). Influence of selected factors on solo and smallensemble festival ratings. Journal of Research in Music Education, 51 (4), 342353.

Bergee, M. and Westfall, C. (2005). Influences on solo and small-ensemble festival ratings. Journal of Research in Music Education, 53 (4), 358-374.

Bolden, B. (2007). Teaching composition in the classroom: What teachers know. Unpublished doctoral Ph.D. dissertation, University of Toronto, Toronto, Ontario, Canada.

Borthwick, S. J. and Davidson, J. W. (2003). Developing a child's identity as a musician: a family "script" perspective. In R. MacDonald, D. Hargreaves and D. Miell (Eds.) Musical Identities, pp. 60-78. London: Oxford University Press.

Boyle, J. D. and Radocy, R. E. (1987). Measurement and evaluation of musical experiences. New York: Schirmer Books.

Broadfoot, P. M. (1996). Assessing assessment: Education, assessment and society. Buckingham: Open University Press.

Brotons, M. (1993). Effects of performing conditions on music performance anxiety and performance quality. Unpublished Ph.D. dissertation, University of Oregon.

Bruin de Bruine, W. (2006). Save the last dance II: Unwanted serial position effects in figure skating judgments. Acta Psychologica, 123 (3), 299-311.

Burck, C. (2005). Comparing qualitative research methodologies for systemic research: The use of grounded theory, discourse analysis and narrative analysis. Journal of Family Therapy, 27, 237-262.

Burke, K. (1992). Authentic assessment: A collection. Palatine, IL: IRI/Skylight Publishing, Inc.

Byo, S. J. (1999). Classrooms teachers' and music specialists' perceived ability to implement the national standards for music education. Journal of Research in Music Education, 47(2), 11-123.

Cameron, L. and Carlisle, K. (2004). What kind of social climate do we create in our music classrooms? In L. Bartel (Ed.) Questioning the Music Education Paradigm, pp. 21-38. Waterloo, ON: Canadian Music Educators Association. 
Campbell, P. S., Connell, C., and Beegle, A. (2007). Adolescents' expressed meanings of music in and out of school. Journal of Research in Music Education, 55 (3), 220236).

Canadian National Conservatory of Music. (2011). A history - our programs. Retrieved from http://www.cncm.ca/our-programs.html.

Charmaz, K. (2003). Grounded theory: Objectivist and constructivist methods. In N. K. Denzin and Y. S. Lincoln (eds.) Strategies of qualitative inquiry (pp. 249-291). Thousand Oaks, CA: Sage Publications.

Clandinin, D. J. and Connelly, F. M. (2000). Narrative inquiry: Experience and story in qualitative research. San Francisco: Jossey-Bass.

Colwell, R. (2006). Assessment's potential in music education. In R. Colwell (Ed.) MENC Handbook of Research Methodologies. New York: Oxford University Press.

Colwell, R. (1995). Will voluntary national standards fix the potholes of arts education? Arts Education Policy Review, 96(5), 2-11.

Conservatory Canada. (n.d.) About: Our heritage. Retrieved from http://www.conservatorycanada.ca/about.

Consortium of National Arts Education Associations (1994). National standards for arts education.

Cooper, T. (2001). Adults' perceptions of piano study: achievements and experiences. Journal of Research in Music Education, 49 (2), 156-168.

Corno, L. (2001). Volitional aspects of self-regulated learning. In B. J. Zimmerman and D. H. Schunk (eds). Self-regulated learning and academic achievement: Theoretical perspectives. $2^{\text {nd }}$ ed. Mahwah, NJ: Lawrence Erlbaum Associates, Publishers. (pp. 191-225)

Costa-Giomi, E. (2005). "I do not want to study piano!" Early predictors of student dropout behaviour. Bulletin of the Council for Research in Music Education, 161$162,57-64$.

Costa-Giomi, E., Flowers, P., Sasaki, W. (2005). Piano lessons of beginning students who persist or drop out: teacher behaviour, student behaviour, and lesson progress. Journal of Research in Music Education, 53 (3), 234-247.

Creech, A. (2010). Learning to play an instrument: The case for parental support. Music Education Research, 12(1), 13-32. 
Creswell, J. W. (2005). Educational research: Planning, conducting, and evaluating quantitative and qualitative research. Upper Saddle River, NJ: Pearson Education, Inc.

Crocker, L. (2005). Teaching for the test: How and why test preparation is appropriate. In R. Phelps (Ed.) Defending Standardized Testing, (pp. 159-174). Mahwah, NJ: Lawrence Erlbaum Associates, Inc.

Custodero, L. A. (2002). Seeking challenge, finding skill: flow experience and music education. Arts Education Policy Review, 103 (3), 3-8.

Cziksentmihalyi, Mihaly (1997). Finding Flow: The psychology of engagement with everyday life. New York: Basic Books.

Cziksentmihalyi, Mihaly (1991). Flow: The psychology of optimal experience. New York: Harper Perennial Modern Classics.

Davidson, J. W. (1999). Self and desire: a preliminary exploration of why students start and continue with music learning. Research Studies in Music Education, 12, 3037.

Davidson, J. W., Howe, M. J. A., Moore, D. G. and Sloboda, J. A. (1996). The role of parental influences in the development of musical performance. British Journal of Developmental Psychology, 14, 399-412.

Davidson, J. W., Pitts, S. E., and Correia, J. S. (2001). Reconciling technical and expressive elements in musical instrument teaching: working with children. Journal of Aesthetic Education, 35(3), 51-62.

Davidson, J. \& Scutt, S. (1999). Instrumental teaching with exams in mind: a case study investigating teacher, student and parent interactions before, during and after a music examination. British Journal of Music Education, 16 (1), 79-95.

Davies, B.N., Donaldson, G.C. and Joels, N. (1995). Do the competition rules of synchronized swimming encourage undesirable levels of hypoxia? British Journal of Sports Medicine, 29(1), 16-19.

DeBlaere, D.M. (2009). A grounded theory exploration of parent-to-child verbal aggression and development of an integrative theoretical model for understanding recipient impact. Unpublished Psy. D. dissertation, Alliant International University, San Diego, CA.

Decker, E. (2004). How's my child doing? Can a standardized test score answer this question? In M. Moll (Ed.) Passing the test: The false promises of standardized testing (pp.260267). Ottawa, ON: Canadian Centre for Policy Alternatives. 
DeNora, T. (2000). Music in everyday life. Cambridge: Cambridge University Press.

Dey, I. (2007). Grounding Categories. In A. Bryant and K. Charmaz (eds.) The Sage handbook of grounded theory (pp. 167-190). Thousand Oaks, CA: Sage Publications.

Duke, R. A., Flowers, P. J., \& Wolfe, D. E. (1997). Children who study piano with excellent teachers in the United States. Bulletin of the Council for Research in Music Education, 132, 51-84.

Dweck, C.S. (1986). Motivational processes affecting learning. American Psychologist, $41,1040-1048$.

Eisenberger, J. and Thompson, W.F. (2011). The effects of competition on improvisers' motivation, stress and creative performance. Creativity Research Journal, 23(2), $129-136$.

Eisner, E.W. (2001). What does it mean to say a school is doing well? Phi Delta Kappan, $82(5), 367-372$.

Eisner, E. W. (1998). The enlightened eye: Qualitative inquiry and the enhancement of educational practice. Upper Saddle River, NJ: Prentice Hall.

Elliot, A.J. and Dweck, C.S. (2005). Competence and motivation: Competence as the core of achievement motivation. In A.J. Elliot and C.S. Dweck (eds.) Handbook of competence and motivation (pp. 1-15). NY: The Guildford Press.

Elliott, D.J. (1995) Music Matters: A New Philosophy of Music Education. New York: Oxford University Press.

Frederickson, W. E. (2007). Perceptions of college-level music performance majors teaching applied music lessons to young students. International Journal of Music Education, 25 (1), 72-81.

Freedman-Doan, C., Wigfield, A., Eccles, J. S., Blumenfeld, P., Arbreton, A., and Harold, R. D. (2000). What am I best at? Grade and gender differences in children's beliefs about ability improvement. Journal of Applied Developmental Psychology, 21 (4), 379-402.

Frick, B. (2011). Gender differences in competitiveness: Empirical evidence from professional distance running. Labor Economics, 18 (3), 389-398.

Froehlich, H. C. (2007). Sociology for music teachers: Perspectives for practice. Upper Saddle River, NJ: Prentice Hall. 
Gagné, F. (2003). Transforming gifts into talents: The DMGT as a developmental theory. In N. Colangelo and G.A. Davis (eds), Handbook of gifted education (pp. 60-74) $\left(3^{\text {rd }}\right.$ edn). Boston, MA: Allyn and Bacon.

Gallops, W. (2005). Developing a healthy paradigm for performers and teachers. Journal of Music Teacher Education, 15(1), 15-22.

Geelan, D. (2003). Weaving narrative nets to capture classrooms: Multi-method qualitative approaches for educational research. Boston: Kluwer Academic Publishers.

Glaser, B. (1992). Basics of grounded theory analysis: emergence vs. forcing. Mill Valley, CA: Sociology Press.

Goodman, D. \& Hambleton, R. K. (2005). Some misconceptions about large-scale educational assessment. In R. Phelps (Ed.) Defending Standardized Testing, (pp. 91-110). Mahwah, NJ: Lawrence Erlbaum Associates, Inc.

Green, L. (2002). How popular musicians learn. Burlington, VT: Ashgate Publishing Company.

Grosskopf, K. (2009). Exploring the complexities of learning motivation in pre-service teacher education students: A grounded theory approach. Unpublished Ph.D. dissertation, University of Nebraska, Lincoln, Nebraska.

Haeffele, J. (2008). A grounded theory approach to the process of successful and advanced weight maintenance. Unpublished Ph.D. dissertation, University of Utah.

Hampton, W. (2004). Measuring school and school system effectiveness. In M. Moll (Ed.) Passing the test: The false promises of standardized testing (pp.257-259). Ottawa, ON: Canadian Centre for Policy Alternatives.

Hargreaves, D. J., Miell, D., and MacDonald, R. A. R. (2003). What are musical identities and why are they important? In R. MacDonald, D. Hargreaves and D. Miell (Eds.) Musical Identities, pp. 1-20. London: Oxford University Press.

Hibbard, D. R., and Buhrmester, D. (2010). Competitiveness, gender, and adjustment among adolescents. Sex Roles, 63 (5), 412-424.

Hines, S. and Groves, D. L. (1989). Sports competition and its influence on self-esteem development. Adolescence, 24 (96), 861-869.

Hitchcock, G. \& Hughes, D. (1995). Research and the teacher: A qualitative introduction to school-based research $\left(2^{\text {nd }} \mathrm{ed}\right)$. London: Routledge. 
Huberman, A. (2004). The experience of growing up in tandem with another and its implications for parenting and educating: An inquiry into the stories of twins and other multiples. Unpublished Ed. D. dissertation, University of Toronto, Toronto, ON.

Hurley, G. (1996). Musical chairs: The psychological and social impact of competition. Dialogue in Instrumental Music Education, 20, 77.

Janesick, V. J. (2001). The assessment debate: A reference handbook. Santa Barbara, CA: ABC-CLIO, Inc.

John, B. (2004). Relating music and affect: An alternative model for structuring music instruction. In Bartel, L. Questioning the Music Education Paradigm (pp. 258269). Waterloo: Canadian Music Educators' Association.

Jorgensen, E. R. (2003). Transforming music education. Bloomington and Indianapolis: IndianaUniversity Press.

Jorgensen, E. R. (1997). In search of music education. Urbana and Chicago: University of Illinois Press.

Kellaghan, T., Madaus, G. F., \& Raczek, A. (1997). The use of external examinations to improve student motivation. Washington, DC: American Educational Research Association.

Kelle, U. (2007). The development of categories: Different approaches in grounded theory. In A. Bryant and K. Charmaz (eds.) The Sage handbook of grounded theory (pp.191-213).Thousand Oaks, CA: Sage Publications.

Kiwanis Music Festival of Greater Toronto. (2012). Music Syllabus. Retrieved from http://kiwanismusictoronto.org/music_syllabus.html.

Kogan, J. (1987). Nothing but the best: The struggle for perfection at The Juilliard School. New York: Random House.

Kohn, A. (2000). The case against standardized testing. Portsmouth, NH: Heinemann.

Lacaille, N., Koestner, R., and Gaudreau, P. (2007). On the value of intrinsic rather than traditional achievement goals: A short-term prospective study. International Journal of Music Education, 25 (3), 245-257.

Lamont, A. (2003). Musical identities and the school environment. In R. MacDonald, D. Hargreaves and D. Miell (Eds.) Musical Identities, pp. 41-59. London: Oxford University Press. 
LaPointe-Crump, J. (2007). Competition and dance education. Journal of Physical Education, Recreation, and Dance, 78 (7), 4-5, 9.

Lebler, D. (2007). Student-as-master? Reflections on a learning innovation in popular music pedagogy. International Journal of Music Education, 25 (3), 205-221.

Lee, J. (2008). Outlier aversion in subjective evaluation: Evidence from world figure skating championships. Journal of Sports Economics, 9 (2), 141-159.

Legette, R. M. (1998). Causal beliefs of public school students about success and failure in music. Journal of Research in Music Education, 46 (1), 102-111.

Lentz, R. S. (2004). Reconceptualizing transvestites: A grounded theory approach. Unpublished D. Psych. Dissertation, Alliant International University, San Francisco, CA.

MacArthur, L. J. (2008). The drive to strive: Exploring the experiences of elite-level adolescent artistic performers. Unpublished doctoral dissertation. University of Toronto, Canada.

MacLean, J. and Hamm, S. (2008). Values and sport participation: Comparing participants groups, age, and gender. Journal of Sport Behaviour, 31 (4), 352-367.

Macmillan, J. (2004). Learning the piano: A study of attitudes toward parent involvement. British Journal of Music Education, 21 (3), 295-311.

Maroon, M. T. (2003). Potential contributors to performance anxiety among middle school students performing at solo and ensemble contests. Unpublished Ph.D. dissertation. Kent State University, United States.

Martin, A. J. (2007). Motivation and engagement in music and sport: Testing a multidimensional framework in diverse performance settings. Journal of Personality, 76 (1), 135-170.

McCormick, J. and McPherson, G. (2003). The role of self-efficacy in a musical performance examination: An exploratory structural equation analysis. Psychology of Music, 31(1), 37-51.

McCormick, J., and McPherson, G. (2000). The contribution of motivational factors to instrumental performance on a music examination. Research Studies in Music Education, 15, 31-39.

McPherson, G., and McCormick, J. (2006). Self-efficacy and music performance. Psychology of Music, 34(3), 322-336. 
Meaghan, D. E. \& Cases, F. R. (2004). Bias in standardized testing and the misuse of test scores: Exposing the Achilles heel of educational reform. In M. Moll (Ed.) Passing the test: The false promises of standardized testing (pp.35-50). Ottawa, $\mathrm{ON}$ : Canadian Centre for Policy Alternatives.

Melnick, C.R. (1991). Linking the in and out of school curricumlum. International Journal of Educational Research, 15, 201-214.

Merriam, S.B. (1988). Case study research in education: A qualitative approach. San Francisco : Jossey-Bass.

Miksza, P. (2006). Relationships among impulsiveness, locus of control, sex, and music practice. Journal of Research in Music Education, 54 (4), 308-322.

Miller, R.E. (1994). A dysfunctional culture: Competition in music. Music Educators' Journal, 81(3), 29-33.

Moll, Marita. (2004). Large scale educational testing: The new face of testing. In M. Moll (Ed.) Passing the test: The false promises of standardized testing (pp.11-16). Ottawa, ON: Canadian Centre for Policy Alternatives.

Morris, G. (2008). Artistry or mere technique? The value of the ballet competition. Research in Dance Education, 9 (1), 39-54.

Morse, J. M. (2007). Sampling in grounded theory. In A. Bryant and K. Charmaz (eds.) The Sage handbook of grounded theory (pp. 229-244). Thousand Oaks, CA: Sage Publications.

Music Educators' National Conference (1997). Where we stand: A position paper of the music educators national conference. Music Educators Journal, 84(2), 41-44.

National Symposium on Arts Education (2001). Sharing the vision: A national framework for arts education in Canadian Schools.

Nichols, S. L. and Berliner, D. C. (2007). Collateral Damage: How high-stakes testing corrupts America's schools. Cambridge, MA: Harvard Education Press.

Nicolas, M., Gaudreau, P. and Franche, V. (2011). Perception of coaching behaviors, coping, and achievement in a sport competition. Journal of Sport and Exercise Psychology, 33 (3), 460-468.

Nielsen, S. G. (2004). Strategies and self-efficacy beliefs in instrumental and vocal individual practice: A study of students in higher music education. Psychology of Music, 32 (4), 418-431. 
O’Neill, S. A. (2003). The self-identity of young musicians. In R. MacDonald, D. Hargreaves and D. Miell (Eds.), Musical Identities, pp. 79-96. London: Oxford University Press.

O'Neill, S. A. and Sloboda, J. A. (1997). The effects of failure on children's ability to perform a musical test. Psychology of Music, 25, 18-34.

Orman, E. K. (2002). Comparison of the national standards for music education and elementary music specialists' use of class time. Journal of Research in Music Education, 50(2), 155164.

Paris, S. G., Byrnes, J. P., and Paris, A. H. (2001). Constructing theories, identities, and actions of self-regulated learners. In B. J. Zimmerman and D. H. Schunk (eds). Self-regulated learning and academic achievement: Theoretical perspectives. $2^{\text {nd }}$ ed. Mahwah, NJ: Lawrence Erlbaum Associates, Publishers. (pp. 253-287).

Phelps, R. P. (2005). The rich, robust research literature on testing's achievement benefits. In R. Phelps (Ed.) Defending Standardized Testing, (pp. 55-90). Mahwah, NJ: Lawrence Erlbaum Associates, Inc.

Pierson, S. (2005). An investigation of the effects of the formal reporting process on primary students' self-efficacy. Ed.D. dissertation, Ontario Institute for Studies in Education, University of Toronto, Toronto, Ontario, Canada.

Pitts, S. E. (2004) Lessons in learning: learning, teaching and motivation at a music summer school. Music Education Research, 6 (1), 81-95.

Popovich, K. (2006). Designing and implementing "exemplary content, curriculum and assessment in art education." Art Education, 56 (6), 33-39.

Power, F. C. (2010). True competition: A guide to pursuing excellence in sport and society. Journal of Moral Education, 39 (2), 251-253.

Price, J. (2008). Gender differences in the response to competition. Industrial and Labor Relations Review, 61(3), 320-333.

Regelski, T. (2006). Reconnecting music education with society. Action, Criticism, and Theory for Music Education, 5(2). Retrieved from http://act.maydaygroup.org/articles/Regelski5_2.pdf on April 3, 2007.

Reimer, B. (2004). Reconceiving the standards and the school music program. Music Educators Journal, 91(1), 33.

Rife, N. A., Scnek, Z. M., Lauby, J. L., and Lapidus, L. B. (2001). Children's satisfaction with private music lessons. Journal of Research in Music Education, 49 (1), 2132. 
Robinson, T. T. and Carron, A. V. (1982). Personal and situational factors associated with dropping out versus maintaining participation in competitive sport. Journal of Sport and Exercise Psychology, 4 (4), 364-378.

Ross, V. (2009). External music examiners: Micro-macro tasks in quality assurance practices. Music Education Research, 11(4), 473-484.

Royal Conservatory of Music. (n.d.) Background and history. Retrieved from http://examinations.rcmusic.ca/background-and-history.

Royal Conservatory of Music. (2008). Piano syllabus: The Royal Conservatory of Music official examination syllabus (RCM Examinations and the National Music Certificate Program). Mississauga, ON: Frederick Harris Music Company.

Ruben, H. L. (1981). Competing. New York: Pinacle Books.

Ryan, C., Wapnick, J., Lacaille, N. and Darrow, A-A. (2006). The effects of various physical characteristics of high-level performers on adjudicators' performance ratings. Psychology of Music, 34 (4), 559-572.

Ryan, R. M., and Deci, E. L. (2000). Self-determination theory and the facilitation of intrinsic motivation, social development, and well-being. American Psychologist ,55 (1), pg. 68-78.

Salaman, W. (1994). The role of graded examinations in music. British Journal of Music Education, 11, 209-221.

Schmidt, C. P. (2005). Relations among motivation, performance achievement, and music experience variables in secondary instrumental music students. Journal of Research in Music Education, 53 (2), 134-147.

Schunk, D. H. (2001). Social cognitive theory and self-regulated learning. In B. J. Zimmerman and D. H. Schunk (eds). Self-regulated learning and academic achievement: Theoretical perspectives. $2^{\text {nd }}$ ed. Mahwah, NJ: Lawrence Erlbaum Associates, Publishers. (pp. 125-151)

Schunk, D. H., Pintrich, P. R., and Meece, J. L. (2007). Motivation in education: Theory, research, and applications. Upper Saddle River, NJ: Pearson.

Schnitt, D. (1990). Psychological issues in dancers: An overview. Journal of Physical Education, Recreation, and Dance,61 (9), 32-34.

Senyshyn, Y. (2004) Popular music and the intolerant classroom. In Bartel, L. Questioning the Music Education Paradigm (pp. 110-120). Waterloo: Canadian Music Educators' Association. 
Sinden, L. M. (1999). Music performance anxiety: contributions of perfectionism, coping style, self-efficacy, and self-esteem. Unpublished Ph.D. dissertation, University of Arizona.

Sireci, S. G. (2005). The most frequently unasked questions about testing. In R. Phelps (Ed.) Defending Standardized Testing, (pp. 111-121). Mahwah, NJ: Lawrence Erlbaum Associates, Inc.

Small, C. (1998). Musicking: The meanings of performing and listening. Middletown, Connecticut: Wesleyan University Press.

Small, C. (1977). Music, society, education. London: Wesleyan University Press.

Smith, B. P. (2005). Goal orientation, implicit theory of ability, and collegiate instrumental music practice. Psychology of Music, 33 (1), 36-57.

Snowman, J., McCown, R., Biehler, R. (2009). Psychology Applied to Teaching. New York: Houghton Mifflin Company.

Stanley, M., Brooker, R. and Gilbert, R. (2002). Examiner perceptions of using criteria in music performance assessment. Research Studies in Music Education, 18 (1), 4656.

Stipek, D. (2002). Motivation to learn: Integrating theory and practice, $4^{\text {th }} \mathrm{ed}$. London: Allyn and Bacon.

Stollak, G.E. (1996). Competition in choral education: Adults' memories of early choir experiences. The Choir Journal,37(1), 21-27.

Strauss, A. and Corbin, J. (1998). Basics of qualitative research: Techniques and procedures for developing grounded theory, $2^{\text {nd }}$ ed. Thousand Oaks, CA: Sage Publications.

Temmerman, N. (2005). Children's participation in music: connecting the cultural contexts - an Australian perspective. British Journal of Music Education, 22 (2), 113-123.

Trevarthen, C. (2003). Origins of musical identity: evidence from infancy for musical social awareness. In R. MacDonald, D. Hargreaves and D. Miell (Eds.) Musical Identities, pp. 21-40. London: Oxford University Press.

Tye, J. K.-C. (2004). A survey of the current status and practices of piano teachers in Penang, Malaysia: Preparation for the practical piano examinations of the Associated Board of the Royal Schools of Music, London. Unpublished D.M.A. dissertation, University of South Carolina, Columbia, South Carolina, United States of America. 
Valiquette, S. M. (1995). The effects of the gymnast's body shape on the judging of gymnastics. Unpublished M.A. thesis, McGill University, Montreal, Quebec, Canada.

Wapnick, J., Darrow, A., Kovacs, J., and Dalrymple, L. (1997). Effects of physical attractiveness on evaluation of vocal performance. Journal of Research in Music Education, 45(3), 470-479.

Wapnick, J. and Ekkolm, E. (1997). Expert consensus in solo voice performance evaluation. The Journal of Voice, 11(4), 429-436.

Wapnick, J., Flowers, P., Alegant, M., and Jasinskas, L. (1993). Consistency in piano performance evaluation. Journal of Research in Music Education, 41(4), 282-292.

Wapnick, J., Mazza, J., and Darrow, A. (2000). Effects of performer attractiveness, stage behavior, and dress on evaluation of children's piano performances. Journal of Research in Music Education, 48(4), 323-335.

Wapnick, J., Mazza, J., and Darrow, A. (1998). Effects of performer attractiveness, stage behavior, and dress on violin performance evaluation. Journal of Research in Music Education, 46(4), 510-521.

Weiner, B. (1986). An Attributional Theory of Motivation and Emotion. New York: Springer-Verlag.

Wigfield, A., and Eccles, J. (2000). Expectancy-value theory of achievement motivation. Contemporary Educational Psychology, 25 (1), 68-81.

William, D. (2011). What is assessment for learning? Studies in Educational Evaluation. 37, 3-14.

Winter, N. (1993). Music performance assessment: A study of the effects of training and experience on the criteria used by music examiners. International Journal of Music Education, 22, 34-39.

Wood, D. R. (2007). A grounded theory of teacher sensemaking in a climate of change. Unpublished Ed.D. dissertation, University of Montana, Missoula, Montana.

Woody, R. H. (2001). Learning from the experts: applying research in expert performance to music education. Update: applications of research in music education, 19 (2), 9-14.

Wu, S.S., and Yang, M. C. K. (2004). Evaluation of the current decision rule in figure skating and possible improvements. The American Statistician, 58(1), 46-54. 
Yun Dai, D. and Schader, R. (2001). Parents' reasons and motivations for supporting their child's music training. Roeper Review, 24 (1), 23-26.

Zeidner, M. and Matthews, G. (2005). Evaluation anxiety: Current theory and research. In A.J. Elliot and C.S. Dweck (eds.) Handbook of competence and motivation (pp. 141-167). NY: The Guildford Press.

Zenic, N., Peric, M., Zubcevic, N.G., Ostojic, Z., and Ostojic, L. (2010). Comparative analysis of substance use in ballet, dance sport, and synchronized swimming. Medical Problems of Performing Artists, 25(2), 75.

Zenker, R. (2004). Music as a lifelong pursuit: educating for a musical life. In L. Bartel, (ed. ) Questioning the Music Education Paradigm (pp. 121-135). Waterloo: Canadian Music Educators' Association.

Zimmerman, B. J. (2001). Theories of self-regulated learning and academic achievement; an overview and analysis. In B. J. Zimmerman and D. H. Schunk (eds). Selfregulated learning and academic achievement: Theoretical perspectives. $2^{\text {nd }}$ ed. Mahwah, NJ: Lawrence Erlbaum Associates, Publishers. (pp. 1-37). 


\section{Appendix A: Interview and Journal Guides}

\section{(The interviews were semi-structured. The following questions provided a starting point for conversation, but some variation occurred based on the information shared by individual participants.)}

\section{Interview Guide - Student Interviews}

\section{Interview \#1}

Thank you for meeting with me today. I would like to ask you some questions to find out more about you and your piano studies. If you're not sure what a question is trying to ask, please don't hesitate to ask me to clarify. You can choose not to answer any question. You can also choose to stop the interview at any time. With your permission, I will be recording our conversation.

1. Can you tell me about the object you brought today? What makes it special to you? How is it connected to your piano studies?

2. Please tell me about your background as a piano student. (Possible probing questions: What do you like best about learning to play the piano? Are there things you find boring or frustrating? Can you tell me about your practicing? Do your parents or your teacher help you with knowing what to practice and how often?)

3. Please tell me about any other musical background that you have. (Possible probing questions: Are you involved in any other musical activities besides your piano lessons? (If yes, describe) How do you use music to express yourself? Do you make music with other people? (If yes, describe when/with whom/feelings about these activities) Do you play the piano for other people? (for example, friends, family members))

4. Please tell me about your experiences as a performer. (Possible probing questions: How do you feel about performing in public? How do you feel about performing for an examiner or adjudicator? What made you decide to participate in your upcoming festival/exam/competition?)

Thank you again for spending time talking to me today.

\section{Interview \#2}

Thank you for meeting with me today. I would like to ask you some questions to find out more about your upcoming festival/exam/competition. If you're not sure what a question is trying to ask, please don't hesitate to ask me to clarify. You can choose not to answer any question. You can also choose to stop the interview at any time. With your permission, I will be recording our conversation.

1. Please tell me about the experience of writing your journal over the last few weeks. (Possible probing questions: Did you notice anything interesting about 
your learning or your practicing while you were writing your journals? How are you feeling about your exam/festival/competition? What kinds of things have you done to prepare for your exam/festival/competition? Could you tell me more about [a certain aspect of] this entry?)

2. What kind of performance would make you really happy?

Thank you again for spending time talking to me today.

\section{Interview \#3}

Thank you for meeting with me today. I would like to ask you some questions to find out more about your experience at your recent festival/exam/competition. If you're not sure what a question is trying to ask, please don't hesitate to ask me to clarify. You can choose not to answer any question. You can also choose to stop the interview at any time. With your permission, I will be recording our conversation.

1. Can you tell me about your drawing? (Possible probing questions: What stood out about your experience at your exam/festival/competition? What went well? Was there anything you wish had gone better? How would you describe the environment at your exam/festival/competition? Did you feel well-prepared for your performance? What did you do to prepare? Did you feel nervous before your performance? What kinds of strategies do you use to help you control your nerves? How did you feel about the examiner/adjudicator (for example, was he or she friendly? Intimidating? Did he or she do anything specific to try to put you at ease?))

2. Would you want to participate in a performance like this again?

3. How did this experience compare with other evaluations/tests/competitions you have been involved in? (for example, tests at school, sports events)

Thank you again for spending time talking to me today.

Interview \#4 (may be combined with interview \#3 if the student received his or her results immediately after the performance)

Thank you for meeting with me today. I would like to ask you some questions to find out more about the feedback you received for your recent festival/exam/competition. If you're not sure what a question is trying to ask, please don't hesitate to ask me to clarify. You can choose not to answer any question. You can also choose to stop the interview at any time. With your permission, I will be recording our conversation.

1. How do you feel about the feedback you got from the examiner/adjudicator? (Possible probing questions: Do you think the feedback is accurate/fair? Is there any part of the report that you don't understand? Was there anything that surprised you? Did your teacher or parents talk about the feedback with you? If so, what did they say about it?)

2. What do you consider a good result? Why? 
3. What do you think makes students successful in exams/festivals/competitions? What makes students unsuccessful?

4. How do you think this feedback will influence your preparations for future performances? (Possible probing questions: Were there any suggestions that you thought were particularly helpful? How did this feedback compare with the feedback you received from your teacher while you were preparing?

Thank you again for spending time talking to me today. 


\section{Interview Guide - Parent Interview}

Thank you for meeting with me today. I would like to ask you some questions to find out more about your child's piano studies and your views on festivals/exams/competitions. If you're not sure what a question is trying to ask, please don't hesitate to ask me to clarify. You can choose not to answer any question. You can also choose to stop the interview at any time. With your permission, I will be recording our conversation.

1. Please tell me about [child's] background as a piano student. (Possible probing questions: How long has [child] been taking piano lessons? What made you decide to register [child] for lessons? What made you choose [teacher]?)

2. What do you think are the main benefits to children taking piano lessons? What are the challenges or drawbacks?

3. Please tell me about your child's involvement in exams/festivals/competitions. (Possible probing questions: How did you first find out about the exam/festival/competition your child is performing in? What made you decide to register [child] for the exam/festival/competition? What do you think is the purpose for participating in exams/festivals/competitions? How does your child feel about participating in exams/festivals/competitions?)

Thank you again for spending time talking to me today. 


\section{Interview Guide - Teacher Interview}

Thank you for meeting with me today. I would like to ask you some questions to find out more about views on the role of festivals/exams/competitions in student learning. If you're not sure what a question is trying to ask, please don't hesitate to ask me to clarify. You can choose not to answer any question. You can also choose to stop the interview at any time. With your permission, I will be recording our conversation.

1. Please tell me about your background as a teacher. (Possible probing questions: How long have you been teaching? What kind of training did you do in preparation for teaching? What do you like best about teaching piano? What do you find most challenging?)

2. What are your values as a teacher? (Possible probing questions: What skills do you think are most important? Who should take piano lessons? How would you describe your relationship with your students?)

3. How do you approach festivals, competitions, and exams with your students? (Possible probing questions: Do all students participate in these performances? If not, what factors do you take into account when recommending that a student participate? What do you see as the benefits and drawbacks of students participating in evaluative performances? If a student is preparing for an evaluative performance, does that affect the way you teach that particular student? If yes, in what way(s)?)

4. How do you think your students' performances relate to your abilities as a teacher?

Thank you again for spending time talking to me today. 


\section{Interview Guide - Former Students}

Thank you for your interest in my research. Please answer the questions as honestly and thoroughly as you can. You can choose not to answer any question(s). If this interview is being conducted via e-mail, I might send you some follow-up questions to learn more about any interesting points you bring up.

1. Please tell me about your background as a piano student. (When did you start? What made you interested in learning to play the piano? What were/are your favourite/least favourite parts of learning to play the piano? What kind(s) of music do you enjoy?)

2. How do/did you feel about performing in public? What kinds of performances were you involved in as a piano student?

3. What influenced you to take exams/play in festivals?

4. Can you describe some of your experiences playing in exams and festivals? (What were some of the positive aspects and drawbacks of exams and festivals? What kinds of feedback did you receive from the adjudicator/examiner? Was it helpful? How did you feel about the adjudicators/examiners? Were they friendly/intimidating/helpful/etc? What was the atmosphere like during the performances?)

5. What made you decide to stop taking exams/playing in festivals?

6. If you're still playing the piano, what do you play? Do you still perform? (If so, where?)

7. If you're not playing the piano anymore, what made you want to stop? Do you think you would ever want to go back to it? What factors would influence that decision?

8. Did you ever experience performance anxiety/nervousness? If so, what did that feel like? Did you have any strategies for coping with the nerves? How did feeling nervous affect your performances? If not, what do you think helped you feel confident in performance?

9. Some people think that when students participate in festivals or exams, they will be more motivated to study the piano. What do you think of this statement?

10. Many students I've interviewed have quite specific goals regarding their piano studies and the level they would like to reach or music they would like to be able to play. What were some of your goals as a piano student? When you stopped taking lessons, did you feel that you had achieved those goals?

11. Is there anything else that is significant about your time as a piano student or your experiences with festivals and exams that you would like to tell me about? 


\section{Journal Guides}

\section{To be completed after a lesson:}

Please complete the following sentences. You may choose not to answer any question or to add further comments at the end if you wish.

1. Today we worked on

2. The best part of today's lesson was

3. The worst part of today's lesson was

4. This is how I feel about my upcoming festival/exam/competition

5. This is how I think my teacher feels about my upcoming festival/exam/competition

6. These are my goals for the coming week

7. This is how I will achieve those goals

\section{To be completed after a practice session:}

Please complete the following sentences. You may choose not to answer any question or to add further comments at the end if you wish.

1. Today I practiced

2. I wanted to achieve

3. These are the strategies I used

4. This is how I feel about today's practice session

5. This is how I feel about my upcoming festival/exam/competition 


\section{Appendix B: Survey}

SurveyMonkey - Question Builder

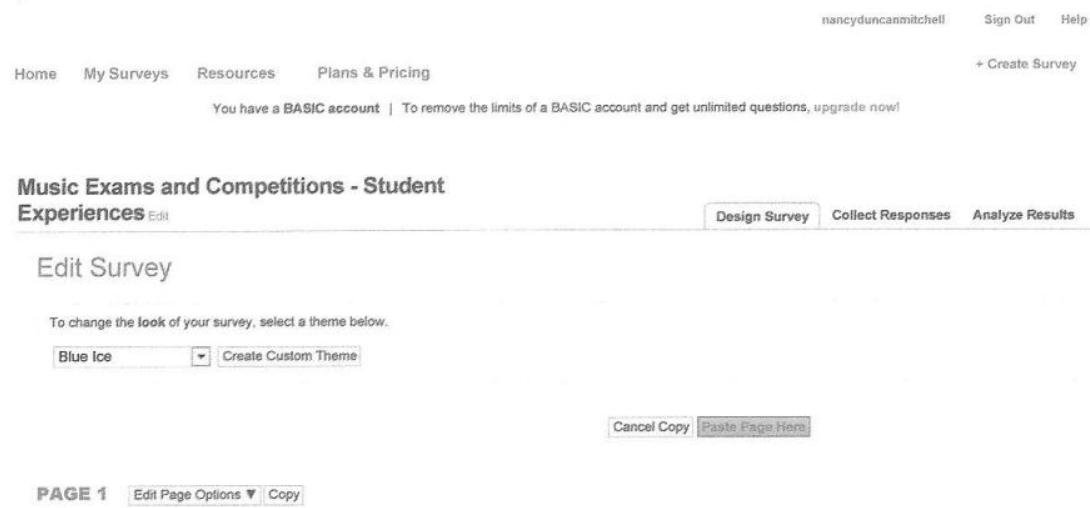

\section{Gender}

$\div$

Geographic Location

+ Add Question V Split Page Here

Q2 Edit Question V Move Copy Delete

2. Please sefect the response that best describes you in each category:

Years of Study Main Method of Instruction Main Instrument $\quad$ Studies Began Achieved (on Other Than

http://www.surveymonkey.com/MySurvey_EditorFull.aspx?sm=4jh1U1kPtBcCStZZDC... 04/06/2012 


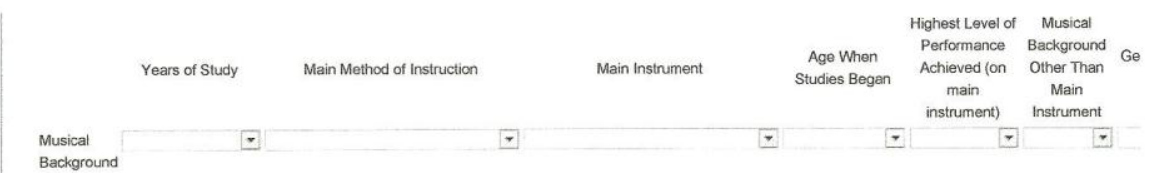

If you selected "some" or "extensive" to describe your musical background outside of your studies on your main instrument, please describe briefly (ex. sang in school che lessons).

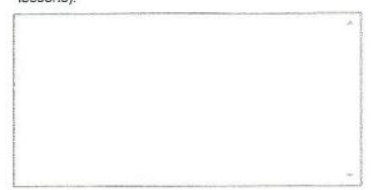

+Add Question $\mathbf{V}$ Split Page Here

Q3 Edit Question $v$ Add Question Logic Move Copy Delete

3. Please indicate the kind(s) of evaluations in which you participated. (Check all that apply.)

1. Conservatory Examination

Rated Festival (received a ratimg such as "gold" or "superior," or :

Competition (received a rank, such as first, second, third) not compared to other participants)

Non-compettive Festival (received comments only, no mark, ratin

+ Add Question V Split Page Here

Q4 Edit Question $>$ Move Copy Delete

4. Please select the reponse that best describes you in each category:

Number of Evaluations in Which You Overall Level of Achievement Age at First Evaluation Age at I
Performed

Experiences with Exams, Performed

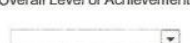

Competitions, and Festivals

Q5 Eotit Question $\mathbf{v}$ Move Copy Delete

5. Based on your experiences, how accurately does each of the following statements complete the sentence below?

Performing in exams, competitions, or festivals...

Not accurately at all Not very accurately Sort of accurately Quite accurately $\quad$ Very accurately

was enjoyable

was stressful.

gave me a sense of accomplishment

was something I looked forward to

motivated me to practice more

helped me improve as a musician

was important to my parents.

was important to my teacher.

was important to me.

If you participated in different kinds of evaluations (for example, exams and competitions) and feel differently about the different evaluations, please describe briefiy.

http://www.surveymonkey.com/MySurvey_EditorFull.aspx?sm=4jh1U1kPtBcCStZZDC... 04/06/2012 


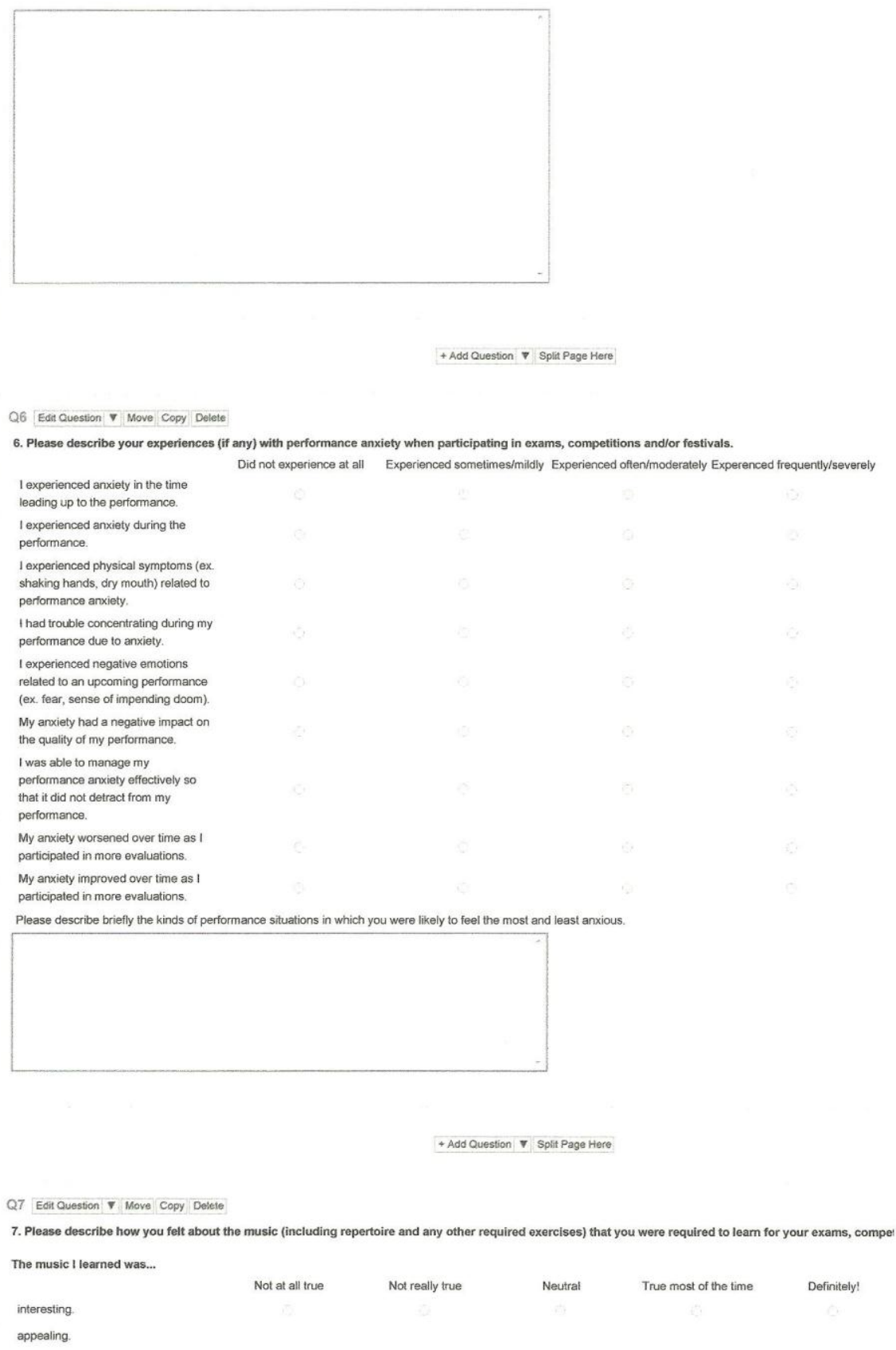

http://www.surveymonkey.com/MySurvey_EditorFull.aspx?sm=4jh1U1kPtBcCStZZDC... 04/06/2012 


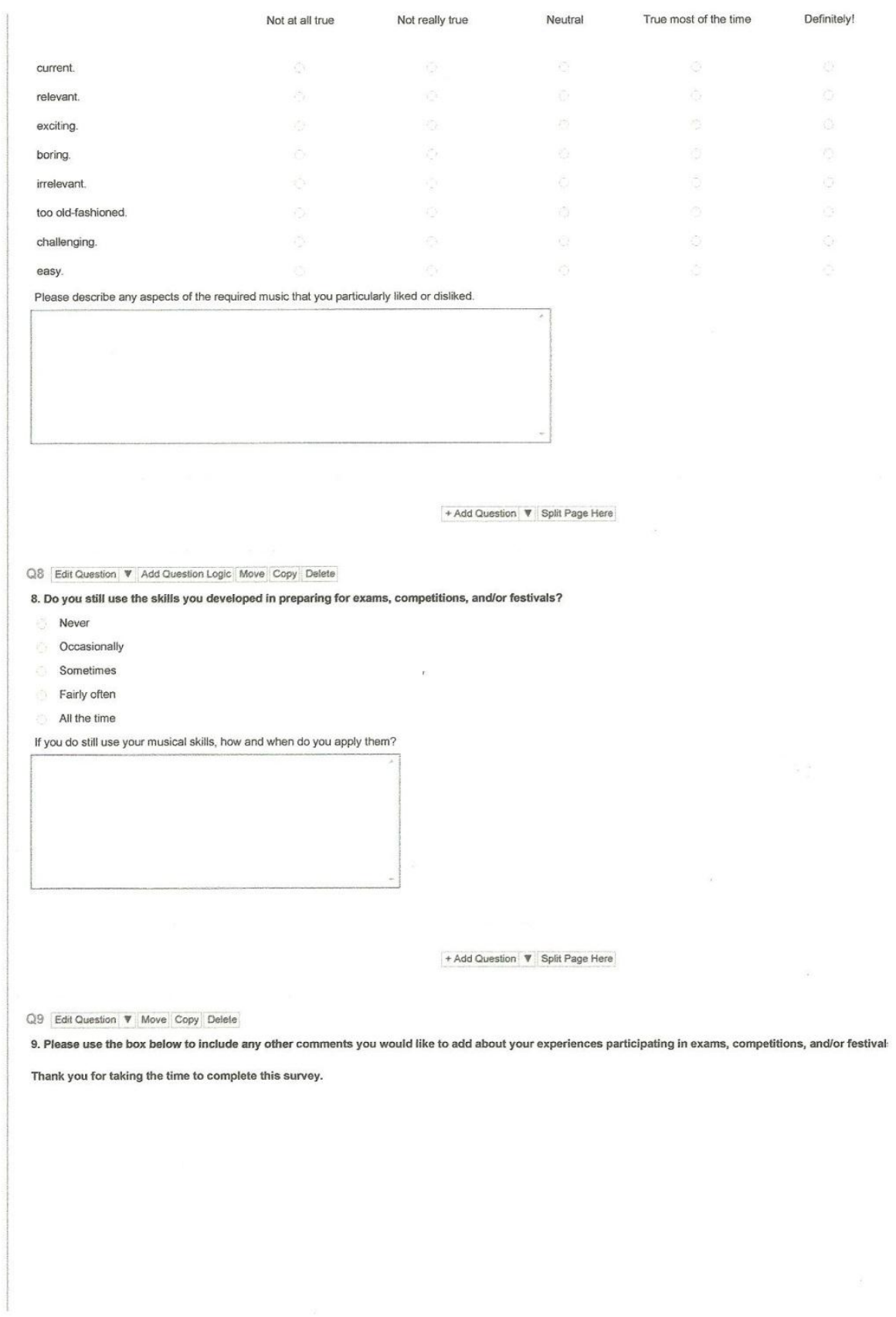

http://www.surveymonkey.com/MySurvey_EditorFull.aspx?sm=4jh1U1kPtBcCStZZDC... 04/06/2012 


\section{Appendix C: Information and Consent Letters}

\section{(All letters were printed on official institutional letterhead, with the exception of the initial information letter to teachers, which was sent as an email.)}

\section{Initial Information Letter - Teacher Participants \\ Dear Colleague of the Piano Teaching Community,}

I am a piano teacher and graduate student conducting research into beginning and intermediate piano students' experiences participating in festivals, exams, and competitions as part of my Ph.D. work in music education at the University of Toronto. I am hoping to work with 10 students and their parents and teachers. I will be gathering information through interviews and lesson observations. If you choose to participate, I would ask you to distribute an information letter to your students. Your involvement as a participant would consist of one interview lasting approximately 45 minutes and video taping lessons with the students who also choose to participate.

Please do not hesitate to contact me if you have any questions or if you would like more information. If you are interested in this research, I will send you a consent form which contains detailed information about the research and about the rights of participants. You can reach me by phone at (416)528-3412 or by email at n.mitchell@utoronto.ca.

Thank you for considering this project. I look forward to hearing from you soon.

Sincerely,

Nancy Mitchell

Ph.D. candidate, Music Education Department

Faculty of Music

University of Toronto 


\section{Initial Information Letter - Parent Participants and Student Participants Under Age 16}

Dear Parent/Guardian,

I am conducting research into beginning and intermediate piano students' experiences participating in festivals, exams, and competitions as part of my Ph.D. work in music education at the University of Toronto. I am hoping to work with 10 students and their parents and teachers. I will be gathering information through interviews with all the participants and through lesson observations. If you choose to participate, your involvement as a participant would consist of one interview lasting approximately 45 minutes. Your child would be interviewed 3 or 4 times leading up to and immediately following his or her performance in an upcoming festival, exam, or competition. He or she would also have six lessons video taped in the weeks before the performance.

If you are interested in this project, please contact me and I will send you a consent form which contains detailed information about the research and about the rights of participants. Please do not hesitate to contact me if you have any questions. You can reach me by phone at (416)528-3412 or by email at n.mitchell@utoronto.ca.

Sincerely,

Nancy Mitchell

Ph.D. candidate, Music Education Department

Faculty of Music

University of Toronto 


\section{Initial Information Letter - Student Participant (16 years or older)}

\section{Dear Piano Student,}

I am conducting research into beginning and intermediate piano students' experiences participating in festivals, exams, and competitions as part of my Ph.D. work in music education at the University of Toronto. I am hoping to work with 10 students and their parents and teachers. I will be gathering information through interviews with all participants and through lesson observations. If you choose to participate, your involvement as a participant would consist of being interviewed 3 or 4 times leading up to and immediately following your performance in an upcoming festival, exam, or competition and having six lessons video taped in the weeks before the performance.

If you are interested in this project, please contact me and I will send you a consent form which contains detailed information about the research and about the rights of participants. Please do not hesitate to contact me if you have any questions. You can reach me by phone at (416)528-3412 or by email at n.mitchell@utoronto.ca.

Sincerely,

Nancy Mitchell

Ph.D. candidate, Music Education Department

Faculty of Music

University of Toronto 


\title{
Consent Form - Teacher Participants
}

\author{
Dear Colleague of the Piano Teaching Community,
}

I am a Ph.D. student in the Music Education Department at the University of Toronto and I would like to invite you to participate in a research project I am conducting into beginning and intermediate piano students' experiences with festivals, competitions and exams. This study will form the basis of my dissertation and any other resulting publications. The purpose of the research is to understand how students experience performances in which they are evaluated so that these experiences can be taken into account when teachers and students are making decisions about student participation in future evaluations.

Participation in this study is entirely voluntary. Should you decide to participate, you may withdraw at any time without penalty. Please read the information below to better understand what is involved in this research. If you are willing and able to participate, please sign both copies of the consent form, and return one to me either in the enclosed self-addressed, stamped envelope or in person at our interview. The other copy of the consent form is for your own records

\section{Who will be involved in this study?}

Participants in this study will be 10 beginning and intermediate piano students who are at least eight years of age and who are preparing for an evaluative performance (i.e. a festival, competition, or conservatory exam), along with a parent and teacher for each student. If you would be interested in participating in this study, I will ask you distribute information letters to the parents of all of your students who meet the age and level requirements for participation (in the case of students who are age 16 or older, the information letter can be given directly to the student). This initial letter will contain my contact information so that potential participants can get in touch with me to receive a more detailed consent form.

\section{How will information be collected?}

Data will be collected through interviews and lesson observations and will be analyzed for themes. Participating teachers will be interviewed once (for approximately 45 minutes) to discuss their views regarding the role of festivals, competitions, and exams in student learning. If more than one student in your studio is participating in the study, you will still only need to complete one interview, as we will not be discussing specific information about the participating students. With your consent, I will make an audio recording of the interview in order to have an accurate record of our conversation. The recording will be used to generate a written transcript, which will be sent to you before I begin analyzing data so that you can indicate if there is anything you would like to clarify or have omitted from the analysis. The interview will take place in a location of your choosing for the sake of your comfort and convenience. 
Six lessons will be videotaped for each participating student. The lesson observations will take place during the six weeks immediately before the evaluative performance. Consent from the student (if he or she is at least 16 years of age) or the parent/guardian (if the student is under age 16) will also be necessary in order for the recording to take place. I will let you know which of your students have permission to be recorded. The observations will serve as an illustration of what you and the student will discuss with me in your interviews; they are not intended to be judgmental or evaluative in any way.

\section{How will participants' privacy be protected?}

All data collected will be treated with strict confidentiality. The professors on my thesis committee and I will be the only people to see this information. Participants will choose their own pseudonyms and any other identifying information will be altered. All raw data (such as interview recordings and transcripts and video tapes) will be securely stored at my home and destroyed upon completion of the research.

\section{What are the benefits and risks involved in participating in this research?}

The benefits and risks involved in this study are minimal. Participating in this study will provide you with an opportunity to reflect on the role that evaluative performances play in your students' learning. It is my hope that the findings of this study will be useful for teachers who are trying to make decisions about appropriate curriculum and assessment for their students. There are no significant risks involved in this study; however, participating in the entirety of this research project will require a time commitment of approximately 45 minutes to complete the interview, with additional time to distribute information to parents and students and to set up and take down recording equipment for the lesson observations.

\section{Who do I contact if I have questions?}

If you would like more information before making a decision or if you have any questions or concerns during the study, please do not hesitate to contact me directly at (416)528-3412 or by email at n.mitchell@ utoronto.ca. You may also contact my supervisor, Prof. Lee Bartel by phone at or by email at lbartel@chass.utoronto.ca. For more information on the rights of research participants, you may contact the Ethics Review Office of the University of Toronto by email at ethics.review @utoronto.ca or by phone at (416)946-3273. I will contact participants when the study is complete so that you can receive a written summary of the findings if you wish.

Thank you for considering my request to participate in this study.

Sincerely, 
Nancy Mitchell

Ph.D. candidate, Music Education Department

Faculty of Music

University of Toronto

Please read the form below and check the appropriate boxes to indicate your consent to participate in this research and to be recorded.

\section{Teacher as Participant}

Name of participant:

I have read the above information and consent to participate in this research.

I consent to have an audio recording made of my interview.

I consent to have video recordings made of the lessons that will be observed.

Signature of participant:

Date: 


\title{
Consent Form - Parent Participants and Student Participants Under Age 16
}

\author{
Dear Parent/Guardian,
}

I am a Ph.D. student in the Music Education Department at the University of Toronto and I would like to invite you and your child to participate in a research project I am conducting into beginning and intermediate piano students' experiences with festivals, competitions and exams. This study will form the basis of my dissertation and any other resulting publications. The purpose of the research is to understand how students experience performances in which they are evaluated so that these experiences can be taken into account when teachers and students are making decisions about student participation in future evaluations.

Participation in this study is entirely voluntary. Should you decide to participate, you may withdraw at any time without penalty. Please read the information below to better understand what is involved in this research. If you are willing and able to participate, please sign both copies of the consent form, and return one to me either in the enclosed self-addressed, stamped envelope or in person at our interview. The other copy of the consent form is for your own records

\section{Who will be involved in this research?}

Participants in this study will be 10 beginning and intermediate piano students who are at least eight years of age and who are preparing for an evaluative performance (i.e. a festival, competition, or conservatory exam), along with a parent and teacher for each student. If you and your child would be interested in participating in this study, please sign the form at the bottom of this letter. If your child is under the age of 16 , your consent to his or her participation is required. If your child is 16 years of age or older, he or she will need to sign a separate consent form. Younger children will sign a simplified form indicating that they agree to participate.

\section{How will information be collected?}

Data will be collected through interviews and lesson observations. Participating parents will be interviewed once (for approximately 45 minutes) to discuss their views on why children and adolescents study the piano and the role of festivals, competitions, and exams in student learning. If you have more than one child participating in the study, you will still only need to complete one interview.

Students will be interviewed a total of three or four times, depending on when they receive the feedback from their performance. Each interview will take 15-30 minutes. The first two interviews will take place in the six weeks leading up to the festival, exam, or competition. Using objects and journal entries to focus our conversation, we will discuss the student's background as a pianist and the specific preparations that he or she has undertaken for the upcoming performance. The third and fourth interviews will focus on the student's experience at the performance and his or her feelings about the feedback 
that was given. I will ask students to draw a picture of their experience. With permission from you and your child, the picture may be included in the final report.

With consent from you and your child, I will make an audio recording of the interviews in order to have an accurate record of our conversation. The recordings will be used to generate written transcripts, which will be used as I look for themes in the data. You will have an opportunity to review your transcript before I begin the analysis. In some cases, the interview transcripts will be used to generate narratives (participant stories) to be included in the final report. In cases where a story comes from one participant, I will send the story to the participant to check for accuracy and to ensure that the participant is comfortable with the information included before I add it to the thesis. The interviews will take place in a location of your choosing for the sake of your comfort and convenience. At your child's request, you may be in the room with your child during his or her interviews.

Six lessons will be videotaped for each participating student. The lesson observations will take place during the six weeks immediately before the evaluative performance. Consent from the student (if he or she is at least 16 years of age) or the parent/guardian (if the student is under age 16) will also be necessary in order for the recording to take place. The observations will serve as an illustration of what the student and teacher will discuss with me in the interviews; they are not intended to be judgmental or evaluative in any way of either the student or the teacher.

\section{How will participants' privacy be protected?}

All data collected will be treated with strict confidentiality. Participants will choose their own pseudonyms and any other identifying information will be altered. All raw data (such as interview recordings and transcripts and video tapes) will be securely stored at my home and destroyed upon completion of the research. I will be the only person to see this information. You and your child are free to discuss any information from the interviews; however, I will not share any information from interviews with other participants.

\section{What are the benefits and risks involved in participating in this study?}

The benefits and risks involved in this study are minimal. Participating in this study will provide you with an opportunity to reflect on the role that evaluative performances play in your students' learning. It is my hope that the findings of this study will be useful for teachers who are trying to make decisions about appropriate curriculum and assessment for their students. There are no significant risks involved in this study; however, participating in the entirety of this research project will require a time commitment of approximately 45 minutes to complete the interview. The time commitment for students will be more significant, with approximately 2 hours needed for the interviews and another 2-3 hours to complete the journals.

\section{Who do I contact if I have questions?}

If you would like more information before making a decision or if you have any questions or concerns during the study, please do not hesitate to contact me directly at 
(416)528-3412 or by email at n.mitchell@utoronto.ca. You may also contact my supervisor, Prof. Lee Bartel by phone at or by email at lbartel@ chass.utoronto.ca. For more information on the rights of research participants, you may contact the Ethics Review Office of the University of Toronto by email at ethics.review @utoronto.ca or by phone at (416)946-3273. I will contact participants when the study is complete so that you can receive a written summary of the findings if you wish.

Thank you for considering my request to participate in this study.

Sincerely,

Nancy Mitchell

Ph.D. candidate, Music Education Department

Faculty of Music

University of Toronto

Please read the form below and check the appropriate boxes to indicate your consent to participate in this research and to be recorded. If your child is 16 years of age or older, you do not need to fill in the second part of the form, as your child will sign his or her own consent form.

\section{Parent as Participant}

Name of participant:

I have read the above information and consent to participate in this research.

I consent to have an audio recording made of my interview.

Signature of participant:

Date:

\section{Child (under age 16) as Participant}

Name of Participant: 
Name of Parent/Guardian:

I have read the above information and consent to my child participating in this research.

I consent to have audio recordings made of my child's interviews.

I consent to have video recordings made of the lessons that will be observed.

Parent/Guardian's Signature:

Date: 


\title{
Consent Form - Student Participants (Age 16 and Older)
}

\author{
Dear Piano Student,
}

I am a Ph.D. student in the Music Education Department at the University of Toronto and I would like to invite you to participate in a research project I am conducting into beginning and intermediate piano students' experiences with festivals, competitions and exams. This study will form the basis of my dissertation and any other resulting publications. The purpose of the research is to understand how students experience performances in which they are evaluated so that these experiences can be taken into account when teachers and students are making decisions about student participation in future evaluations.

Participation in this study is entirely voluntary. Should you decide to participate, you may withdraw at any time without penalty. Please read the information below to better understand what is involved in this research. If you are willing and able to participate, please sign both copies of the consent form, and return one to me either in the enclosed self-addressed, stamped envelope or in person at our interview. The other copy of the consent form is for your own records

\section{Who will be involved in this research?}

Participants in this study will be 10 beginning and intermediate piano students who are at least eight years of age and who are preparing for an evaluative performance (i.e. a festival, competition, or conservatory exam), along with a parent and teacher for each student.

\section{How will information be collected?}

Data will be collected through interviews and lesson observations. With your consent, I will make audio recordings of the interviews in order to have an accurate record of our conversation. The interviews will take place in a location of your choosing for the sake of your comfort and convenience. You will be interviewed a total of three or four times, depending on when they receive the feedback from their performance. Each interview will take 15-30 minutes. The first two interviews will take place in the six weeks leading up to the festival, exam, or competition. Using objects and journal entries to guide our conversations, we will talk about your background as a piano student and the specific preparations you have been making for your upcoming performance. The third and fourth interviews will take place after the performance and will focus on your experience and your feelings about the feedback you received. I will ask you to draw a picture of your performing experience. With your permission, the picture may be included in the final report.

Six lessons will be videotaped for each participating student. The lesson observations will take place during the six weeks immediately before the evaluative performance. The recording will take place with consent from both you and your teacher. The observations will serve as an illustration of what you and your teacher will discuss with me in the interviews; they are not intended to be judgmental or evaluative in any way. 


\section{How will participants' privacy be protected?}

All data collected will be treated with strict confidentiality. The professors on my thesis committee and I will be the only people to see this information. Participants will choose their own pseudonyms and any other identifying information will be altered. All raw data (such as interview recordings and transcripts and video tapes) will be securely stored at my home and destroyed upon completion of the research. You are free to discuss what we talk about with your parents and/or your teacher; however, I will not share any information from your interviews with other participants.

I will include narrative accounts (stories from participants) in the final report. In cases where a story comes from one participant, I will send the story to the participant to check for accuracy and to ensure that the participant is comfortable with the information included before I add it to the thesis.

\section{What are the benefits and risks involved in participating in this research?}

The benefits and risks involved in this study are minimal. Participating in this study will provide you with an opportunity to reflect on your own learning and on the role that evaluative performances play in your studies. There are no significant risks involved in this study; however, participating in this research project will require a time commitment of approximately 2 hours for the interviews and another 2-3 hours to complete the journals.

\section{Who do I contact if I have questions?}

If you would like more information or if you have any questions or concerns during the study, please do not hesitate to contact me directly at (416)528-3412 or by email at n.mitchell@utoronto.ca. You may also contact my supervisor, Prof. Lee Bartel by phone at or by email at lbartel@ chass.utoronto.ca. For more information on the rights of research participants, you may contact the Ethics Review Office of the University of Toronto by email at ethics.review@ utoronto.ca or by phone at (416)946-3273. I will contact participants when the study is complete so that you can receive a written summary of the findings if you wish.

Thank you for considering my request to participate in this study.

Sincerely,

Nancy Mitchell

Ph.D. candidate, Music Education Department

Faculty of Music

University of Toronto 
Please read the form below and check the appropriate boxes to indicate your consent to participate in this research and to be recorded.

\section{Student as Participant (Age 16 or older)}

Name of participant:

I have read the above information and consent to participate in this research.

I consent to have audio recordings made of my interviews.

I consent to have video recordings made of the lessons that will be observed.

Signature of participant:

Date: 


\title{
Assent Letter - Student Participants Under Age 16
}

\author{
Dear Piano Student,
}

I am a Ph. D. student at the University of Toronto doing research into piano students' experiences participating in festivals, exams, and competitions. Since you will be involved in a performance like this in the near future, I would like to find out about your preparations and how you feel about the performance once it is over.

To gather information for this research, I would like to meet and talk with you three or four times, for about 15-30 minutes each time. For our first meeting, I would like you to bring an object that is connected to your piano studies in some way. If you can't bring the actual object, think about one that you could describe. To prepare for our second conversation, I would like you to write some short journal entries describing what you are working on in your lessons and practice sessions. The third and fourth meetings would happen after your performance. During these conversations, we would talk about how you felt about the performance and about the feedback you received. To help us focus our conversation, I will ask you to draw a picture of your performance. So that I have an accurate record of our conversations, I will make an audio recording as we talk.

Another way that I will be gathering information is through observing a few of your lessons leading up to your performance. I would like to make a video of these lessons so that I don't disturb you and your teacher while you are working. Watching the videos will help me understand how you and your teacher have been preparing for your performance. I won't be criticizing or judging either you or your teacher.

Your privacy will be protected in several ways. I will not use your real name in my thesis (you will get to choose your own nickname). I and the professors who are supervising my project will be the only people to see or listen to the information that is collected through our conversations and the lesson observations. When the research is finished, I will destroy the recordings. You can talk to your parents or teacher about anything we discuss, but I won't share information from our conversations with them.

Being part of this research will give you an opportunity to reflect on how you learn and on how you experience preparing for a performance where you will be evaluated. The downside to participating in this research is that it will take up some of your time (about 2 hours combined for the interviews and another 2-3 hours combined to complete the journals).

If you would like to be part of this research project, please sign the form below. Your parents have been given a permission form to sign as well. Their form also has contact information for me, my professor, and the university office in charge of research if you or your parents have any questions.

Thank you for considering this request to be involved in my research. 
Sincerely,

Nancy Mitchell

Ph.D. candidate, Music Education Department

Faculty of Music

University of Toronto

Please complete and sign the form below if you would like to participate in this study.

\section{Student as Participant (Under Age 16)}

Name of Participant:

I agree to participate in this research.

I agree to have audio recordings made of my interviews.

I agree to have video recordings made of the lessons that will be observed.

Signature of participant:

Date: 


\title{
Consent Form - Current and Former Student Participants (Age 16 and Older)
}

\author{
Dear Former Piano Student,
}

I am a Ph.D. student in the Music Education Department at the University of Toronto and I would like to invite you to participate in a research project I am conducting into beginning and intermediate piano students' experiences with festivals, competitions and exams. This study will form the basis of my dissertation and any other resulting publications (for example, journal articles or conference presentations). The purpose of the research is to understand how students experience performances in which they are evaluated so that these experiences can be taken into account when teachers and students are making decisions about student participation in future evaluations.

Participation in this study is entirely voluntary. Should you decide to participate, you may withdraw at any time without penalty. Please read the information below to better understand what is involved in this research. If you are willing and able to participate, please sign both copies of the consent form, and return one to me at our interview. The other copy of the consent form is for your own records

\section{Who will be involved in this research?}

Participants in this study will be 10 beginning and intermediate piano students who are at least 8 years of age and who are preparing for an evaluative performance (i.e. a festival, competition, or conservatory exam) or who have participated in one of these performances in the past.

\section{How will information be collected?}

To hear your perspective on this topic, I would like to meet with you for one interview lasting 15 to 30 minutes. With your consent, I will make an audio recording of the interview in order to have an accurate record of our conversation. The interview will take place in a location of your choosing for the sake of your comfort and convenience. I will ask you questions about your background as a piano student and your experiences with festivals and exams.

\section{How will participants' privacy be protected?}

All data collected will be treated with strict confidentiality. Participants will choose their own pseudonyms and any other identifying information will be altered. All raw data (such as interview recordings and transcripts) will be securely stored at my home and destroyed upon completion of the research. I will be the only person to see this information.

\section{What are the benefits and risks involved in participating in this research?}

The benefits and risks involved in this study are minimal. Participating in this study will provide you with an opportunity to reflect on your own learning and on the role that evaluative performances played in your music studies. There are no significant risks involved in this study; however, participating in this research project will require a time commitment of up to 30 minutes for the interview. 


\section{Who do I contact if I have questions?}

If you would like more information or if you have any questions or concerns during the study, please do not hesitate to contact me directly at (416)528-3412 or by email at n.mitchell@utoronto.ca. You may also contact my supervisor, Prof. Lee Bartel by email at lbartel@ chass.utoronto.ca. For more information on the rights of research participants, you may contact the Ethics Review Office of the University of Toronto by email at ethics.review@utoronto.ca or by phone at (416)946-3273. I will contact participants when the study is complete so that you can receive a written summary of the findings if you wish.

Thank you for considering my request to participate in this study.

Sincerely,

Nancy Mitchell

Ph.D. candidate, Music Education Department

Faculty of Music, University of Toronto

Please read the form below and check the appropriate boxes to indicate your consent to participate in this research and to be recorded.

\section{Former Student as Participant (Age 16 or older)}

Name of participant:

I have read the above information and consent to participate in this research.

I consent to have audio recordings made of my interviews.

Signature of participant:

Date: 


\title{
Consent Form - Current and Former Student Participants Under Age 16
}

\author{
Dear Parent/Guardian,
}

I am a Ph.D. student in the Music Education Department at the University of Toronto and I would like to invite your child to participate in a research project I am conducting into beginning and intermediate piano students' experiences with festivals, competitions and exams. This study will form the basis of my dissertation and any other resulting publications. The purpose of the research is to understand how students experience performances in which they are evaluated so that these experiences can be taken into account when teachers and students are making decisions about student participation in future evaluations.

Participation in this study is entirely voluntary. Should your child decide to participate, he or she may withdraw at any time without penalty. Please read the information below to better understand what is involved in this research. If your child is willing and able to participate, please sign both copies of the consent form, and return one to me either in the enclosed self-addressed, stamped envelope or in person at our interview. The other copy of the consent form is for your own records

\section{Who will be involved in this research?}

Participants in this study will be 10 beginning and intermediate piano students who are at least 8 years of age and who are preparing for an evaluative performance (i.e. a festival, competition, or conservatory exam) or have participated in one of these performances in the past. If your child is under the age of 16, your consent to his or her participation is required. If your child is 16 years of age or older, he or she will need to sign a separate consent form. Younger children will sign a simplified form indicating that they agree to participate.

\section{How will information be collected?}

To hear your child's perspective on this topic, I would like to meet with him or her for one interview lasting approximately 30 minutes, during which I will ask questions about his or her background as a piano student and experiences playing in festivals or exams. With consent from both of you, I will make an audio recording of the interview in order to have an accurate record of our conversation. The interview will take place in a location of your choosing for the sake of your comfort and convenience. At your child's request, you may be in the room with him or her during the interviews.

\section{How will participants' privacy be protected?}

All data collected will be treated with strict confidentiality. Participants will choose their own pseudonyms and any other identifying information will be altered. All raw data (such as interview recordings and transcripts) will be securely stored at my home and destroyed upon completion of the research. I and the professors supervising my research will be the only people to see this information. 
What are the benefits and risks involved in participating in this study?

The benefits and risks involved in this study are minimal. Participating in this study will provide participants with an opportunity to reflect on the role that evaluative performances play in students' learning. It is my hope that the findings of this study will be useful for teachers who are trying to make decisions about appropriate curriculum and assessment for their students. There are no significant risks involved in this study; however, participating in this research will require a time commitment of approximately 30 minutes to complete the interview.

\section{Who do I contact if I have questions?}

If you would like more information before making a decision or if you have any questions or concerns during the study, please do not hesitate to contact me directly at (416)528-3412 or by email at n.mitchell@utoronto.ca. You may also contact my supervisor, Prof. Lee Bartel by email at lbartel@ chass.utoronto.ca. For more information on the rights of research participants, you may contact the Ethics Review Office of the University of Toronto by email at ethics.review@utoronto.ca or by phone at (416)9463273. I will contact participants when the study is complete so that you can receive a written summary of the findings if you wish.

Thank you for considering my request to participate in this study.

Sincerely,

Nancy Mitchell

Ph.D. candidate, Music Education Department

Faculty of Music

University of Toronto

Please read the form below and check the appropriate boxes to indicate your consent to participate in this research and to be recorded. If your child is 16 years of age or older, you do not need to fill in the second part of the form, as your child will sign his or her own consent form.

\section{Child (under age 16) as Participant}

Name of Participant:

Name of Parent/Guardian:

I have read the above information and consent to my child participating in this research.

I consent to have audio recordings made of my child's interviews.

Parent/Guardian's Signature:

Date: 


\title{
Consent Form - Current and Former Student Participants Under Age 16
}

\author{
Dear Parent/Guardian,
}

I am a Ph.D. student in the Music Education Department at the University of Toronto and I would like to invite your child to participate in a research project I am conducting into beginning and intermediate piano students' experiences with festivals, competitions and exams. This study will form the basis of my dissertation and any other resulting publications. The purpose of the research is to understand how students experience performances in which they are evaluated so that these experiences can be taken into account when teachers and students are making decisions about student participation in future evaluations.

Participation in this study is entirely voluntary. Should your child decide to participate, he or she may withdraw at any time without penalty. Please read the information below to better understand what is involved in this research. If your child is willing and able to participate, please sign both copies of the consent form, and return one to me either in the enclosed self-addressed, stamped envelope or in person at our interview. The other copy of the consent form is for your own records

\section{Who will be involved in this research?}

Participants in this study will be 10 beginning and intermediate piano students who are at least 8 years of age and who are preparing for an evaluative performance (i.e. a festival, competition, or conservatory exam) or have participated in one of these performances in the past. If your child is under the age of 16, your consent to his or her participation is required. If your child is 16 years of age or older, he or she will need to sign a separate consent form. Younger children will sign a simplified form indicating that they agree to participate.

\section{How will information be collected?}

To hear your child's perspective on this topic, I would like to meet with him or her for one interview lasting approximately 30 minutes, during which I will ask questions about his or her background as a piano student and experiences playing in festivals or exams. With consent from both of you, I will make an audio recording of the interview in order to have an accurate record of our conversation. The interview will take place in a location of your choosing for the sake of your comfort and convenience. At your child's request, you may be in the room with him or her during the interviews.

\section{How will participants' privacy be protected?}

All data collected will be treated with strict confidentiality. Participants will choose their own pseudonyms and any other identifying information will be altered. All raw data (such as interview recordings and transcripts) will be securely stored at my home and destroyed upon completion of the research. I and the professors supervising my research will be the only people to see this information. 


\section{What are the benefits and risks involved in participating in this study?}

The benefits and risks involved in this study are minimal. Participating in this study will provide participants with an opportunity to reflect on the role that evaluative performances play in students' learning. It is my hope that the findings of this study will be useful for teachers who are trying to make decisions about appropriate curriculum and assessment for their students. There are no significant risks involved in this study; however, participating in this research will require a time commitment of approximately 30 minutes to complete the interview.

\section{Who do I contact if I have questions?}

If you would like more information before making a decision or if you have any questions or concerns during the study, please do not hesitate to contact me directly at (416)528-3412 or by email at n.mitchell@utoronto.ca. You may also contact my supervisor, Prof. Lee Bartel by email at lbartel@ chass.utoronto.ca. For more information on the rights of research participants, you may contact the Ethics Review Office of the University of Toronto by email at ethics.review@ utoronto.ca or by phone at (416)9463273. I will contact participants when the study is complete so that you can receive a written summary of the findings if you wish.

Thank you for considering my request to participate in this study.

Sincerely,

Nancy Mitchell

Ph.D. candidate, Music Education Department

Faculty of Music

University of Toronto

Please read the form below and check the appropriate boxes to indicate your consent to participate in this research and to be recorded. If your child is 16 years of age or older, you do not need to fill in the second part of the form, as your child will sign his or her own consent form.

\section{Child (under age 16) as Participant}

Name of Participant:

Name of Parent/Guardian:

I have read the above information and consent to my child participating in this research.

I consent to have audio recordings made of my child's interviews.

Parent/Guardian's Signature:

Date: 


\section{Assent Letter - Current or Former Student Participants Under Age 16}

\section{Dear Current or Former Piano Student,}

I am a $\mathrm{Ph}$. D. student at the University of Toronto doing research into piano students' experiences participating in festivals, exams, and competitions. Since you have participated in these kinds of performances in the past, I am interested in hearing your perspective on what that experience was like.

To gather information for this research, I would like to meet and talk with you for about 15-30 minutes. So that I have an accurate record of our conversations, I will make an audio recording as we talk.

Your privacy will be protected in several ways. I will not use your real name in my thesis (you will get to choose your own nickname). I and the professors who are supervising my project will be the only people to see or listen to the information that is collected through our conversation. When the research is finished, I will destroy the recording.

Being part of this research will give you an opportunity to reflect on how you learn and on how you experience preparing for a performance where you will be evaluated. The only downside to participating in this research is that it will take up a bit of your time.

If you would like to be part of this research project, please sign the form below. Your parents have been given a permission form to sign as well. Their form also has contact information for me, my professor, and the university office in charge of research if you or your parents have any questions.

Thank you for considering this request to be involved in my research.

Sincerely,

Nancy Mitchell

Ph.D. candidate, Music Education Department

Faculty of Music

University of Toronto

Please complete and sign the form below if you would like to participate in this study.

\section{Student as Participant (Under Age 16)}

Name of Participant:

I agree to participate in this research.

I agree to have audio recordings made of my interviews.

Signature of participant:

Date: 